UNIVERSIDADE DE SÃO PAULO

ESCOLA DE ENGENHARIA DE SÃO CARLOS

DEPARTAMENTO DE HIDRÁULICA E SANEAMENTO

ANDRES FELIPE HATUM PONTON

Determinação empírica da evapotranspiração em zona ripária e áreas vizinhas (Cerrado stricto sensu e eucalipto)

VERSÃO CORRIGIDA

São Carlos, SP

2017 



\title{
Determinação empírica da evapotranspiração em zona ripária e áreas vizinhas (Cerrado stricto sensu e eucalipto)
}

\author{
Dissertação apresentada à Escola de Engenharia \\ de São Carlos, da Universidade de São Paulo, \\ como parte dos requisitos para obtenção do \\ título de Mestre em Ciências: Engenharia \\ Hidráulica e Saneamento.
}

Orientador: Prof. Titular Edson C. Wendland.

VERSÃO CORRIGIDA

São Carlos, SP 
AUTORIZO A REPRODUĈ̃O E DIVULGAÇÃO TOTAL OU PARCIAL DESTE TRABALHO, POR QUALQUER MEIO CONVENCIONAL OU ELETRÔNICO, PARA FINS DE ESTUDO E PESQUISA, DESDE QUE CITADA A FONTE.

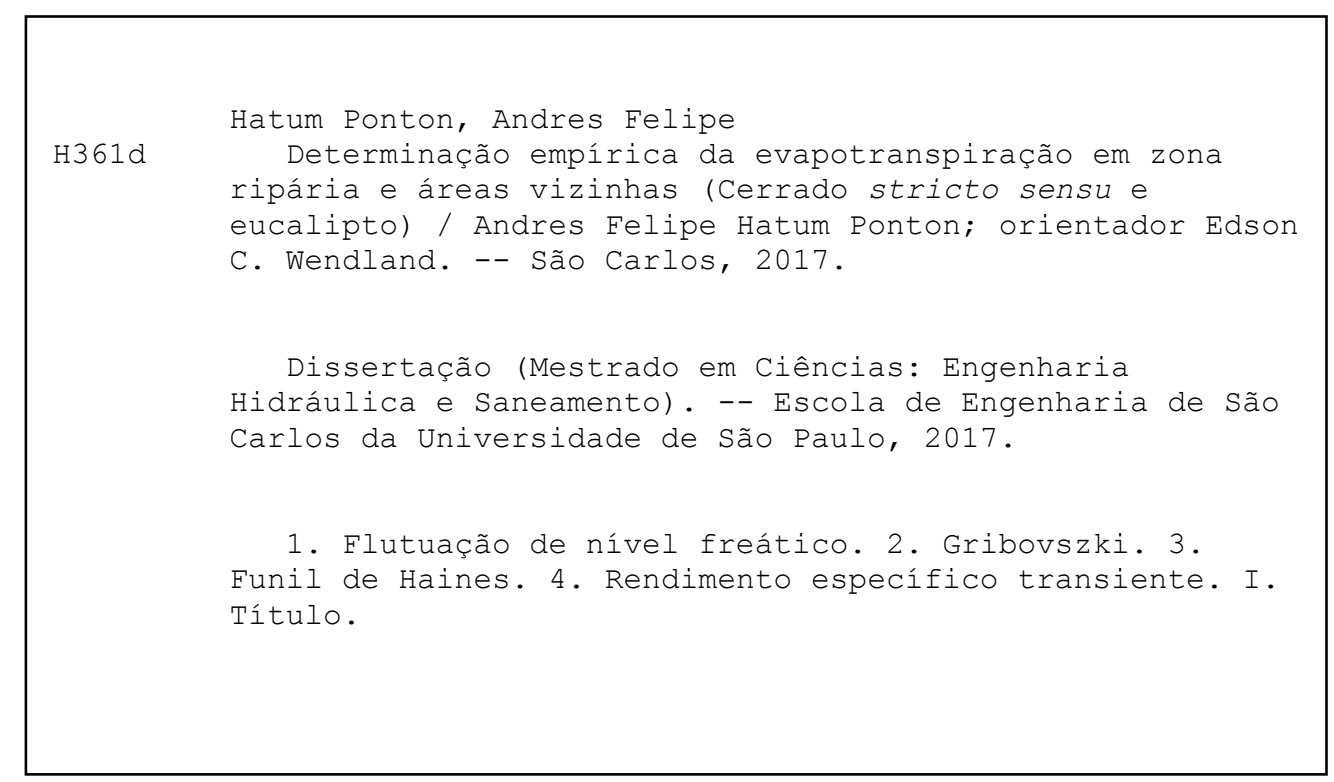




\section{FOLHA DE JULGAMENTO}

Candidato: Engenheiro ANDRES FELIPE HATUM PONTON.

Título da dissertação: "Determinação empírica da evapotranspiração em zona ripária e áreas vizinhas (cerrado strictu sensu e eucalipto)".

Data da defesa: 03.03.2017.

Comissão Julgadora:

Prof. Titular Edson Cezar Wendland (Orientador)

(Escola de Engenharia de São Carlos/EESC)

Dr. Silvio Crestana

(EMBRAPA)

Prof. Dr. Walter Collischonn

(Universidade Federal do Rio Grande do Sul/UFRGS)
Resultado:
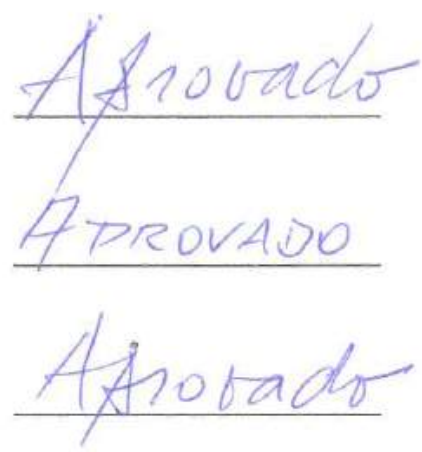

Coordenadora do Programa de Pós-Graduação em Engenharia Hidráulica e Saneamento:

Profa. Associada Maria Bernadete A. Varesche Silva

Presidente da Comissão de Pós-Graduação:

Prof. Associado Luís Fernando Costa Alberto 

A Deus por me abençoar muito mais do que eu mereço, e aos meus pais, Tufith e Miriam Luz, por todos os sacrifícios que fizeram em favor de um melhor futuro para os meus irmãos e para mim. 



\section{AGRADECIMENTOS}

Em primeiro lugar a Deus Pai, por ter me dado forças e a proteção em todo momento, a qualquer hora e lugar. A Nosso Senhor Jesus Cristo, por ser o meu caminho, a verdade e a vida, e por guiar os meus passos para o melhor rumo. Ao Espírito Santo, por manifestar os seus dons em mim e me dar discernimento em todos os meus atos.

Aos meus pais Tufith e Miriam Luz, por serem o meu exemplo, porque sempre posso encontrar neles o amor, compreensão, apoio incondicional e por ser a minha grande motivação em tudo o que faço na minha vida.

A minha noiva Mileidys, por ser minha companheira constante de lutas, por me amar de uma forma linda e especial, por ser a minha outra grande motivação, e por ser o meu tudo.

Às meus avós Tita, Carmen e Juan por serem os meus segundos pais, por me oferecerem muito apoio em cada objetivo que me coloco.

Aos meus irmãos Juan e Sebas e as minhas cunhadas Michelle e Jéssica, por rezarem para que Deus sempre proteja e encha de felicidade a nossa família.

Ao meu tio Jorge "El Mono" Saade e a sua família, por me abrirem as portas da a sua casa e me fazerem viver momentos inesquecíveis quando cheguei pela primeira vez no Brasil.

Aos meus amigos do peito: Juan P. Perez, a sua esposa Alessandra e seu filho Miguel "El Migue", por me fazerem sentir como um integrante da a sua família e por todo o seu respaldo durante o tempo que cursei o mestrado.

Ao meu orientador, professor Edson Wendland, pelo exemplo de dedicação e coragem para liderar trabalhos em equipe e por contribuir na minha pesquisa através dos seus interessantes aportes intelectuais.

Aos meus amigos e colegas do LHC: Murilo, Camilo, Tiago, Paulo e Dulce (Obrigado pelos seus conselhos e sugestões no o meu projeto). Lívia, Camila, Derly, Nathe, Ana e Vinícius (Obrigado pela boa convivência e compartilhar momentos cheios de risada e amizade). Davi e Jamil (Obrigado pela sua boa disposição em me ajudar), Gabriel e David (A dupla dinâmica, obrigado pela a sua ajuda em campo e boa convivência).

Ao técnico Roberto Bérgamo por ter me acompanhado durante esses dois últimos anos no trabalho de campo na Bacia do Ribeirão da Onça e pela construção dos diferentes equipamentos para o meu projeto.

Ao grupo de canto da Paróquia Nossa Senhora de Fátima por me permitir fazer 
parte da sua equipe, pela a sua amizade e por compartilhar comigo a palavra de Deus.

À professora Valeria G. S. Rodrigues, à Eng. Jacqueline e ao técnico Oscar dos Santos (Gente fina) pelas diferentes orientações na hora que eu precisei realizar trabalhos no Departamento de Geotecnia da EESC-USP.

Ao Dr. Carlos M. P. Vaz e ao Eng. Júnio Martins por me permitir realizar a análise granulométrica na EMBRAPA.

Às secretarias do SHS, Sá, Priscila e Rose, por sempre me dar um atendimento ótimo e serem tão eficientes em suas funções.

Aos funcionários da biblioteca da Escola de Engenharia de São Carlos.

À Universidad del Magdalena, pela excelente formação como Engenheiro Civil, que tem sido a base acadêmica para um ótimo desenvolvimento do meu estudo de mestrado.

À Coordenação de Aperfeiçoamento de Pessoal de Nível Superior (CAPES) pela concessão da bolsa de mestrado. 
"Clame a mim e eu responderei e direi a você coisas grandiosas e insondáveis que você não conhece". (Bíblia Sagrada, Jeremias 33:3) 



\section{RESUMO}

HATUM, A. F. Determinação empírica da evapotranspiração em zona ripária e áreas vizinhas (Cerrado stricto sensu e eucalipto). 2017. 144 p. Dissertação (Mestrado) - Escola de Engenharia de São Carlos, Universidade de São Paulo, São Carlos, 2017.

Em zonas ripárias o nível freático encontra-se próximo à superfície do solo e tem contato com as raízes da vegetação. Como resultado, as taxas de evapotranspiração $(E T)$ são elevadas, gerando flutuações diárias do nível de água subterrânea. Apesar da riqueza hídrica que a América Latina possui, estudos sobre a evapotranspiração nas suas zonas ripárias são raros. Os prováveis motivos da pouca investigação na área podem ser atribuídos ao difícil acesso econômico para adquirir equipamentos necessários para a sua medição. Além disso, a aplicação de técnicas como sensoriamento remoto, eddy covariance ou a razão de Bowen é limitada, devido à bordadura das zonas ripárias, que geralmente é estreita. O objetivo deste trabalho foi determinar a ET em zona ripária e áreas vizinhas através de métodos baseados na flutuação diária do nível de água subterrânea. No desenvolvimento deste estudo foram instalados poços de monitoramento na bacia hidrográfica do Ribeirão da Onça. A profundidade do nível freático foi registrada em dataloggers em intervalos de 15 minutos, no período de 09/2015 a 10/2016. O rendimento específico transiente $\left(S_{y}^{*}\right)$ foi estimado através da modernização do funil de Haines acoplado a uma balança de precisão. Em função do regime de flutuação diária do nível freático, foi adotado o $S_{y}^{*}$ correspondente a 6 horas de drenagem. Os resultados mostram que na zona ripária a evapotranspiração oscila entre 2,74 e 14,90 mm/d. Para o Cerrado stricto sensu e o eucalipto, a variação da ET é de 1,23 a 2,02 $\mathrm{mm} / \mathrm{d}$ e 1,96 a $5,45 \mathrm{~mm} / \mathrm{d}$, respectivamente, sendo coerentes com resultados prévios obtidos no Brasil. A aplicação de métodos da flutuação diária mostra ser economicamente viável e ter potencial para estimar a evapotranspiração em áreas estreitas.

Palavras-chave: Flutuação do nível freático. Gribovszki. Funil de Haines. Rendimento específico transiente. 



\section{ABSTRACT}

HATUM, A. F. Empirical determination of evapotranspiration in the riparian zone and neighboring areas (Cerrado stricto sensu and eucalyptus). 2017. 144 p. Dissertação (Mestrado) - Escola de Engenharia de São Carlos, Universidade de São Paulo, São Carlos, 2017.

In riparian zones the groundwater is close to the soil surface and the roots of its vegetation have contact with it. As a result, evapotranspiration (ET) rates are high, generating diurnal groundwater level fluctuations. Despite Latin America's water resources wealth, reports of evapotranspiration in its riparian zones are scarce. The probable reasons of little investigation in the area can be attributed to the economical difficulties to access the equipments necessary for this kind of measurement. Furthermore, the application of techniques as remote sensing, eddy covariance or Bowen ratio is limited, due to the usual narrow fetch that are found in the riparian zones. The aim of this study was to determine the ET in the riparian zone and its surroudings areas, using methods based on the diurnal groundwater level fluctuations. To develop this study, monitoring wells were installed in the Ribeirão da Onça basin. The water table depth was recorded in dataloggers using a 15-minute interval, from 09/2015 to 10/2016. The transient specific yield was estimated by improving the Haines funnel coupled to a precision balance. In function of the daily fluctuation regime of the groundwater table, it was adopted the $S_{y}^{*}$ corresponding to 6 hours of drainage. The results show that, in the riparian zone, evapotranspiration ranges from 2,74 to 14,90 mm/d. For Cerrado stricto sensu and eucalyptus, the ET variations are 1,23 to $2,02 \mathrm{~mm} / d$ and 1,96 to $5,45 \mathrm{~mm} / \mathrm{d}$, respectively, being consistent with previous studies performed in Brazil. The application of diurnal groundwater level fluctuations methods shows to have the potential to estimate evapotranspiration in narrow areas, with low economic investment.

Key-words: Water table fluctuation. Gribovszki. Haines funnel. Transient specific yield. 



\section{LISTA DE ILUSTRAÇÕES}

Figura 1 - Flutuação diária do nível de água subterrânea na zona ripária do Rio de Arkansas, Kansas, USA. . . . . . . . . . . . . . . . . . . . 34

Figura 2 - Flutuação do nível freático em um dia, indicado dentro da janela verde. A linha de traços representa o aporte constante do fluxo lateral durante as $24 h$ do dia e a tendência que deveria ter seguido a hidrógrafa na ausência do evento de evapotranspiração. A vermelha mostra os dados registrados entre as $0 h 00$ até $4 h 00$ para o cálculo de $r_{h}$. A pontilhada é a projeção horizontal do nível freático ás $0 h 00$ no começo do dia. . . . 35

Figura 3 - Flutuação do nível freático em um dia indicado dentro da janela verde. As linhas de traços extrapoladas até o meio-dia representam a quantidade de água evapotranspirada durante as $24 h . \quad$. . . . . . . . . . . 36

Figura 4 - Flutuação do nível freático em um dia indicado dentro da janela verde. Entre $h_{M a x 1}$ e $h_{\min }$ a evapotranspiração gera a queda do nível freático. Entre $h_{\min }$ e $h_{\text {Max } 2}$ é calculado o fluxo lateral. . . . . . . . . . . . 37

Figura 5 - Modelo esquemático da na zona ripária (ponto $\boldsymbol{A}$ ) onde as raízes atingem o nível freático do aquífero e a zona distante (ponto $\boldsymbol{B}$ ) em que o nível de água subterrânea é profundo. . . . . . . . . . . . . . . . 38

Figura 6 - a) Flutuação do nível freático de um dia indicado dentro da janela azul.

b) Gráfico da taxa de nível de água subterrânea, sendo colocados os $Q_{\text {liqMax }}$ e $Q_{\text {liqmin }}$ na mesmas abcissas de $h_{\min }$ e $h_{\text {Max }}$, respetivamente no mesmo dia.

Figura 7 - Flutuações do nível de água subterrânea no ponto $\boldsymbol{A}$ e $\boldsymbol{B}$. As suas declividades são as mesmas.

Figura 8 - Nível de água subterrânea com flutuação inclinada no ponto $\boldsymbol{A}$ e assumido como uma linha inclinada em $\boldsymbol{B}$, para um período menor a 2 dias.

Figura 9 - Nível de água subterrânea com flutuação no ponto $\boldsymbol{A}$ e assumido como uma linha reta em $\boldsymbol{B}$, com inclinações removidas, para um período menor a 2 dias.

Figura 10 - Representação da água que fica imóvel nos microporos e aquela que consegue drenar nos macroporos interconectados. 
Figura 11 - Variação do $S_{y}$ em um volume de controle (retângulo vermelho). a) Durante o dia o nível freático do aquífero desce pelo efeito da evapotranspiração $(E T)$ e o volume de controle (VC) permanece fora da zona saturada um número de horas $t^{*}$, sendo o valor do rendimento específico igual a $S_{y}^{*}$. b) Durante a noite o nível freático aumenta pela não existência de evapotranspiração, mas sim do fluxo lateral $(r)$. O volume de controle permanece dentro da zona saturada um número de horas $t^{* *}$, sendo o valor do rendimento específico igual $S_{y}^{* *}$. Portanto

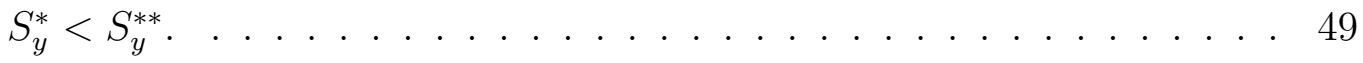

Figura 12 - Analisador Granulométrico. . . . . . . . . . . . . . . . 50

Figura 13 - Localização do Sistema Aquífero Guarani na América do Sul. . . . . . 51

Figura 14 - Localização da bacia do Ribeirão da Onça. . . . . . . . . . . . . . . . 52

Figura 15 - Representação dos poços de monitoramento em zona ripária, Cerrado stricto sensu e eucalipto na fazenda Monte Alegre. (a) Vista em planta.

(b) Vista lateral. . . . . . . . . . . . . . . . . . . . . . . 53

Figura 16 - Altimetria da Bacia Ribeirão da Onça. . . . . . . . . . . . . . . 55

Figura 17 - Mapa geológico na região da bacia do Ribeirão da Onça. . . . . . . . . 56

Figura 18 - Mapa pedológico na região da bacia do Ribeirão da Onça. . . . . . . . 57

Figura 19 - Localização dos poços de monitoramento na bacia do Ribeirão da Onça. 58

Figura 20 - Locais de coleta de amostras indeformadas de solo na BRO. . . . . . . 59

Figura 21 - Realização dos filtros nos poços em laboratório. . . . . . . . . . . . . . 60

Figura 22 - (a) Escavação no solo para os poços. (b) Instalação das bocas dos Poços.

(c) Instalação do poço finalizada . . . . . . . . . . . . . . . . . . . . 60

Figura 23 - Variáveis da compensação barométrica . . . . . . . . . . . . . . . . 62

Figura 24 - Regressão Polinomial Local Ponderada (Loess) . . . . . . . . . . . . . . 62

Figura 25 - (a) Coleta de amostras indeformadas na zona ripária. (b) Trado Uhland. 63

Figura 26 - a) Amostra indeformada de solo no poço 27. b) Amostra de solo do poço 27 contida em um anel de PVC . . . . . . . . . . . . . . . . 64

Figura 27 - Tripé de sondagem à percussão (SPT) Adaptado. a )Esquema gráfico.

b) Cilindro PVC para amostragem de solo. c) Escavação preliminar com trado. d) Acoplamento de varias hastes . . . . . . . . . . . . . 65

Figura 28 - Representação esquemática do funil de Haines. (a) Saturação da amostra. (b) Aplicação da tensão h. . . . . . . . . . . . . . . . . . . . . 66

Figura 29 - a) Funil de Haines modernizado. b) Saturação das amostras através de pedras porosas. c) Ordem do posicionamento do O'Ring, placa porosa, anel de pressão e amostra do solo coberta com tecido silk screen. d) Pesagem da amostra do solo depois do ensaio. . . . . . . . . . . . 67

Figura 30 - Esquema do número de medições [curvas $S_{y}(t)$ ] por cada poço . . . . . 69 Figura 31 - a) Amostras de solo dentro da mufla. b) Dessecador . . . . . . . . . . . 71 
Figura 32 - Processo de atenuação no analisador granulométrico . . . . . . . . . . . 71

Figura 33 - a) Agitador de Wagner. b) Aplicação da lei de Stokes através do analisador granulométrico . . . . . . . . . . . . . . . 72

Figura 34 - Classes texturais para solos. . . . . . . . . . . . . . 73

Figura 35 - Estação meteorológica localizada na fazenda Monte Alegre . . . . . . . 74

Figura 36 - a) Microlisímetros no telhado sobre bandejas com água para evitar "efeito oásis". b) Reposição da água perdida nos MLs até a mesma umidade do dia da coleta. . . . . . . . . . . . . . . . . . . . 76

Figura 37 - Semana do mês de setembro de 2015 em que pode ser observada a aplicação da filtragem passa baixa (Loess) nos dados do poço 27 (Zona Ripária).

Figura 38 - Comportamento da flutuação diária do nível freático quando não tem ocorrência de precipitação (20/09/2015 - 25/09/2015) e quando tem (25/09/2015 - 27/09/2015).

Figura 39 - Flutuação diária da profundidade do nível freático do poço 27 contra a temperatura média horária do ar (cor vermelha - a), umidade relativa do ar (cor verde - b) e irradiância solar (cor preta - c), em uma semana de Setembro de 2015. Para a análise com a irradiância solar, foram usados somente os horários de brilho solar. a1), b1) e c1) mostram que profundidade do nível freático é diretamente proporcional à temperatura do ar e à irradiância solar, e inversa à umidade relativa do ar. a2), b2) e c2) mostram que as correlações cruzadas entre a profundidade do nível freático e as variáveis meteorológicas possuem os máximos valores [0,95; -0,93 (correlação inversa) e 0,85 para a temperatura do ar, umidade relativa do ar e irradiância solar, respectivamente] com lag de -2 horas.

Figura 40 - Variação da amplitude da flutuação diária do nível freático nos diferentes poços de monitoramento.

Figura 41 - Tempo médio em que acontece a evapotranspiração diária. Flutuação obtida no poço 16 com uma frequência de coleta de 15 min. . . . . . . 82

Figura 42 - (a) Curvas do $S_{y}(t)$ e a média para o anel 02 do poço 27 - zona ripária. (b)Curvas da média dos $S_{y}(t)$ dos anéis 02, 03 e 05, com a média ponderada para poço 27 - zona ripária.

Figura 43 - a) Curva granulométrica média (linha vermelha) da segunda triplicata da amostra de solo do poço 28 a $3 \mathrm{~m}$ de profundidade a partir da superfície. b) Curva granulométrica média total (linha vermelha) da amostra de solo do poço 28 a $3 \mathrm{~m}$ de profundidade.

Figura 44 - Resultados da evapotranspiração diária na zona ripária (poço 27) através da aplicação dos métodos da flutuação diária do nível freático, em dias sem precipitação. 
Figura 45 - Resultados da evapotranspiração diária na zona de transição (poço 28) através da aplicação dos métodos da flutuação diária do nível freático, em dias sem precipitação. . . . . . . . . . . . . . . . . . . 88

Figura 46 - Resultados da evapotranspiração diária no Cerrado stricto sensu (poço 29) através da aplicação dos métodos da flutuação diária do nível freático, em dias sem precipitação.

Figura 47 - Resultados da evapotranspiração diária no eucalipto (poço 16) através da aplicação dos métodos da flutuação diária do nível freático, em dias sem precipitação.

Figura 48 - Variação do fluxo lateral $\left[Q_{l i q}(t)\right]$ em uma semana de setembro de 2015. A linha preta representa a interpolação spline entre os pontos máximos $\left(Q_{\text {liqMax }}\right)$ e mínimos $\left(Q_{\text {liqmin }}\right)$. O $d h / d t$ é a taxa de variação de nível de água subterrânea.

Figura 49 - Resultados da evapotranspiração diária pelo método de Gribovszki et al. (2008), escolhidos como os mais confiáveis, para todas as zonas de estudo.

Figura 50 - Boxplots da evapotranspiração diária na zona ripária e da temperatura máxima diária para períodos em que não houve precipitações. Os rótulos numéricos em cada boxplot representam as medianas e o asterisco um valor atípico.

Figura 51 - Boxplots da evaporação diária do Tanque Classe A em comparação com a evapotranspiração diária na zona ripária determinada pelo método de Gribovszki et al. (2008), para períodos em que não houve precipitações. Os rótulos numéricos representam as medianas e os asterisco valores atípicos.

Figura 52 - Boxplots da evapotranspiração de referência padrão FAO em comparação com a evapotranspiração diária na zona ripária determinada pelo método de Gribovszki et al. (2008), para períodos em que não houve precipitações. Os rótulos numéricos em cada boxplot representam a mediana.

Figura 53 - a) Solo da zona ripária antes de acontecer a evaporação diária. b) Solo da zona ripária depois de acontecer a evaporação diária.

Figura 54 - a) Resultados da evaporação do solo na zona ripária por exposição direta à radiação solar. b) Variação da temperatura do ar no local onde foram colocados os MLs.

Figura 55 - Boxplots da evapotranspiração diária na zona de transição. Os rótulos numéricos em cada boxplot representam a mediana e os asterisco valores atípicos. 
Figura 56 - Boxplots da evapotranspiração diária no Cerrado stricto sensu. Os rótulos numéricos em cada boxplot representam a mediana e os asterisco valores atípicos. . . . . . . . . . . . . . . . . . . . . . . 96

Figura 57 - Boxplots da evapotranspiração diária no eucalipto. Os rótulos numéricos em cada boxplot representam a mediana e os asterisco valores atípicos. $\quad 97$ 



\section{LISTA DE TABELAS}

Tabela 1 - Resumo dos métodos diretos e indiretos para a determinação da evapotranspiração . . . . . . . . . . . . . . . . . . . . . 31

Tabela 2 - Resumo dos métodos de estimativa de ET a partir da flutuação diária do nível de água subterrânea . . . . . . . . . . . . . . . . . . 43

Tabela 3 - Publicações de estimativas da evapotranspiração em zona ripária em áreas de estudo internacionais . . . . . . . . . . . . . . . . . 45

Tabela 4 - Publicações das estimativas da evapotranspiração no Cerrado stricto sensu em áreas de estudo no Brasil . . . . . . . . . . . . . . . . . 46

Tabela 5 - Publicações de estimativas da evapotranspiração no eucalipto em áreas de estudo no Brasil . . . . . . . . . . . . . . . . . . . . . . . 47

Tabela 6 - Caracterização fisiográfica da bacia do Ribeirão da Onça . . . . . . . . 54

Tabela 7 - Rendimento específico nos diferentes pontos de coleta . . . . . . . . . 59

Tabela 8 - Sensores disponíveis na estação meteorológica e variáveis monitoradas . 75

Tabela 9 - Resultado dos ensaios de Porosidade $(\eta)$, Retenção específica $\left(S_{r}\right)$, Rendimento específico $\left(S_{y}\right)$ e Rendimento específico transiente $\left[S_{y}^{*}=\right.$

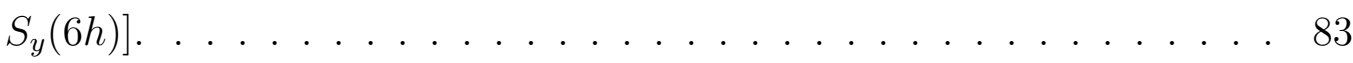

Tabela 10 - Teor de matéria orgânica no solo ao redor dos poços em diferentes profundidades . . . . . . . . . . . . . . . . 84

Tabela 11 - Percentuais das frações, texturas e densidade das partículas (Dp) das amostras de solo. A nomenclatura P27 $(0,30 \mathrm{~m})$ significa: amostra de solo do poço 27 a $0,30 m$ de profundidade a partir da superfície do solo. Para o poço 16 Gomes (2008) obteve valores de 13,92 \% (argila + silte), $34,08 \%$ (areia fina) e 52,00\% (areia grossa) em profundidades de 3,00 $-4,50$ m. . . . . . . . . . . . . . . . 86 



\section{LISTA DE SÍMBOLOS}

$\begin{array}{ll}E T & \text { Evapotranspiração }[\mathrm{mm}] \\ E T_{d} & \text { Evapotranspiração diária }[\mathrm{mm} / \mathrm{d}] \\ E T_{o} & \text { Evapotranspiração de referência }[\mathrm{mm}] \\ E & \text { Evaporação }[\mathrm{mm}] \\ K & \text { Condutividade hidráulica }[\mathrm{m} / \mathrm{s}] \\ \eta & \text { Porosidade [\%] } \\ r_{h} & \text { Taxa média horária de elevação do nível freático entre as } 0 h 00 \text { e } 4 h 00 \\ & {[m m / h]} \\ \Delta s & \text { Queda líquida do nível freático em um período de tempo de } 24 h \\ & {[m m / d i a]} \\ r_{15} & \text { Taxa média a cada } 15 \text { min de fluxo lateral de água subterrânea }[\mathrm{mm} / 15 \mathrm{~min}] \\ S_{y} & \text { Rendimento específico [\%] } \\ S_{y}^{*} & \text { Rendimento específico transiente [\%] } \\ S_{r} & \text { Retenço específica }[\%]\end{array}$





\section{LISTA DE ABREVIATURAS E SIGLAS}

SAG Sistema Aquífero Guarani

BRO Bacia do Ribeirão da Onça

CRHEA Centro de Recursos Hídricos e Estudos Ambientais

EESC Escola de Engenharia de São Carlos

EMBRAPA Empresa Brasileira de Pesquisa Agropecuária

EUA Estados Unidos da América

EVI Enhanced Vegetation Index

FAO Food and Agriculture Organitation

IPT Instituto de Pesquisas Tecnológicas

LHC Laboratório de Hidráulica Computacional

MODIS Moderate Resolution Imaging Spectroradiometer

SBCS Sociedade Brasileira de Ciência do Solo

USDA United States Department of Agriculture

USGS United States Geological Survey 



\section{SUMÁRIO}

INTRODUÇÃO $\ldots \ldots \ldots \ldots \ldots \ldots \ldots \ldots$

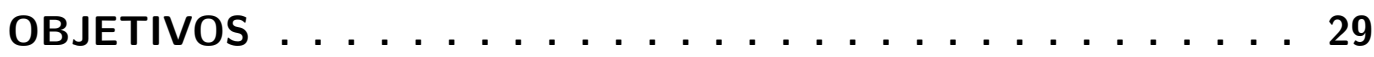

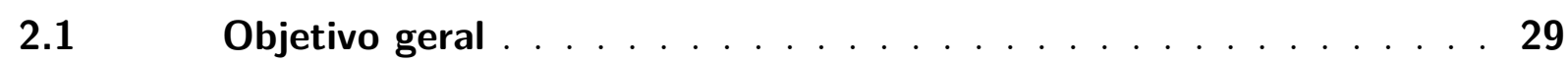

$2.2 \quad$ Etapas específicas $\ldots \ldots \ldots \ldots \ldots$

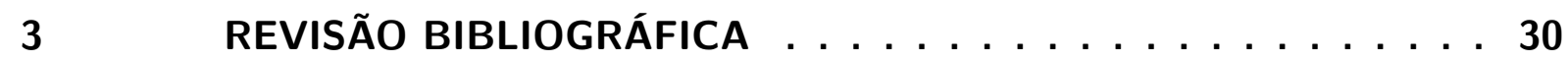

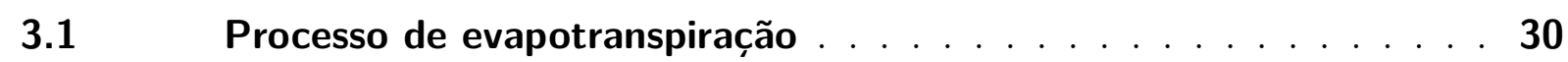

$3.1 .1 \quad$ Método do Penman Monteith - FAO $56 \ldots \ldots$. . . . . . . . 32

3.2 Métodos para a estimativa da evapotranspiração a partir da flutuação diária do nível de água subterrânea . . . . . . . . . . . 33

3.2.1 Método de White (1932) . . . . . . . . . . . . . . . . 33

3.2.2 Método de Dolan et al. (1984) . . . . . . . . . . . . . . . . . . 35

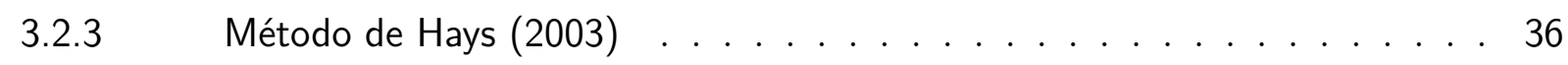

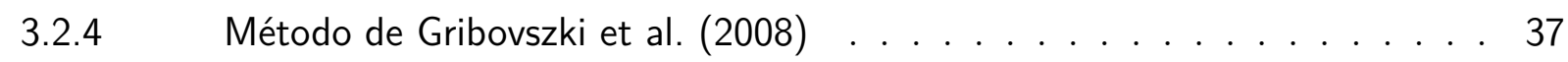

3.2.5 Método de Loheide II (2008) . . . . . . . . . . . . . . . . . 40

3.3 Compensação barométrica e filtragem passa-baixa . . . . . . . . 43

3.4 Estimativas de evapotranspiração em zona ripária, Cerrado stricto sensu e eucalipto . . . . . . . . . . . . . . . . . . 44

$3.5 \quad$ Ensaios para caracterização física do solo . . . . . . . . . . 47

3.5.1 Porosidade, retenção específica, rendimento específico e rendimento específico transiente . . . . . . . . . . . . . . . . . . . . . . 47

3.5.2 Análise granulométrica e densidade das partículas de solo por raios gama . 49

$4 \quad$ ÁREA DE ESTUdO $\ldots \ldots \ldots \ldots \ldots \ldots \ldots$

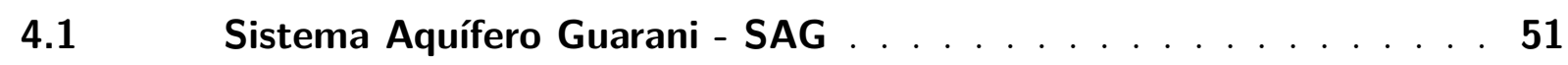

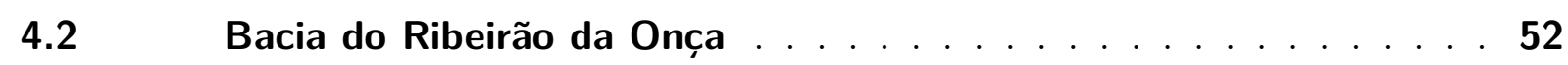

$4.2 .1 \quad$ Localização . . . . . . . . . . . . . . . . . . . . . . . . 52

$4.2 .2 \quad$ Climatologia $\ldots \ldots \ldots \ldots \ldots \ldots$

$4.2 .3 \quad$ Características físicas . . . . . . . . . . . . . . . . . . . 54

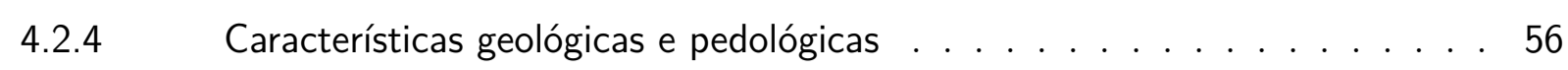

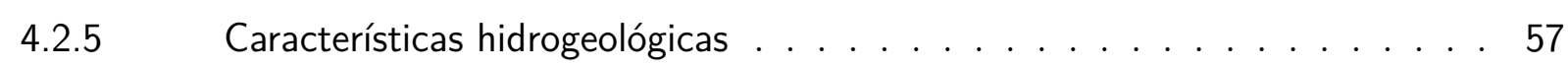

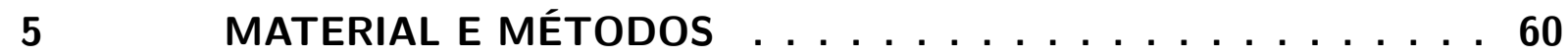

5.1 Construção e instalação de novos poços de monitoramento . . . . 60

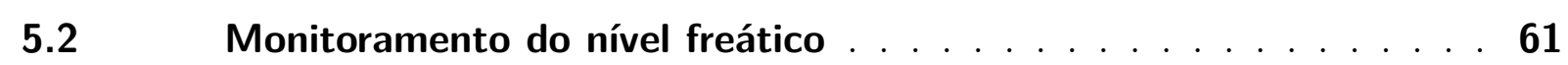


5.2.1 Compensação barométrica e filtragem passa baixa . . . . . . . . . . . . 61

$5.3 \quad$ Determinação das características físicas do solo . . . . . . . . . . . 63

5.3.1 Porosidade, retenção específica, rendimento específico e rendimento específico transiente . . . . . . . . . . . . . . . . . 63 63

5.3.1.1 Coleta de amostras indeformadas . . . . . . . . . . . . . . . . 63

5.3.1.2 Método de tensão da água no solo . . . . . . . . . . . . . . 66

5.3.2 Teor de matéria orgânica do solo . . . . . . . . . . . . . . . . 70

5.3.3 Análise granulométrica e densidade das partículas de solo por raios gama $\quad 70$

5.3.4 Classificação textural do solo . . . . . . . . . . . . . . . . . 72

$5.4 \quad$ Determinação da evapotranspiração . . . . . . . . . . . . . . 73

5.4.1 Aplicação dos métodos baseados na flutuação diária do nível freático . . . . 73

5.4.2 Monitoramento das variáveis meteorológicas e aplicação do método de Penman Monteith - FAO 56 . . . . . . . . . . . . . . . . . . . . . . . . . 74

5.4.3 Estimativa da evaporação do solo da zona ripária por exposição direta à radiação solar . . . . . . . . . . . . . . . . . . . . . . 75

6 RESULTADOS E DISCUSSÕES . . . . . . . . . . . . . . 77

$6.1 \quad$ Flutuações do nível freático nos poços de monitoramento . . . . . . 77

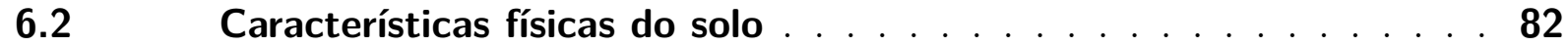

6.2.1 Porosidade, retenção específica, rendimento específico e rendimento específico transiente . . . . . . . . . . . . . . . . . . . . 82

6.2.2 Teor de matéria orgânica . . . . . . . . . . . . . . . . 84

6.2.3 Curvas granulométricas, densidade das partículas de solo por raios gama e classificação da textura do solo . . . . . . . . . . . . . . . . . . . 85

6.3 Determinação da evapotranspiração nas zonas ripária, de transição, de Cerrado stricto sensu e eucalipto . . . . . . . . . . . . . . . . . . . 87

6.3.1 Análise de resultados da ET na poço zona ripária - poço 27 . . . . . . . 91

6.3.1.1 Estimativa da evaporação do solo da zona ripária por exposição direta à radiação solar . 94

6.3.2 Análise de resultados da ET na zona de transição (poço 28) e de Cerrado stricto sensu (poço 29) . . . . . . . . . . . . . . . . . . . . . 95

6.3.3 Análise de resultado da ET na área de eucalipto (poço 16) . . . . . . . . 97

$7 \quad$ CONCLUSÃO $\ldots \ldots \ldots \ldots \ldots$

Referências ........................ 100

$\begin{array}{ll}\text { APÊNDICES } & 107\end{array}$

APÊNDICE A - RELATÓRIO DE POÇOS . . . . . . . . . 108

A.1 Relatório do poço 27 - Zona ripária . . . . . . . . . . . . 108 
A.2 Relatório do poço 28 - Zona de transição . . . . . . . . . . . . . 109

A.3 Relatório do poço 29 - Cerrado stricto sensu . . . . . . . . . . . . . . 110

A.4 Relatório do poço 16 - Eucalipto . . . . . . . . . . . 111

APÊNDICE B - BOCA DOS POÇOS . . . . . . . . . . . . 112

APÊNDICE C - PEDRA POROSA . . . . . . . . . . 113

APÊNDICE D - SCRIPTS EM MATLAB DOS MÉTODOS BASEADOS FLUTUAÇÃO DIARIA DO NÍVEL FREÁ-

TICO .................... . 115

D.1 Script do método de White (1932) . . . . . . . . . . . 115

D.2 Script do método de Dolan et al. (1984) . . . . . . . . . . . . . . 117

D.3 Script do método de Hays (2003) . . . . . . . . . . . . . . . . . 119

D.4 Script do método de Gribovszki et al. (2008) . . . . . . . . . . . . 121

D.5 Script do método de Loheide II (2008) . . . . . . . . . . . . . . 125

APÊNDICE E - PROFUNDIDADES DO NÍVEL FREÁTICO . . . . 129

APÊNDICE F - VARIAÇÃO DO $S_{y}$ COM O TEMPO . . . . . . 133

F.1 Zona ripária - Poço $27 \ldots \ldots$. . . . . . . . . . . . . . . . . . . .

F.2 Zona de transição - Poço $28 \ldots \ldots$. . . . . . . . . . . . . . 134

F.3 Área de Cerrado stricto sensu - Poço $29 \ldots$. . . . . . . . . . . . . 134

F.4 Área de eucalipto - Poço $16 \ldots$. . . . . . . . . . . . . . . 135

APÊNDICE G - CURVAS MÉdIAS GRANULOMÉTRICAS . . . 136

G.1 Zona ripária - Poço $27 \ldots \ldots$. . . . . . . . . . . . . . . . . .

G.2 Zona de transição - Poço $28 \ldots$. . . . . . . . . . . . . . . . . 136

G.3 Área de Cerrado stricto sensu - Poço $29 \ldots 137$

APÊNDICE H - VARIÁVEIS METEOROLÓGICAS MONITORADAS

APÊNDICE I - CONDUTIVIDADE HIDRÁULICA $(K)$ - SLUG TEST . . . . . . . . . . . . . 139 



\section{INTRODUÇÃO}

A evapotranspiração $(E T)$ é uma componente significativa do ciclo hidrológico que precisa ser estimada e monitorada, com o fim de gerenciar eficientemente os recursos hídricos. O entendimento dessa variável também permite a compreensão da interação entre a vegetação, solo e a atmosfera, em termos de transferência de massa e calor (ESMAEILABADI, 2014).

Na superfície terrestre, a ET representa aproximadamente o $60 \%$ da precipitação total que é devolvida para a atmosfera, enquanto nas regiões áridas e semi-árias, pode atingir até 90\% (BRUTSAERT, 2005).

Valores elevados de ET podem ser encontrados em zonas ripárias, devido à proximidade que existe entre o nível de água subterrânea (ou franja capilar) e a superfície do solo, permitindo o seu contato com as raízes da vegetação (LOHEIDE II; BUTLER; GORELICK, 2005). Além disso, nessas áreas existem depósitos aluviais que produzem solos de coloração escura, ricos em nutrientes e material orgânico, e com albedo pequeno, isto é, maior aproveitamento da energia solar.

As zonas ripárias contribuem para a manutenção da saúde ambiental nas microbacias através da retenção de sedimentos transportados pelo escoamento superficial, assegurando a estabilidade das margens dos rios e formando importantes corredores ecológicos. Além disso, grande parte dos cultivos agrícolas são beneficiados por estarem localizados em áreas adjacentes às zonas ripárias, dado que nelas existe pouca restrição hídrica em função do nível freático relativamente raso. Entender o processo de evapotranspiração nessas zonas é importante para a avaliação da quantidade e qualidade da água disponível seu ecossistema e para diversos tipos de culturas (NISH et al., 2000).

Embora seja conhecida a importância do estudo da ET nas zonas ripárias, poucos trabalhos ao redor do mundo têm sido publicados sobre este tema (DEVITT et al., 1998; GOODRICH et al., 2000; LAUTZ, 2008; GRIBOVSZKI et al., 2008; MARTINET et al., 2009). Na América Latina existe a necessidade de estudos como este devido à riqueza hídrica do continente, que possui um grande número de rios, nos quais o efeito da $E T$ pode não estar sendo considerado.

Um dos prováveis motivos da pouca investigação nesta matéria pode ser atribuído ao difícil acesso econômico para adquirir equipamentos necessários para a aplicação de métodos como o eddy covariance ou a razão de Bowen. Além disso, a aplicação desses métodos é complexa nestes lugares, já que precisam de grandes bordaduras que geralmente não são possíveis de encontrar nas zonas ripárias (GOODRICH et al., 2000). 
A estimativa da evapotranspiração para as zonas ripárias através do método de Penman Monteith - FAO 56 (ALLEN et al., 1998) é limitada pois não existem na literatura valores apropriados do coeficiente de cultura $\left(K c_{i}\right)$. Ademais, a construção de lisímetros para a obtenção direta da ET é complexa, pois o solo nessas áreas é instável, devido ao elevado teor de matéria orgânica e presença de fluxo lateral perto da superfície.

Em vista das limitações apresentadas para os equipamentos e metodologias mencionadas, os métodos da estimativa da ET baseados nas flutuações diárias do nível freático de água subterrânea representam uma solução chave na quantificação do balanço hídrico nessas zonas (LOHEIDE II; BUTLER; GORELICK, 2005). Além disso, não precisam de alto investimento econômico e possuem a capacidade de fazer estimativas da ET em áreas menores.

Portanto, pretende-se determinar a ET em zona ripária e em vegetações vizinhas, que neste caso são o Cerrado stricto sensu e o eucalipto, utilizando métodos baseados na flutuação diária do nível de água subterrânea. Para o desenvolvimento deste trabalho também será necessário o estudo de parâmetros físicos da heterogeneidade do solo, para aplicação eficaz dos métodos. 


\section{OBJETIVOS}

\subsection{Objetivo geral}

Determinar a evapotranspiração em zona ripária e áreas vizinhas (Cerrado stricto sensu e eucalipto) por meio da aplicação de métodos baseados na flutuação diária do nível de água subterrânea.

\subsection{Etapas específicas}

a) Instalar poços de monitoramento para coletar a informação da flutuação diária do nível de água subterrânea em cada vegetação;

b) Determinar o rendimento específico transiente e as características físicas do solo onde serão instalados os poços;

c) Aplicar diferentes métodos baseados na flutuação diária do nível de água subterrânea, para estimar a evapotranspiração em cada vegetação. 


\section{REVISÃO BIBLIOGRÁFICA}

\subsection{Processo de evapotranspiração}

A evapotranspiração $(E T)$ é a transferência de água para à atmosfera através combinação dos processos de evaporação na superfície do solo e da transpiração da vegetação. Esses processos ocorrem de forma simultânea e geralmente torna-se difícil saber como eles atuam de forma separada (ALLEN et al., 1998). Os principais fatores que controlam a ET são a energia solar, as características da vegetação, o poder evaporante do ar e o suprimento de água do solo às plantas (PEREIRA; SEDIYAMA; NOVA, 2013).

Para a determinação da evapotranspiração existem métodos diretos e indiretos. As principais técnicas utilizadas são a lisimetria e a física teórica dos elementos climáticos que envolvem uma área de estudo. As abordagens que compõem esses métodos serão apresentadas resumidamente a seguir.

Os lisímetros são usualmente empregados para a medição direta da ET. Podem ser definidos como volumes de solo fechados artificialmente nos quais a vegetação que se pretende analisar é plantada. Além disso, são enterrados ao mesmo nível do solo adjacente e com área superficial de 1 a $150 m^{2}$ (DINGMAN, 2015).

A forma de medir da evapotranspiração depende do tipo de lisímetro, isto é, nos lisímetros de pesagem a perda de água é obtida pela mudança da sua massa. Nos lisímetros de drenagem é medida a quantidade de água que drena, coletada no fundo, e subtraindo-se da quantidade total de água ingressada (ALLEN et al., 1998).

Para os métodos indiretos encontramos uma maior classificação, em que são usadas abordagens empíricas, micrometeorológicas, de sensoriamento remoto e de combinação de teorias (PEREIRA; SEDIYAMA; NOVA, 2013).

Nas abordagens empíricas, primeiramente, podem ser encontradas as que utilizam apenas medidas de temperatura do ar, como os métodos de Thornthwaite (THORNTHWAITE, 1948), Camargo (CAMARGO; M.B.P., 1983; CAMARGO; PEREIRA, 1990; CAMARGO; M.B.P., 2000) e Hargreaves- Samani (HARGREAVES; ALLEN, 2003). Segundo, as que usam simultaneamente a temperatura e a radiação solar, como os métodos de Jensen Haise (JENSEN; H.R., 1963), Makkink (MAKKINK, 1957) e Priestley-Taylor (PRIESTLEY; TAYLOR, 1972). Terceiro, as que utilizam a flutuação diária do nível de água subterrânea (WHITE, 1932; DOLAN et al., 1984; HAYS, 2003; GRIBOVSZKI et al., 2008; LOHEIDE II, 2008) ${ }^{1}$.

$\overline{1}$ Estes métodos são detalhados no item 3.2 e foram aplicados para o desenvolvimento deste trabalho. 
As abordagens micrometeorológicas mais comuns são: o método da correlação de turbilhões (eddy covariance) (BURBA, 2013), a razão de Bowen - balanço de energia (BOWEN, 1926) e o aerodinâmico (MONTEITH; UNSWORTH, 1990).

A estimativa da evapotranspiração por sensoriamento remoto é geralmente realizada quando a área de estudo possui escala global. Os algoritmos regularmente usados são: Surface energy balance algorithm for land (SEBAL), Mapping ET at high spatial resolution width internalized calibration (METRIC), Simplified surface energy balance index (S-SEBI) e Two source energy balance (TSEB) (PEREIRA; SEDIYAMA; NOVA, 2013).

Por ultimo, existem os métodos que resultaram da combinação de diferentes teorias, um desses é o Penman-Monteith (ALLEN et al., 1998), o qual é amplamente usado por diferentes pesquisadores. Com fim de utilizar um método padrão para a estimativa da evapotranspiração de referência, a Food and Agriculture Organization of the United Nations (FAO) parametrizou o método de Penman-Monteith ${ }^{2}$. A Tabela 1 mostra um resumo dos métodos diretos e indiretos.

Tabela 1 - Resumo dos métodos diretos e indiretos para a determinação da evapotranspiração

\begin{tabular}{|c|c|c|c|c|}
\hline Medida & Tipo & Método & Escala temporal & Escala espacial \\
\hline \multirow[t]{6}{*}{ DIRETA } & Lisímetro & $\begin{array}{l}\text { Pesagem } \\
\text { Drenagem }\end{array}$ & $0,5 h-$ anual & Pontual \\
\hline & \multirow{6}{*}{ Empírico } & Thornthwaite & & \multirow{5}{*}{ Regional } \\
\hline & & Camargo & Mensal & \\
\hline & & Hargreaves - Samani & & \\
\hline & & $\begin{array}{l}\text { Jensen - Haise } \\
\text { Makkink }\end{array}$ & semanal & \\
\hline & & Priestley-Taylor & Diária & \\
\hline \multirow[t]{5}{*}{ INDIRETA } & & $\begin{array}{c}\text { Flutuação diária do nível de água } \\
\text { subterrânea }\end{array}$ & Subdiária - diária & Pontual \\
\hline & \multirow{2}{*}{$\begin{array}{c}\text { Micrometeo- } \\
\text { lógicas }\end{array}$} & Correlação de turbilhões (eddy covariance) & \multirow[b]{2}{*}{$0,5 h-$ anual } & $>100: 1^{a}$ \\
\hline & & $\begin{array}{c}\text { Razão de Bowen - balanço de energia } \\
\text { Aerodinâmico }\end{array}$ & & $>20: 1$ \\
\hline & Combinado & $\begin{array}{c}\text { Penman-Monteith } \\
\text { Penman Monteith - FAO } 56\end{array}$ & Diária & Regional \\
\hline & Orbital & Sensoriamento Remoto & Diária & Global \\
\hline
\end{tabular}

${ }^{\text {a }} 100: 1=100 m$ de bordadura a cada $1 m$ de elevação na vertical.

Fonte: Adaptado de Wang e Dickinson (2012).

$\overline{2}$ Este método é detalhado no item 3.1.1, dado que será comparado com os métodos da flutuação diária do nível de água subterrânea. 


\subsubsection{Método do Penman Monteith - FAO 56}

Este método introduzido pelo boletim FAO Irrigation and Drainage 56 fornece o cálculo da evapotranspiração de referência $\left(E T_{o}\right)$ estimada pela equação de Penman Monteith parametrizada. Produz uma estimativa confiável da $E T_{o}$ em diversos tipos de clima e é utilizada como padrão internacional para avaliar diferentes métodos de estimativa da ET. Este método substitui em muitas situações medidas lisimétricas (ALLEN et al., 1998).

A equação genérica de Penman - Monteith foi parametrizada introduzindo o conceito de superfície de referência. Foi definido por Allen et al. (1998) como: "uma vegetação hipotética, com altura fixa de 0,12 $\mathrm{m}$, resistência ao transporte de vapor de água $\left(r_{c}\right)$ constante e igual a $70 \mathrm{~s} \mathrm{~m}^{-1}$, e albedo de 0,23". A equação é a seguinte:

$$
E T_{o}=\frac{0,408 \Delta\left(R_{n}-G\right)+\gamma \frac{900}{T+273} u_{2}\left(e_{s}-e_{a}\right)}{\Delta+\gamma\left(1+0,34 u_{2}\right)} \quad\left[m m d^{-1}\right]
$$

sendo $R_{n}$ o saldo de radiação [MJ $\left.m^{-2} d^{-1}\right] ; G$ o fluxo de calor sensível no solo $\left[M J m^{-2}\right.$ $\left.d^{-1}\right] ; \gamma$ o coeficiente psicométrico $\left[\mathrm{kPa}^{\circ} \mathrm{C}^{-1}\right] ; \mathrm{T}$ a temperatura média diária a $2 \mathrm{~m}$ de altura $\left[{ }^{\circ} \mathrm{C}\right] ; u_{2}$ a velocidade do vento a $2 m$ de altura $\left[m s^{-1}\right] ; e_{s}$ a pressão de saturação de vapor $[k P a] ; e_{a}$ a pressão de vapor atual $[k P a] ; e_{s}-e_{a}$ o déficit de pressão de saturação de vapor $[k P a] ; \Delta$ a tangente à curva de pressão de saturação no gráfico psicrométrico $\left[k P a{ }^{\circ} C^{-1}\right]$. 


\subsection{Métodos para a estimativa da evapotranspiração a partir da flutuação diária do nível de água subterrânea}

White (1932) foi o precursor no estudo das flutuações diárias do nível de água subterrânea, como ferramenta para a estimativa da evapotranspiração em zonas onde o nível freático se encontra perto da superfície do solo, por exemplo, zonas ripárias e pântanos.

Baseados nesta metodologia surgiram diferentes pesquisas realizadas por Dolan et al. (1984), Hays (2003), Gribovszki et al. (2008), Loheide II (2008), com o propósito de aprimorar a estimativa da evapotranspiração. Estas diferentes abordagens serão apresentadas de forma resumida em seguida.

\subsubsection{Método de White (1932)}

White (1932) desenvolveu um método para estimar a evapotranspiração diária em um aquífero livre, a partir de registros horários da flutuação diária do nível de água subterrânea pouco profunda.

Esse autor indicou que durante o dia, quando os raios do sol têm contato com a vegetação e é iniciado o processo de fotossíntese (junto com aumento da temperatura no solo), ocorre uma queda no nível freático pelo efeito da evapotranspiração das águas subterrâneas $\left(E T^{g w}\right)$. Durante a noite a $E T^{g w}$ é desprezível, ocorrendo uma elevação no nível devido ao fluxo subterrâneo lateral (Figura 1).

Este fenômeno pode ser observado somente nas épocas sem precipitações, dado que as ocorrências de chuva alteram o padrão flutuante do nível freático. Quando não ocorrem precipitações, é considerada a evapotranspiração de águas subterrâneas ( $\left.E T^{g w}\right)$ igual à evapotranspiração total ( $E T)$, pois não existiria evapotranspiração na superfície do terreno $\left(E T^{s w}\right)$ e no solo exposto $\left(E T^{u z}\right)$. Portanto, a $E T$ será a única variável relacionada à evapotranspiração que aparecerá nos diferentes equacionamentos neste trabalho, já que os métodos baseados na flutuação diária, serão aplicados nas épocas sem precipitações. A equação da ET para eventos sem precipitação pode ser determinada como:

$$
E T=Q_{l i q}-\Delta S
$$

em que $Q_{l i q}$ é o fluxo lateral líquido de água subterrânea. $\Delta S(L / T)$ é a variação de armazenamento de água no solo. Outro fator importante que influi fortemente na amplitude das flutuações é a caracterização do solo, representada neste caso pelo rendimento especifico $\left(S_{y}\right)$. Para aplicação correta desta metodologia, Loheide II, Butler e Gorelick (2005) sugerem as seguintes suposições chaves: 
Figura 1 - Flutuação diária do nível de água subterrânea na zona ripária do Rio de Arkansas, Kansas, USA.

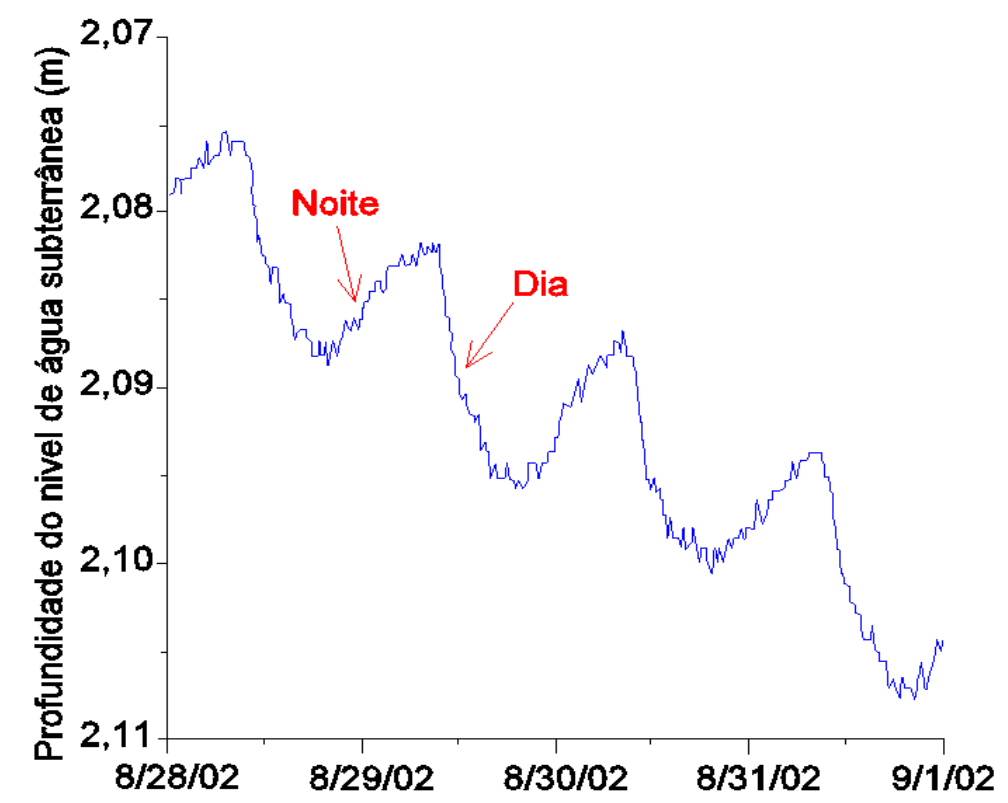

Fonte: Adaptado de Loheide II, Butler e Gorelick (2005).

a) Os valores da evapotranspiração da água subterrânea são mínimos em comparação com o fluxo lateral de água subterrânea entre as $0 h 00$ e $4 h 00$.

b) O fluxo lateral perto dos poços de monitoramento é constante durante o dia.

c) As flutuações acontecem em zonas com níveis de água subterrânea pouco profundas, onde as raízes da vegetação tem contato com o nível freático ou pelo menos com a zona de capilaridade. Assim, deve ser considerado para fins de equacionamento, apenas o rendimento específico transiente $\left(S_{y}^{*}\right)^{3}$.

A partir da equação 3.2, White (1932) desenvolveu o seguinte equacionamento para a determinação da evapotranspiração diária $\left(E T_{d}\right)$ :

$$
E T_{d}=S_{y}^{*}\left(24 r_{h} \pm \Delta s\right)
$$

em que $S_{y}^{*}$ é o rendimento especifico transiente $\left(L^{3} / L^{3}\right) . r_{h}$ é a taxa média horária de elevação do nível freático entre as $0 h 00$ e 4h00, que precisa ser multiplicado por 24 e pelo $S_{y}^{*}$ para representar o aporte constante do fluxo lateral durante as $24 h$ do dia $\left(Q_{\text {liq }} /\right.$ dia $\left.=24 \times S_{y}^{*} \times r_{h}\right) . \Delta s(L / T)$ é a queda líquida diária do nível freático, sendo $\Delta S=S_{y}^{*} \times \Delta s$ (Figura 2).

3 O $S_{y}^{*}$ é a quantidade percentual de água que pode ser drenada de um solo por gravidade, no período de flutuação diária do nível de água subterrânea. A definição dessa variável é aprofundada no item 3.5.1. 
Figura 2 - Flutuação do nível freático em um dia, indicado dentro da janela verde. A linha de traços representa o aporte constante do fluxo lateral durante as $24 \mathrm{~h}$ do dia e a tendência que deveria ter seguido a hidrógrafa na ausência do evento de evapotranspiração. A vermelha mostra os dados registrados entre as $0 h 00$ até $4 h 00$ para o cálculo de $r_{h}$. A pontilhada é a projeção horizontal do nível freático ás $0 h 00$ no começo do dia.

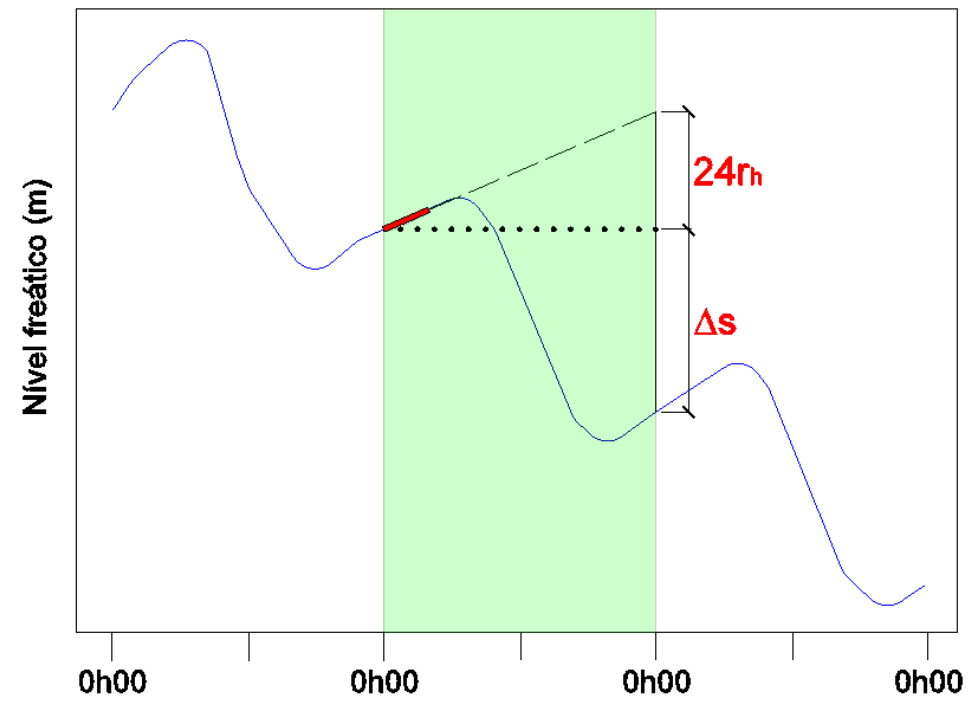

Fonte: Adaptado de White (1932).

\subsubsection{Método de Dolan et al. (1984)}

Segundo Dolan et al. (1984), as estimativas da evapotranspiração baseadas na flutuação diária do nível de água subterrânea, além de não poderem ser aplicadas em épocas chuvosas, devem prevalecer as seguintes condições:

a) Que nas zonas ripárias a direção do fluxo de água subterrânea seja em condição de rio efluente, a fim de que o rio não tenha influência nas flutuações do nível freático do aquífero.

b) Não deve haver, próximo da área de estudo, extração de água subterrânea através de poços.

No que se refere ao equacionamento, Dolan et al. (1984) consideraram que a integração da taxa média horária de elevação do nível freático $\left(r_{h}\right)$ de dois dias consecutivos poderia aprimorar a estimativa da $E T$.

O método consiste em extrapolar a taxa média horária de elevação do nível freático do dia em estudo, $r_{1}(L / T)$, e do dia próximo, $r_{2}(L / T)$, até as $12 h 00$ (Figura 3). O cálculo de $r_{1}$ e $r_{2}$ pode ser efetuado entre as $0 h 00$ e $4 h 00$ como no método de White (1932). 
Figura 3 - Flutuação do nível freático em um dia indicado dentro da janela verde. As linhas de traços extrapoladas até o meio-dia representam a quantidade de água evapotranspirada durante as $24 h$.

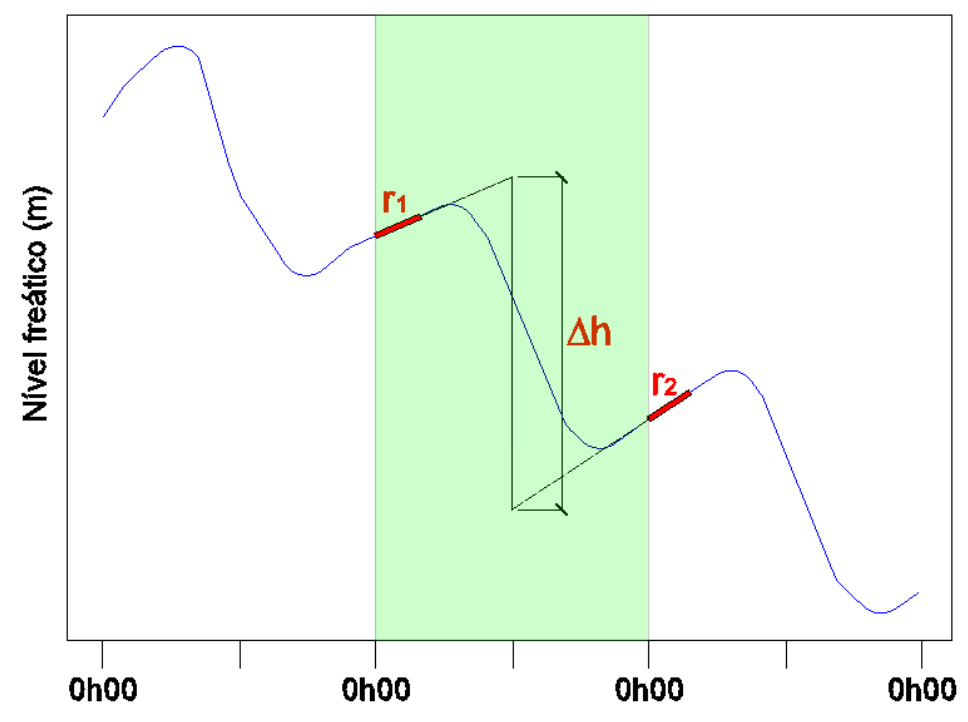

Fonte: Adaptado de Dolan et al. (1984).

Para estimar $E T_{d}$ a diferença entre as extrapolações de $r_{1}$ e $r_{2}$ até as $12 h 00(\Delta h)$, é multiplicada por $S_{y}^{*}$ :

$$
E T_{d}=S_{y}^{*}(\Delta h)
$$

\subsubsection{Método de Hays (2003)}

Hays (2003) apresentou em sua tese um método que também são considerados dados de dois dias consecutivos. Um aspecto relevante no seu equacionamento é que, diferentes dos métodos anteriores, não é baseado em extrapolações, mas utiliza os dados extremos das flutuações e o tempo que existe entre eles (equação 3.5).

$$
E T_{d}=S_{y}^{*}\left[h_{M a x 1}-h_{\min }+\left(h_{M a x 2}-h_{\min }\right) \frac{t_{d 1}}{t_{d 2}}\right]
$$

em que $h_{M a x 1}$ é o nível máximo de água do dia em estudo $(L) ; h_{\min }$ o nível mínimo de água do dia em estudo $(L) ; h_{M a x 2}$ o nível máximo de água do dia seguinte $(L) ; t_{d 1}$ o intervalo de tempo entre $h_{\text {Max } 1}$ e $h_{\min }(T)$ e $t_{d 2}$ o intervalo de tempo entre $h_{\min }$ e $h_{\text {Max } 2}$ $(T)$. O fluxo lateral $S_{y}^{*}\left[\left(h_{\text {Max } 2}-h_{m i n}\right) / t_{d 2}\right]$ é calculado na noite seguinte e o efeito da evapotranspiração acontece entre $h_{M a x 1}$ e $h_{\min }$ (Figura 4). 
Figura 4 - Flutuação do nível freático em um dia indicado dentro da janela verde. Entre $h_{M a x 1}$ e $h_{\min }$ a evapotranspiração gera a queda do nível freático. Entre $h_{\min } \mathrm{e}$ $h_{\text {Max2 }}$ é calculado o fluxo lateral.

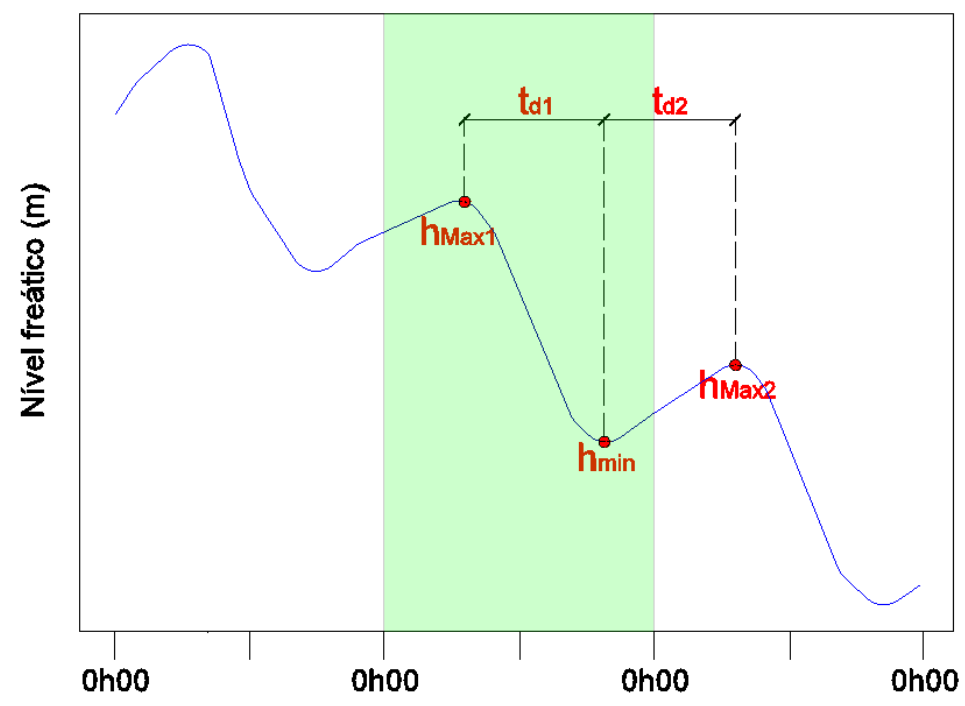

Fonte: Adaptado de Hays (2003).

\subsubsection{Método de Gribovszki et al. (2008)}

Os autores deste método desenvolveram o seu estudo em uma zona ripária, ponto $\boldsymbol{A}$ (Figura 5), onde a direção do fluxo de água subterrânea é em condição de rio efluente. Desse modo que não há influência nas flutuações do nível freático do aquífero e as raízes da vegetação atingem o nível de água subterrânea ou pelo menos a zona de capilaridade.

Segundo Gribovszki et al. (2008), a ET no ponto $\boldsymbol{A}$ causa um rebaixamento do nível de água subterrânea. Consequentemente é gerado um aumento do gradiente hidráulico entre a zona ripária e uma zona distante, ponto $\boldsymbol{B}$, com maior cota topográfica. Esse ponto compartilha as mesmas linhas de fluxo com o ponto $\boldsymbol{A}$ e o nível de água é profundo em relação à superfície do solo (Figura 5). Essa diferença de carga hidráulica origina um aumento do fluxo lateral desde $\boldsymbol{B}$ até $\boldsymbol{A}$. Além disso, em $\boldsymbol{B}$ acontecem leves flutuações diárias de forma indireta, porque embora nele não faça efeito a $E T$, há mudanças diárias de gradiente hidráulico com a zona ripária.

Para aplicação deste método, primeiramente devem ser registrados os dados dos níveis de água subterrânea $(h)$ com um intervalo de tempo entre 10 min e 1 hora, com o fim de calcular a taxa de variação do nível de água subterrânea $(d h / d t)$. Em seguida, constrói-se um gráfico de $h$ vs tempo $t$ (Figura 6a), e outro de $(d h / d t)$ vs tempo $t$ (Figura $6 b)$.

A série de tempo $S_{y}^{*} d h / d t=\Delta S$ pode ser assumida como diretamente proporcional à diferença entre o fluxo lateral $\left[Q_{l i q}(t)\right]$ e à evapotranspiração no tempo $t[E T(t)]$ no ponto $\boldsymbol{A}$. Estas variáveis fazem parte da equação da conservação da massa na época de 
estiagem:

$$
\frac{d S}{d t}=S_{y}^{*} \frac{d h}{d t}=Q_{l i q}(t)-E T(t)
$$

Figura 5 - Modelo esquemático da na zona ripária (ponto $\boldsymbol{A}$ ) onde as raízes atingem o nível freático do aquífero e a zona distante (ponto $\boldsymbol{B}$ ) em que o nível de água subterrânea é profundo.

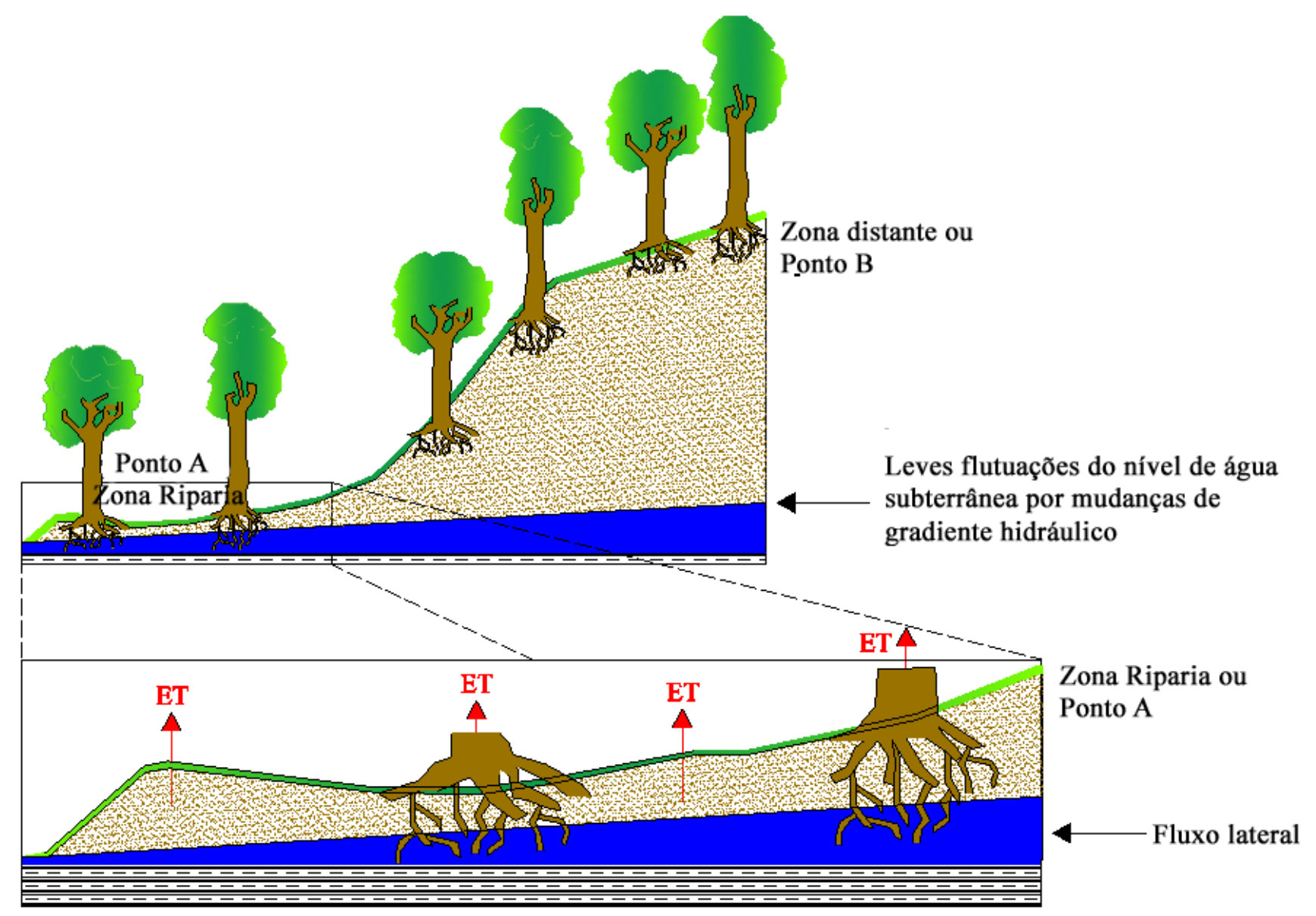

Fonte: Adaptado de Gribovszki et al. (2008).

Diferentemente dos método anteriores, Gribovszki et al. (2008) afirmam que o fluxo lateral não é constante, e varia durante o dia, dependendo do valor do gradiente hidráulico entre $\boldsymbol{B}$ e $\boldsymbol{A}$. Consequentemente, esses autores propuseram determinar dois pontos do $\left[Q_{l i q}(t)\right]$, i. e., o máximo $\left(Q_{\text {liqMax }}\right)$ e o mínimo $\left(Q_{\text {liqmin }}\right)$, e a partir deles estimar o fluxo lateral transiente.

O valor de $Q_{\text {liqMax }}$ para cada dia, é calculado através da seleção da maior $d h / d t$ (positiva) na hidrógrafa do dia em estudo, assumindo que $Q_{l i q}(t) \approx S_{y}^{*}(d h / d t)$. $Q_{\text {liqmin }}$ é obtido pelo cálculo da média entre as $S_{y}^{*}(d h / d t)$ no intervalo das $0 h 00$ às $6 h 00$. Os valores de $Q_{\text {liqMax }}$ são plotados no gráfico $d h / d t$ vs $t$, com a mesma abcissa dos níveis mínimos de 
água subterrânea $\left(h_{\text {min }}\right)$, do gráfico $h$ vs $t$ e os valores de $Q_{\text {liqmin }}$ nas mesmas abcissas dos níveis máximos de água subterrânea $\left(h_{M a x}\right)$ (Figura $\left.6 b\right)$.

Figura 6 - a) Flutuação do nível freático de um dia indicado dentro da janela azul. b) Gráfico da taxa de nível de água subterrânea, sendo colocados os $Q_{l i q M a x}$ e $Q_{\text {liqmin }}$ na mesmas abcissas de $h_{\min }$ e $h_{\text {Max }}$, respetivamente no mesmo dia.

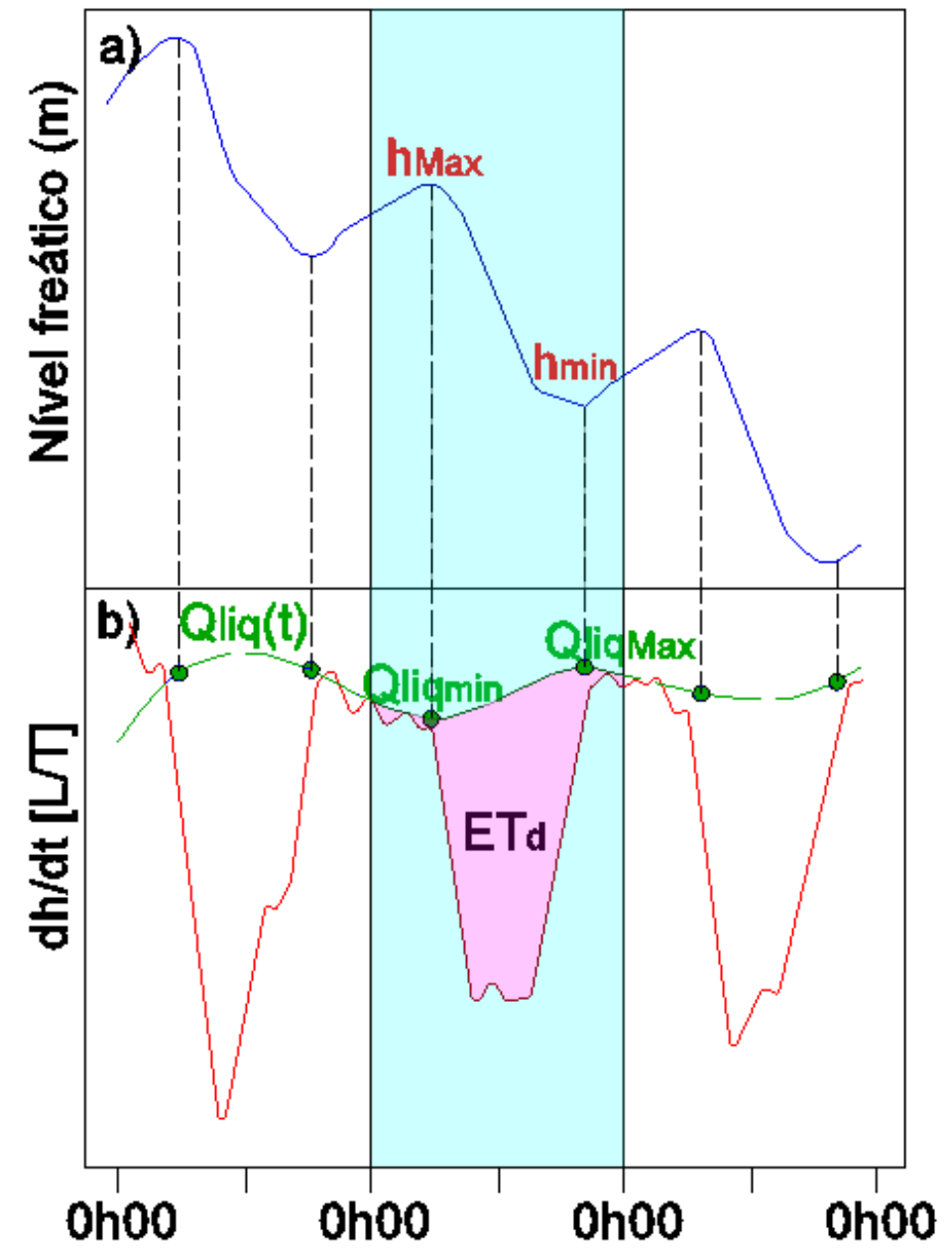

Fonte: Fonte: Adaptado de Gribovszki et al. (2008).

Os valores de $Q_{\text {liqMax }}$ e $Q_{\text {liqmin }}$ serão os dois pontos conhecidos em um mesmo dia, para depois fazer uma interpolação spline entre eles, a qual descreve o $\left[Q_{l i q}(t)\right][L / T]$. A evapotranspiração no tempo $t$ é calculada como:

$$
E T(t)=Q_{l i q}(t)-S_{y}^{*}\left(\frac{d h}{d t}\right)
$$

A evapotranspiração diária é dada por:

$$
E T_{d}=\int\left\{Q_{l i q}(t)-S_{y}^{*}\left[\frac{d h(t)}{d t}\right]\right\} d t
$$




\subsubsection{Método de Loheide II (2008)}

Loheide II (2008) usando a mesma abordagem de Gribovszki et al. (2008), assumiu que a variação do fluxo lateral é função da diferença do gradiente hidráulico entre o nível de água subterrânea na zona ripária (ponto $\boldsymbol{A}$ ) e na zona distante (ponto $\boldsymbol{B}$ ). Além disso, o ponto $\boldsymbol{B}$ sofreria leves flutuações diárias no nível de água, com a mesma declividade das flutuações no ponto $\boldsymbol{A}$ (Figura 7).

Figura 7 - Flutuações do nível de água subterrânea no ponto $\boldsymbol{A}$ e $\boldsymbol{B}$. As suas declividades são as mesmas.

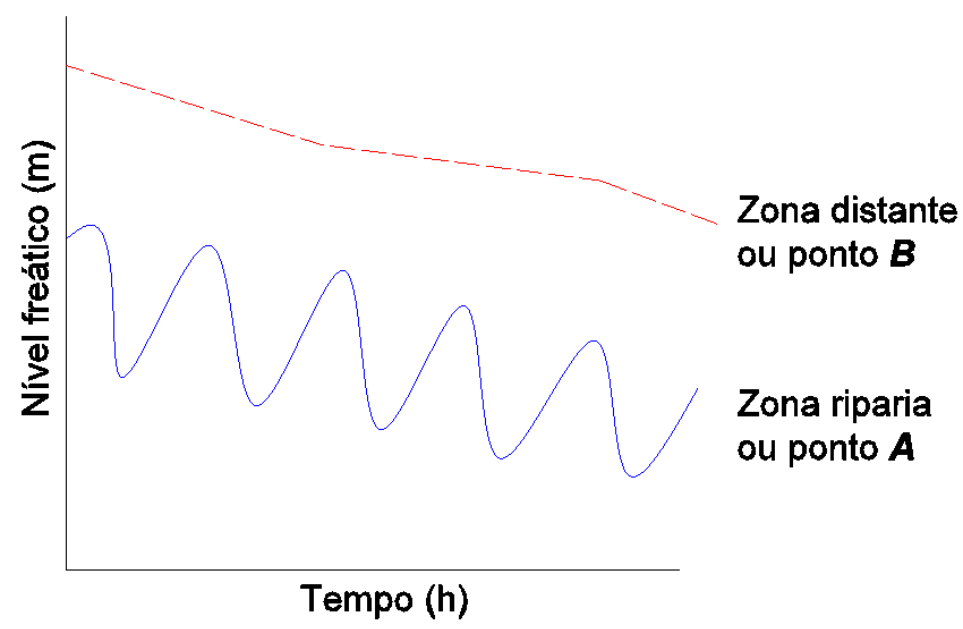

Fonte: Adaptado de Loheide II (2008).

O autor estabeleceu como profundidade zero o nível freático na superfície do solo, e essa medida aumenta negativamente proporcional à profundidade, i. e., as profundidades são expressas em números negativos.

Nesta metodologia mostra-se que para um período curto de tempo, de 1 a 2 dias, os registros dos níveis de água subterrânea em $\boldsymbol{B}$ são assumidos como uma linha reta, dado que as flutuações são muito baixas, mas conservando a sua declividade. Como a inclinação do rebaixamento do nível de água em $\boldsymbol{B}$ acontece de forma paralela com os níveis em $\boldsymbol{A}, W T$, ela pode ser calculada de forma indireta através de uma regressão linear das flutuações na zona ripária, representado na seguinte equação:

$$
\text { Regressão linear em } A=m_{A B} \times t+b
$$

sendo $m_{A B}$ a declividade do rebaixamento do nível de água subterrânea em $\boldsymbol{A}$ e $\boldsymbol{B}, b$ a intercepção e $t$ o tempo (Figura 8). 
Figura 8 - Nível de água subterrânea com flutuação inclinada no ponto $\boldsymbol{A}$ e assumido como uma linha inclinada em $\boldsymbol{B}$, para um período menor a 2 dias.

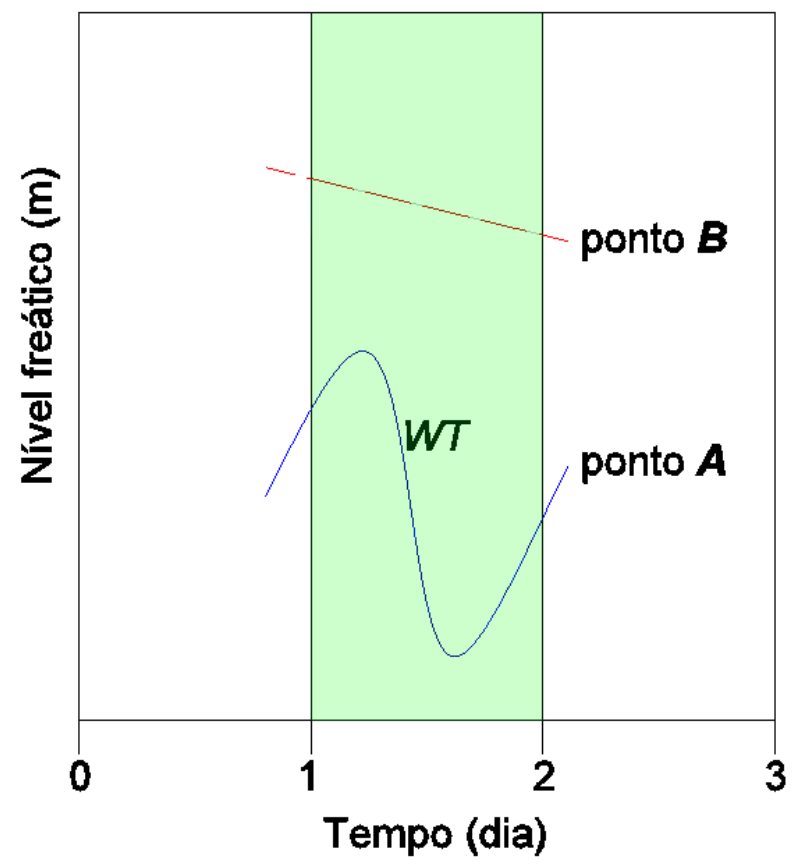

Fonte: Adaptado de Loheide II (2008).

O objetivo de estimar a declividade é removê-la dos dados da profundidade do nível de água subterrânea no ponto $\boldsymbol{A}, W T_{D T}$, dado pela equação:

$$
W T_{D T}=W T-m_{A B} \times t-b
$$

O fato de remover a inclinação dos níveis na zona ripária, faz que automaticamente seja aplicado também no ponto $\boldsymbol{B}$, resultando numa linha horizontal (Figura 9), visto que o rebaixamento é paralelo entre $\boldsymbol{A}$ e $\boldsymbol{B}$.

Todo o procedimento de remoção da declividade é feito para aprimorar o cálculo do fluxo lateral, que ficaria dependendo apenas da flutuação do nível de água subterrânea no ponto $\boldsymbol{A}$, porque o nível no ponto $\boldsymbol{B}$ passaria a ser constante (uma linha reta horizontal para um período curto de tempo).

A aplicação deste procedimento de remoção da tendência fornece uma relação para prever $W T_{D T} / d t$ como uma função da profundidade do nível de água subterrânea com tendência removida na zona ripária $\Gamma\left(W T_{D T}\right)$ para períodos entre $0 h 00$ e $6 h 00$ (na manhã do dia em estudo e na manhã do dia seguinte) quando a ET esteja muito perto de zero (Equação 3.11)

$$
\Gamma\left(W T_{D T}\right)=\frac{d W T_{D T}}{d t}
$$


Figura 9 - Nível de água subterrânea com flutuação no ponto $\boldsymbol{A}$ e assumido como uma linha reta em $\boldsymbol{B}$, com inclinações removidas, para um período menor a 2 dias.

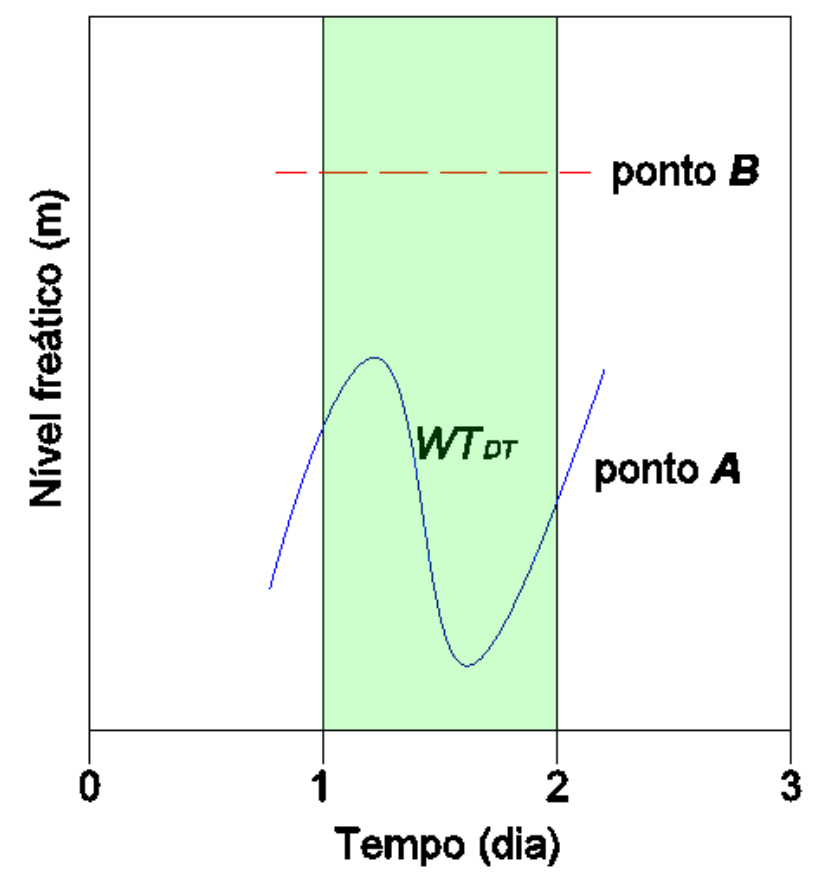

Fonte: Adaptado de Loheide II (2008).

$\Gamma\left(W T_{D T}\right)$ pode ser calculada através de regressão linear dos dados das variáveis $d W T_{D T}$ e $W T_{D T}$. A soma de $m_{A B}$ ao $\Gamma\left(W T_{D T}\right)$ e multiplicado pelo rendimento especifico transiente, representa o cálculo do fluxo lateral através do tempo $\left[Q_{L i q}(t)\right]$ :

$$
Q_{L i q}(t)=S_{y}^{*}\left[\Gamma\left(W T_{D T}\right)+m_{A B}\right]
$$

Assim, a evapotranspiração no tempo t é calculada como:

$$
E T(t)=Q_{L i q}(t)-S_{y}^{*}\left(\frac{d W T}{d t}\right)
$$

A evapotranspiração diária é estimada com a equação 3.8 .

Pode-se inferir que este procedimento proposto por Loheide II (2008) é diferente do método de Gribovszki et al. (2008) apenas em termos de cálculo taxa de fluxo lateral através do tempo, $Q_{L i q}(t)$.

A Tabela 2 apresenta um resumo das características básicas dos diferentes métodos da flutuação diária do nível freático de água subterrânea. 
Tabela 2 - Resumo dos métodos de estimativa de ET a partir da flutuação diária do nível de água subterrânea

\begin{tabular}{cccc}
\hline $\begin{array}{c}\text { Autores dos } \\
\text { métodos }\end{array}$ & $\begin{array}{c}\text { Caracterização do } \\
\text { solo }\end{array}$ & Fluxo lateral & Estimativas da ET \\
\hline White (1932) & $\begin{array}{c}\text { Rendimento } \\
\text { Dolan et al. }(1984)\end{array}$ & Constante & Diária \\
Hays (2003) & $\left(S_{y}^{*}\right)$ & Transiente & Subdiária \\
\cline { 2 - 4 } $\begin{array}{c}\text { Gribovszki et al. }(2008) \\
\text { Loheide II }(2008)\end{array}$ & & & \\
\hline
\end{tabular}

Fonte: Autor.

\subsection{Compensação barométrica e filtragem passa-baixa}

As medições contínuas de nível freático são geralmente feitas por meio de transdutores de pressão, os quais medem a pressão absoluta que age sobre uma membrana contida no dispositivo. Equipamentos semelhantes, instalados à pressão atmosférica, são então utilizados para realizar a compensação barométrica.

Quando a frequência da coleta nesses dispositivos é alta, podem ser observadas marés atmosféricas e perturbações da pressão atmosférica (APP - atmospheric pressure perturbation) (DELYUKOV; DIDYK, 1999). As APP são ruídos gerados pela turbulência e a variação de densidade do fluxo de ar, e pela mudança de temperatura.

O tratamento matemático que pode ser feito para a remoção do ruído em uma coleta de dados é a utilização da filtragem passa-baixa, porque permite a atenuação das frequências altas, tendo uma influencia quase nula nas frequências baixas. Gribovszki et al. (2008) recomendaram o uso de filtragem passa-baixa com o fim de reduzir os erros que poderiam ser produzidos com a utilização de dados com ruído (pulsos de alta frequência), sem gerar alterações nas amplitudes dos pulsos de baixas frequências.

A Regressão Polinomial Local Ponderada (Loess) é um tipo de filtragem passabaixa proposto originalmente por Cleveland (1979) e desenvolvida por Devlin (1986). Esse método combina a regressão linear por mínimos quadrados, com a flexibilidade da regressão não linear, a fim de encaixar modelos simples para subconjuntos localizados de dados e construir uma função que descreve a sua variação, ponto por ponto.

Esse tipo de processo é usado principalmente para suavizar ou atenuar o ruído de dados de uma série temporal. É considerado local, porque como o método da média móvel, cada valor suavizado é determinado por uma faixa de dados vizinhos. 


\subsection{Estimativas de evapotranspiração em zona ripária, Cerrado stricto sensu e eucalipto}

Esta seção apresenta uma revisão de estudos a respeito da estimativa da evapotranspiração diária visando estabelecer uma base comparativa para os resultados obtidos na presente pesquisa. No Brasil, há vários trabalhos a respeito da estimativa de ET diária em Cerrado stricto sensu e eucalipto. Para a zona ripária, não foram encontradas publicações no Brasil, nem na América Latina, em nenhuma escala de tempo.

Para a zona ripária foram organizados cronologicamente os seguintes resultados da evapotranspiração diária:

a) Devitt et al. (1998) aplicando o método da razão de Bowen obtiveram valores de ET entre $<1,0$ e 15,0 mm/d no Virgin River no nordeste do estado de Nevada, EUA. As estimativas foram realizadas entre os anos 1994 - 1996 e a variação de temperatura foi de $2{ }^{\circ} \mathrm{C}$ no inverno até $45^{\circ} \mathrm{C}$ no verão.

b) Goodrich et al. (2000) mostraram uma faixa de ET entre 4,0 e 16,0 mm/d através de estimativas realizadas com imagens de sensoriamento remoto, calibradas com o método de Penman Monteith. O estudo foi realizado no ano 1997 na bacia San Pedro no sudeste de Arizona, EUA, com variações de temperatura de $8{ }^{\circ} \mathrm{C}$ no outono a $26{ }^{\circ} \mathrm{C}$ no Verão.

c) Aplicando o modelo matemático de Priestley-Taylor, Lautz (2008) obteve resultados de 10,0 a 17,3 mm/d no Red Canyon Creek, Wyoming, EUA. O período de estudo foi entre julho e outubro de 2005 e entre maio e junho do 2006, e a variação de temperatura foi de $-3{ }^{\circ} \mathrm{C}$ no inverno até $18^{\circ} \mathrm{C}$ no verão.

d) No ocidente no Sopron Hills, Hungría, Gribovszki et al. (2008) estimaram resultados de 3,0 a 15,0 mm/d. A região possui árvores com uma altura média de $15 \mathrm{~m}$, índice de área foliar de 7,4 e temperaturas de $0{ }^{\circ} \mathrm{C}$ no inverno e $17^{\circ} \mathrm{C}$ no verão. A profundidade da água subterrânea variou entre 60 e $90 \mathrm{~cm}$ a partir da superfície do solo.

e) Através do método do eddy covariance, Martinet et al. (2009) obtiveram valores entre 1,0 e 10,0 mm/d com um registro de medições de 7 anos no Rio Grande, New México, EUA.

A Tabela 3 mostra um resumo dos artigos publicados sobre evapotranspiração em zona ripária. 
Tabela 3 - Publicações de estimativas da evapotranspiração em zona ripária em áreas de estudo internacionais

\begin{tabular}{|c|c|c|c|c|}
\hline Autor & Localização & Método & Temp. $\left({ }^{\circ} C\right)$ & $\begin{array}{l}\text { Faixa de } E T \\
\quad\left(m m d^{-1}\right)\end{array}$ \\
\hline Devitt et al. (1998) & $\begin{array}{c}\text { Virgin River, Estado } \\
\text { de Nevada, EUA }\end{array}$ & Razão de Bowen & $\begin{array}{l}2 \text { (Inverno) - } \\
45 \text { (Verão) }\end{array}$ & $<1,0-15,0$ \\
\hline Goodrich et al. (2000) & $\begin{array}{c}\text { Bacia San Pedro, } \\
\text { Arizona, EUA }\end{array}$ & Sensoriamento remoto & $\begin{array}{l}8 \text { (outono) - } \\
26 \text { (Verão) }\end{array}$ & $4,0-16,0$ \\
\hline Lautz (2008) & $\begin{array}{l}\text { Red Canyon Creek, } \\
\text { Wyoming, EUA }\end{array}$ & $\begin{array}{l}\text { Modelo matemático } \\
\text { Priestley-Taylor }\end{array}$ & $\begin{array}{c}-3 \text { (Inverno) - } \\
18 \text { (Verão) }\end{array}$ & $10,0-17,3$ \\
\hline Gribovszki et al. (2008) & $\begin{array}{l}\text { Sopron Hills, } \\
\text { Hungria }\end{array}$ & $\begin{array}{c}\text { Flutuação diária do nível } \\
\text { de água subterrânea }\end{array}$ & $\begin{array}{l}0 \text { (Inverno) - } \\
17 \text { (Verão) }\end{array}$ & $3,0-15,0$ \\
\hline Martinet et al. (2009) & $\begin{array}{c}\text { Rio Grande, New } \\
\text { México, EUA }\end{array}$ & Eddy covariance & $\begin{array}{l}\text { Não indicada } \\
\text { pelos autores }\end{array}$ & $1,0-10,0$ \\
\hline
\end{tabular}

Fonte: Autor.

Para o Cerrado stricto sensu foram organizados cronologicamente trabalhos de resultados da evapotranspiração diária:

a) Através de dados obtidos do volume de água em perfis de solo, da precipitação e a drenagem do solo, Oliveira et al. (2005) estimaram a ET na Reserva Ecológica do Instituto Brasileiro de Geografia e Estadística (RECOR-IBGE) a $35 \mathrm{~km}$ do sul de Brasília, entre os anos 1996 e 1998. A faixa de valores esteve entre 1,4 e 5,8 mm/d.

b) Giambelluca et al. (2009) obtiveram resultados de $E T$ entre 1,7 e 3,2 $\mathrm{mm} / \mathrm{d}$, aplicando o método do eddy covariance durante um período de 2 anos. A área de estudo está localizada em Brasília com variações de temperatura média entre 20,1 e $23,5{ }^{\circ} \mathrm{C}$.

c) Oliveira et al. (2015) desenvolveram um modelo empírico para o cálculo da evapotranspiração do Cerrado stricto sensu, localizado no Instituto Arruda Botelho-IAB, município de Itirapina, SP. Esse método foi desenvolvido a partir de dados do enhanced vegetation index - EVI (Obtidos através do sensor Moderate Resolution Imaging Spectroradiometer - MODIS) e calibrado com o método de eddy covariance e da evapotranspiração de referência. As estimativas foram realizadas entre 2011 e 2014 e estiveram entre de 1,91 e $2,60 \mathrm{~mm} / \mathrm{d}$.

d) Aplicando o método de eddy covariance durante 3 anos, Cabral et al. (2015) obtiveram resultados da $E T$ entre 1,0 e 7,1 mm/d. A área de estudo está localizada na reserva Pé do Gigante - município de Santa Rita do Passa Quatro, SP com uma temperatura média diária de $22,1 \pm 0,5^{\circ} \mathrm{C}$.

A Tabela 4 mostra um resumo dos artigos publicados sobre evapotranspiração do Cerrado stricto sensu no Brasil. 
Tabela 4 - Publicações das estimativas da evapotranspiração no Cerrado stricto sensu em áreas de estudo no Brasil

\begin{tabular}{ccccc}
\hline Autor & Localização & Método & Temp. $\left({ }^{\circ} \mathrm{C}\right)$ & $\begin{array}{c}\text { Faixa de } E T \\
\left(\mathrm{~mm} d^{-1}\right)\end{array}$ \\
\hline Oliveira et al. (2005) & $\begin{array}{c}\text { RECOR-IBGE - } \\
\text { Brasília, BR }\end{array}$ & Balanço Hídrico & $\begin{array}{c}\text { Não indicada } \\
\text { pelos autores }\end{array}$ & $1,4-5,8$ \\
Giambelluca et al. (2009) & Brasília, BR & Eddy covariance & $20,1-23,5$ & $1,7-3,2$ \\
Oliveira et al. (2015) & IAB - Itirapina, SP, BR & $\begin{array}{c}\text { Modelo empírico } \\
\text { (Eddy C.- imagens EVI) }\end{array}$ & 20,8 & $1,91-2,60$ \\
Cabral et al. (2015) & $\begin{array}{c}\text { R. Pé de Gigante - } \\
\text { Santa Rita do Passa } \\
\text { Quatro, SP, BR }\end{array}$ & Eddy covariance & 22,1 & $1,0-7,1$ \\
\hline
\end{tabular}

Fonte: Autor.

Para o eucalipto foram organizados cronologicamente, também, os trabalhos referentes a evapotranspiração diária:

a) Soares e Almeida (2001) estimaram a ET para eucaliptos de 9 anos de idade, aplicando o método de Penman Monteith. Os valores de ET oscilaram entre 2,0 e $5,0 \mathrm{~mm} / d$. A área de estudo está localizada na cidade de Aracruz, Espírito Santo e possui uma temperatura média de $24,4^{\circ} \mathrm{C}$.

b) Carneiro et al. (2008) obtiveram valores de $E T$ entre 2,5 e $3,8 \mathrm{~mm} / \mathrm{d}$, aplicando o método de Penman Monteith em eucaliptos de 2 anos de idade. O experimento em questão foi realizado no Município de Belo Oriente, Estado de Minas Gerais. A temperatura média anual é de $25,2{ }^{\circ} \mathrm{C}$.

c) Através do método de eddy covariance, Cabral et al. (2010) obtiveram valores entre 1,2 e $5,4 \mathrm{~mm} / \mathrm{d}$ com um registro de medições de 2 anos no Estado de São Paulo. A temperatura média anual $22,1 \pm 0,5^{\circ} \mathrm{C}$, variando entre 19 e $24{ }^{\circ} \mathrm{C}$.

d) Com aplicação do algoritmo SEBAL e de imagem do sensor TM do satélite Landsat 5, Menezes et al. (2011) estimaram a ET para eucaliptos de aproximadamente 7 anos de idade. A área de estudo está localizada no Município de Santa Bárbara, Estado de Minas Gerais, com temperatura média anual entre 19 e $20^{\circ} \mathrm{C}$. A evapotranspiração média diária foi de $6,72 \mathrm{~mm}$.

e) Outro resultado importante para o eucalipto foi o obtido por Alves et al. (2013). Eles estimaram o coeficiente de cultura $\left(k c_{i}\right)$ com um valor médio de 0,82 . A área de estudo está localizada no estado de Minas Gerais.

A Tabela 5 mostra um resumo dos artigos publicados sobre evapotranspiração do eucalipto no Brasil. 
Tabela 5 - Publicações de estimativas da evapotranspiração no eucalipto em áreas de estudo no Brasil

\begin{tabular}{|c|c|c|c|c|}
\hline Autor & Localização & Método & Temp. $\left({ }^{\circ} C\right)$ & $\begin{array}{l}\text { Faixa de } E T \\
\quad\left(m m d^{-1}\right)\end{array}$ \\
\hline Soares e Almeida (2001) & $\begin{array}{c}\text { Aracruz, Espírito } \\
\text { Santo, BR }\end{array}$ & Penman Monteith & 24,4 & $2,0-5,0$ \\
\hline Carneiro et al. (2008) & $\begin{array}{c}\text { Belo Oriente, } \\
\text { Minas Gerais, BR }\end{array}$ & Penman Monteith & 25,2 & $2,5-3,8$ \\
\hline Cabral et al. (2010) & $\begin{array}{c}\text { Estado de } \\
\text { São Paulo, BR }\end{array}$ & Eddy covariance & 22,1 & $1,2-5,4$ \\
\hline Menezes et al. (2011) & $\begin{array}{l}\text { Santa Bárbara, } \\
\text { Minas Gerais, BR }\end{array}$ & Sensoriamento remoto & $19-20$ & 6,72 \\
\hline
\end{tabular}

Fonte: Autor.

\subsection{Ensaios para caracterização física do solo}

\subsubsection{Porosidade, retenção específica, rendimento específico e rendimento específico transiente}

A porosidade $(\eta)$ é a relação entre o volume de vazios e o volume total de uma amostra. Seu conhecimento é importante para a realização de estudos hidrogeológicos, pois é nos poros do solo onde se encontra as reservas de água de um aquífero.

Klute (1986) apresentou várias técnicas, equipamentos de laboratório e de campo para a sua determinação, mas muitas delas fazem medições pontuais que dificultam a compreensão da heterogeneidade de uma zona de estudo.

Anteriormente à elevação do nível freático de um aquífero, o espaço poroso entre as partículas do solo encontra-se parcialmente ocupado por água. Ela pode ser medida em forma de percentagem com respeito ao volume total do solo, sendo chamada de retenção específica $\left(S_{r}\right)$. A parte restante da porosidade é chamada de rendimento específico $\left(S_{y}\right)$, a qual, segundo Childs (1972) é a quantidade de água que pode drenar de um solo se o nível piezométrico diminui uma unidade de longitude.

Na Figura 10 pode ser observado que a água subterrânea pode escoar somente através dos poros que se encontram interconectados e suficientemente grandes, os quais são chamados de macroporos. Aqueles poros pequenos que retém a água, pelo efeito da adsorção e das forças capilares, são chamados microporos.

Por esse motivo, pesquisadores como Millar (1988), Queiroz, Cruciani e Libardi (1995) consideram o rendimento especifico um parâmetro equivalente à macroporosidade e a retenção especifica equivalente à microporosidade. A porosidade $(\eta)$ de um solo é definida como a soma entre o rendimento específico (macroporosidade) e a retenção específica (microporosidade): $\eta=S_{y}+S_{r}$ 
Figura 10 - Representação da água que fica imóvel nos microporos e aquela que consegue drenar nos macroporos interconectados.

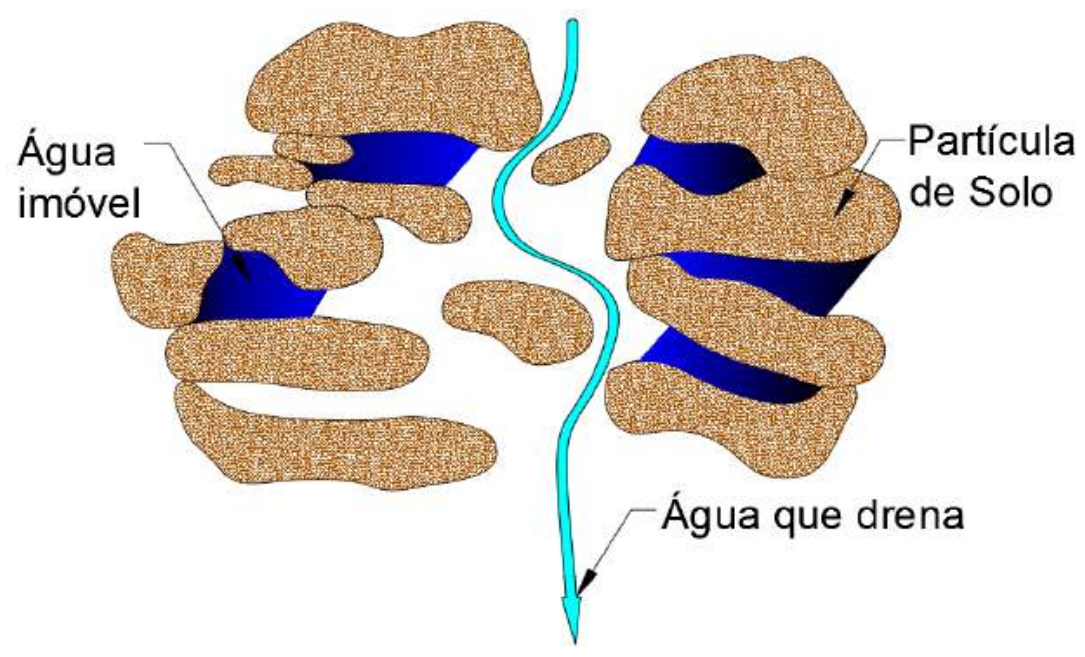

Fonte: Adaptado de Ramos et al. (1989).

Oliveira (1968) apresentou um método para a determinação da macro e microporosidade através da mesa de tensão, sugerida por Leamer e Shaw (1941). Baseado em vários autores (PEELE, 1949; UHLAND, 1949; DOREN; KLINGEBIEL, 1949; GROHMANN, 1960), considerou como limite de separação entre a macro e a microporosidade uma tensão de $60 \mathrm{~cm}$ de coluna de água (c.c.a) ou $6 \mathrm{kPa}$ sobre uma amostra de solo. Esse limite corresponde aos poros de diâmetros igual a $0,05 \mathrm{~cm}$.

A utilização de $60 \mathrm{~cm}$ de tensão permite gerar uma sucção na amostra de solo capaz de levá-la do ponto de saturação até a capacidade de campo. Dessa forma é cessado o processo de drenagem e é gerado um equilíbrio estático entre a força de gravidade e a capilaridade (QUEIROZ; CRUCIANI; LIBARDI, 1995).

O conceito do rendimento específico $\left(S_{y}\right)$, apresentado até agora, é aquele que assume um valor constante para condições de níveis de água subterrânea profunda, onde não existem flutuações diárias do nível freático. Contudo, esta definição do $S_{y}$ (constante e total) não é aplicável para o estudo de níveis de água subterrânea pouco profundas devido à flutuação diária do nível freático gerada pelo efeito da evapotranspiração ${ }^{4}$.

Nesses casos a espessura saturada através da qual o escoamento ocorre é variável, logo o $S_{y}$ varia ao longo do dia para uma dada coluna de solo de acordo com o nível de água. Esse fenômeno ocasiona, durante o dia, uma drenagem parcial da água contida nos macroporos, sendo interrompida no período da noite quando o nível freático começa de novo a aumentar (Figura 11).

4 Fenômeno detalhado no item 3.2.1. 
Figura 11 - Variação do $S_{y}$ em um volume de controle (retângulo vermelho). a) Durante o dia o nível freático do aquífero desce pelo efeito da evapotranspiração $(E T)$ e o volume de controle (VC) permanece fora da zona saturada um número de horas $t^{*}$, sendo o valor do rendimento específico igual a $S_{y}^{*}$. b) Durante a noite o nível freático aumenta pela não existência de evapotranspiração, mas sim do fluxo lateral $(r)$. O volume de controle permanece dentro da zona saturada um número de horas $t^{* *}$, sendo o valor do rendimento específico igual $S_{y}^{* *}$. Portanto $S_{y}^{*}<S_{y}^{* *}$.

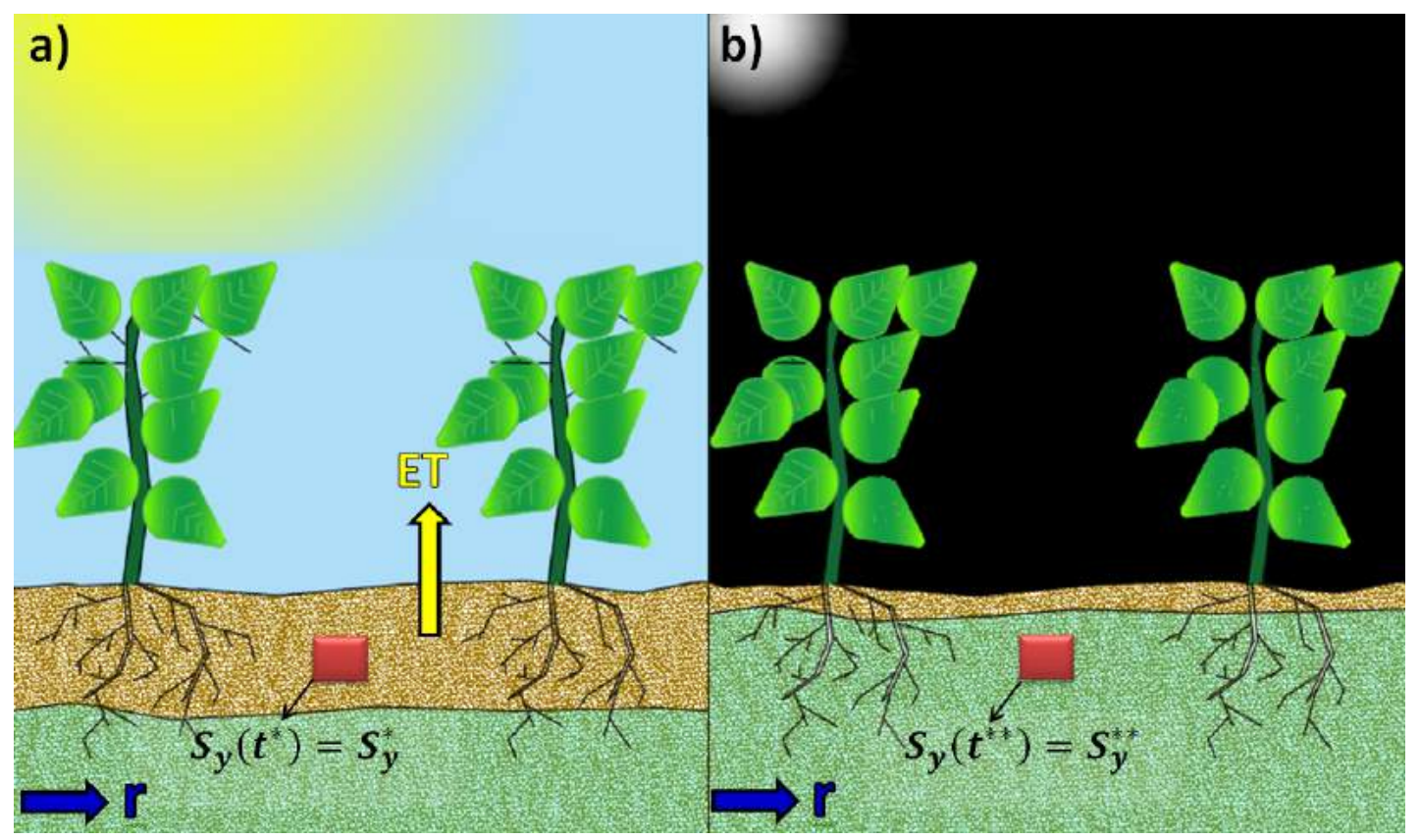

Fonte: Autor.

Para calcular um $S_{y}^{*}$ representativo para zonas com níveis de água subterrânea pouco profundas, Meyboom (1964) sugeriu reduzir em $50 \%$ o valor de $S_{y}$ quando ele for estimado em laboratório, lhe chamando readily available specific yield. Nachabe (2002) nomeou ele como transient specific yield e criou uma metodologia para a sua estimativa em campo. Portanto, neste trabalho a variável $S_{y}^{*}$ é chamada como rendimento específico transiente.

\subsubsection{Análise granulométrica e densidade das partículas de solo por raios gama}

Baseado no princípio de atenuação da radiação gama por um dado material (Lei de Lambert-Beer) e da velocidade de queda de uma partícula no meio líquido (Lei de Stokes), Vaz et al. (1997) desenvolveram um equipamento para a determinação da distribuição do tamanho, textura e densidade de solos (Figura 12). Esse equipamento encontra-se operando na EMBRAPA Instrumentação, na cidade de São Carlos, SP. Esse método para a determinação da granulometria foi introduzido por Vaz et al. (1992), sendo, posteriormente, modificado por Oliveira et al. (1997). 
Figura 12 - Analisador Granulométrico.

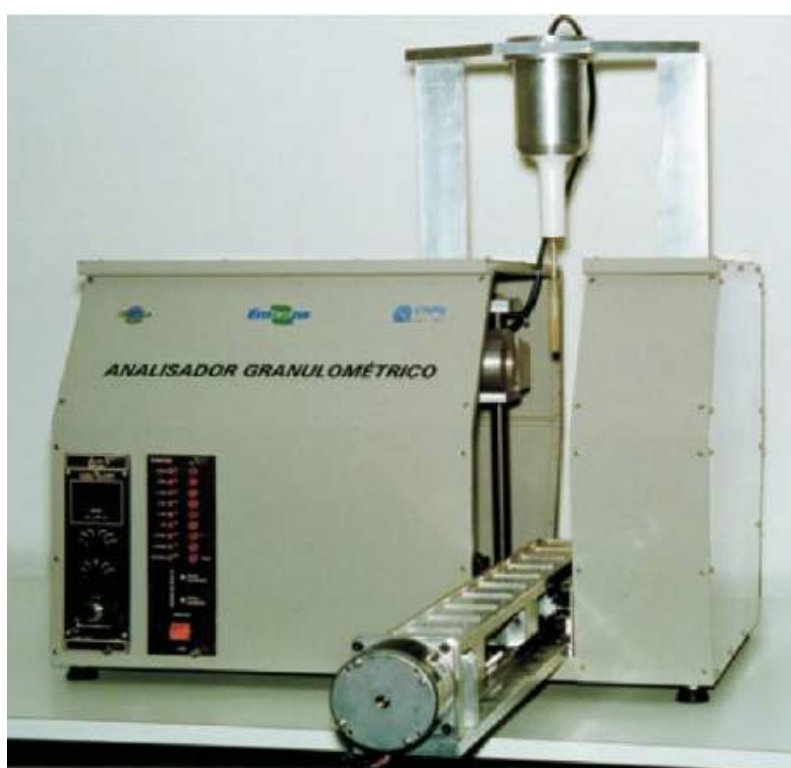

Fonte: Vaz et al. (1997).

Por ser um equipamento automatizado e controlado via computador, possui as seguintes vantagens sobre os métodos tradicionais da pipeta e do densímetro de Bouyoucos (GEE; BAUDER, 1986; EMBRAPA, 2011):

a) Possibilita a medição de forma direta de todas as frações (areia, slite e argila) pelo processo de sedimentação.

b) A amostra não precisa ser peneirada com malha de 0,053 $\mathrm{mm}$ ( $\left.n^{\circ} 270\right)$, evitando o erro argila e silte permanecerem agregados na areia, após o processo de lavagem.

c) As medições das diferentes frações da amostra não são feitas manualmente, e sim por raios gama controlados por um computador, acelerando o processo.

Informações adicionais sobre o equipamento e a técnica, podem ser encontradas em Vaz et al. (1995), Vaz, Naime e Macedo (1996a), Vaz, Naime e Macedo (1996b), Vaz, Naime e Macedo (1996c), Vaz, Naime e Macedo (1997a), Vaz, Naime e Macedo (1997b). 


\section{4 ÁREA DE ESTUDO}

\subsection{Sistema Aquífero Guarani - SAG}

O Sistema Aquífero Guarani é considerado o maior reservatório de água subterrânea da América do Sul e um dos maiores do mundo, com um volume de água estimado em $57 \times 10^{2} \mathrm{~km}^{3}$ e uma área aproximada de $119.5000 \mathrm{~km}^{2}$. Encontra-se localizado no centro-sul da América do Sul (Figura 13) e a sua extensão abrange os seguintes países: Brasil (839.800 $\left.\mathrm{km}^{2}-70 \%\right)$, Argentina (225.500 km $\left.\mathrm{km}^{2}-18.9 \%\right)$, Paraguai $\left(71.700 \mathrm{~km}^{2}-6 \%\right)$, e Uruguai $\left(58.500 \mathrm{~km}^{2}-4.9 \%\right)$ (ARAUJO; FRANCA; POTTER, 1999; OEA, 2009).

Figura 13 - Localização do Sistema Aquífero Guarani na América do Sul.

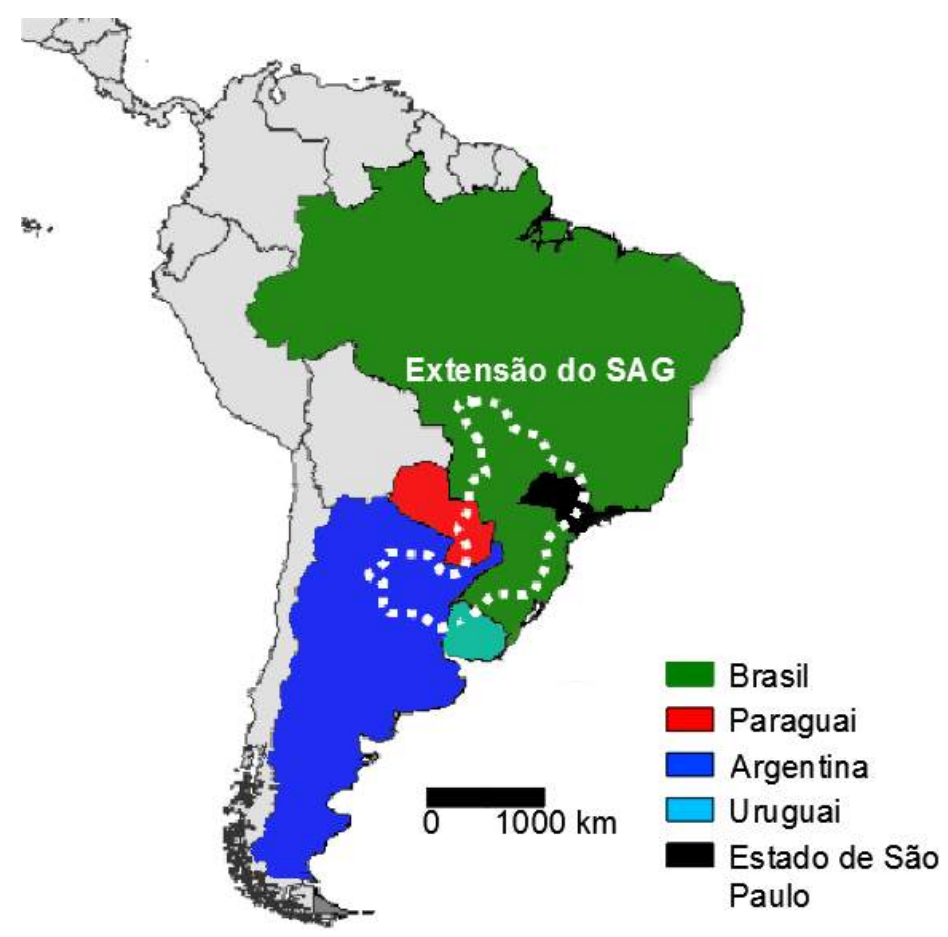

Fonte: Adaptado de Höyng et al. (2014).

No Brasil, o SAG localiza-se em diferentes estados: Mato Grosso do Sul (213.200

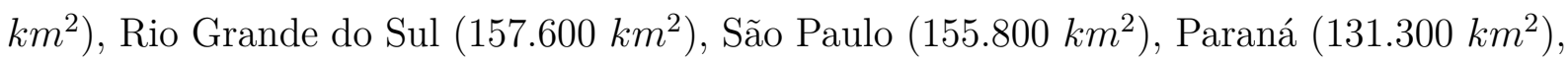
Goiás $\left(55.000 \mathrm{~km}^{2}\right)$, Minas Gerais $\left(51.300 \mathrm{~km}^{2}\right)$, Santa Catarina $\left(49.200 \mathrm{~km}^{2}\right)$ e Mato Grosso (26.400 km²)(ARAUJO; FRANCA; POTTER, 1999).

As formações geológicas do aquífero da bacia do Paraná e Chaco-Paraná datam aproximadamente de 130 milhões de anos. Elas são compostas por arenitos de granulação média a fina, do período Jurássico (Formação Botucatu) depositados pela ação eólica e por arenitos do período Triássico (Formação Pirambóia) de origem flúvio-lacustres (RABELO; 
WENDLAND, 2009). A Formação Botucatu se encontra sobreposta à Formação sedimentar Pirambóia e ambas ocorrem sob rochas basálticas da Formação Serra Geral e às camadas sedimentares do grupo Bauru (SRACEK; HIRATA, 2002).

O SAG é essencialmente confinado porque possui uma zona de afloramento que corresponde a $10 \%$ de sua área total que tem o comportamento de um aquífero livre, onde ocorre a sua recarga, tornando-o vulnerável à contaminação (IPT, 2011).

\subsection{Bacia do Ribeirão da Onça}

\subsubsection{Localização}

A Bacia do Ribeirão da Onça (BRO) tem uma área de $65 \mathrm{Km}^{2}$ que pertence à zona de afloramento do Sistema Aquífero Guarani (SAG). Localiza-se no município de Brotas no centro-leste do estado de São Paulo entre os paralelos $22^{\circ} 10^{\prime}$ e $22^{\circ} 15^{\prime} S$ e entre os meridianos $47^{\circ} 55^{\prime}$ e $48^{\circ} 00^{\prime} W$ (Figura 14). O Ribeirão da Onça é um dos formadores do Rio Jacaré-Guaçú, afluente do Rio Tietê.

Figura 14 - Localização da bacia do Ribeirão da Onça.

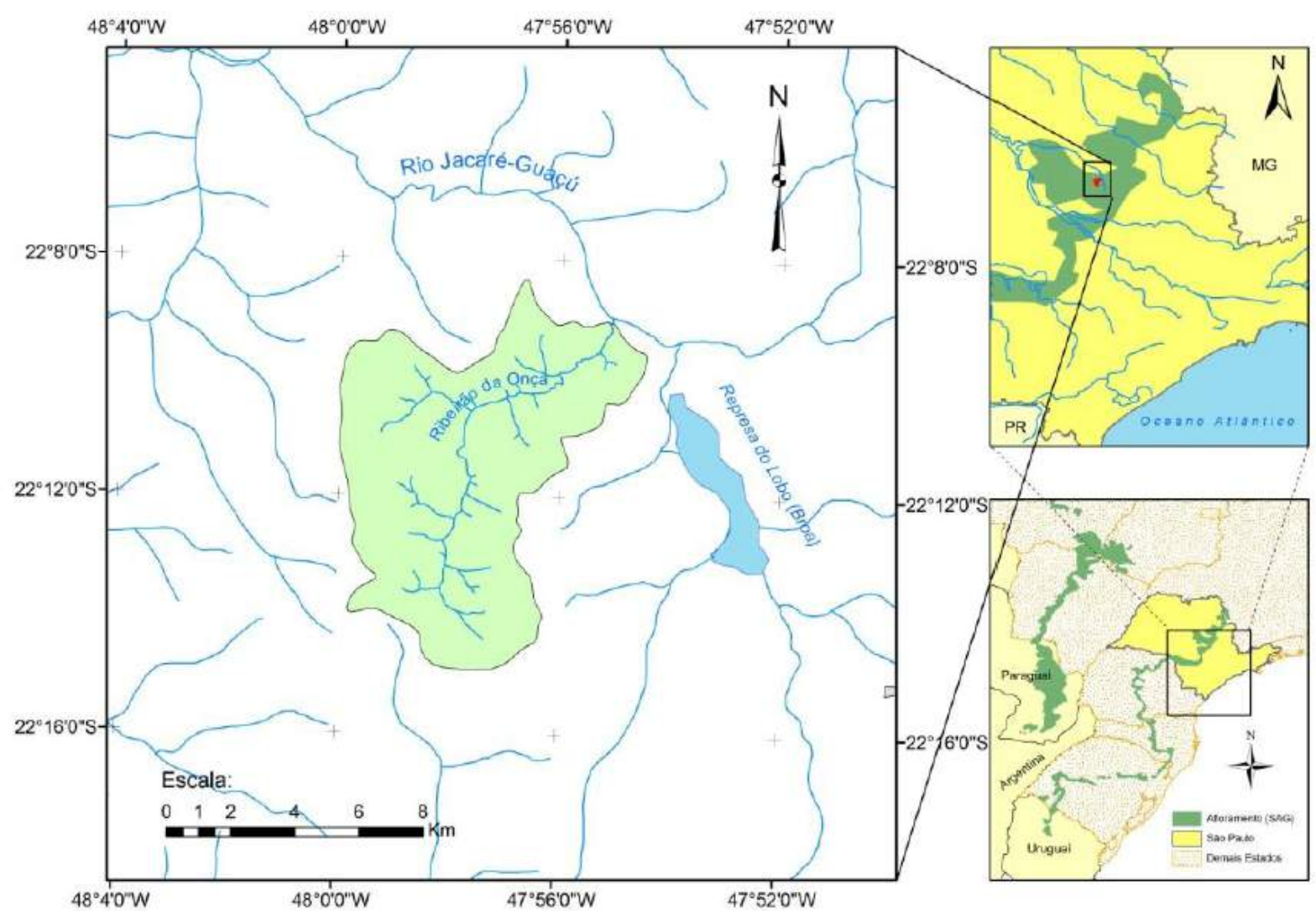

Fonte: Guanabara (2011). 
Para este trabalho, foram utilizados dados de poços localizados no norte da bacia, na fazenda Monte Alegre (Figura 15). Os poços 16, 17, 18 e 19 estiveram cercados por pastagem desde o ano de 2004 até 2012, quando tornou-se plantação de clones de eucaliptos híbridos (E. grandis x E. urophyla), também conhecido como 'Urograndis' (WENDLAND; BARRETO; GOMES, 2007; LUCAS et al., 2015; MELO; WENDLAND; GUANABARA, 2015).

Figura 15 - Representação dos poços de monitoramento em zona ripária, Cerrado stricto sensu e eucalipto na fazenda Monte Alegre. (a) Vista em planta. (b) Vista lateral.
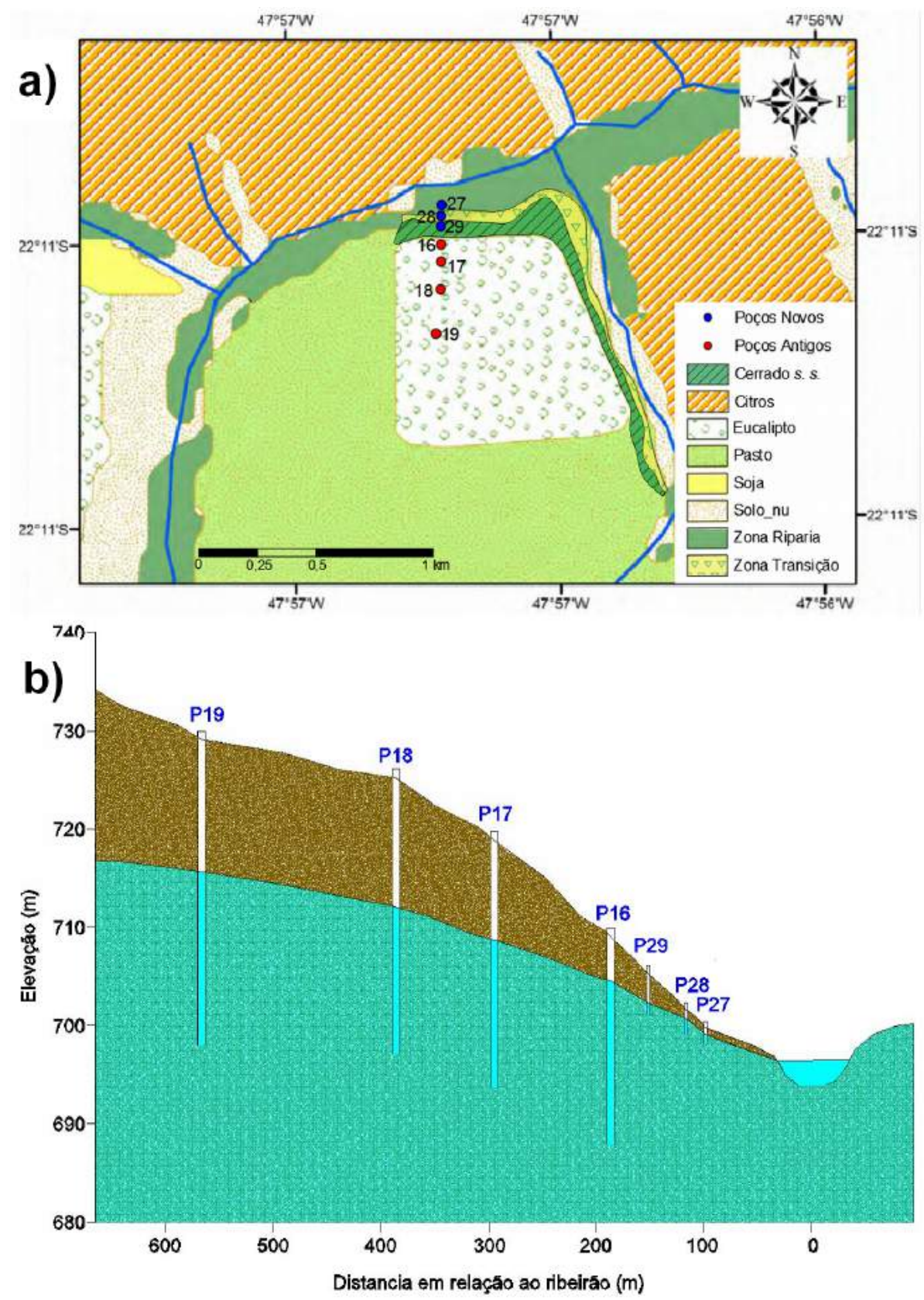

Fonte: Autor. 
Os poços novos $(27,28$, e 29), construídos para o desenvolvimento deste trabalho, se encontram localizados em zona ripária, zona de transição (entre a ripária e Cerrado) e Cerrado stricto sensu, respectivamente. Eles foram instalados próximos e perpendicular ao Ribeirão da Onça, e alinhados com os poços antigos (16, 17, 18 e 19), utilizando um nível ótico.

Na localização dos poços novos as raízes da vegetação têm contato com a água subterrânea para permitir o efeito da flutuação diária do nível freático causado pela $E T$. O poço 27 está distante aproximadamente $18 \mathrm{~m}$ do 28 ; o 28 do $29,35 \mathrm{~m}$; o 29 do 16, 35 $m$ e o 16 do 19, $380 m$ (Figura 15). Os relatórios dos poços podem ser encontrados no Apêndice A. Neste projeto foram usados somente os poços 16 (2004 - presente), 27, 28 e 29 (2015 - presente) para a determinação da evapotranspiração diária.

\subsubsection{Climatologia}

A classificação climática de Köppen-Geiger para a região é de Cwa, indicando que a bacia possui um clima subtropical úmido com chuvas de verão apresentando variação para clima tropical úmido com inverno seco (OLIVEIRA et al., 1997).

Através dos dados do Centro de Recursos Hídricos e Estudos Ambientais (CRHEA), obteve-se para a região, as médias diárias de temperatura e de umidade relativa do ar de $21,6{ }^{\circ} \mathrm{C}$ e $71 \%$, respectivamente; e a precipitação média anual entre 1979 e 2014 é de 1486 $m m$ (CABRERA et al., 2016).

\subsubsection{Características físicas}

As principais características físicas da bacia (Tabela 6) foram levantadas por Mattos et al. (1984) e Preto Filho (1985) apud Pompêo (1990), através de mapas em escala $1: 10.000$.

Tabela 6 - Caracterização fisiográfica da bacia do Ribeirão da Onça

\begin{tabular}{cc}
\hline Área de drenagem & $65 \mathrm{~km}^{2}$ \\
Perímetro & $42 \mathrm{~km}$ \\
Comprimento axial & $11 \mathrm{~km}$ \\
Extensão do curso d' água principal & $16 \mathrm{~km}$ \\
Comprimento total dos cursos d' água & $55 \mathrm{~km}$ \\
Altitude máxima & $840 \mathrm{~m}$ \\
Altitude mínima & $640 \mathrm{~m}$ \\
Declividade média & $7,6 \mathrm{~m} / \mathrm{km}$ \\
\hline
\end{tabular}

A altimetria da Bacia Ribeirao da Onça, seus cursos d' água e área de drenagem 
(Figura 16) foram realizadas a partir de imagens tipo SRTM (Shuttle Radar Topography Mission) junto com visitas de campo (MATTOS, 2015).

Figura 16 - Altimetria da Bacia Ribeirão da Onça.

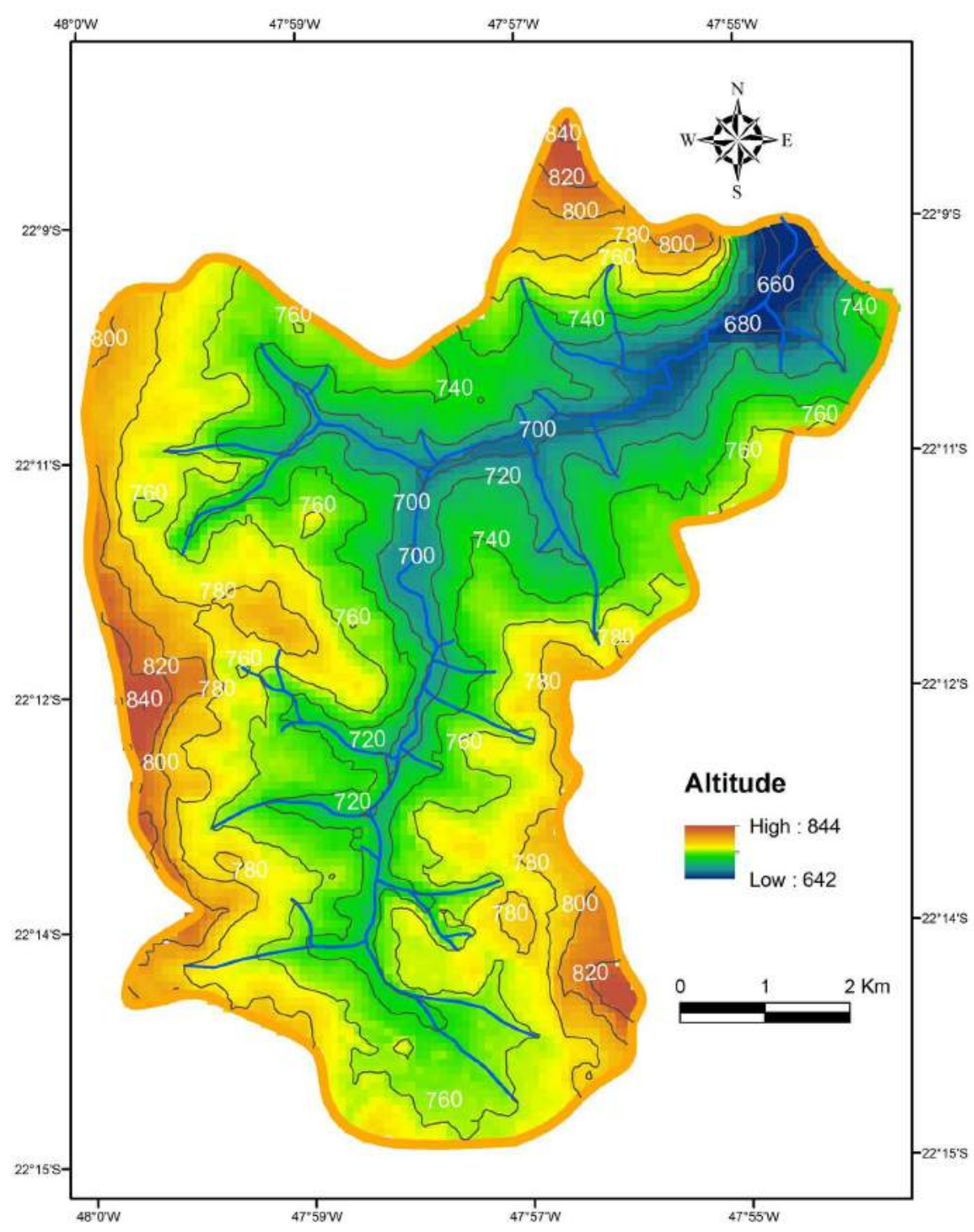

Fonte: Mattos (2015).

O sistema de drenagem apresenta um desenvolvimento mediano, porque o índice de densidade de drenagem $\left(D_{d}\right)$ para a BRO possui um valor de $0,95 \mathrm{~km} / \mathrm{km}^{2}$, entre os valores limites $0,75 \mathrm{~km} / \mathrm{km}^{2}$ para drenagem pobre e $1,5 \mathrm{~km} / \mathrm{km}^{2}$ para drenagem rica. Este índice é calculado, através da razão entre o comprimento total dos cursos d' água e a área de drenagem. 


\subsubsection{Características geológicas e pedológicas}

A geologia da Bacia do Ribeirão da Onça (Figura 17) é caracterizada por rochas com origem principalmente da Formação Botucatu e uma pequena extensão da Formação Serra Geral. Essa formação se encontra a jusante da bacia e da Formação Pirambóia que é caracterizada por arenitos finos a médios com elevado teor de argila, bem como arenitos grossos e conglomeráticos (CASTRO JUNIOR, 2008).

Embora não haja certeza da existência de afloramentos da Formação Botucatu na BRO, ela pode ser observada nas coberturas das colinas amplas e médias pela presença areias quartzosas com uma textura parecida aos grãos de quartzo que constituem os arenitos eólicos (CASTRO JUNIOR, 2008).

Figura 17 - Mapa geológico na região da bacia do Ribeirão da Onça.

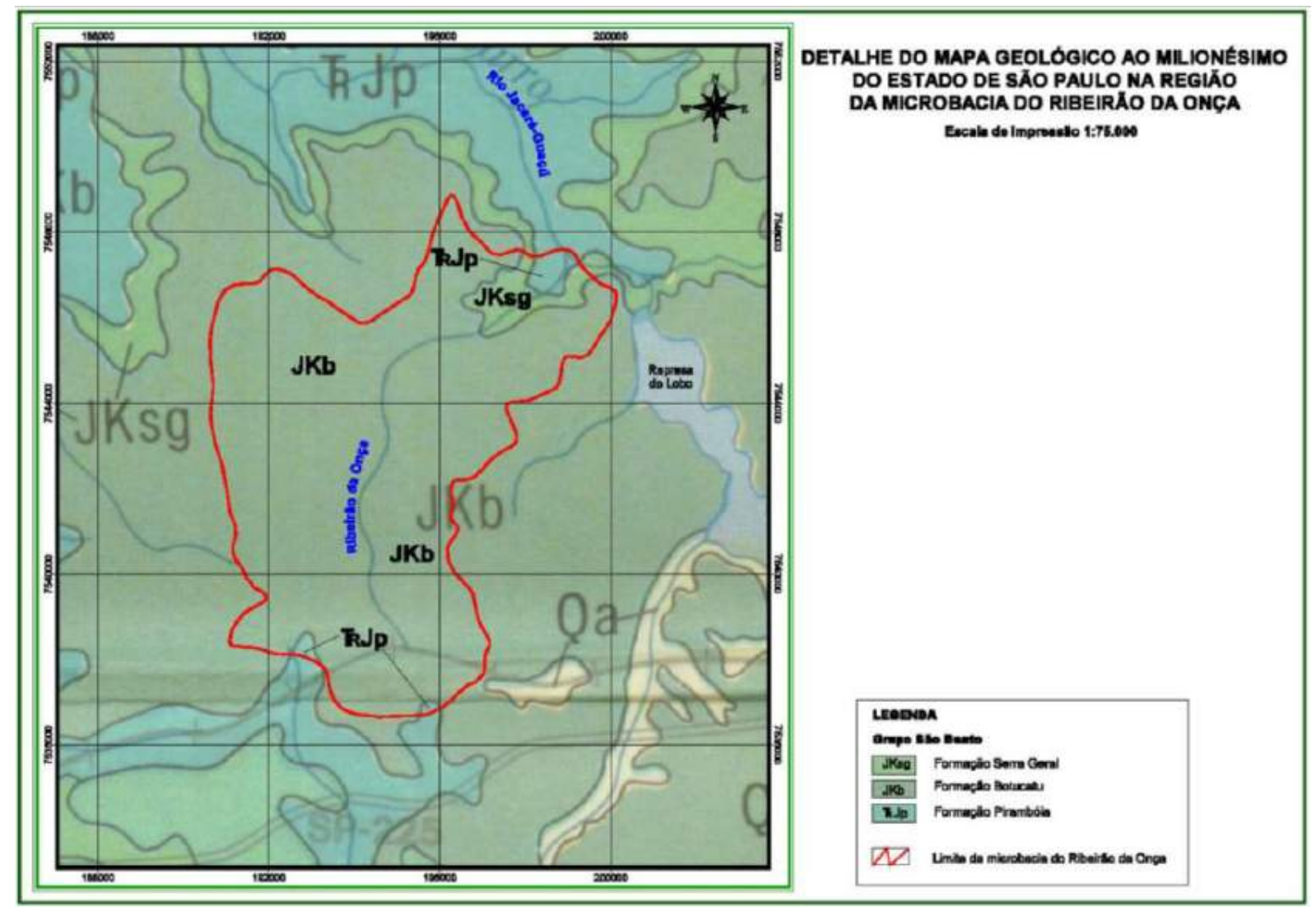

Fonte: Castro Junior (2008).

Sobre a caracterização pedológica, Castro Junior (2008) descreveu os tipos de solos da BRO, agrupando eles em 5 tipos pedológicos principais (Figura 18): areia quartzosa profunda (AQ), latossolo vermelho-amarelo álico (LV-2), latossolo roxo eutrófico (LRe), terra roxa estruturada distrófica ou eutrófica (TE2), solos hidromórficos (Hi) e latossolo vermelho-escuro distrófico ou álico (LE-1). 
Figura 18 - Mapa pedológico na região da bacia do Ribeirão da Onça.

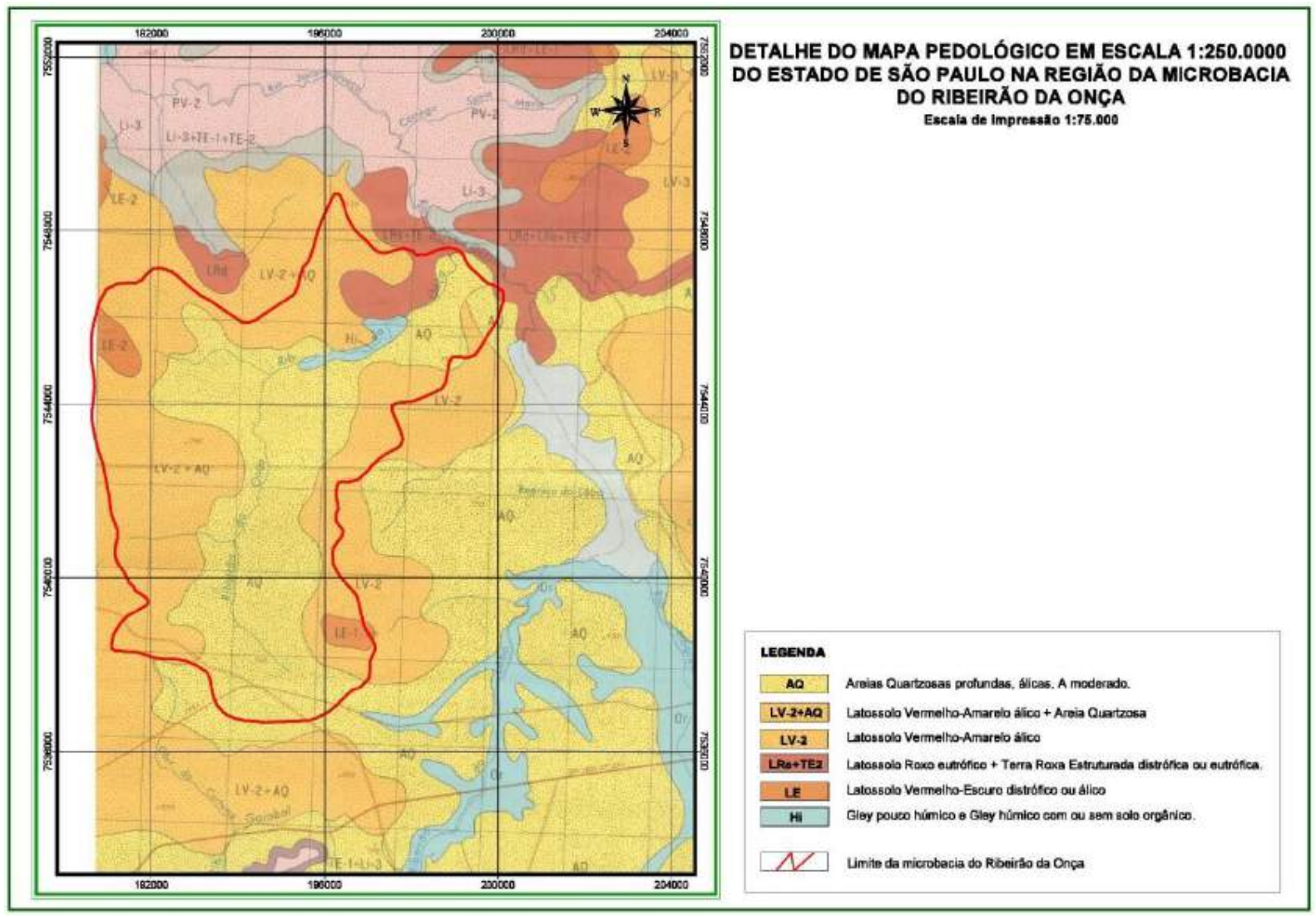

Fonte: Castro Junior (2008).

\subsubsection{Características hidrogeológicas}

$\mathrm{Na}$ BRO existem dois aquíferos, um superior que possui uma espessura de máximo $20 m$ que permite a renovação das reservas de água e outro inferior, profundo e mais estável, constituído pelos arenitos Botucatu e Pirambóia, que representam o Sistema Aquífero Guarani (DAVINO, 1984 apud Contin Neto (1987)).

Com o fim de saber o comportamento destes aquíferos foram construídos 26 poços de monitoramento (Figura 19), localizados em diferentes áreas da BRO. Eles têm providenciado informação sobre o fluxo de água subterrânea que escoa desde as áreas de recarga até o rio.

Segundo Lucas et al. (2015), a recarga média nesta bacia foi de $440 \mathrm{~mm} /$ ano no período entre 2004-2012, representando aproximadamente $29 \%$ da precipitação média histórica (1514 mm/ano). Segundo Wendland, Gomes e Troeger (2015), a recarga esteve entre $14 \%$ e $38 \%$ da precipitação média entre fevereiro do 2004 e janeiro do 2007. A água subterrânea na BRO escoa principalmente sobre arenitos da formação Botucatu, mas em seu exutório, o escoamento ocorre em um complexo de Botucatu-Basalto.

Segundo Wendland, Barreto e Gomes (2007), a bacia está coberta por solos de 
Figura 19 - Localização dos poços de monitoramento na bacia do Ribeirão da Onça.

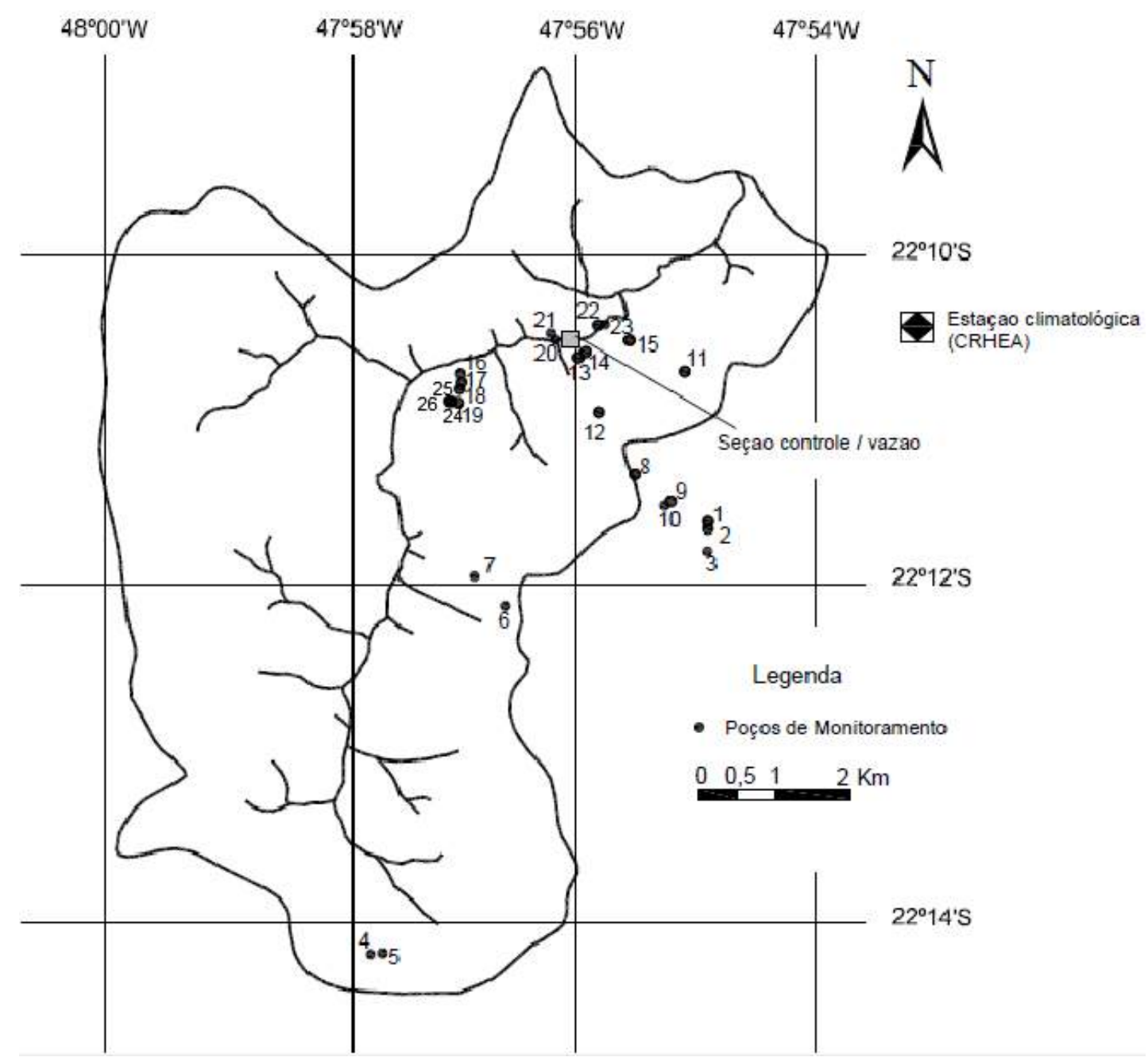

Fonte: Adaptado de Gomes (2008).

idade Quaternária, os quais possuem uma faixa de valores de condutividade hidráulica entre $1,5 \times 10^{-5}$ e $4,3 \times 10^{-6} \mathrm{~m} / \mathrm{s}$. O rendimento específico $(S y)$ foi determinado durante campanhas de coletas de amostras de solo indeformadas. Elas foram realizadas em pontos específicos (Figura 20) e profundidades distintas (Tabela 7) diferentes onde acontece a flutuação do nível freático de água subterrânea (WENDLAND; GOMES; TROEGER, 2015). O valor médio foi de $12 \%( \pm 2,9 \%)$, o qual foi determinado através da técnica do funil munido de placa porosa (funil de Haines). 
Figura 20 - Locais de coleta de amostras indeformadas de solo na BRO.

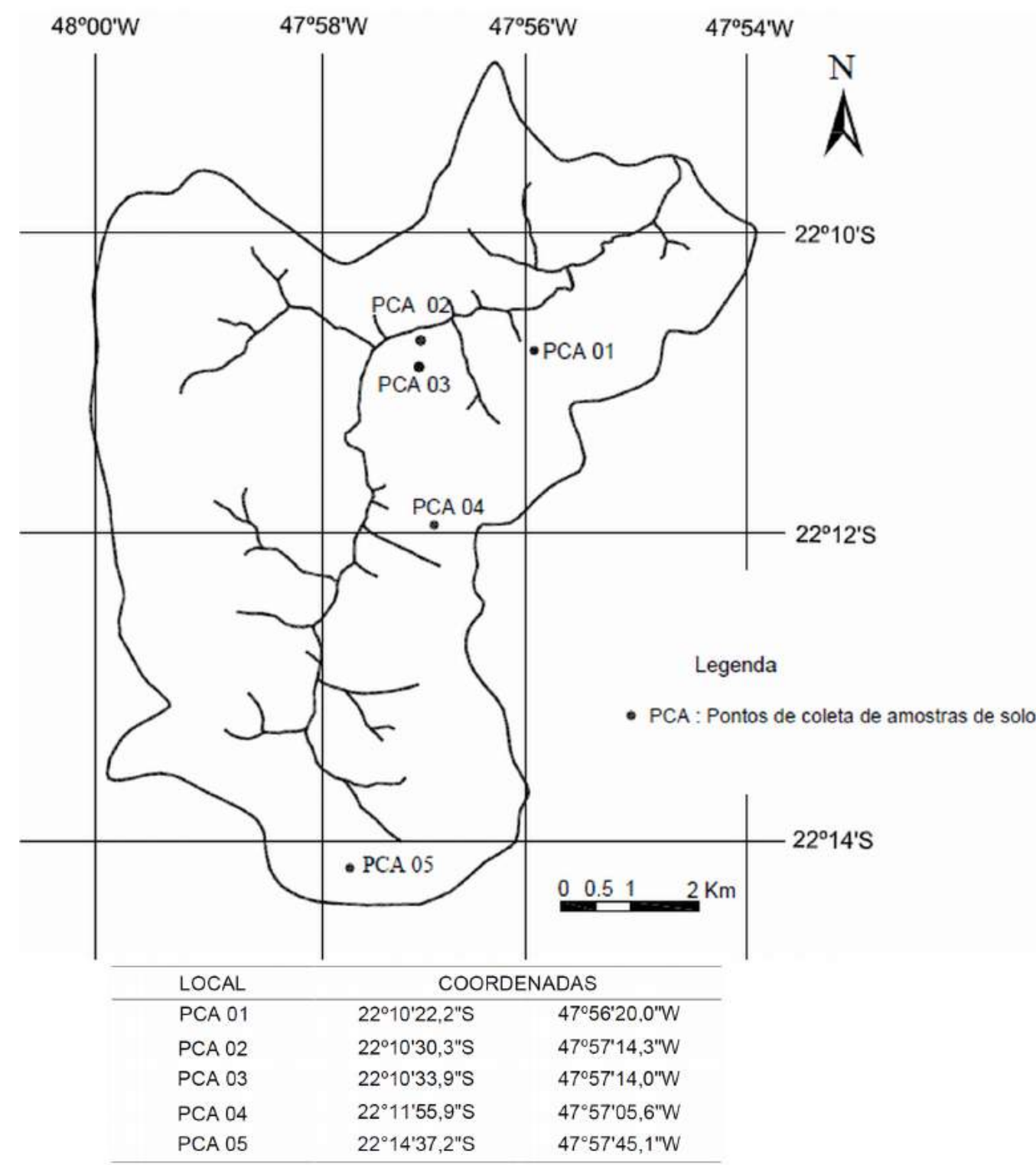

Fonte: Gomes (2008).

Tabela 7 - Rendimento específico nos diferentes pontos de coleta

\begin{tabular}{|c|c|c|c|c|c|c|c|c|c|}
\hline \multicolumn{10}{|c|}{ Pontos de coleta de amostras de solo (PCA) } \\
\hline \multicolumn{2}{|c|}{ PCA 01} & \multicolumn{2}{|c|}{ PCA 02} & \multicolumn{2}{|c|}{ PCA 03} & \multicolumn{2}{|c|}{ PCA 04} & \multicolumn{2}{|c|}{ PCA 05} \\
\hline Prof.(m) & $S_{y}$ & Prof.(m) & $S_{y}$ & Prof.(m) & $S_{y}$ & Prof.(m) & $S_{y}$ & Prof.(m) & $S_{y}$ \\
\hline 13,00 & $8,7 \%$ & 3,00 & $15,4 \%$ & 6,10 & $12,4 \%$ & 14,80 & $9,6 \%$ & 4,40 & $16,8 \%$ \\
\hline 14,00 & $7,8 \%$ & 4,00 & $15,2 \%$ & 7,10 & $12,2 \%$ & 16,00 & $10,4 \%$ & 5,40 & $15,7 \%$ \\
\hline 15,80 & $9,0 \%$ & 4,50 & $14,7 \%$ & 8,40 & $8,9 \%$ & 16,90 & $11,1 \%$ & 6,00 & $15,1 \%$ \\
\hline- & - & - & - & 9,30 & $10,4 \%$ & 18,10 & $12,7 \%$ & - & - \\
\hline- & - & - & - & - & - & 19,10 & $9,0 \%$ & - & - \\
\hline Média & $8,5 \%$ & Média & $15,1 \%$ & Média & $11,3 \%$ & Média & $10,6 \%$ & Média & $15,9 \%$ \\
\hline Desvio & $0,6 \%$ & Desvio & $0,4 \%$ & Desvio & $1,7 \%$ & Desvio & $1,4 \%$ & Desvio & $0,9 \%$ \\
\hline
\end{tabular}

Fonte: Gomes (2008). 


\section{MATERIAL E MÉTODOS}

\subsection{Construção e instalação de novos poços de monitoramento}

Para a elaboração dos poços 27, 28 e 29 foram utilizados tubos de PVC com diâmetro interno de $75 \mathrm{~mm}$ e comprimentos de 2,00,3,14 e 4,85 $\mathrm{m}$, respectivamente. Na parte inferior do tubo foram construídos filtros de $50 \mathrm{~cm}$ (Figura 21) e sobre eles foi afixada uma malha geotêxtil, a qual não permite que as ranhuras fiquem entupidas de solo.

Figura 21 - Realização dos filtros nos poços em laboratório.

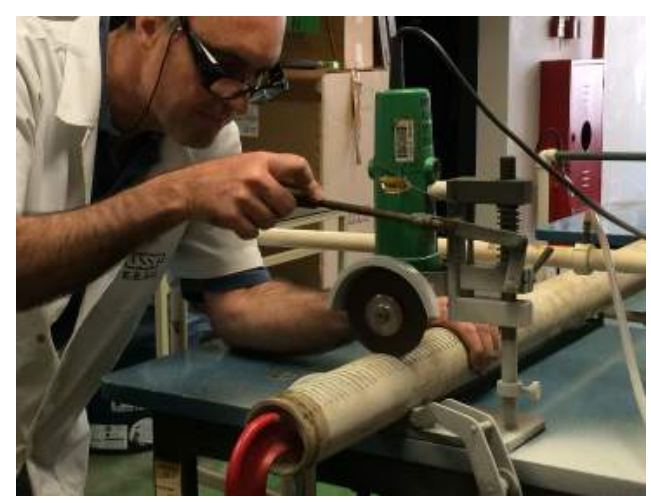

Fonte: Autor.

A perfuração do terreno para a instalação dos poços (Figura 22a) foi realizada de forma manual com a ajuda de um trado de $150 \mathrm{~mm}$ de diâmetro. Nesse procedimento foram extraídas amostras deformadas a cada metro de profundidade, visando a realização do análise granulométrica. A profundidade das perfurações foram 1,44, 2,74 e 4,80 $\mathrm{m}$ para o poço 27,28 e 29 , respectivamente.

Figura 22 - (a) Escavação no solo para os poços. (b) Instalação das bocas dos Poços. (c) Instalação do poço finalizada

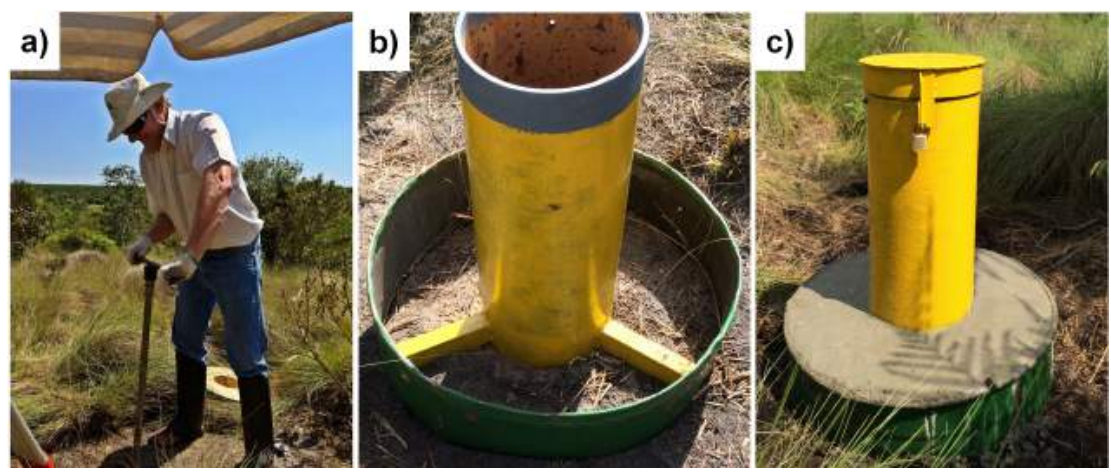

Fonte: Autor. 
Depois de inseridos os tubos de PVC no solo, foram feitas as bocas dos poços com tubos de ferro previamente adaptados com suportes laterais (Apêndice B) os quais foram fixados no solo com concreto (Figura 22 b,c).

\subsection{Monitoramento do nível freático}

Os poços 27, 28, 29, 16 e 19 foram monitorados com transdutores de pressão, Levelogger (B) Edge Model 3001, com uma resolução de 15 min e de forma manual com um medidor de nível geralmente cada 15 dias. Os transdutores mediram a pressão absoluta, isto é, a pressão atmosférica $\left(P_{\text {bar }}\right)$ mais a hidrostática $\left(P_{\text {hidro }}\right)$, sendo necessária a remoção da $P_{b a r}{ }^{1}$, com o fim de se observar a flutuação do nível de água subterrânea a partir da $P_{\text {hidro }}$.

\subsubsection{Compensação barométrica e filtragem passa baixa}

A influência da pressão atmosférica local exercida sobre o nível de água subterrânea nos poços de monitoramento foi removida através de um processo chamado compensação barométrica:

$$
W T=h_{p}-\left[C_{c}-\frac{\left(P_{a b s}-P_{b a r}\right)}{\rho g}\right]
$$

sendo $W T$ o nível freático nos poços medido a partir do fundo dos poços $(L)$ (dessa forma é utilizado nos métodos da flutuação diária), $h_{p}$ a profundidade do poço $(L), C_{c}$ o comprimento do cabo em que se encontra suspenso o transdutor de pressão $(L), P_{a b s}$ a pressão absoluta $\left(M / L T^{2}\right), P_{b a r}$ a pressão barométrica $\left(M / L T^{2}\right), \rho$ a densidade da água $\left(M / T^{3}\right), g$ a gravidade $\left(L / T^{2}\right)$ (Figura 23$)$.

Como a frequência da coleta de dados nos transdutores foi de 15 min e os poços de monitoramento em estudo têm pouca profundidade, foram observados ruídos nos dados coletados semelhantes aos apresentados no método de White (1932) (Figura 1). Esses ruídos foram gerados pela turbulência, pela variação de densidade do fluxo de ar e pela mudança de temperatura. Se esse tipo de perturbação não fosse removida, seria impossível a aplicação das diferentes metodologias baseadas na flutuação diária do nível de água subterrânea.

$\overline{1}$ Medida em uma estação meteorológica (item 5.4.2) a uma distância aproximada de $1,5 \mathrm{~km}$ dos poços em estudo. 
Figura 23 - Variáveis da compensação barométrica

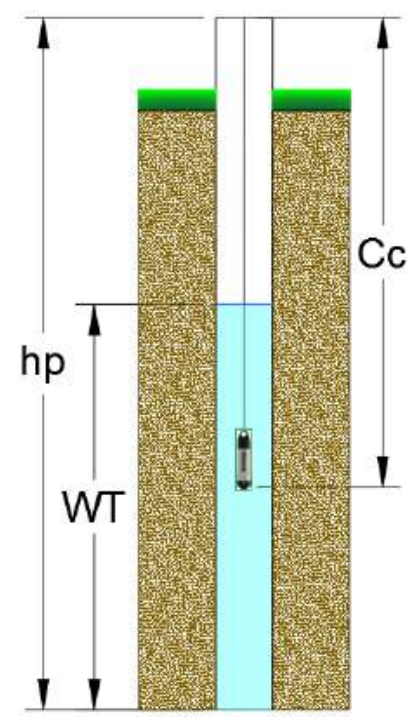

Fonte: Autor.

Portanto, para a remoção dos ruídos dos dados coletados nos poços 16, 27, 28 e 29 foi usado um tipo de filtragem passa-baixa chamada Regressão Polinomial Local Ponderada (Loess) (DEVLIN, 1986). Para a sua aplicação, primeiro, realizou-se uma regressão ponderada através da equação tricúbica de Kernel:

$$
p_{i}=\left(1-\left|\frac{y-y_{i}}{d(y)}\right|^{3}\right)^{3}
$$

sendo $y$ o dado predito associado com o valor de resposta, $y_{i}$ são os dados que se encontram mais perto de $y, d(y)$ é o tamanho da faixa de valores dos dados vizinhos de $y$. Para finalizar o procedimento completo da Loess, foi realizada uma regressão polinomial de segundo grau, para depois continuar o mesmo procedimento com cada dado da série temporal (Figura 24).

Figura 24 - Regressão Polinomial Local Ponderada (Loess)

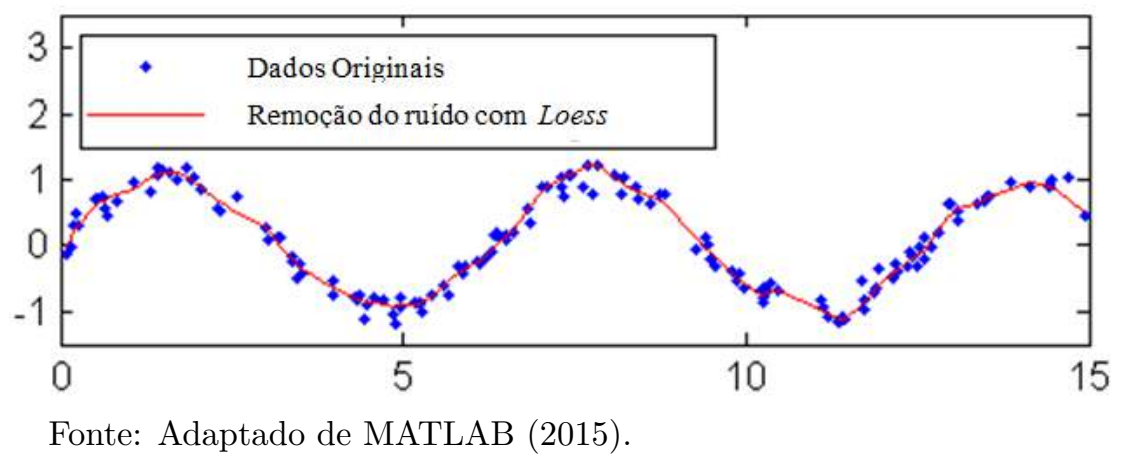




\subsection{Determinação das características físicas do solo}

\subsubsection{Porosidade, retenção específica, rendimento específico e rendimento específico transiente}

\subsubsection{Coleta de amostras indeformadas}

A coleta de amostras indeformadas no solo ao redor dos poços 27, 28, 29 e 16, foi realizada durante o período de estiagem, de modo a extrair amostras nas profundidades onde ocorrem as flutuações diárias. Esse processo foi divido em duas etapas:

A primeira corresponde ao dia 06/Agosto/2016 quando foram coletadas 5 amostras indeformadas do solo no poço 27, a $30 \mathrm{~cm}$ de profundidade. Para isso, foi utilizado um trado Uhland ${ }^{2}$, que possui cilindros de alumínio, com $70 \mathrm{~mm}$ de diâmetro interno e 71 $m m$ de altura (Figura 25). Cada amostra indeformada ficou dentro do cilindro de alumínio coberto com papel filme para o seu posterior tratamento no laboratório.

Figura 25 - (a) Coleta de amostras indeformadas na zona ripária. (b) Trado Uhland.
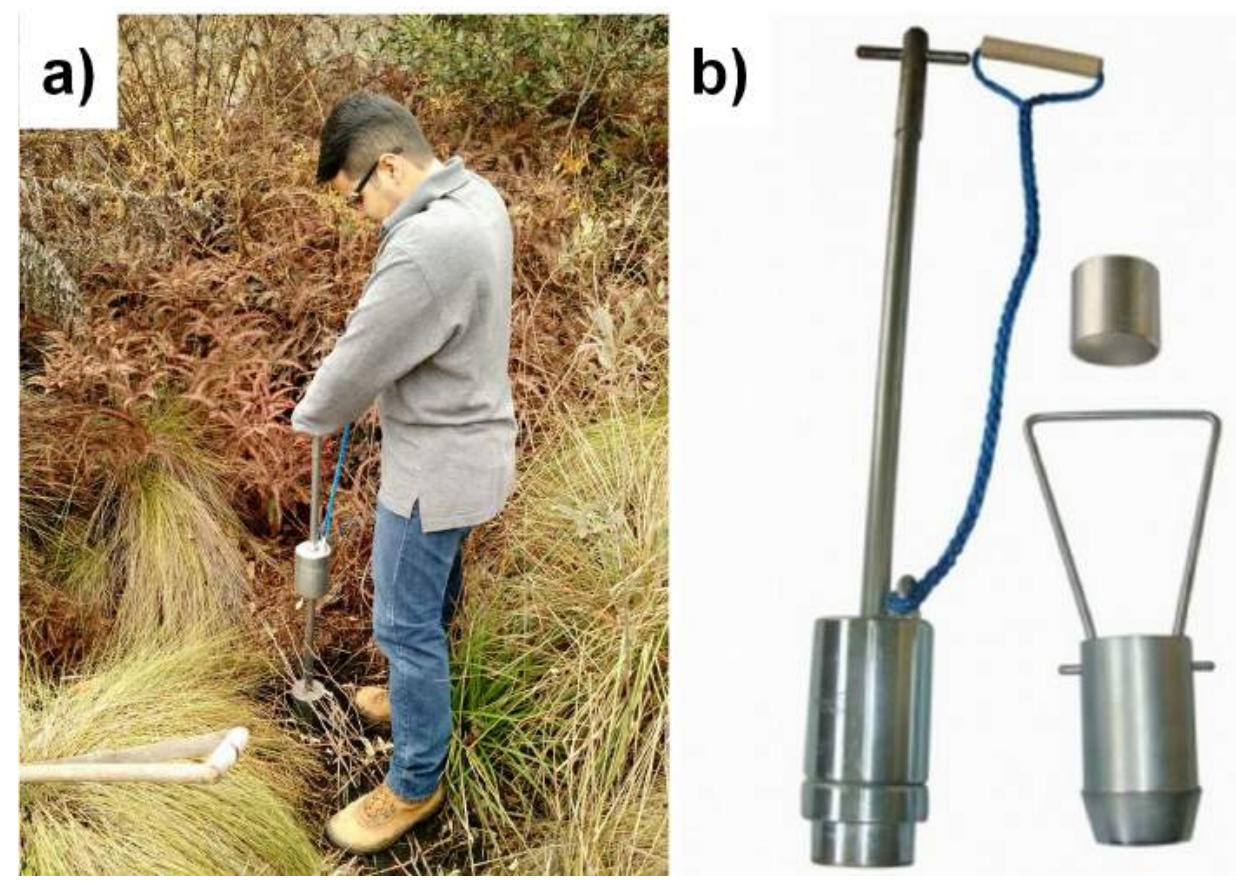

Fonte: Autor.

Com ajuda de um embolo do mesmo diâmetro interno dos cilindros, as 5 amostras foram retiradas. Simultaneamente, aplicou-se parafina ao redor das amostras com o objetivo de conservar a sua estrutura do solo (Figura 26a).

O último passo foi colocar o solo da parte central das amostras indeformadas cobertas com parafina dentro de 3 anéis de PVC, com diâmetro médio de 44,2 $\mathrm{mm}$ e 
altura média $15.8 \mathrm{~mm}$ (Figura 26 b). A decisão de utilizar 3 anéis em 5 amostras foi por prevenção, dado que o processo de manuseio é complexo.

Figura 26 - a) Amostra indeformada de solo no poço 27. b) Amostra de solo do poço 27 contida em um anel de PVC
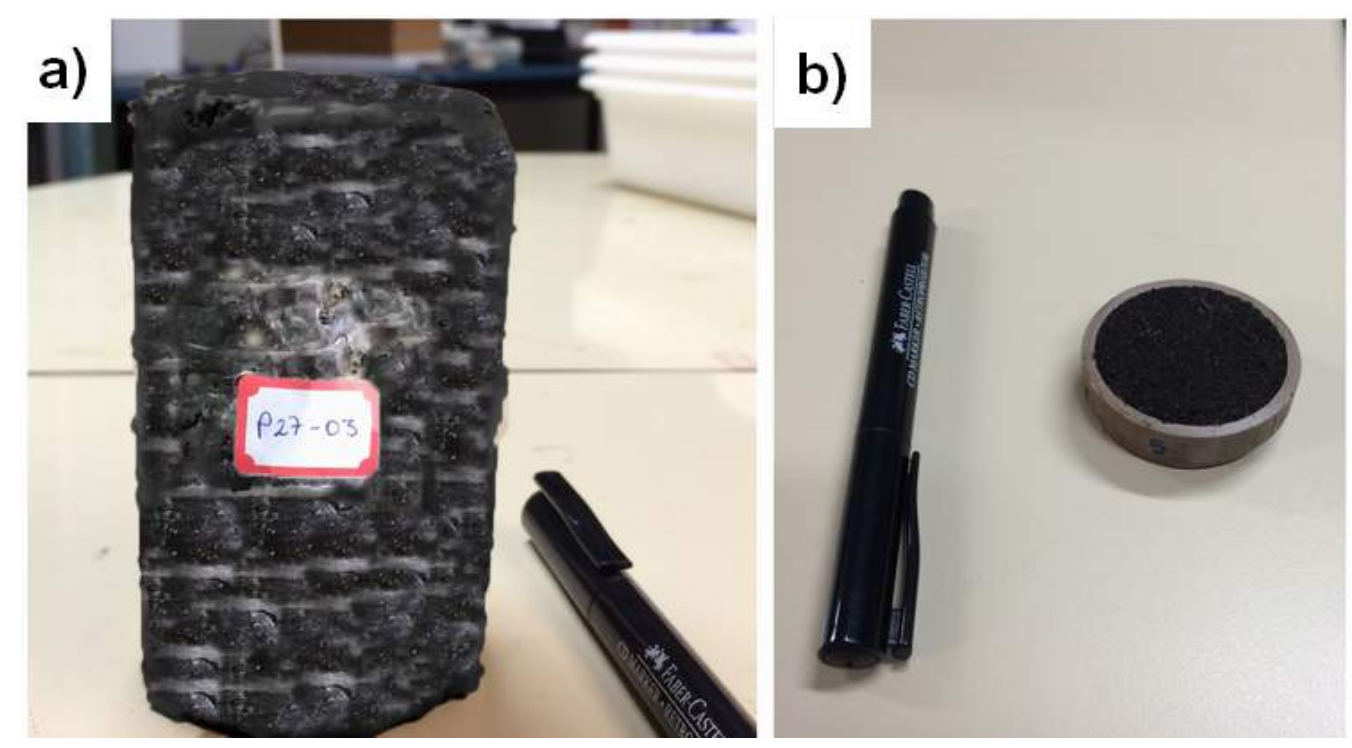

Fonte: Autor.

A segunda campanha de coleta de amostras indeformadas ocorreu no dia 27/09/2016, quando foram coletadas 15 amostras indeformadas, 5 para cada um dos solos nos poços 28, 29 e 16. Primeiro, foi realizada uma escavação a $3 m$ de distância de cada poço com um trado de 6" de diâmetro até uma profundidade próxima ao ponto de cada coleta.

O segundo passo foi a utilização de um tripé de sondagem à percussão (SPTStandard Penetration Test), adaptado para os propósitos deste projeto (Figura 27 a,c,d). As ferramentas que fazem parte dele são: tripé, roldana, corda e hastes rosqueadas (ocas), com diâmetro interno de 2 1⁄2" e externo de 3". Cilindros de PVC (Figura 27b) com 10 cm de altura e os mesmos diâmetros das hastes, um extremo rosqueado e outro biselado, foram posicionados no final das hastes para a coleta de cada amostra.

As coletas foram realizadas em profundidades entre $0,60-1,20 m ; 2,80-3,40 m$ e 5,30 - 5,90 $m$ para os solos nos poços 28, 29 e 16, respetivamente, que correspondem às faixas de flutuação do nível de água subterrânea para cada um deles. O processo de encaixe dos solos nos anéis de PVC foi feito da mesma maneira no poço 27. 
Figura 27 - Tripé de sondagem à percussão (SPT) Adaptado. a )Esquema gráfico. b) Cilindro PVC para amostragem de solo. c) Escavação preliminar com trado. d) Acoplamento de varias hastes
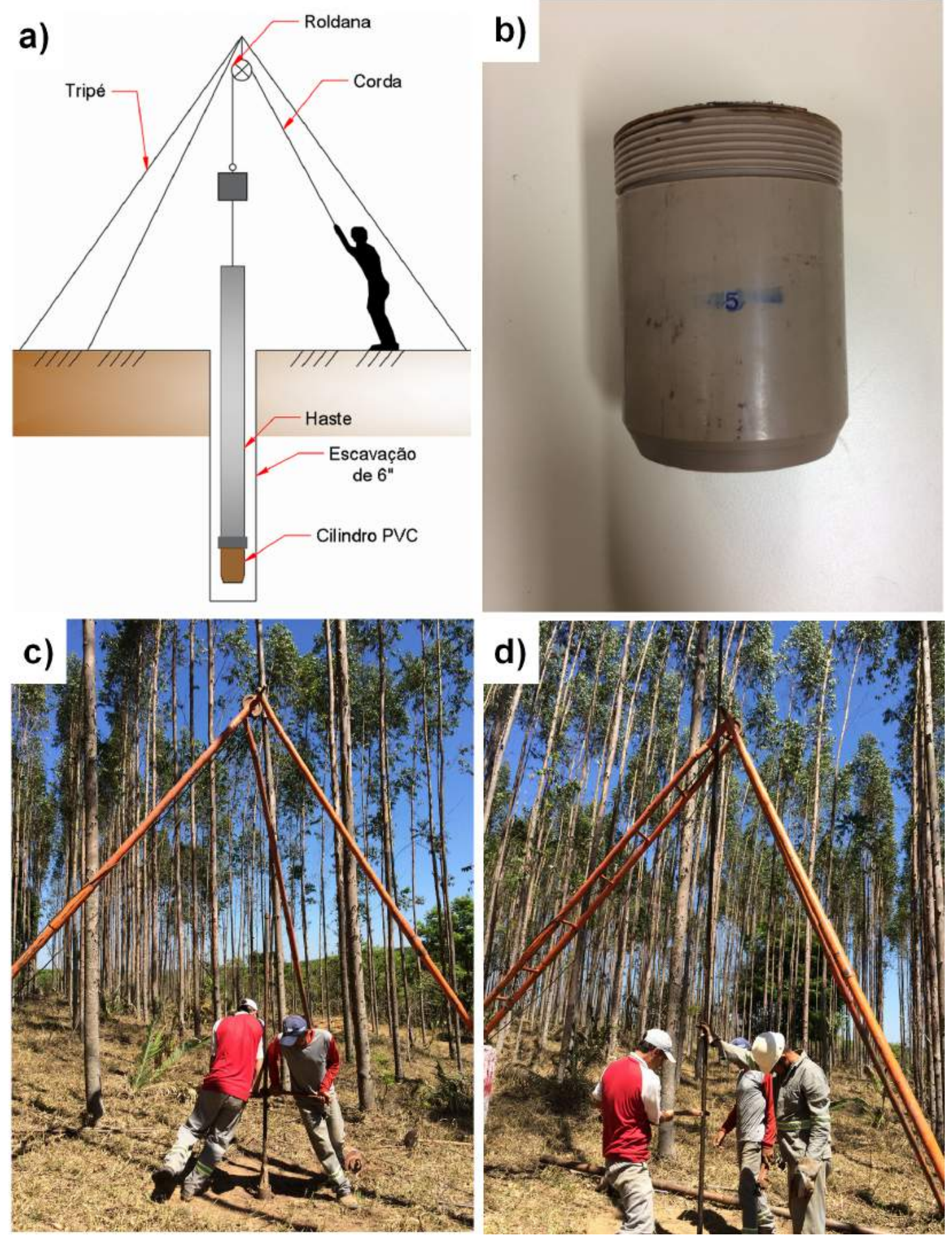

Fonte: Autor. 


\subsubsection{Método de tensão da água no solo}

A aplicação deste método foi executada através da reconstrução e modernização do funil de Haines feito por Gomes (2008). No trabalho de Gomes (2008) o funil de Haines original teve como finalidade determinar o rendimento específico $\left(S_{y}\right)$ com base no potencial matricial da amostra. Neste trabalho, a modernização desse equipamento constitui de um aperfeiçoamento inédito para não apenas determinar o rendimento específico, mas também a sua variação em função do tempo de drenagem do solo $\left[S_{y}(t)\right]$. Essa adaptação, moderniza a sua estrutura usando menos equipamentos que aqueles utilizados por Loheide II, Butler e Gorelick (2005), Fahle e Dietrich (2014).

O equipamento original constitui-se de um funil munido de placa porosa na parte inferior do seu corpo. As duas etapas mais importantes do ensaio são apresentadas na Figura 28 e uma explicação detalhada sobre os princípios do seu funcionamento são descritas em Hillel (1998), Libardi (2005).

Figura 28 - Representação esquemática do funil de Haines. (a) Saturação da amostra. (b) Aplicação da tensão h.

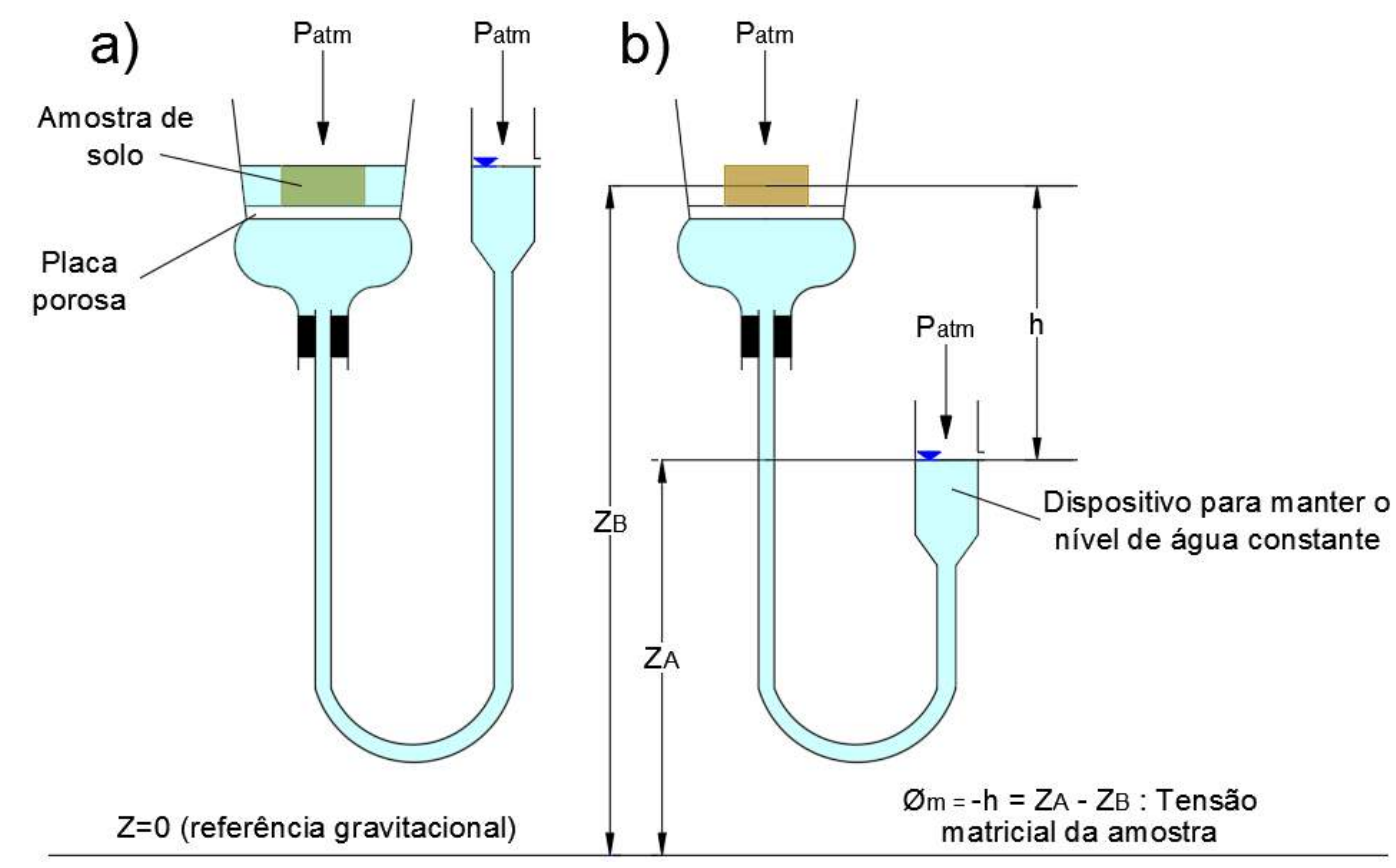

Fonte: Adaptado de Libardi (2005).

Para a modernização do funil de Haines foi utilizada uma balança de precisão que constantemente registra a massa do volume de água que sai da amostra do solo. A conexão entre o funil e a balança foi a combinação de 1 mangueira e 1 pipeta (Figura 29a). Também foi incorporado o uso do tecido silk screen no lugar de papel filtro, para evitar perda de material de solo nos anéis durante o seu manuseio.

Todos os itens utilizados no ensaio foram: funil (fabricado em PVC), anéis de pressão (fabricado em PVC), placa porosa, pedra porosa (Apêndice C), tecido silk screen 


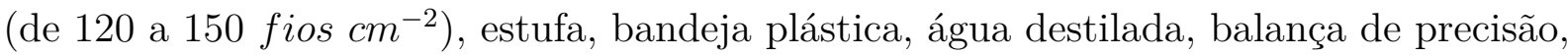
tampa de isopor, pipeta, mangueira plástica, grampo retangular, anel de borracha O'Ring e reservatório de plástico.

Figura 29 - a) Funil de Haines modernizado. b) Saturação das amostras através de pedras porosas. c) Ordem do posicionamento do O'Ring, placa porosa, anel de pressão e amostra do solo coberta com tecido silk screen. d) Pesagem da amostra do solo depois do ensaio.
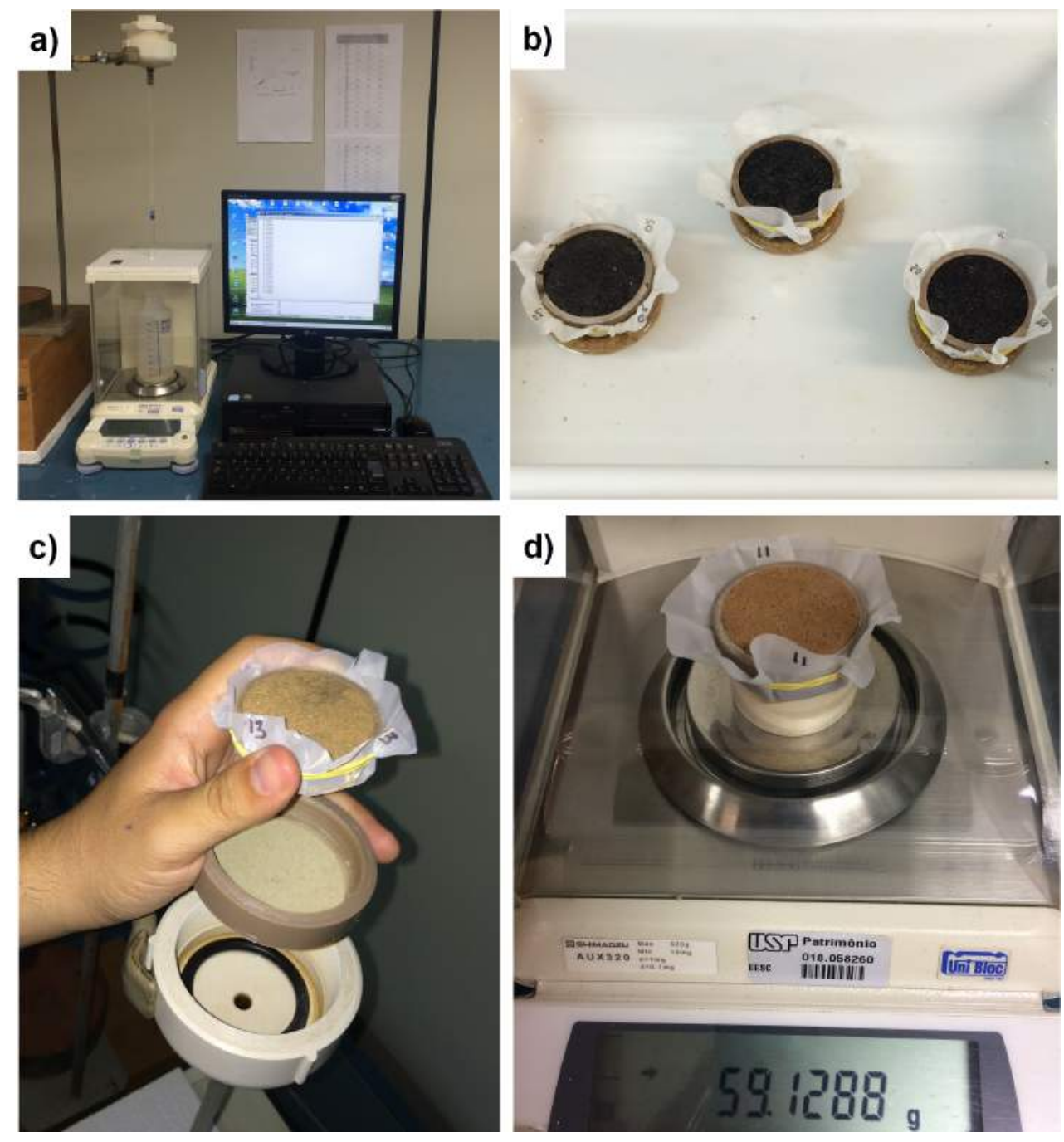

Fonte: Autor.

A amostra a ser ensaiada foi saturada previamente durante $24 h$ através da pedra porosa pelo efeito de capilaridade utilizando o tecido silk screen (material hidrófugo) como condutor (Figura 29b). Passado o tempo de saturação foi registrada a pesagem inicial da amostra. Além disso, o sistema foi preenchido com água destilada e sem bolhas de ar. Em seguida a amostra foi colocada dentro do funil junto com a placa porosa, o anel de borracha O'Ring e o anel de pressão (Figura 29c). Todo o conjunto foi fechado com um grampo retangular.

A balança de precisão foi configurada para exportar os dados da massa para o 
computador a cada $15 \mathrm{~min}$, logo colocou-se dentro dela o reservatório plástico preenchido com água com a extremidade da pipeta dentro dela (Figura 29a). A distância entre o nível de água no reservatório e a placa porosa dentro do funil foi de $61,3 \mathrm{~cm}$ para gerar uma sucção de $6 \mathrm{kPa}$ em uma temperatura de $20^{\circ} \mathrm{C}$ e possibilitar a retirada de água que se encontra nos macroporos da amostra de solo. A parte de acima do funil e da balança de precisão foi selada com uma tampa de isopor, para evitar a evaporação, deixando nelas uma entrada mínima da pressão atmosférica.

Para iniciar o ensaio, ativou-se a contagem da balança, e afrouxou-se o grampo retangular da mangueira, possibilitando a entrada de a água no reservatório de plástico até atingir o equilíbrio estático e cessar a drenagem da amostra do solo. Após o fim do processo, a amostra foi retirada do funil para aferição da massa e comparação com os resultados da balança (Figura 29d). Durante $24 \mathrm{~h}$ a amostra foi seca em estufa a $110{ }^{\circ} \mathrm{C}$ para determinar a microporosidade (ou retenção específica - $S_{r}$ ) e a porosidade total $(\eta)$.

Como o tipo de solo em cada poço possui diferentes granulometrias e distribuições de vazios, a interrupção da drenagem dos anéis para cada poço é dado em tempos diferentes, sendo esses tempos necessários para o cálculo do rendimento especifico.

Como foi explicado no item 5.3.1.1, foram coletadas 5 amostras indeformadas de solo por cada poço e delas foram retiradas 3 amostras menores contidas em anéis de PVC. Elas ficaram dentro do funil no momento de cada teste. Para cada anel preenchido com uma amostra de solo, foram realizadas 3 curvas do rendimento especifico $\left(S_{y}\right)$ vs tempo $(t)$, gerando um total de 9 curvas para cada poço.

Para obter uma curva total que represente o $S_{y}(t)$ para o solo de cada poço, foi realizada uma análise de incerteza. Ela consistiu em gerar diferentes curvas do $S_{y}$ vs $t$ para cada anel de solo de um mesmo poço, e estimar uma média aritmética entre elas $(\bar{X})$, o desvio padrão amostral $(\sigma)$ e o desvio padrão da média ou erro padrão $\left(\sigma_{\bar{X}}\right)$ (Eq. 5.3 a 5.5).

$$
\begin{gathered}
\bar{X}_{i}=\frac{\sum X_{i j}}{N} \\
\sigma_{i}=\sqrt{\frac{1}{N-1} \sum_{i=1}^{N}\left(X_{i j}-\bar{X}_{i}\right)^{2}} \\
\sigma_{\bar{X}_{i}}=\frac{\sigma}{\sqrt{N}}
\end{gathered}
$$

em que $\bar{X}_{i}$ são os valores médios das curvas $S_{y}(t)$ para o anel $i, X_{i j}$ os valores dos dados de $S_{y}(t)$ do anel $i$ e curva $j, N$ número de curvas de um anel (3), $\sigma_{i}$ o desvio padrão amostral 
de cada curva $S_{y}(t)$ do anel $i, \sigma_{\bar{X}_{i}}$ o desvio padrão da curva média ou erro padrão do $S_{y}(t)$ para o anel $i$.

É importante diferenciar o desvio padrão amostral $\left(\sigma_{i}\right)$ e o desvio padrão da média $\left(\sigma_{\bar{X}_{i}}\right)$. O primeiro é a incerteza média de cada curva j e o segundo representa a incerteza da curva média do $S_{y}(t)$ para o anel $i$, pois introduz o fator $\sqrt{N}$ que permite aumentar lentamente a precisão da estimativa quando o número de medições aumenta.

O último passo para obter uma curva que $S_{y}(t)$ que represente o solo de cada poço, foi realizar uma combinação das curvas médias e as incertezas de cada anel de solo de um mesmo poço. Este procedimento foi realizado através do uso da média ponderada $\left(\bar{X}_{m p}\right)$ e o desvio padrão da média ponderada $\left(\sigma_{m p}\right)$, como mostram as equações $5.6,5.7$ e 5.8 .

$$
\begin{gathered}
\bar{X}_{m p}=\frac{\sum W_{i} \bar{X}_{i}}{\sum W_{i}} \\
W_{i}=\frac{1}{\sigma_{\bar{X}_{i}}^{2}} \\
\sigma_{m p}=\frac{1}{\sqrt{\sum W_{i}}}
\end{gathered}
$$

A dedução dessas diferentes equações pode ser aprofundada em Taylor (2009) e um esquema que representa o número de medições (curvas) por cada poço é mostrado na Figura 30.

Figura 30 - Esquema do número de medições [curvas $S_{y}(t)$ ] por cada poço

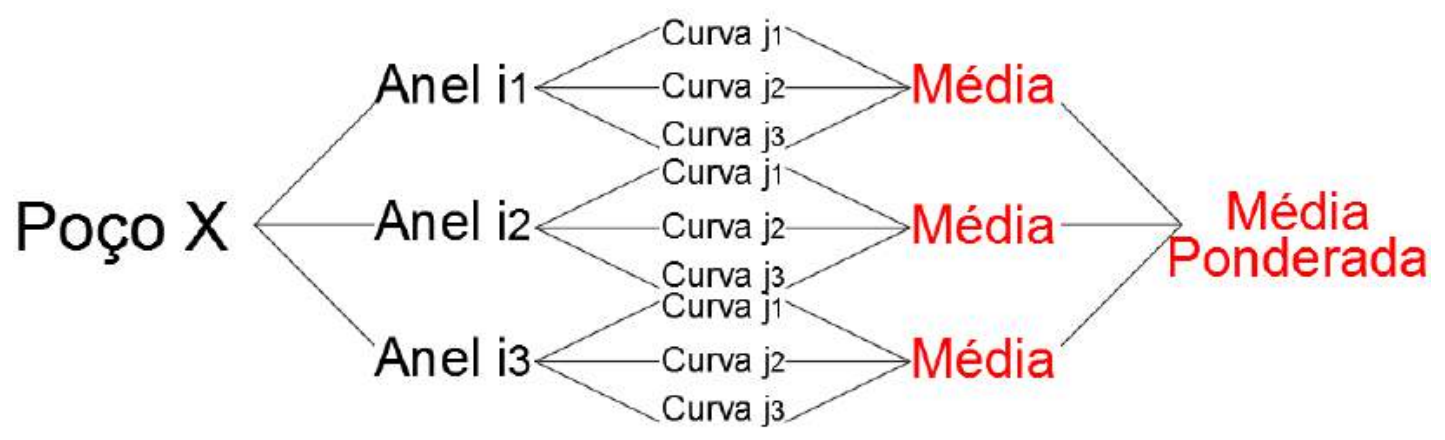

Fonte: Autor.

Para a determinação do rendimento específico transiente $\left(S_{y}^{*}\right)$ do solo ao redor de cada poço foi necessário calcular o tempo médio diário em que aconteceu a evapotranspiração na área de estudo (tempo em que o volume de controle permanece fora da zona saturada - Figura 11), obtida através dos dados coletados da flutuação diária do nível freático. Esse dado, junto com as curvas médias ponderadas de $S_{y}(t)$, possibilitou a determinação do $S_{y}^{*}$ do solo em cada poço. 
Para o cálculo de um valor que represente as diferentes medidas da retenção específica, foram aplicadas a mesmas equações estatísticas. Para a determinação da porosidade foram somados os valores médios do $S_{y}$ (Valor máximo da curva média ponderada) e o $S_{r}$. A sua incerteza, foi calculada com a equação geral de propagação de erros:

$$
\delta \eta=\sqrt{\left(\frac{\partial \eta}{\partial \bar{X}_{m p}} \sigma_{m p}\right)^{2}+\left(\frac{\partial \eta}{\partial \bar{X}_{r}} \sigma_{r}\right)^{2}}
$$

sendo $\delta \eta$ a incerteza da porosidade do solo em cada poço; $\bar{X}_{r}$ a média aritmética do $S_{r}$ para o solo de cada poço; $\sigma_{r}$ o desvio padrão da média do $S_{r}$ para o solo de cada poço.

\subsubsection{Teor de matéria orgânica do solo}

A realização deste ensaio teve como objetivo principal identificar qual(ais) das amostras de solo a ser utilizadas para o ensaio granulométrico possuíam uma porcentagem de matéria orgânica maior do que 5\%, para a sua posterior remoção com a mufla (EMBRAPA, 2011).

Essa análise foi realizada no Departamento de Geotecnia da EESC-USP, onde se pesaram aproximadamente $5 \mathrm{~g}$ de cada amostra de solo em uma balança de precisão. Cada uma delas em diferentes cadinhos, para depois serem colocadas em uma mufla a temperatura de $550{ }^{\circ} \mathrm{C}$ durante $24 h$ (Figura 31a). O propósito foi de eliminar toda a matéria orgânica (LANARV, 1983).

Finalmente, as amostras foram colocadas em um dessecador para atingir a temperatura ambiente (Figura 31b). Em seguida, foram pesadas novamente na balança, para estimar o teor de matéria orgânica de cada solo e identificar qual(ais) das amostras continham uma porcentagem de matéria orgânica $\geq 5 \%$.

\subsubsection{Análise granulométrica e densidade das partículas de solo por raios gama}

Esta análise foi realizada na Embrapa Instrumentação localizada na cidade de São Carlos, SP, por meio do analisador granulométrico de raios gama. A análise foi conduzida em triplicata para 8 amostras de solo: P27 $(0,30 m)^{3}$, P28 $(1,00 m)$, P28 $(2,00 m)$, P28 $(3,00 m)$, P29 $(1,00 m)$, P29 $(2,00 m)$, P29 $(3,00 m)$ e P29 $(4,00 m)$. Para cada repetição foram realizadas 3 leituras, gerando um total de 9 resultados por amostra de solo ${ }^{4}$.

$3 \quad \mathrm{P} 27(0,30 \mathrm{~m})=$ amostra de solo no poço 27 a uma profundidade de $0,30 \mathrm{~m}$ a partir da superfície do solo.

4 Este procedimento não foi realizado no solo poço 16, dado que Gomes (2008) tinha realizado a análise granulométrica para a uma faixa $(3,00-4,00 \mathrm{~m}$ de profundidade) que se encontra dentro dos limites de flutuação do nível freático. 
Figura 31 - a) Amostras de solo dentro da mufla. b) Dessecador
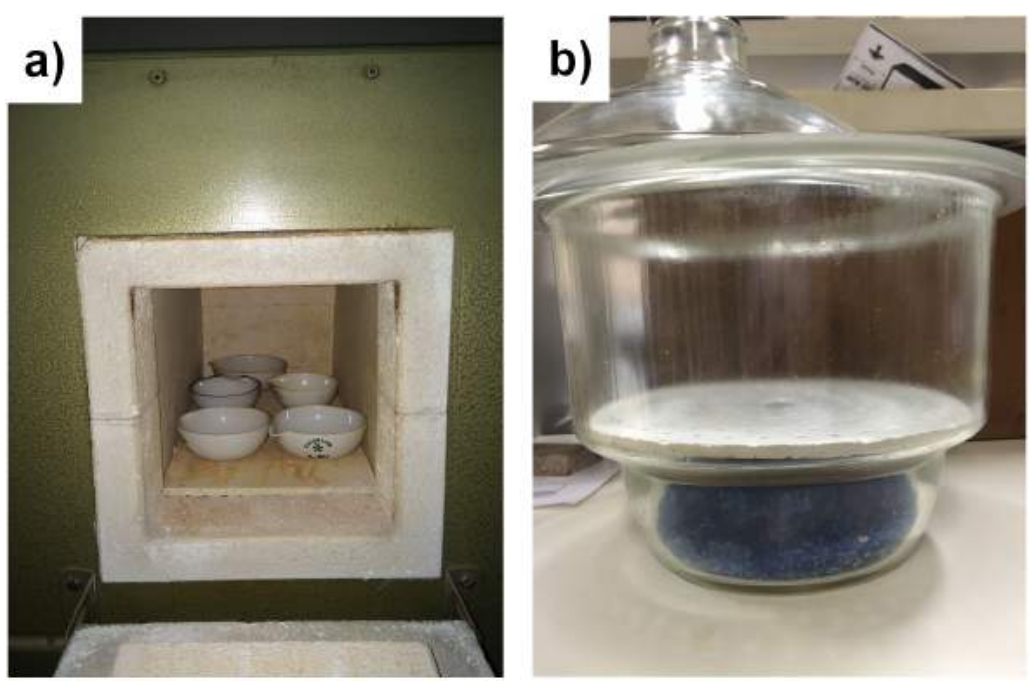

Fonte: Autor.

Os passos realizados nesta análise foram detalhados por Vaz et al. (1997). Primeiro, cada amostra foi secada em estufa a $105{ }^{\circ} \mathrm{C}$ durante $24 h$, depois desse tempo, elas foram passadas pela peneira de $2 \mathrm{~mm}\left(n^{\circ} 10\right)$. Em seguida, colocaram-se dentro de cubetas pequenas padronizadas para a realização do processo de atenuação (Figura 32). O processo demorou aproximadamente $20 \mathrm{~min}$.

Figura 32 - Processo de atenuação no analisador granulométrico

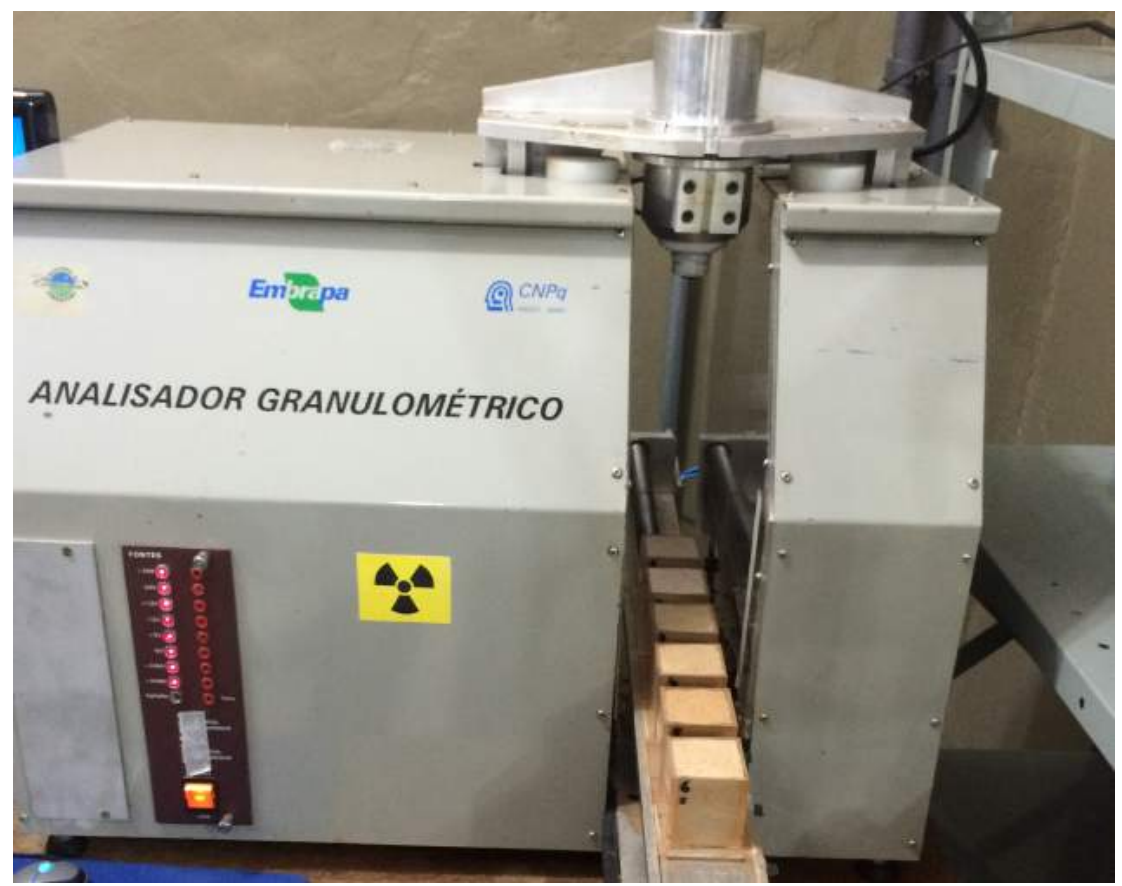

Fonte: Autor. 
A segunda etapa consistiu em pesar $40 \mathrm{~g}$ de cada amostra de solo em triplicata, que foram, em seguida, colocadas dentro de garrafas do agitador de Wagner (Figura 33a), adicionando $10 \mathrm{ml}$ de $\mathrm{NaOH}(1 \mathrm{~N})+150 \mathrm{ml}$ de água destilada. O agitador permaneceu ligado durante $16 \mathrm{~h}$.

A última etapa consistiu em passar o conteúdo das garrafas do agitador de Wagner para cubetas retangulares de acrílico $(5 \times 5 \times 20 \mathrm{~cm})$, as quais foram preenchidas com água destilada até atingir o volume de $400 \mathrm{ml}$. Essas cubetas foram colocadas no analisador para a leitura da distribuição dos tamanhos das frações de solo, através da lei de Stokes e da estimativa da densidade das partículas do solo (Figura 33b).

Figura 33 - a) Agitador de Wagner. b) Aplicação da lei de Stokes através do analisador granulométrico
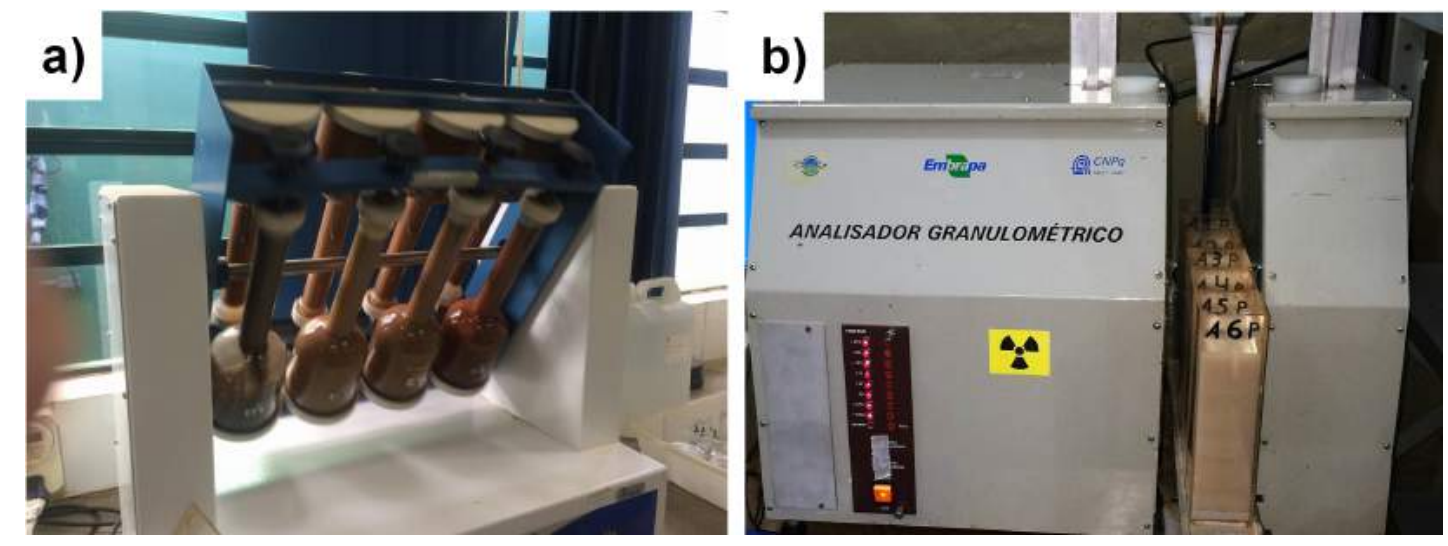

Fonte: Autor.

Os resultados gerados pelo analisador apresentaram a quantidade das frações de argila, silte e areia total. Para a obtenção das diferentes subdivisões da fração de areia, foram repetidas as estimativas desta fração utilizando as peneiras $n^{\circ} 18(1 \mathrm{~mm}), 35(0,5$ $\mathrm{mm}), 60(0,25 \mathrm{~mm}), 140(0,1 \mathrm{~mm})$ e $270(0,05 \mathrm{~mm})$, para melhorar a curva granulométrica.

No Apêndice I é detalhado o ensaio do Slug Test que foi realizado nos poços de monitoramento, com o fim de complementar os resultados da análise granulométrica.

\subsubsection{Classificação textural do solo}

Para classificar cada amostra de solo segundo o tamanho mais frequente das partículas (dado obtido na análise granulométrica), foi necessário seguir o diagrama triangular (Figura 34) criado originalmente pelo United States Department of Agriculture (USDA) e adaptado pela Sociedade Brasileira de Ciência do Solo (SBCS). Os resultados gerados nesta análise permitiu conhecer o tipo de solo que se encontra ao redor de cada poço em diferentes profundidades. 
Figura 34 - Classes texturais para solos.

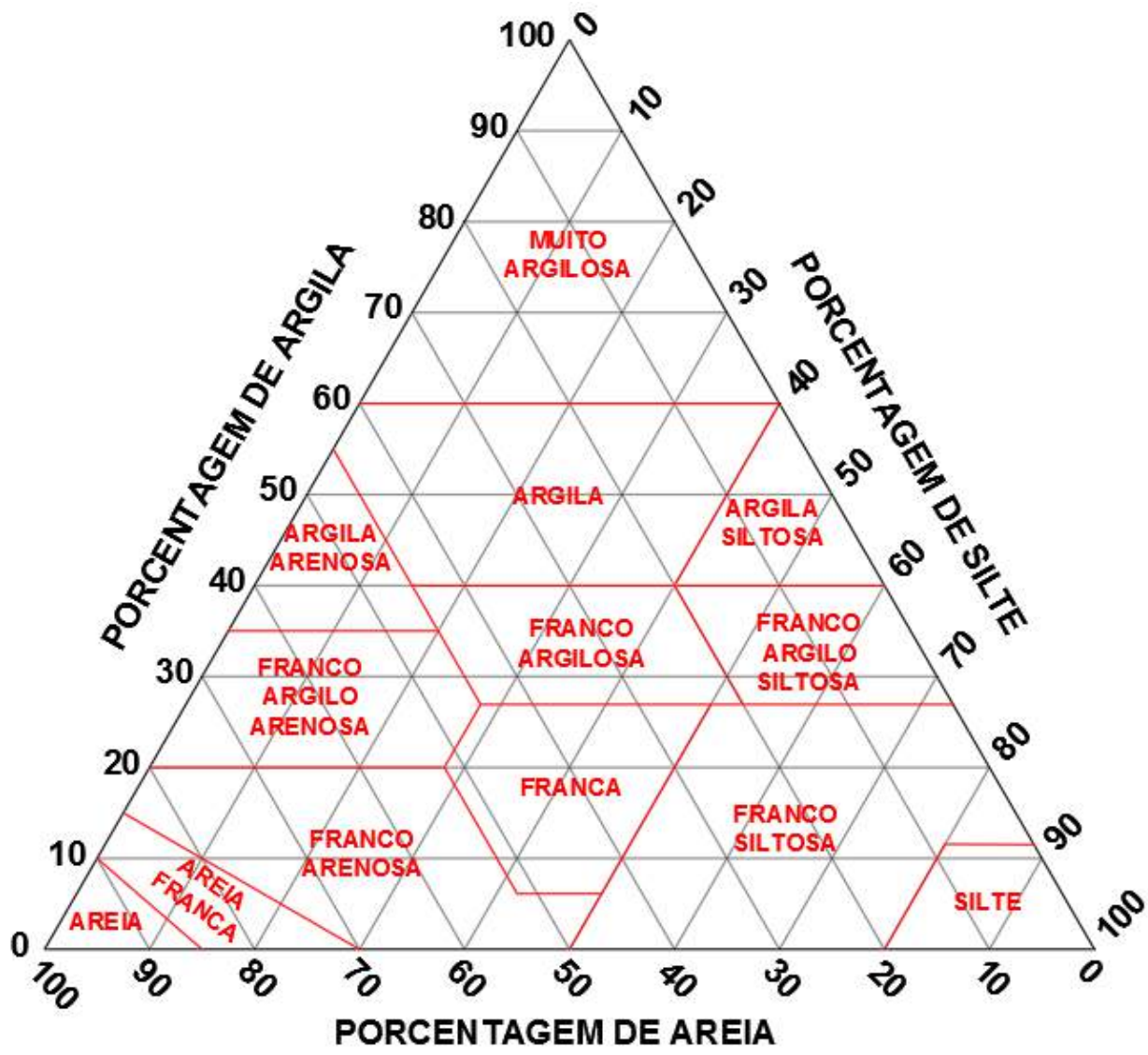

Fonte: Adaptado de SBCS.

\subsection{Determinação da evapotranspiração}

\subsubsection{Aplicação dos métodos baseados na flutuação diária do nível freático}

Para aplicação dos métodos foram realizados as seguintes etapas::

a) Realização da compensação barométrica dos dados coletados com os transdutores de pressão.

b) Remoção dos ruídos nas flutuações do nível de água subterrânea, através da aplicação da filtragem passa-baixa Loess.

c) Elaboração de scripts no software MATLAB R2015a dos diferentes métodos, para obter cálculos rápidos e sistemáticos (Apêndice D).

Como a resolução temporal da coleta do nível de água subterrânea foi de 15 min, algumas equações das diferentes abordagens sofreram modificações. Para o método de White (1932) não foi utilizada a taxa média horária de elevação do nível freático $\left(r_{h}\right)$. 
Entretanto, foi usada uma taxa média a cada 15 min de elevação do nível freático $\left(r_{15}\right)$, sendo multiplicada por 96 (equação 5.10):

$$
E T_{d}=S_{y}^{*}\left(96 r_{15} \pm \Delta S\right)
$$

Nas metodologias de Dolan et al. (1984) e Hays (2003), as equações não tiveram modificações. Em Gribovszki et al. (2008) e Loheide II (2008) o dt utilizado foi de 15 min, sendo determinada a evapotranspiração nesse mesmo intervalo de tempo $\left(E T_{15 \text { min }}\right)$. Portanto a determinação da evapotranspiração diária $\left(E T_{d}\right)$ não foi através de uma integral, como mostrado na equação 3.8, mas de forma discretizada (equação 5.11):

$$
E T_{d}=\sum_{j=1}^{96} E T_{15 \min j}
$$

\subsubsection{Monitoramento das variáveis meteorológicas e aplicação do método de Penman Monteith - FAO 56}

As variáveis meteorológicas foram coletadas em uma estação meteorológica ${ }^{5}$ (Figura 35) localizada a uma distância aproximada de $1,5 \mathrm{~km}$ dos poços em estudo, na fazenda

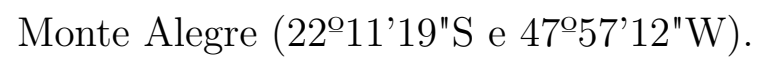

Figura 35 - Estação meteorológica localizada na fazenda Monte Alegre

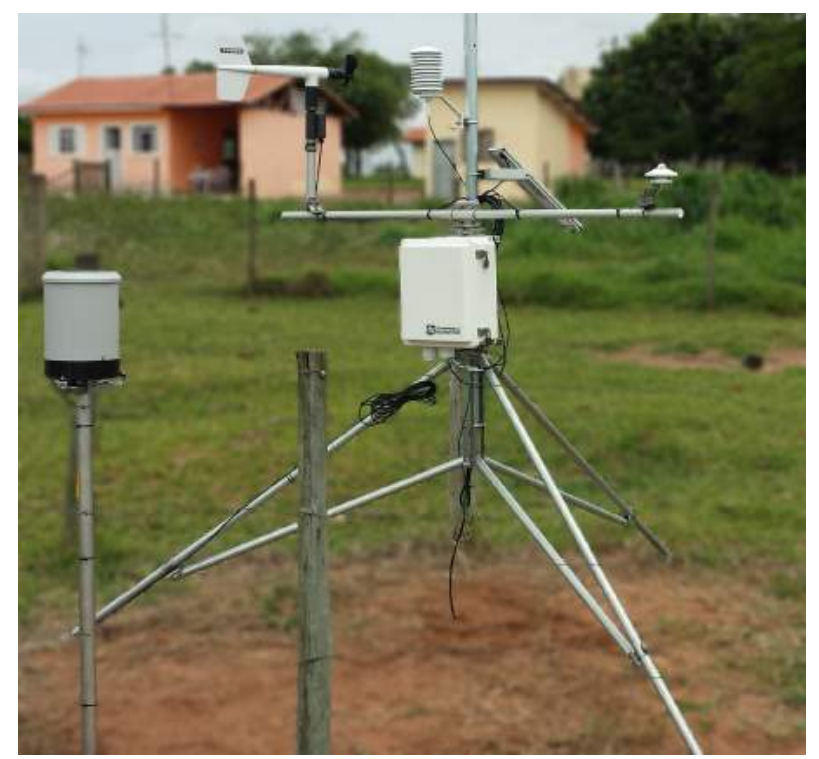

Fonte: Autor.

Estas variáveis foram usadas para a aplicação do método de Penman Monteith FAO 56 e para identificar os dias sem precipitação, dado que é uma restrição na aplicação 
dos métodos da flutuação diária do nível de água subterrânea. A Tabela 8 detalha os sensores disponíveis na estação meteorológica.

Tabela 8 - Sensores disponíveis na estação meteorológica e variáveis monitoradas

\begin{tabular}{ccc}
\hline Variável monitorada & Sensor & Altura $(m)$ \\
\hline Temperatura $\left({ }^{\circ} \mathrm{C}\right)$ e Umidade relativa (\%) & Termo-higrômetro HC2S3 & 2,0 \\
Precipitação $(m m)$ & Pluviômetro Hydrological Services & 1,5 \\
Pressão atmosférica $(m b a r)$ & TB4 Tipping Bucket Rain Gauge & 1,0 \\
Direção $\left(^{\circ}\right)$ e velocidade do vento $\left(\mathrm{m} \mathrm{s}^{-1}\right)$ & Barômetro CS106 & 2,0 \\
Fluxo de radiação solar $\left(M J \mathrm{~m}^{-2}\right)$ & Anemômetro Young 05103 & 2,0 \\
\hline
\end{tabular}

Fonte: Autor.

\subsubsection{Estimativa da evaporação do solo da zona ripária por exposição direta à radiação solar}

A literatura (vide Tabela 3) mostra que os valores de evapotranspiração diária nas zonas ripárias são geralmente elevados, em torno de 10 a $17 \mathrm{~mm}$. Esses valores são o resultado de um alto aporte tanto de transpiração quanto da evaporação do solo, dado que nestas zonas o nível freático encontra-se a centímetros da superfície e o solo tem alto teor de matéria orgânica (coloração escura e menor albedo).

No dia 22 de agosto do 2016 às $9 h 45$ com temperatura do ar a $10,61{ }^{\circ} \mathrm{C}$, foram coletadas 3 amostras indeformadas de solo na zona ripária (com o mesmo procedimento em que foram coletadas as amostras indeformadas de solo do poço 27). Com elas foram construídos 3 microlisímetros (MLs), para estimar a evaporação que acontecia na área do poço 27, para uma condição de contato direto com a radiação solar.

Durante uma semana, os MLs foram posicionados em uma cobertura de um prédio de aproximadamente $4 \mathrm{~m}$ de altura (Figura 36a). O propósito foi de evitar sombras e medir a evaporação de cada um deles de forma diária. Para a instalação e construção dos MLs foram utilizados os seguintes materiais:

a) 3 cilindros em PVC com $10 \mathrm{~cm}$ de altura e 7,5 $\mathrm{cm}$ de diâmetro (corpo dos MLs).

b) Papeis brancos, que cobriram os cilindros PVC.

c) 3 capes brancos (tampa inferior dos MLs).

d) Papel filme, para impermeabilizar o contato entre os cilindros PVC e os capes. 
e) 3 bandejas plásticas preenchidas com água até a metade, a fim de colocar no centro de cada uma delas os MLs e evitar o possível "efeito oásis" gerado pelo aquecimento do telhado.

f) 3 suportes brancos, para evitar o contato entre água contida nas bandejas e os MLs.

g) 1 transdutor de pressão dentro de uma caixa de papelão e colocado na bandeja central (fora do contato com a água), para a medição da temperatura do ar.

Como as medições da evaporação foram diárias, das $18 h 00$ de um dia até as $18 h 00$ do dia seguinte, os MLs eram pesados em uma balança de precisão e depois saturados novamente (Figura 36b), deixando-os com a mesma umidade do dia da coleta.

A estimativa da evaporação através deste método não tinha como propósito a obtenção de um valor exato, mas ter uma aproximação da capacidade evaporativa do solo na zona ripária em uma condição extrema ou de radiação direta sobre ele.

Figura 36 - a) Microlisímetros no telhado sobre bandejas com água para evitar "efeito oásis". b) Reposição da água perdida nos MLs até a mesma umidade do dia da coleta.

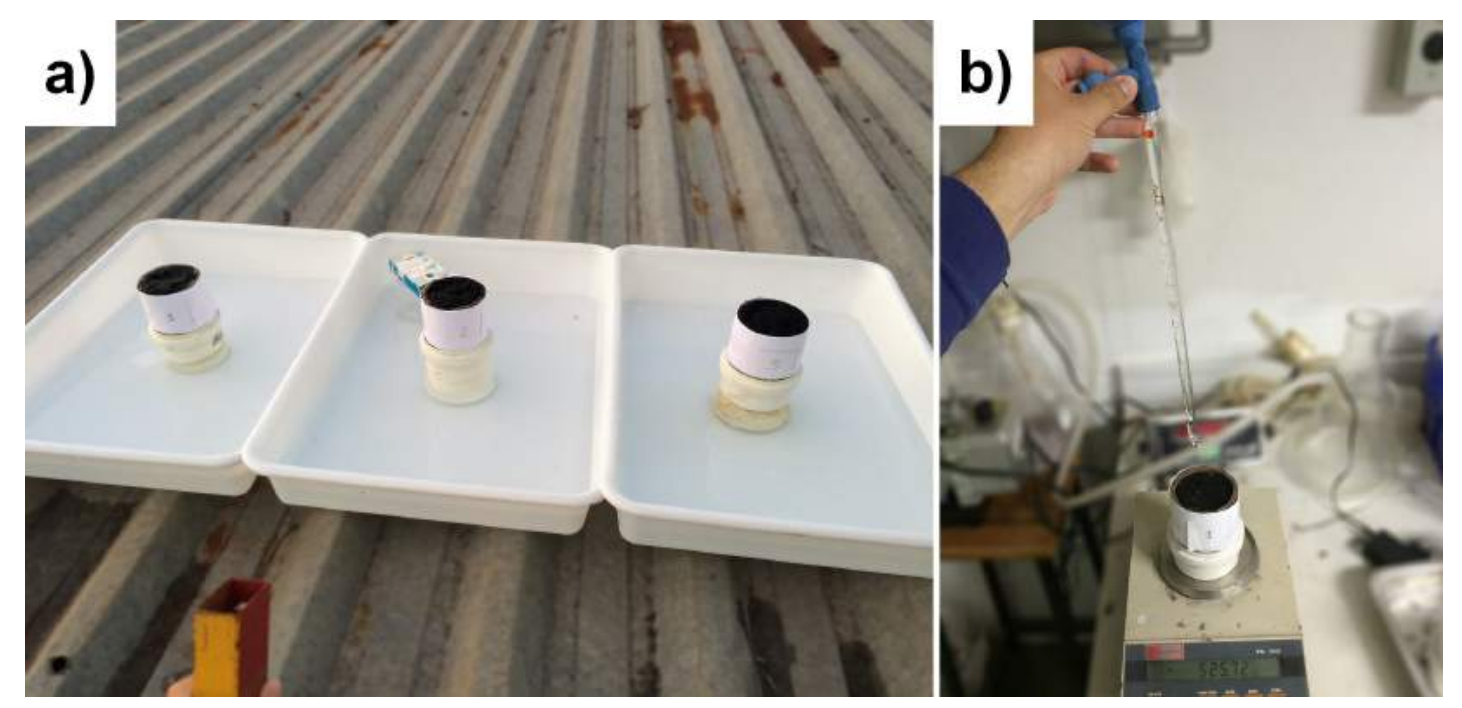

Fonte: Autor. 


\section{RESULTADOS E DISCUSSÕES}

\subsection{Flutuações do nível freático nos poços de monitoramento}

A obtenção de dados do nível freático nos poços de monitoramento ${ }^{1}$ foi realizada através de transdutores de pressão configurados com uma frequência de registro de 15 min. Com eles foram registradas as variações do nível de água durante o dia.

A filtragem passa baixa foi feita através da Regressão Polinomial Local Ponderada (Loess) para suavizar o ruído dos dados obtidos em cada poço. A suavização permitiu a aplicação dos diferentes métodos baseados na flutuação do nível freático e melhorou a visualização da série temporal.

Foi escolhida uma semana modelo do poço 27 (Zona Ripária) para mostrar os resultados obtidos com a Loess (Figura 37). Essa mesma semana de setembro de 2015 é usada para mostrar diferentes características das flutuações nos poços durante todo o tempo de estudo.

Figura 37 - Semana do mês de setembro de 2015 em que pode ser observada a aplicação da filtragem passa baixa (Loess) nos dados do poço 27 (Zona Ripária).

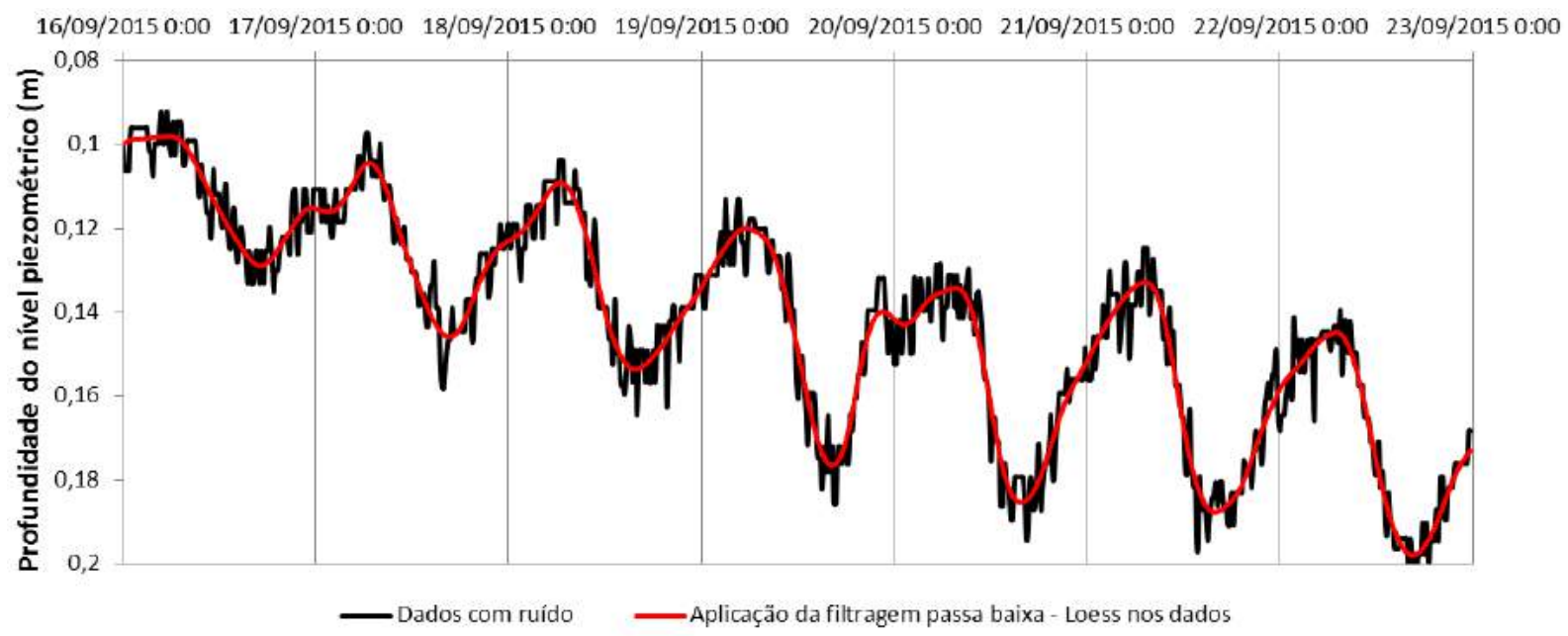

Fonte: Autor.

O tempo total de coleta de dados foi entre 04/09/2015 e 20/10/2016 (413 dias). Foram escolhidos os dias que não houveram precipitações para a aplicação dos diferentes métodos baseados na flutuação diária do nível freático, dado que a precipitação gera flutuações que não são cíclicas. O efeito da precipitação sobre o nível de água subterrânea é mostrado na Figura 38 no final do dia 25 e no começo do 26 de Setembro de 2015.

$\overline{1}$ No Apêndice E se encontram as profundidades médias diárias do nível freático em cada zona de estudo. 
Figura 38 - Comportamento da flutuação diária do nível freático quando não tem ocorrência de precipitação $(20 / 09 / 2015$ - 25/09/2015) e quando tem $(25 / 09 / 2015$ $-27 / 09 / 2015)$.

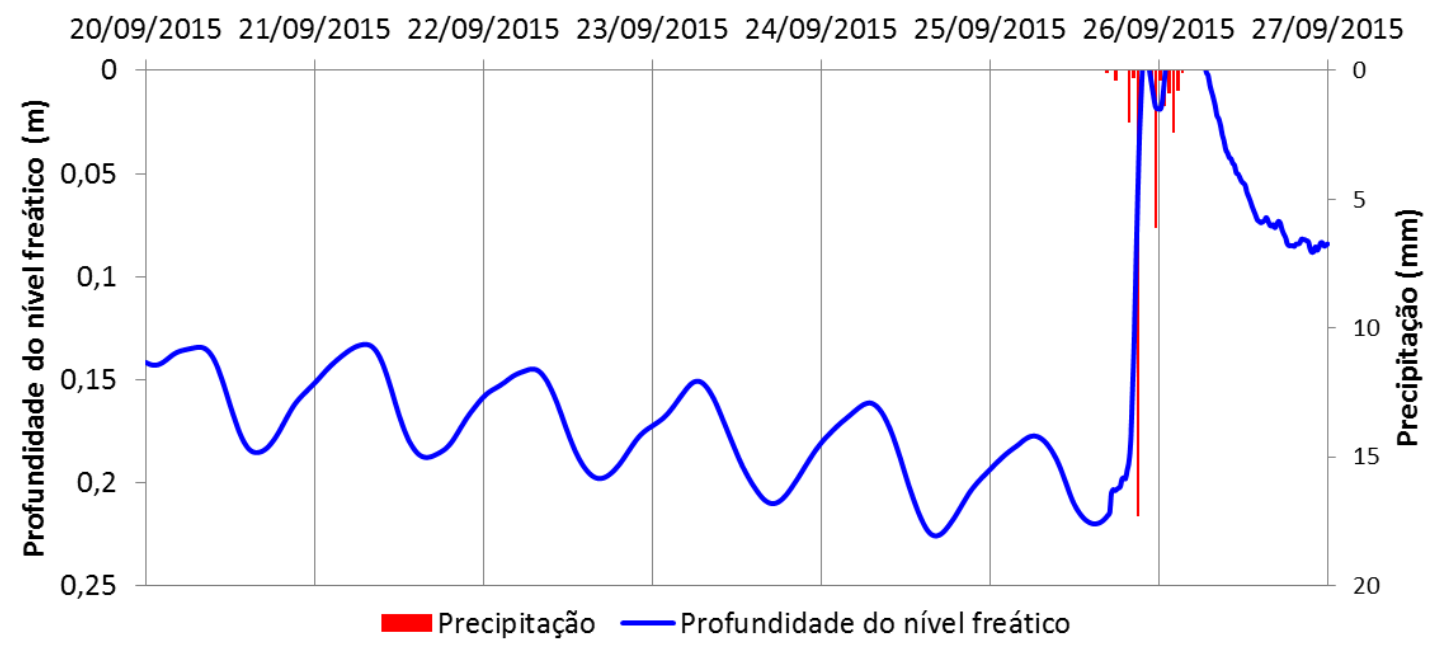

Fonte: Autor.

Pode ser observado que a flutuação diária segue o comportamento da irradiância solar, temperatura do ar e a umidade relativa do ar (Figura 39 a1, b1, c1). Com o fim de determinar qual é a variável que melhor se correlaciona com as flutuações, foi calculada a correlação cruzada entre o nível freático e cada uma dessas variáveis meteorológicas (Figura 39 a2, b2, c2).

Para a realização dessa estatística, foi necessário adaptar os dados da flutuação de 15 min de frequência a $1 h$. Além disso, a série temporal do nível freático é não-estacionária, tendo sido necessário remover a inclinação da flutuação nessa semana ${ }^{2}$, dado que as séries das variáveis meteorológicas são estacionárias ${ }^{3}$.

Essas três variáveis meteorológicas e os dados do nível freático possuem as suas melhores correlações com um lag de -2 horas (Figura 39). Este tempo pode ser interpretado como aquele necessário para que a evapotranspiração cause o rebaixamento do nível freático a partir da incidência dos primeiros raios solares.

Os valores obtidos na correlação cruzada foram: 0,95; -0,93 (inversamente correlacionado) e 0,85 para a temperatura do ar, umidade relativa do ar e irradiância solar, respectivamente. Embora as três possuam valores próximos a 1, os resultados indicam que a temperatura do ar $(R=0,95)$ possui uma forte correlação com as flutuações do nível freático.

2 A remoção dessa inclinação foi feita com a subtração da declividade calculada por regressão linear.

3 Uma séria estacionária é aquela que se desenvolve no tempo de forma aleatória ao redor de uma média constante, mostrando uma forma de equilíbrio estável (GRENANDER; ROSENBLATT, 1957). 
Figura 39 - Flutuação diária da profundidade do nível freático do poço 27 contra a temperatura média horária do ar (cor vermelha - a), umidade relativa do ar (cor verde - b) e irradiância solar (cor preta - c), em uma semana de Setembro de 2015. Para a análise com a irradiância solar, foram usados somente os horários de brilho solar. a1), b1) e c1) mostram que profundidade do nível freático é diretamente proporcional à temperatura do ar e à irradiância solar, e inversa à umidade relativa do ar. a2), b2) e c2) mostram que as correlações cruzadas entre a profundidade do nível freático e as variáveis meteorológicas possuem os máximos valores $[0,95 ;-0,93$ (correlação inversa) e 0,85 para a temperatura do ar, umidade relativa do ar e irradiância solar, respectivamente] com lag de -2 horas.

a1)

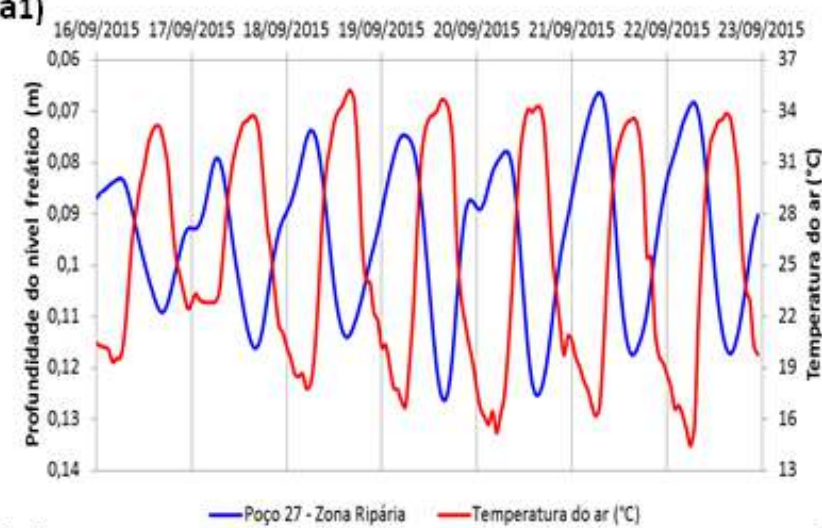

b1)

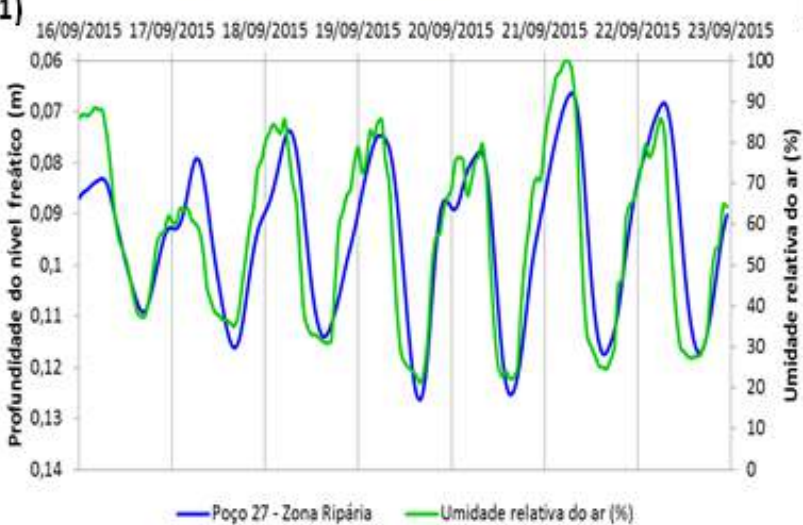

C1)

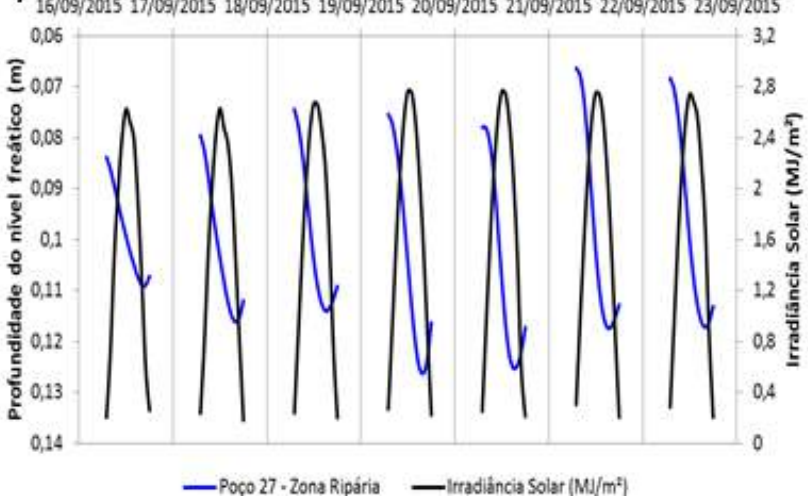

a2)

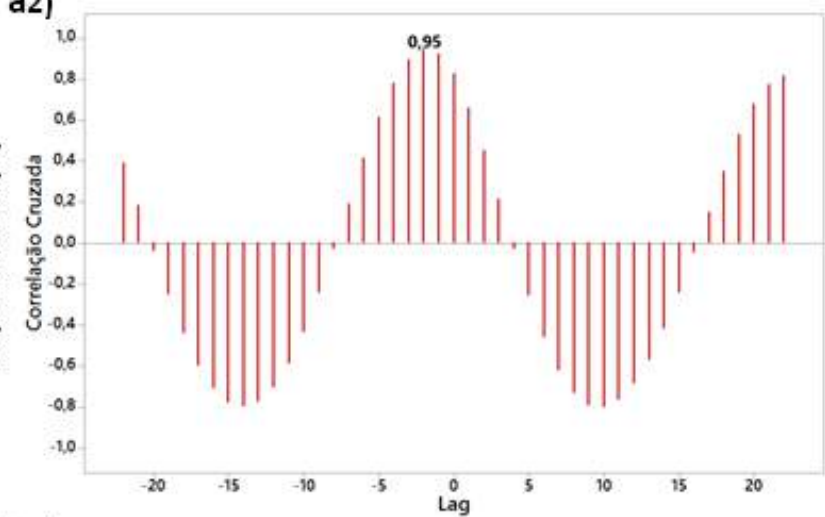

b2)

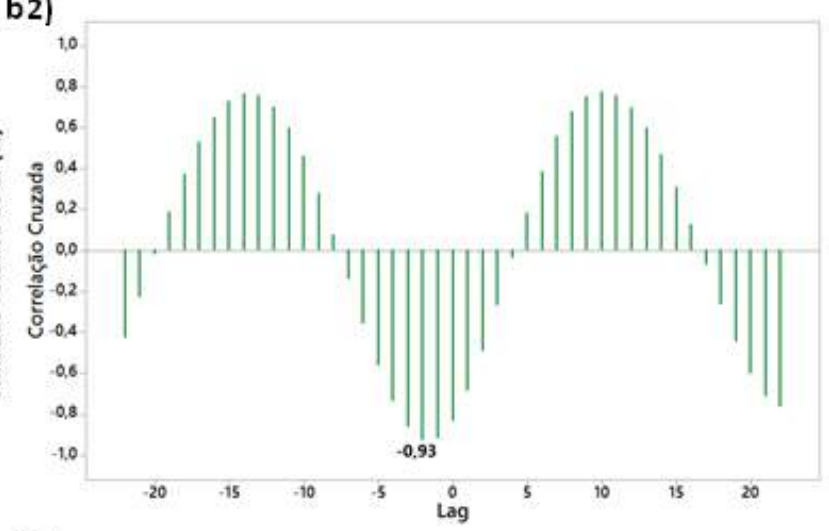

C2)

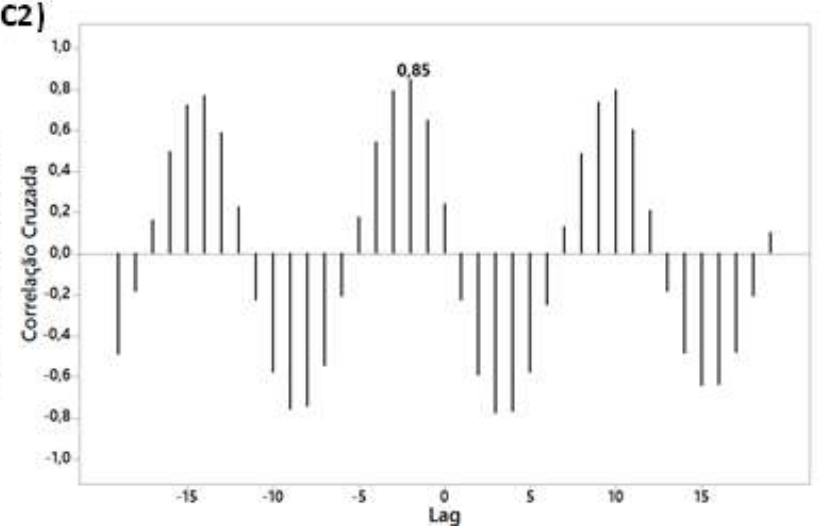

Fonte: Autor. 
Outra característica que pôde ser observada é que profundidade do nível freático nos diferentes poços é inversamente proporcional à amplitude das flutuações do nível de água subterrânea. Com exceção do poço 16, devido ao porte do eucalipto ${ }^{4}$ (Figura 40.). Essa tendência pode ser explicada pelo fato de que quanto mais próximo da superfície encontra-se o nível freático, maior será o aporte de evaporação na ET (MAXWELL; CONDON, 2016).

No poço 19 não foi possível observar a flutuação diária com o mesmo padrão que nos poços 27, 28, 29 e 16, dado que ele fica afastado da zona ripária e o efeito da evapotranspiração é nulo em épocas de estiagem. Essas flutuações do poço 19 podem ser geradas pela variação de gradiente hidráulico que existe com a zona ripária, como foi explicado no método de Gribovszki et al. (2008). Por tal motivo o poço 19 não foi usado para a determinação da evapotranspiração com os métodos da flutuação diária do nível freático.

$4 \quad$ Essa ocorrência é discutida no item 6.3 .3 
Figura 40 - Variação da amplitude da flutuação diária do nível freático nos diferentes poços de monitoramento.

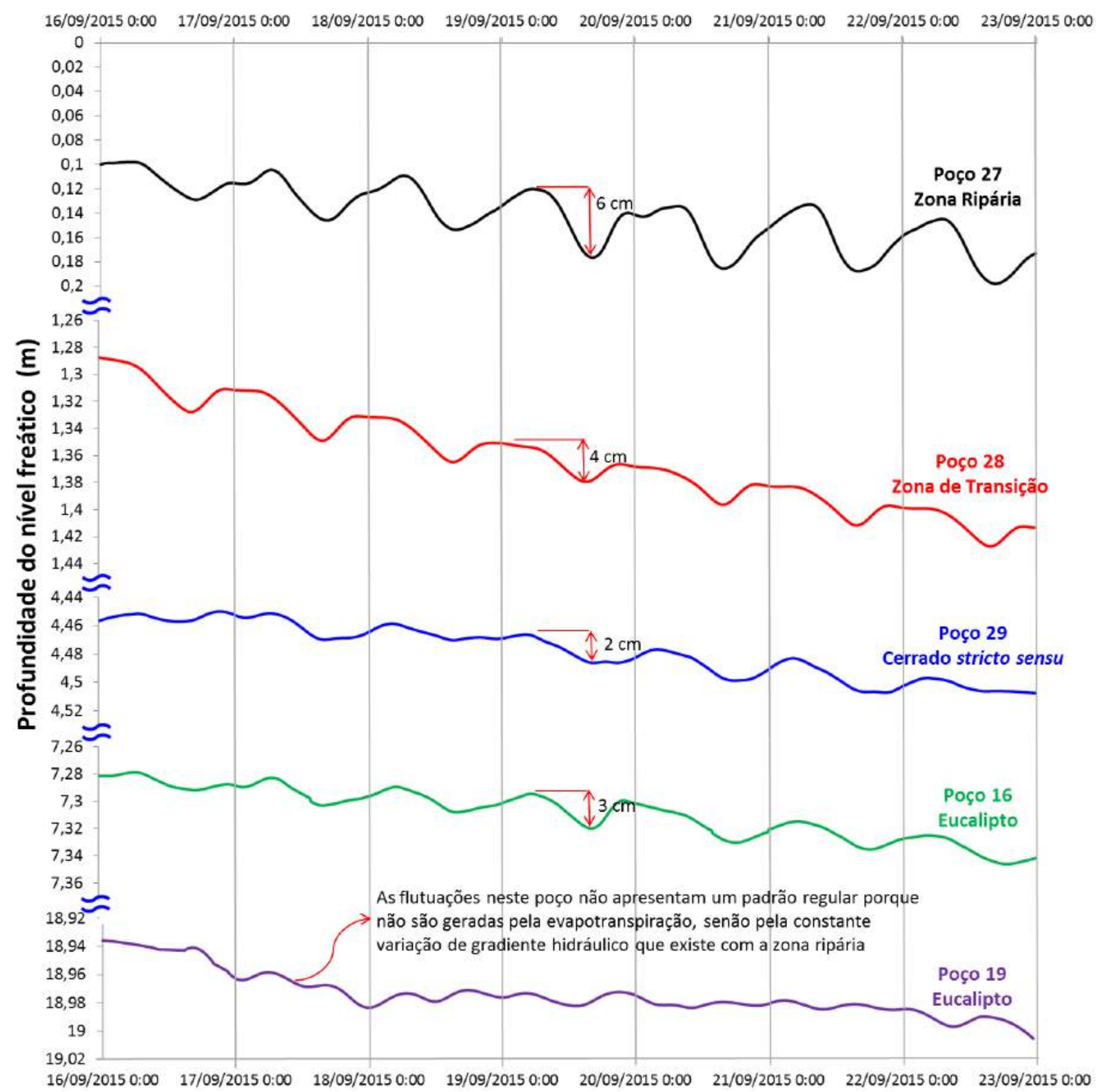

Fonte: Autor. 


\subsection{Características físicas do solo}

Dos resultados obtidos nos ensaios para a determinação das características físicas do solo, o mais importante é o rendimento específico transiente $\left(S_{y}^{*}\right)$. Esta variável possui maior sensibilidade no cálculo da ET, considerando os diferentes métodos da flutuação diária do nível de água subterrânea. Os demais resultados apresentados, como a retenção específica, rendimento específico, porosidade, teor de matéria orgânica e curvas granulométricas, são complementares e permitem uma maior compreensão e posterior discussão dos $S_{y}^{*}$ obtidos.

\subsubsection{Porosidade, retenção específica, rendimento específico e rendimento específico transiente}

Para a determinação do rendimento específico transiente $\left(S_{y}^{*}\right)$ do solo nos poços 27, 28, 29 e 16, primeiramente, foi estimado o tempo médio diário em que ocorreu a evapotranspiração, isto é, o tempo de drenagem do solo durante o dia. A partir dos dados obtidos de flutuação diária do nível freático, constatou-se que a evapotranspiração ocorre, geralmente, entre as 10 e 16 horas (Figura 41).

Figura 41 - Tempo médio em que acontece a evapotranspiração diária. Flutuação obtida no poço 16 com uma frequência de coleta de 15 min.

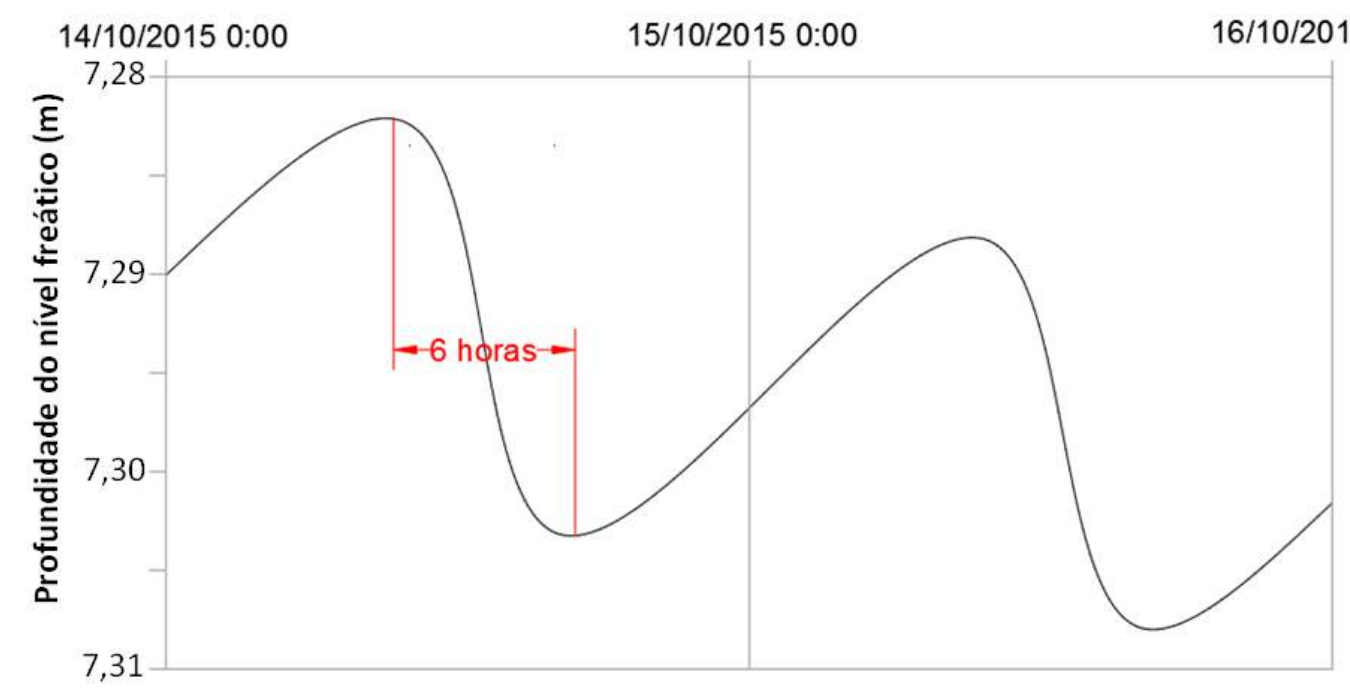

Fonte: Autor.

Com os resultados do funil de Haines modificado, foram obtidas as curvas de variação do rendimento específico no tempo $\left[S_{y}(t)\right]$. As curvas de um mesmo anel foram agregadas no mesmo gráfico, juntamente com a sua curva média (Figura 42a). Em outro gráfico, foram representadas as médias de cada anel com a sua curva da média ponderada (Figura $42 \mathrm{~b}$ ), que indica a variação do $S_{y}(t)$ total para cada poço ou zona de estudo. O conjunto completo dessas curvas pode ser encontrado no Apêndice F. 
O tempo médio diário da evapotranspiração ${ }^{5}$ foi de $6 h$, isto é, $t^{*}=6 h$. Com este resultado foi possível determinar o rendimento específico transiente do solo para cada poço, dado que $S_{y}(6 h)=S_{y}^{*}$. Os valores máximos das curvas médias ponderadas de $S_{y}(t)$, correspondem aos $S_{y}$ (Figura 42b).

Figura 42 - (a) Curvas do $S_{y}(t)$ e a média para o anel 02 do poço 27 - zona ripária. (b)Curvas da média dos $S_{y}(t)$ dos anéis 02, 03 e 05, com a média ponderada para poço 27 - zona ripária.
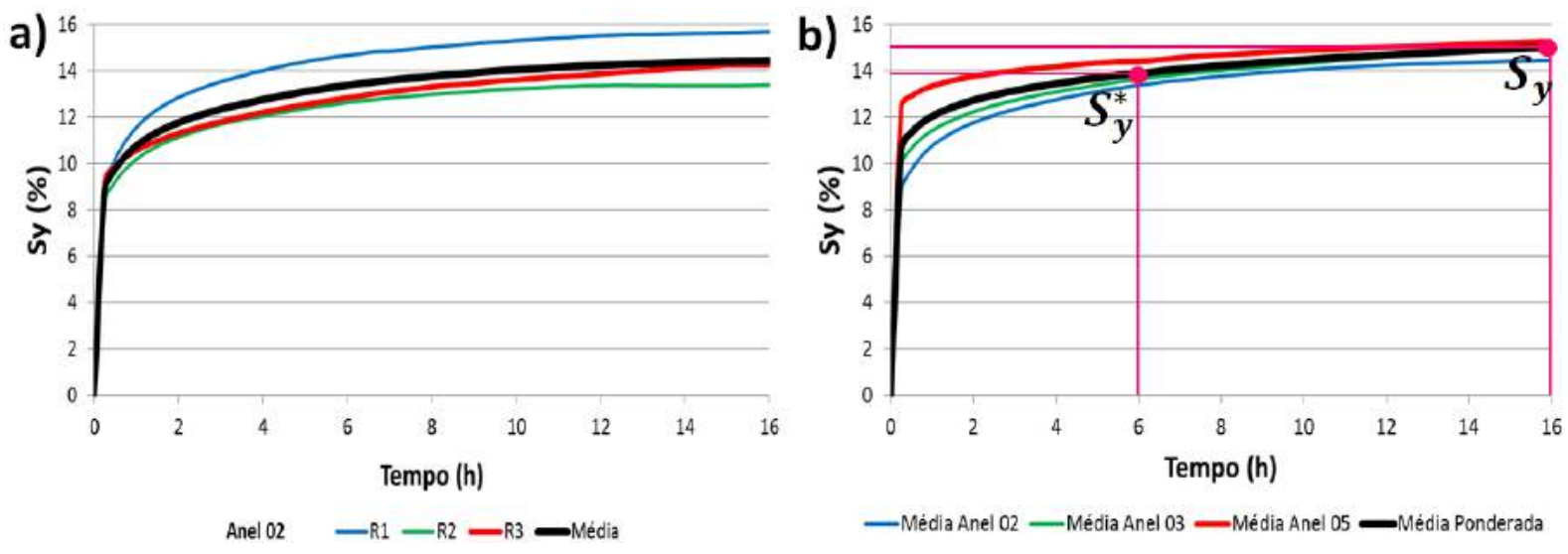

Fonte: Autor.

Após a realização das curvas com o funil de Haines modernizado, cada amostra foi seca em estufa para a determinação das retenções específicas e das porosidades totais. Em seguida, foram somados os resultados de $S_{y}$ e $S_{r}$ e propagadas as suas incertezas para a determinação das porosidades $(\eta)$. A Tabela 9 mostra os resultados obtidos neste ensaio.

Tabela 9 - Resultado dos ensaios de Porosidade $(\eta)$, Retenção específica $\left(S_{r}\right)$, Rendimento específico $\left(S_{y}\right)$ e Rendimento específico transiente $\left[S_{y}^{*}=S_{y}(6 h)\right]$.

\begin{tabular}{ccccc}
\hline & $\begin{array}{c}\text { Poço 27 } \\
\text { Zona ripária }\end{array}$ & $\begin{array}{c}\text { Poço 28 } \\
\text { Zona de transição }\end{array}$ & $\begin{array}{c}\text { Poço 29 } \\
\text { Cerrado stricto sensu }\end{array}$ & $\begin{array}{c}\text { Poço 16 } \\
\text { Eucalipto }\end{array}$ \\
\hline$S_{y}^{*}(\%)$ & $13,90 \pm 0,31$ & $18,35 \pm 0,02$ & $11,20 \pm 0,10$ & $12,73 \pm 0,24$ \\
$S_{y}(\%)$ & $15,18 \pm 0,15$ & $19,16 \pm 0,08$ & $12,10 \pm 0,19$ & $13,14 \pm 0,27$ \\
$S_{r}(\%)$ & $25,62 \pm 0,14$ & $11,23 \pm 0,08$ & $19,21 \pm 0,21$ & $20,44 \pm 0,36$ \\
$\eta(\%)$ & $40,80 \pm 0,21$ & $30,38 \pm 0,12$ & $31,31 \pm 0,28$ & $34,18 \pm 0,44$ \\
\hline
\end{tabular}

Fonte: Autor.

Os valores do rendimento específico obtidos na tabela (Tabela 9) ${ }^{6}$ variam entre $12,10 \pm 0,19$ e 19,16 $\pm 0,15 \%$, sendo mais elevados do que os valores apresentados por Wendland, Gomes e Troeger (2015) (Tabela 7) que variaram entre 8,5 e 15,9\%. Essa

5 Tempo $t^{*}$ em que o volume de controle permanece fora da zona saturada (vide item 3.5.1).

6 Uma ampliação da discussão dos resultados apresentados na Tabela 9 e no Apêndice F, é realizada no item 6.2.3. 
diferença pode ser devido ao fato de que os resultados mostrados por Wendland, Gomes e Troeger (2015) foram estimados para diferentes pontos da bacia Ribeirão da Onça e os resultados deste trabalho foram para a zona ripária e áreas vizinhas onde o solo possui menor compactação.

\subsubsection{Teor de matéria orgânica}

Esta análise foi realizada com o fim de identificar as amostras de solo ricas em matéria orgânica (teor > 5\%), para a posterior análise granulométrica (EMBRAPA, 2011). De acordo com os valores de porcentagem de matéria orgânica apresentados (Tabela 10), foi observado que as amostras de solo cujo percentual excede os $5 \%$ foram: poço $27(0,30$ $m$ ) e poço $28(1,00 m)$. Logo, existe uma tendência de aumento do teor de matéria orgânica a medida que se aproxima da zona ripária.

Tabela 10 - Teor de matéria orgânica no solo ao redor dos poços em diferentes profundidades

\begin{tabular}{ccccc}
\hline Poço & $\begin{array}{c}\text { Profundidade } \\
(m)\end{array}$ & $\begin{array}{c}\text { Peso antes da } \\
\text { mufla }(g)\end{array}$ & $\begin{array}{c}\text { Peso depois da } \\
\text { mufla }(g)\end{array}$ & $\begin{array}{c}\text { Teor de MO } \\
(\%)\end{array}$ \\
\hline 27 & 0,30 & 5,03 & 2,27 & 54,91 \\
28 & 1,00 & 5,02 & 4,63 & 7,70 \\
& 2,00 & 5,03 & 4,83 & 3,87 \\
& 3,00 & 5,01 & 4,96 & 1,04 \\
29 & 1,00 & 5,01 & 4,96 & 1,06 \\
\hline
\end{tabular}

Fonte: Autor.

A totalidade de matéria orgânica contida nas amostras poço $27(0,30 \mathrm{~m})$ e poço 28 $(1,00 \mathrm{~m})$ foi removida para a posterior análise granulométrica. A realização dos ensaios para as profundidades de 2,00, 3,00 e 4,00 $\mathrm{m}$ do poço 29 foi desnecessária, pois ele fica mais afastado da zona ripária. 


\subsubsection{Curvas granulométricas, densidade das partículas de solo por raios gama e classificação da textura do solo}

A análise granulométrica para cada amostra de solo foi feita em triplicata a partir dos resultados gerados pelo analisador de raios gama.

Primeiro, foram elaboradas curvas granulométricas a partir de três leituras de cada triplicata, visando calcular uma média (Figura 43a). Segundo, foram feitas outras curvas a partir das médias obtidas por cada triplicata a fim de calcular uma média total que pudesse representar cada amostra de solo (Figura 43b). Portanto, foi necessário um total de 9 leituras do analisador por amostra. O conjunto de curvas pode ser observadas no Apêndice $\mathrm{G}^{7}$

Figura 43 - a) Curva granulométrica média (linha vermelha) da segunda triplicata da amostra de solo do poço 28 a $3 \mathrm{~m}$ de profundidade a partir da superfície. b) Curva granulométrica média total (linha vermelha) da amostra de solo do poço 28 a $3 \mathrm{~m}$ de profundidade.
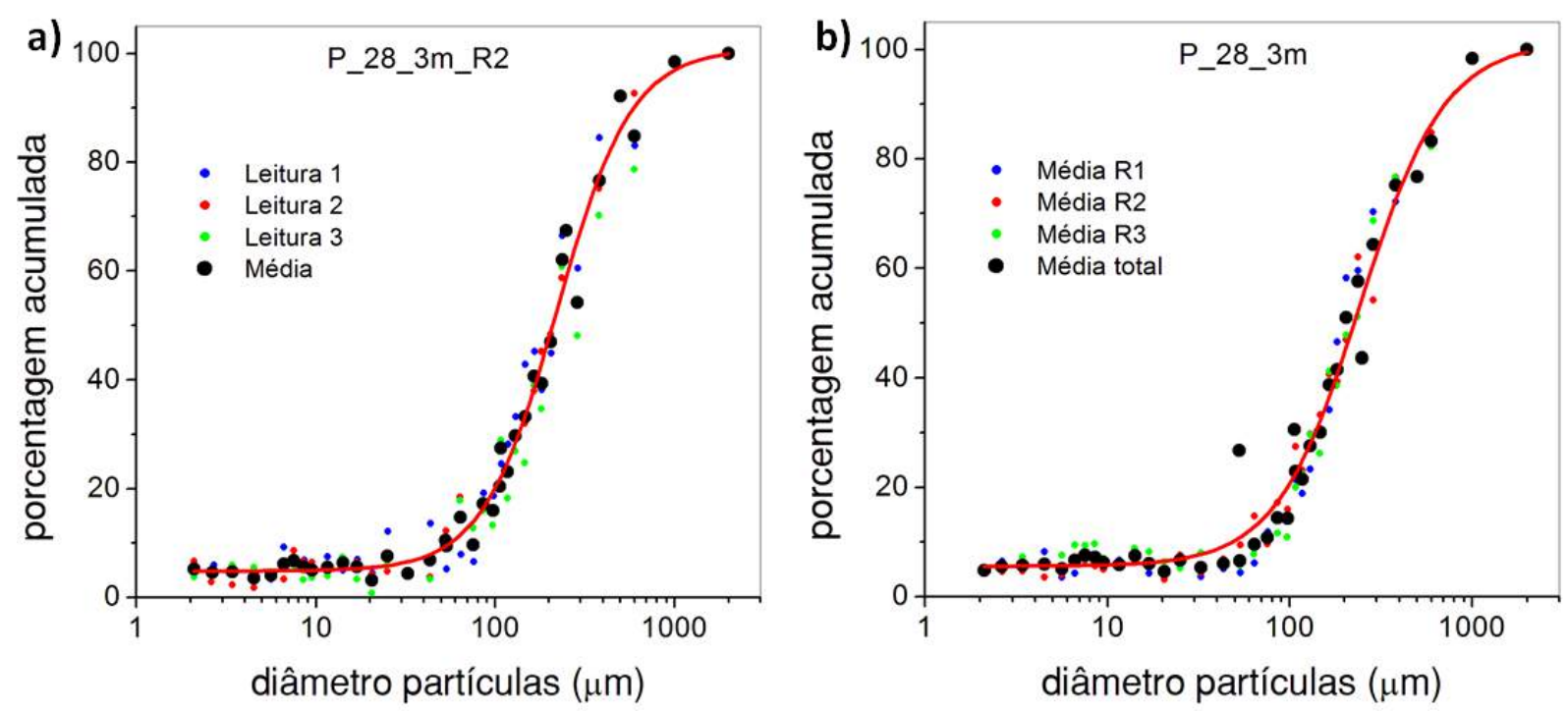

Fonte: Autor.

As curvas granulométricas foram utilizadas para calcular as porcentagens de cada fração de solo. Em seguida, com o auxílio do diagrama triangular (Figura 34), elaborado originalmente pelo United States Department of Agriculture (USDA) e adaptado pela Sociedade Brasileira de Ciência do Solo (SBCS), foi realizada a análise textural do solo (Tabela 11). O analisador providenciou também a densidade das partículas do solo (Dp), mostrando que é praticamente igual em todas as amostras de solo, confirmando o valor de densidade padrão das partículas $\left(2,65 \mathrm{~g} / \mathrm{cm}^{3}\right)$ adotado pela Sociedade Internacional de Ciência de Solos.

7 No Apêndice G somente serão mostradas a curvas granulométricas médias totais de cada amostra de solo. 
Tabela 11 - Percentuais das frações, texturas e densidade das partículas (Dp) das amostras de solo. A nomenclatura P27 $(0,30 \mathrm{~m})$ significa: amostra de solo do poço 27 a $0,30 m$ de profundidade a partir da superfície do solo. Para o poço 16 Gomes (2008) obteve valores de 13,92\% (argila + silte), 34,08\% (areia fina) e 52,00 $\%$ (areia grossa) em profundidades de 3,00-4,50 $\mathrm{m}$.

\begin{tabular}{|c|c|c|c|c|c|c|}
\hline \multirow{2}{*}{ Amostra de solo } & \multicolumn{4}{|c|}{ Fração (\%) } & \multirow{2}{*}{$\underset{\left(g / m^{3}\right)}{\mathbf{D p}}$} & \multirow{2}{*}{ Textura } \\
\hline & Argila & Silte & Areia fina & Areia grossa & & \\
\hline P27 $(0,30 m)$ & 19,38 & 2,72 & 16,14 & 61,76 & 2,61 & Franco arenoso \\
\hline $\mathrm{P} 28(1,00 \mathrm{~m})$ & 1,78 & 2,09 & 20,89 & 75,24 & 2,60 & Areia \\
\hline $\mathrm{P} 28(2,00 \mathrm{~m})$ & 7,73 & 2,32 & 33,06 & 56,89 & 2,61 & Areia \\
\hline P28 $(3,00 m)$ & 5,57 & 4,68 & 24,95 & 64,80 & 2,61 & Areia \\
\hline P29 $(1,00 m)$ & 3,67 & 3,59 & 37,26 & 55,48 & 2,60 & Areia \\
\hline $\mathrm{P} 29(2,00 \mathrm{~m})$ & 5,01 & 3,50 & 29,61 & 61,88 & 2,60 & Areia \\
\hline $\mathrm{P} 29(3,00 \mathrm{~m})$ & 6,45 & 4,19 & 30,57 & 58,79 & 2,61 & Areia \\
\hline $\mathrm{P} 29(4,00 \mathrm{~m})$ & 6,65 & 3,98 & 28,03 & 61,34 & 2,61 & Areia \\
\hline
\end{tabular}

Fonte: Autor.

Estes resultados podem ser comparados com os gráficos do $S_{y}(t)$ no Apêndice F. Nas curvas do poço 27 pode ser observado que a drenagem é realizada com menor rapidez nas primeiras horas quanto as outras curvas dos poços. Isto pode ser explicado pelo alto teor de matéria orgânica que existe na zona ripária, fazendo com que o solo tenha uma estrutura parecida à argilosa. Além disso, nesta zona se encontra a maior quantidade de argila.

Pode ser deduzido que se o ensaio para a estimativa do rendimento específico transiente fosse realizado em zonas argilosas e de alto teor de matéria orgânica, a drenagem poderia ser ainda mais lenta nas primeiras horas. Destaca-se a importância de uma estimativa acurada do $S_{y}^{*}$ para obter a evapotranspiração em uma zona ripária.

No poço 27, o efeito do alto teor de matéria orgânica é observado nos valores das viriáveis na tabela 9 . O valor da retenção específica, independentemente da pouca compactação do solo, neste caso representa a maior percentagem da porosidade total. Essa afirmação indica, que nesta área, grande parte do volume do solo esta composto por água imóvel. Portanto, o solo da zona ripária é caracterizado por pouca compactação do solo (muitos macroporos) e o alto teor de matéria orgânica (muitos microporos) que geram valores elevados de porosidades totais.

Para os poços 28, 29 e 16 (zona de transição, cerrado e eucalipto, respectivamente), pode ser observado nas curvas de $S_{y}(t)$ (Apêndice F), que os $S_{y}^{*}$ são mais próximos dos $S_{y}$. Esse fato é devido a que nessas zonas o solo é arenoso e a drenagem da maior porcentagem da água contida nos macroporos é realizada de maneira rápida nos primeiros minutos. Nas horas restantes a drenagem é de forma lenta. 


\subsection{Determinação da evapotranspiração nas zonas ripária, de tran- sição, de Cerrado stricto sensu e eucalipto}

A determinação da evapotranspiração nas diferentes zonas de estudo foi realizada a partir dos métodos baseados na flutuação diária do nível freático (WHITE, 1932; DOLAN et al., 1984; HAYS, 2003; GRIBOVSZKI et al., 2008; LOHEIDE II, 2008). Para a aplicação desses métodos foram escritos scripts no software MATLAB (Apêndice D) com o fim de realizar cálculos rápidos e sistemáticos.

A coleta de dados nos diferentes poços de monitoramento ${ }^{8}$ foi feita entre $04 / 09 / 2015$ e 20/10/2016 (413 dias). O número de dias sem precipitações foi 259. Desses dias sem precipitações, foram escolhidos 162 para a determinação da evapotranspiração na zona ripária e de Cerrado strito sensu, 125 dias para a zona de transição e 168 dias para área de eucalipto. As diferenças no número de dias escolhido para cada poço é dada pelas seguintes razões:

a) De novembro/2015 a março/2016 o total pluviométrico foi de 1906,4 $\mathrm{mm}$ (Figura 44) e nível freático no poço 27 ficou acima do nível do solo por semanas. Esse fenômeno acontece pois o processo de recarga nessa zona (naturalmente raso ao longo do ano) é praticamente instantâneo. Algumas semanas de agosto e setembro de 2016 também não puderam ser analisadas devido ao mesmo fato.

Figura 44 - Resultados da evapotranspiração diária na zona ripária (poço 27) através da aplicação dos métodos da flutuação diária do nível freático, em dias sem precipitação.

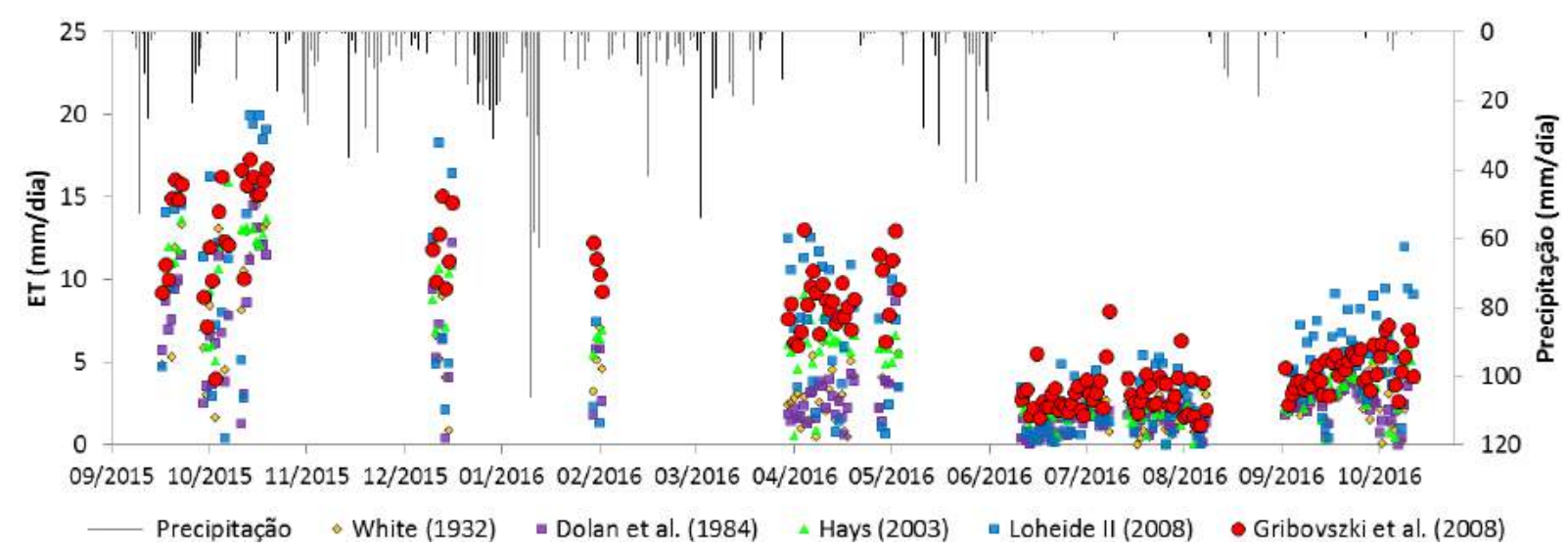

Fonte: Autor.

b) Nos poços 28 e 29, durante a coleta de dados, apresentaram-se falhas na bateria dos transdutores de pressão, que foram substituidas em abril de 2016. Por essa razão, vários dias de coleta, anteriores a essa data, não foram registrados (Figuras 45, 46).

8 Em cada zona estudada foi instalado apenas um poço de monitoramento, devido ao reduzido número de transdutores de pressão disponíveis para este projeto. 
- Em agosto e outubro do 2016 a precipitação não gerou alterações significativas na flutuação do nível freático nos poços 28 e 29. Não aconteceram variações dado que nesses poços o nível de água subterrânea se encontra mais profundo. Esse fato permitiu que desde abril até outubro de 2016 puderam ser estimados mais dias de ET do que na zona ripária (poço 27).

Figura 45 - Resultados da evapotranspiração diária na zona de transição (poço 28) através da aplicação dos métodos da flutuação diária do nível freático, em dias sem precipitação.

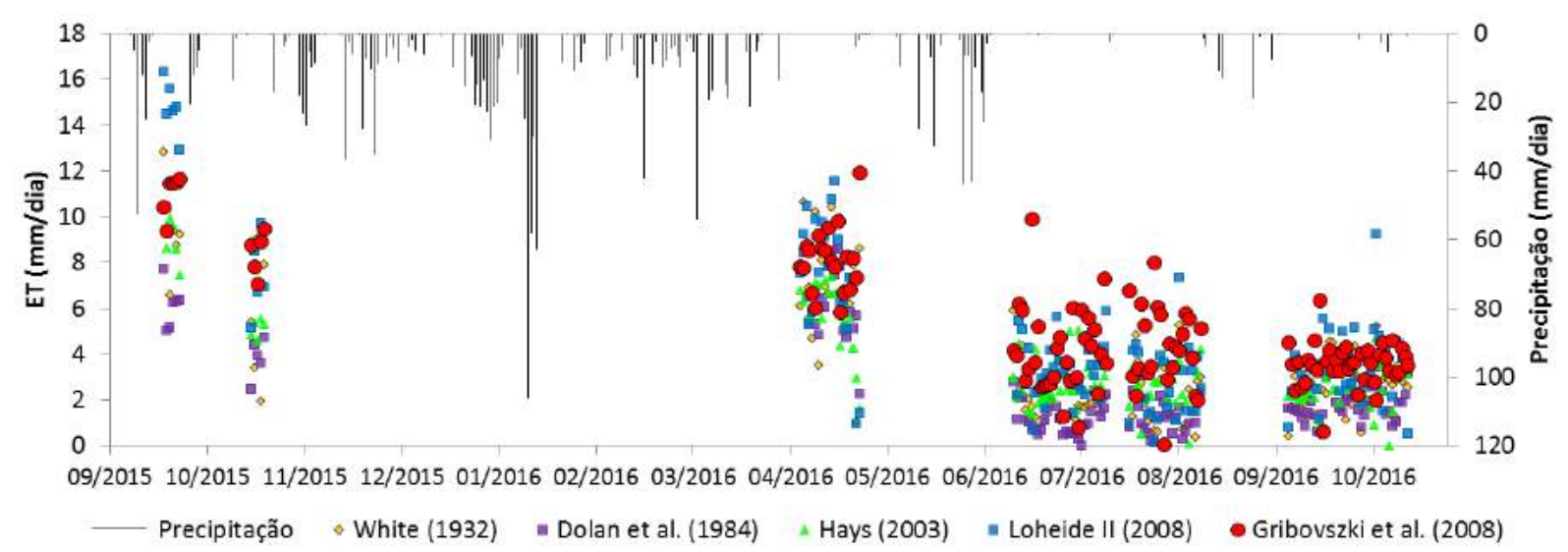

Fonte: Autor.

Figura 46 - Resultados da evapotranspiração diária no Cerrado stricto sensu (poço 29) através da aplicação dos métodos da flutuação diária do nível freático, em dias sem precipitação.

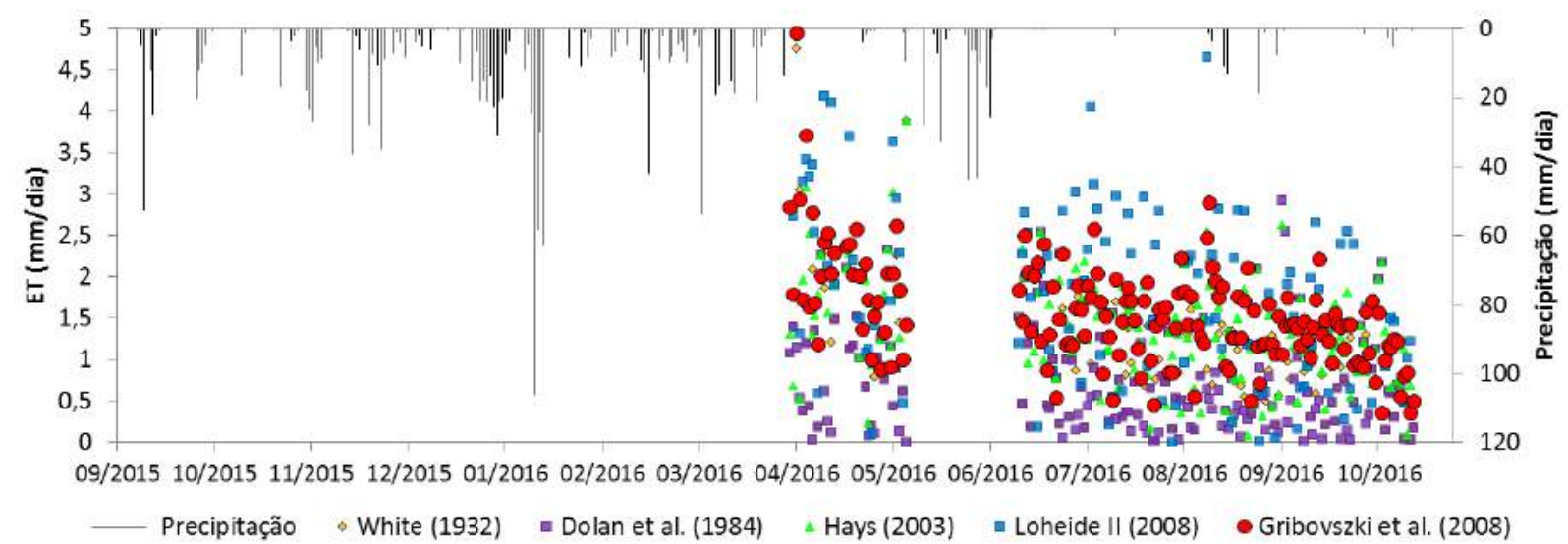

Fonte: Autor.

c) O nível freático no poço 16 apresentou elevações consideráveis que distorceram o comportamento cíclico da flutuação em várias semanas em que não houve precipitação (dezembro/2015 e fevereiro/2016). As flutuações nesse poço voltaram a serem observadas nos últimos dias do mês de março (Figura 47). 
Figura 47 - Resultados da evapotranspiração diária no eucalipto (poço 16) através da aplicação dos métodos da flutuação diária do nível freático, em dias sem precipitação.

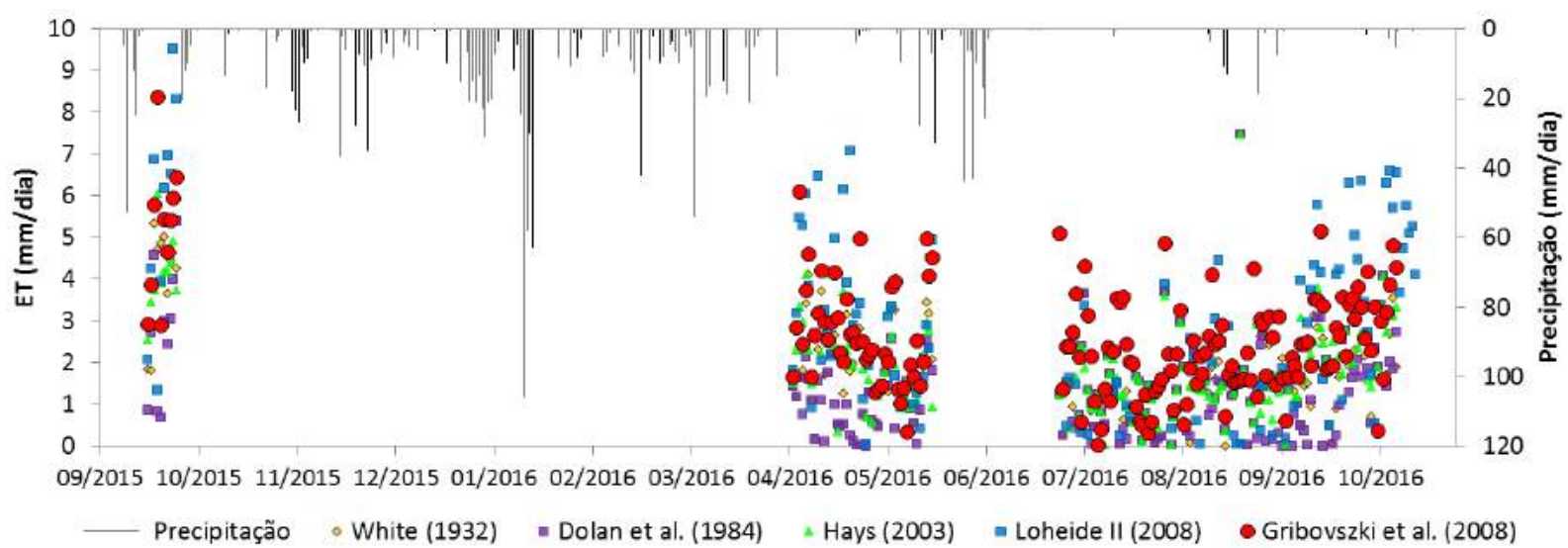

Fonte: Autor.

Nas Figuras 44, 45, 46 e 47 pode ser observado que nas estimativas da ET dos diferentes métodos aplicados existem divergências nos seus resultados. Elas podem ser explicadas fazendo uma análise da forma como cada método calcula o fluxo lateral $\left(Q_{l i q}\right)$.

Nos métodos de White (1932), Dolan et al. (1984), Hays (2003) o cálculo do $Q_{l i q}$ é feito com a suposição de que ele é constante durante o dia (Tabela 2). Autores como Loheide II, Butler e Gorelick (2005), Loheide II (2008), Gribovszki et al. (2008) demostraram que essa suposição não reflete a realidade. Além disso, afirmam que essa suposição gera subestimações na determinação da evapotranspiração, dado que são desprezados picos do $Q_{l i q}$ no fim da tarde de cada dia. Seus métodos foram desenvolvidos considerando que fluxo lateral é transiente e dependente do gradiente hidráulico exercido por zonas afastadas da ripária.

Com o fim de comprovar essas afirmações foi feito um gráfico da variação do $Q_{l i q}$ com o tempo para na zona ripária, utilizando o método de Gribovszki et al. (2008) (Figura 48). Observa-se que o $r$ não é constante durante o dia e possui um mínimo durante a manhã (ponto verde) e um máximo durante a tarde (ponto vermelho).

Os métodos de White (1932), Dolan et al. (1984), Hays (2003) utilizam, portanto o $r$ da manhã (o mínimo) como constante, gerando subestimações na determinação da evapotranspiração. Esses métodos foram descartados no resultado final da ET restando os métodos de Gribovszki et al. (2008) e Loheide II (2008) que trabalham com um $r$ transiente.

As estimativas de ET a partir do método de Loheide II (2008) $\left(E T_{L o h}\right)$ foram, por vezes, iguais àquelas geradas pelo método de Gribovszki et al. (2008) $\left(E T_{\text {Grib }}\right)$. No entanto algumas divergências foram observadas, com $E T_{L o h}>E T_{\text {Grib. }}$. Essas superestimações podem ocorrer em decorrência da remoção da inclinação do nível freático, proposta por 
Figura 48 - Variação do fluxo lateral $\left[Q_{l i q}(t)\right]$ em uma semana de setembro de 2015. A linha preta representa a interpolação spline entre os pontos máximos $\left(Q_{\text {liqMax }}\right)$ e mínimos $\left(Q_{\text {liqmin }}\right)$. O $d h / d t$ é a taxa de variação de nível de água subterrânea.

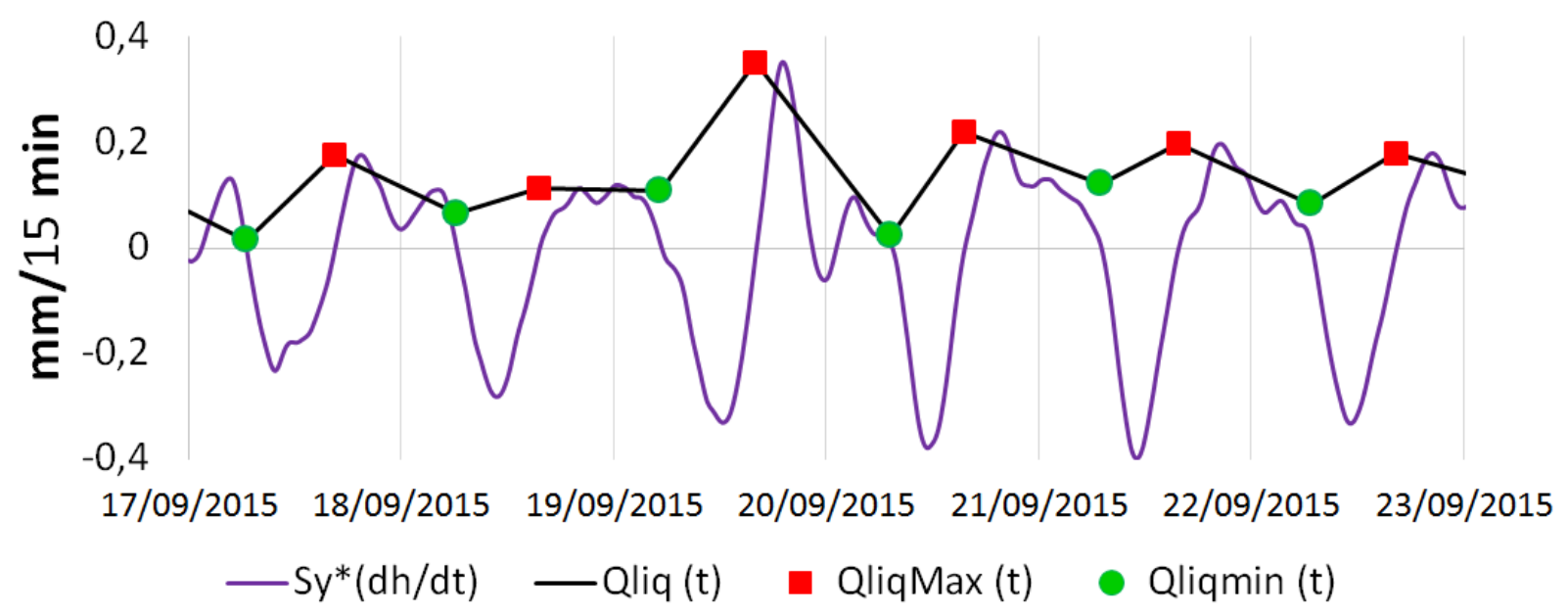

Fonte: Autor.

Loheide II (2008). Essa remoção gera alterações nos pulsos (amplitude) das flutuações e, por conseguinte no resultado final da ET (FAHLE; DIETRICH, 2014).

Dado que os métodos que supõem o fluxo lateral constante geram subestimações na evapotranspiração. Além disso, o método proposto por Loheide II (2008) a superestima. Portanto, os valores apresentados pelo método de Gribovszki et al. (2008) foram escolhidos como os mais confiáveis e confirmados como os únicos que representam a ET nas zonas ripária, de transição, Cerrado stricto sensu e eucalipto (Figura 49).

Figura 49 - Resultados da evapotranspiração diária pelo método de Gribovszki et al. (2008), escolhidos como os mais confiáveis, para todas as zonas de estudo.

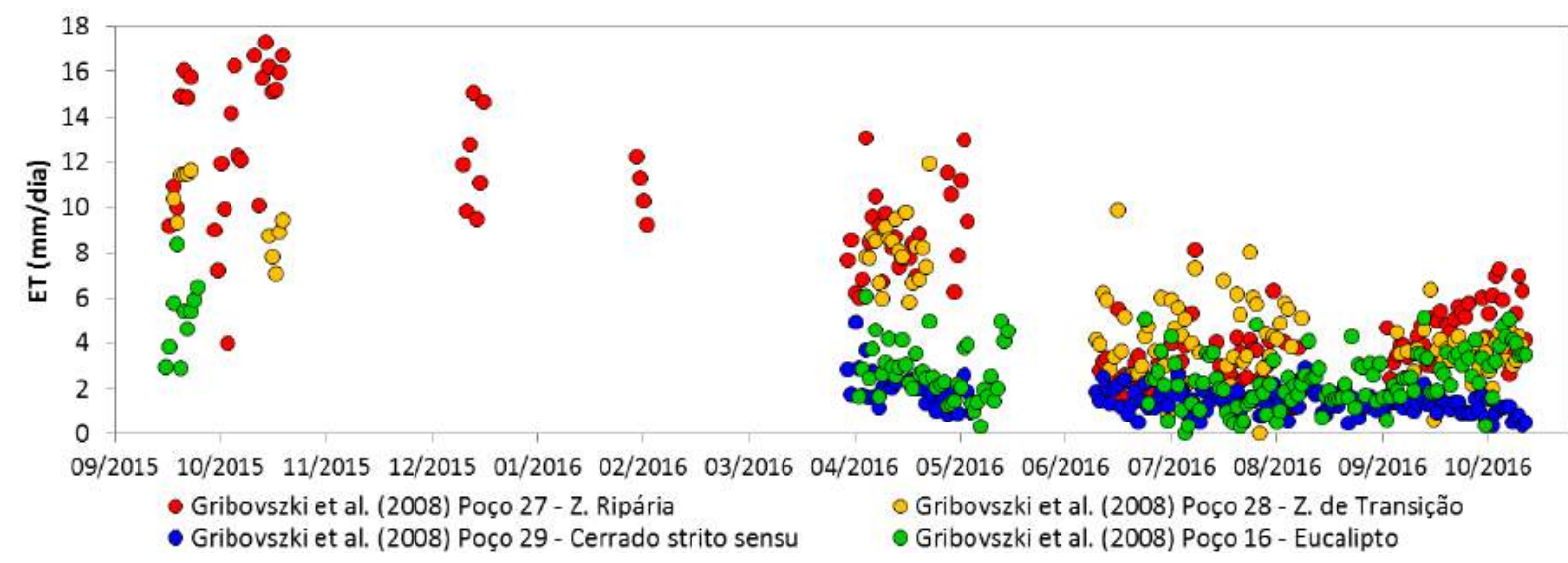

Fonte: Autor. 


\subsubsection{Análise de resultados da ET na poço zona ripária - poço 27}

Dado que não existem resultados de ET da zona ripária na América Latina e poucos ao redor do mundo, a análise de resultados desta zona foi realizada de forma mais aprofundada em comparação com as outras.

Com o fim de facilitar a interpretação e visualização dos resultados da ET na zona ripária, foram realizados grupos de boxplots para cada período (sem precipitações) em que se calcularam as ET. A sua realização foi feita com os resultados da ET escolhidos como confiáveis (obtidos com o método de Gribovszki et al. (2008)). Como existem métodos para estimar a ET que utilizam apenas a temperatura do ar como parâmetro de entrada (THORNTHWAITE, 1948; CAMARGO; M.B.P., 1983; HARGREAVES; ALLEN, 2003) e como a temperatura do ar teve uma forte correlação com as flutuações, na Figura 50 foram realizados outros grupos de boxplots, nos mesmos períodos sem precipitações, para a temperatura máxima diária (Figura 50).

Figura 50 - Boxplots da evapotranspiração diária na zona ripária e da temperatura máxima diária para períodos em que não houve precipitações. Os rótulos numéricos em cada boxplot representam as medianas e o asterisco um valor atípico.

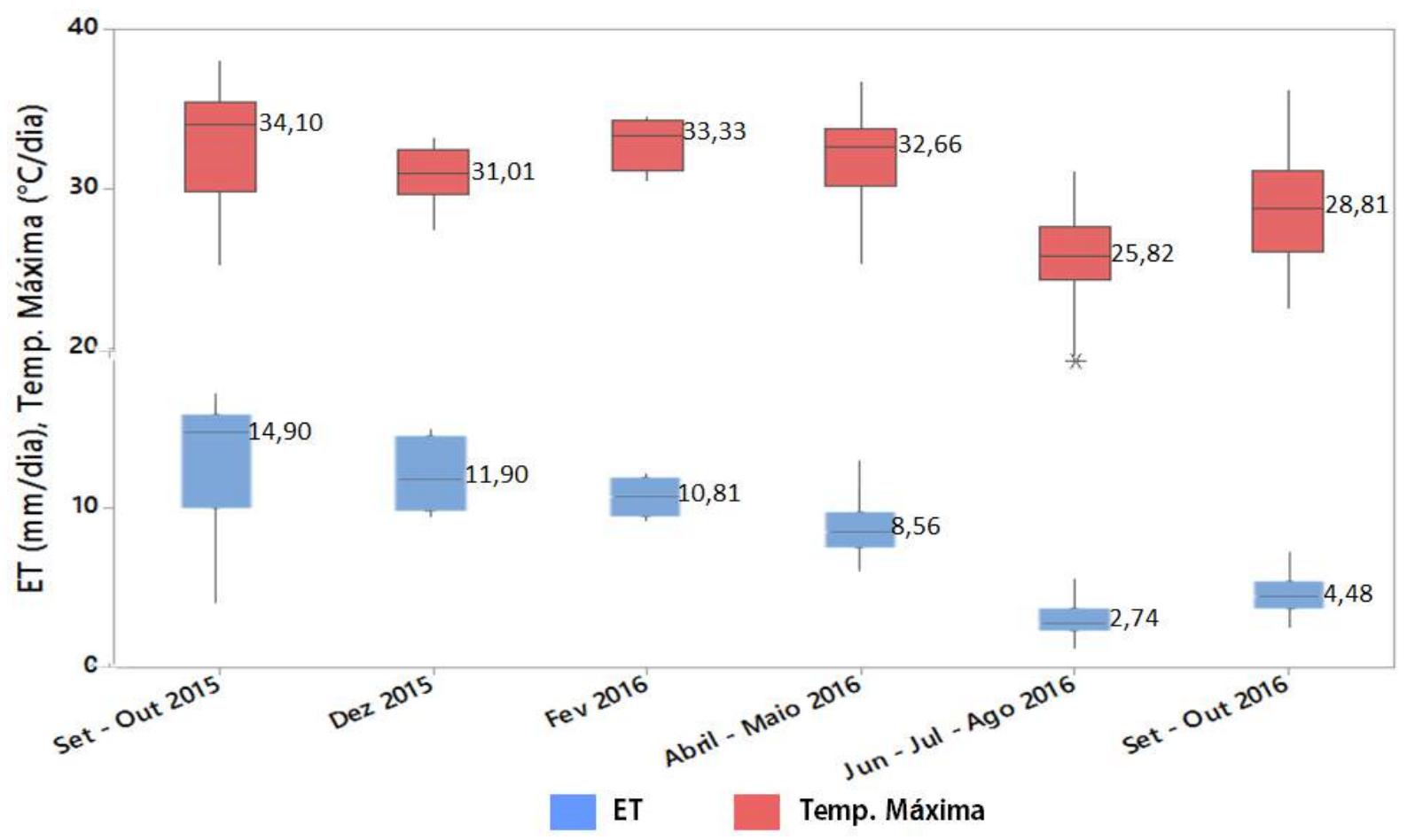

Fonte: Autor.

Na Figura 50 pode ser observado que nas épocas em que a temperatura é elevada, a ET também. A ET atende valores mínimos, na época em que o valor médio da temperatura também é o menor. Mostrando-se que embora no processo de evapotranspiração, se encontrem termos físicos envolvidos como o aerodinâmico e o radiativo, a temperatura do ar pode ser um indicador da variação da $E T$. 
A medida de tendência central escolhida para os bloxplots foi a mediana no lugar da média. A mediana representa o valor central da maior porcentagem de dados e não é influenciada por algum valor extremo ou atípico (mínima ET em um dia nublado, ou máxima $E T$, causada por um dia de extrema (alta) temperatura). Na zona ripária, a faixa de valores de $E T$ diária esteve entre 2,74 e 14,90 mm/d para temperaturas máximas de 25,82 e $34,09{ }^{\circ} \mathrm{C} / d$, respectivamente. O número total de dias em que foi estimada a $E T$ foi de 162,0, e a soma deles tem um valor total de 1073,98 $\mathrm{mm}$. A ET média diária foi de $6,62 \mathrm{~mm} / \mathrm{d}$. Essa faixa de valores da $E T$ foi verificada com resultados encontrados na literatura (DEVITT et al., 1998; GOODRICH et al., 2000; LAUTZ, 2008; GRIBOVSZKI et al., 2008; MARTINET et al., 2009), nos quais foram mostrados variações de ET diária entre 1,00 e $17,30 \mathrm{~mm} / \mathrm{d}$.

Os resultados da ET na zona ripária também foram comparados com a evaporação (E) obtida do Tanque Classe A (Figura 51) e com os resultados da evapotranspiração de referência $\left(E T_{o}\right)$, aplicando o método de Penman Monteith - FAO 56 (Figura 52). O Tanque Classe A se encontra a $6 \mathrm{~km}$ dos poços de monitoramento, na estação climatológica do Centro de Recursos Hídricos e Estudos Ambientais (CRHEA). O método de Penman Monteith - FAO 56 foi aplicado utilizando as variáveis meteorológicas monitoradas (Apêndice H) na estação localizada na fazenda Monte Alegre a uma distância de aproximadamente $1,50 \mathrm{~km}$ dos poços em estudo.

Figura 51 - Boxplots da evaporação diária do Tanque Classe A em comparação com a evapotranspiração diária na zona ripária determinada pelo método de Gribovszki et al. (2008), para períodos em que não houve precipitações. Os rótulos numéricos representam as medianas e os asterisco valores atípicos.

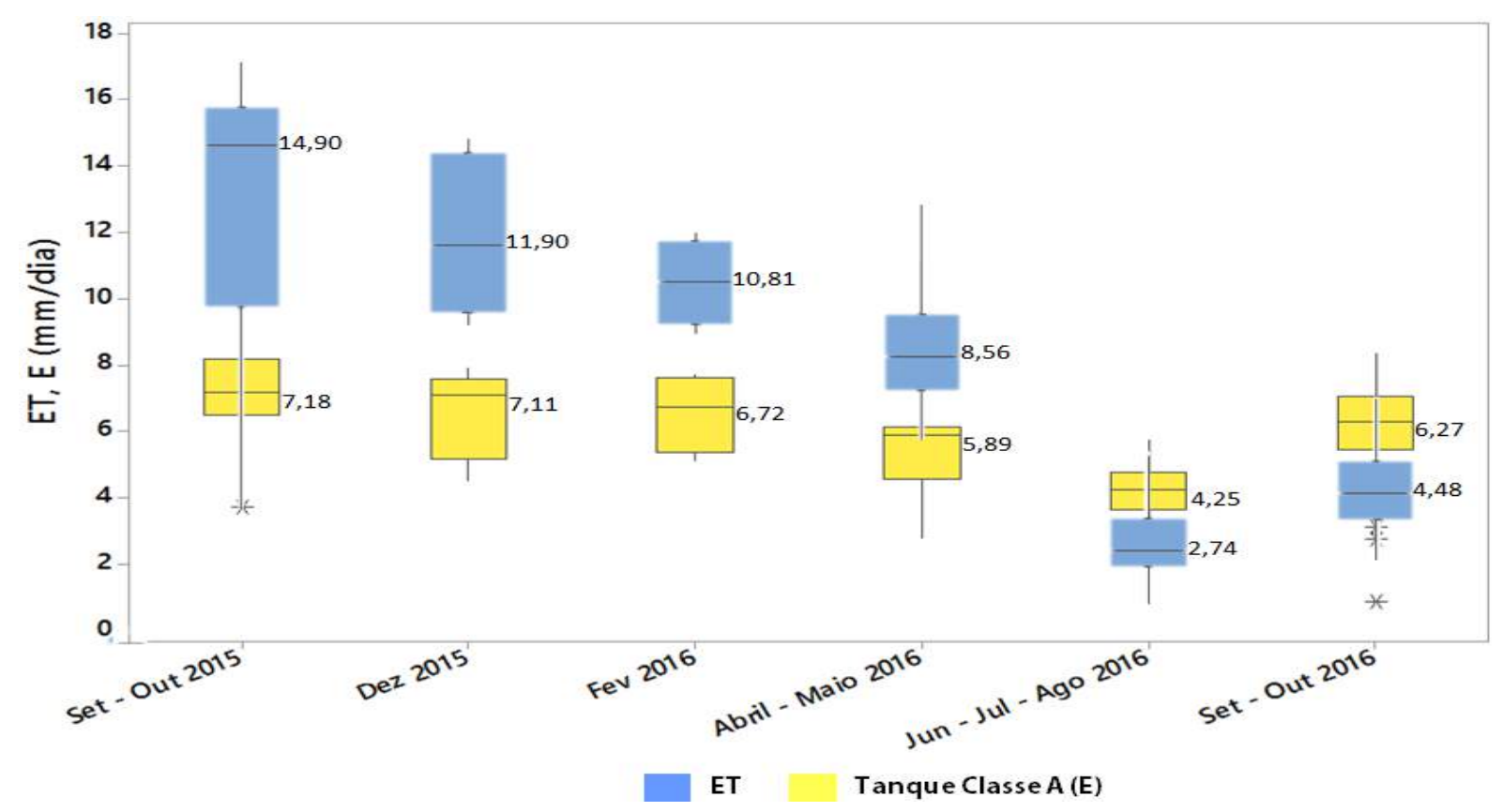

Fonte: Autor. 
Figura 52 - Boxplots da evapotranspiração de referência padrão FAO em comparação com a evapotranspiração diária na zona ripária determinada pelo método de Gribovszki et al. (2008), para períodos em que não houve precipitações. Os rótulos numéricos em cada boxplot representam a mediana.

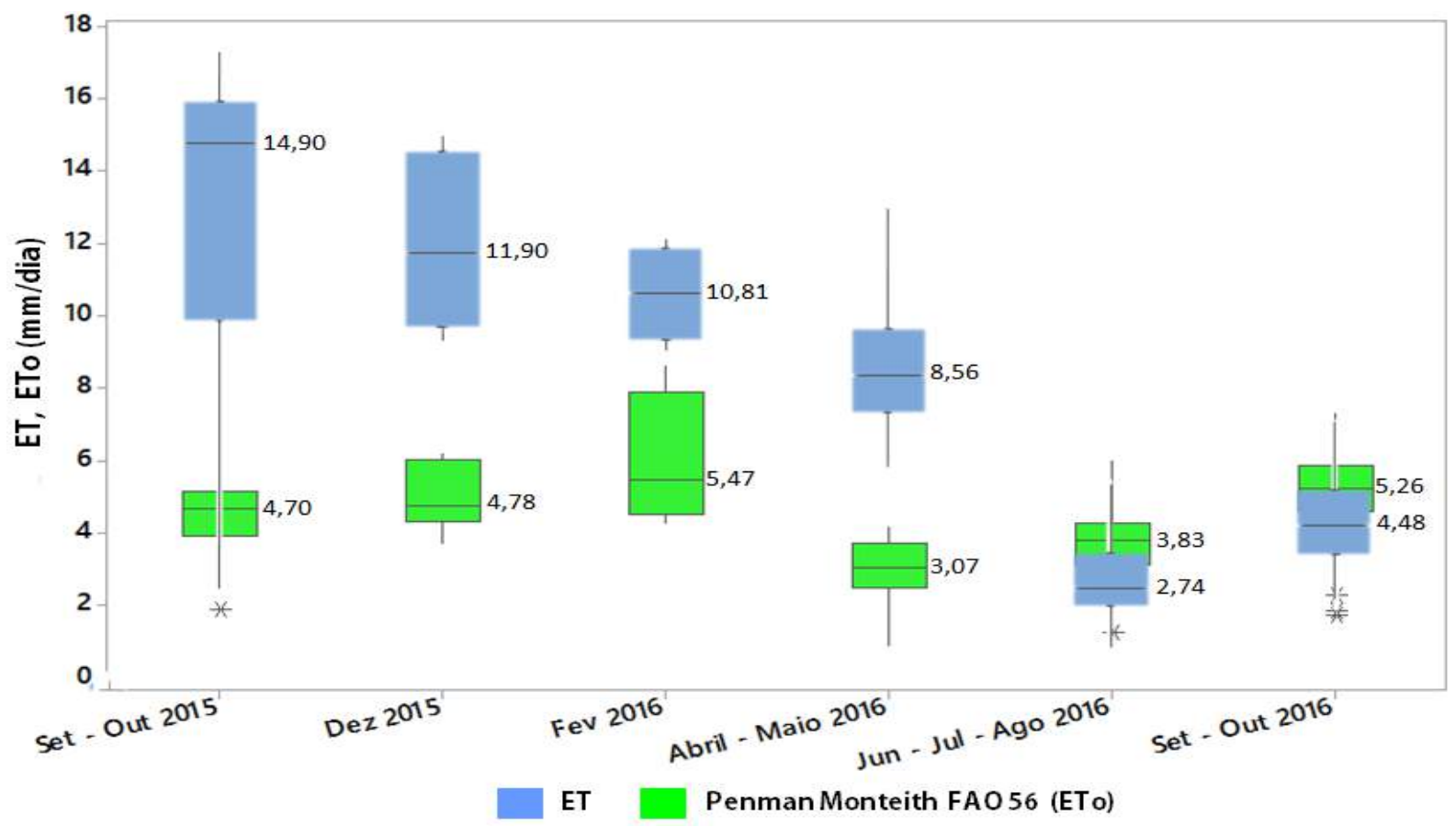

Fonte: Autor.

Entre setembro/2015 e maio/2016, a evapotranspiração na zona ripária foi maior do que a $E$ do Tanque Classe A e a $E T_{o}$ pelo método de Penman Monteith - FAO 56, entre junho e outubro de 2016, observou-se o contrário. Para poder obter uma conclusão desse comportamento da ET na zona ripária seria necessário um período mais longo de monitoramento, dado que na literatura não foram encontrados resultados com esse tipo de comparações. 


\subsubsection{Estimativa da evaporação do solo da zona ripária por exposição direta à radiação solar}

Com o fim de poder encontrar uma explicação para os elevados valores de ET diária na zona ripária, foram elaborados 3 (três) microlisímetros (MLs). Eles estiveram em uma cobertura de um prédio de aproximadamente $4 m$ de altura durante uma semana. O propósito foi medir a evaporação do solo da zona ripária em uma condição extrema, isto é, exposto diretamente à radiação solar.

A primeira análise foi visual (Figura 53), verificando-se que o solo, pelo alto teor de matéria orgânica, teve um comportamento de uma "esponja", pois o volume do solo depois da evaporação em um dia reduziu de forma considerável (Figura 53b). Além disso, a coloração escura do solo sugere que o albedo é pequeno, gerando a absorção de uma alta porcentagem da irradiância solar.

Figura 53 - a) Solo da zona ripária antes de acontecer a evaporação diária. b) Solo da zona ripária depois de acontecer a evaporação diária.
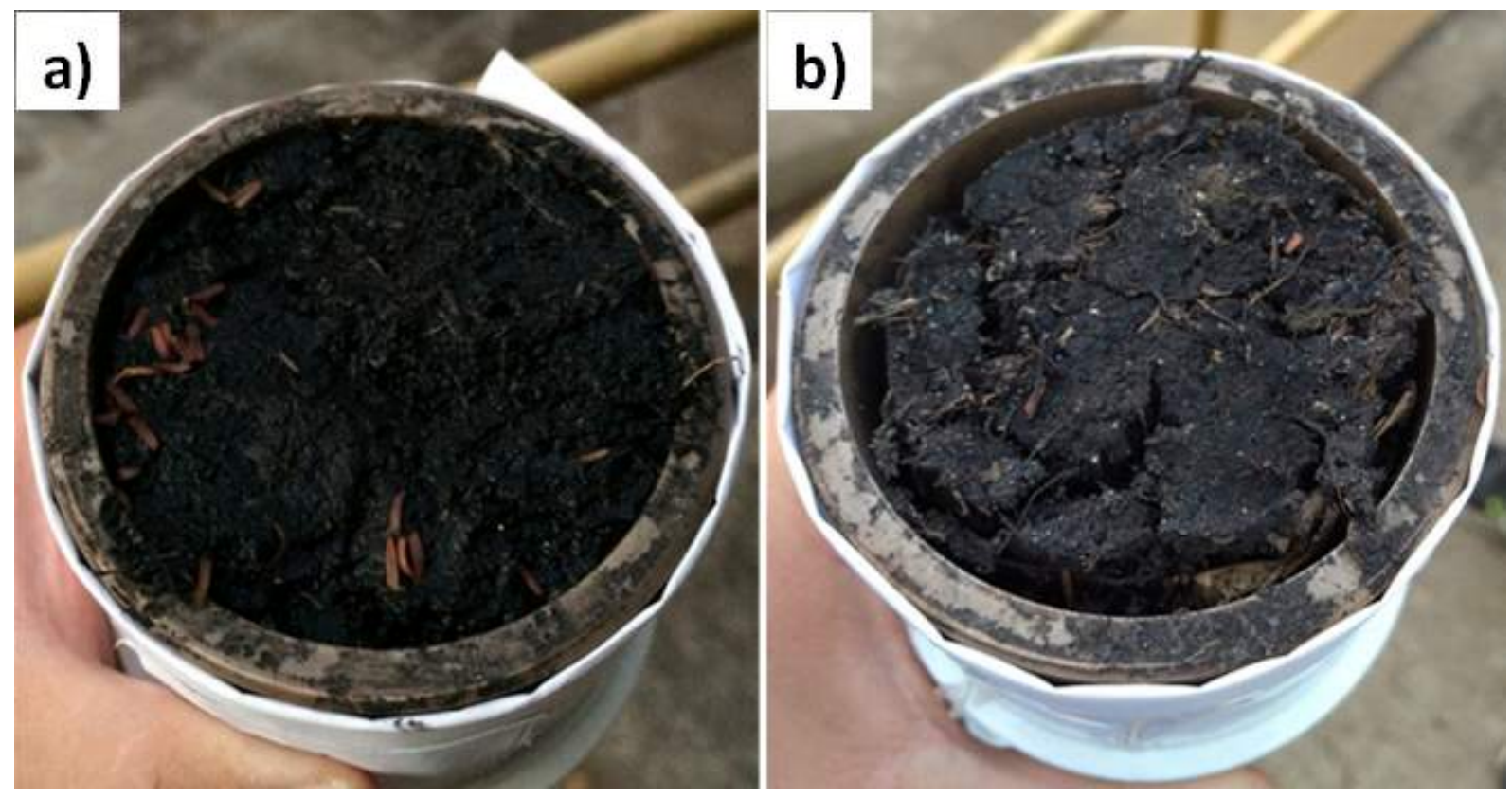

Fonte: Autor.

Os resultados da evaporação diária dos MLs (Figura 54) correspondem do dia 23/09/2016 até o 30/09/2016. Os valores mostrados, em uma condição de exposição direta à radiação solar, são elevados e parecidos com valores máximos da $E T$ na zona ripária.

Pode ser concluído que mesmo com uma menor exposição do solo da zona ripária à radiação solar (como ocorre de fato na área de estudo), o aporte de evaporação será significativo por fatores que favorecem o seu aumento. Dentre esses fatores, estão o albedo pequeno (cor do solo preta), nível de água subterrânea pouco profunda e alto teor de matéria orgânica, e somando um alto aporte da transpiração. 
Figura 54 - a) Resultados da evaporação do solo na zona ripária por exposição direta à radiação solar. b) Variação da temperatura do ar no local onde foram colocados os MLs.
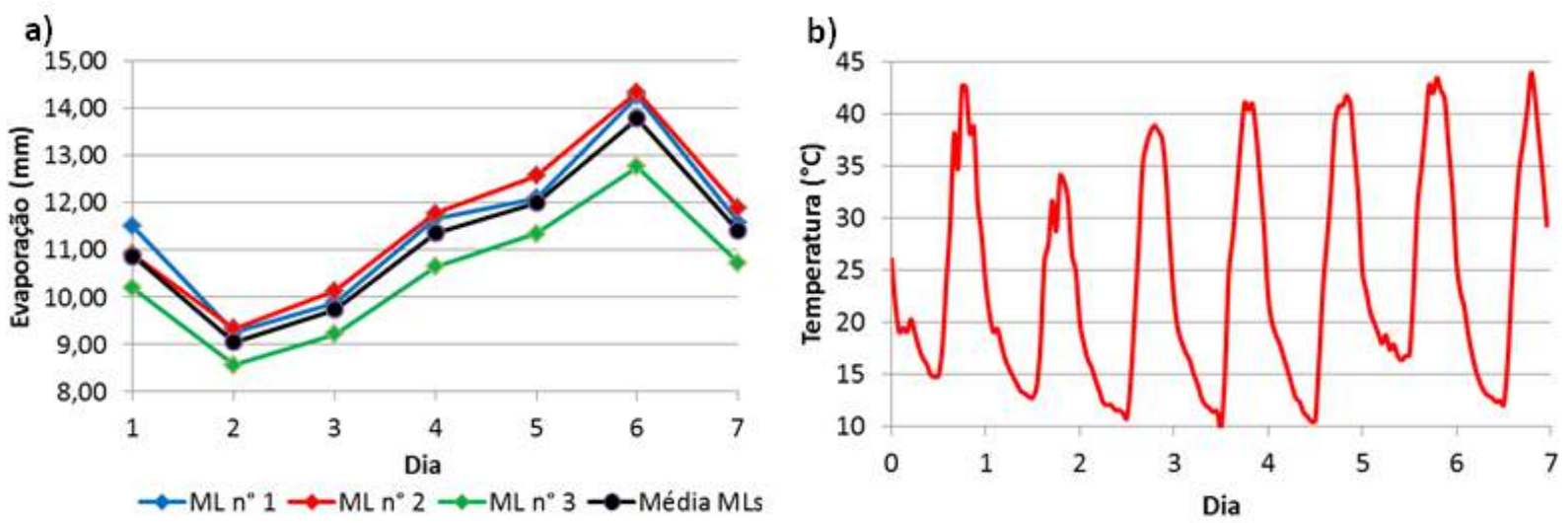

Fonte: Autor.

\subsubsection{Análise de resultados da ET na zona de transição (poço 28) e de Cerrado stricto sensu (poço 29)}

A zona de transição possui resultados de ET influenciados pelo Cerrado stricto sensu e a zona ripária, pois encontra no meio delas e a sua bordadura é aproximadamente de $30 \mathrm{~m}$ de largura. A faixa dos valores da ET diária na zona de transição foi entre 3,63 e 9,48 mm/d (Figura 55). O número de dias em que foi estimada a $E T$ foi de 125 , e a soma deles tem um valor total de 640,30 $\mathrm{mm}$ com uma ET média diária de 5,12 $\mathrm{mm} / \mathrm{d}$. Esse resultado não pôde ser comparado com outros, dado que na literatura não foi possível encontrar resultados de uma zona de transição com as características descritas neste trabalho.

A faixa de valores da ET diária no Cerrado stricto sensu (poço 29) foi entre 1,23 e 2,02 mm/d (Figura 56). O número de dias em que foi estimada a ET foi de 162,00, e a soma deles tem um valor total de 250,09 $\mathrm{mm}$ com uma ET média diária de 1,54 $\mathrm{mm} / \mathrm{d}$. Esses valores puderam ser verificados com resultados encontrados na literatura (OLIVEIRA et al., 2005; GIAMBELLUCA et al., 2009; OLIVEIRA et al., 2015; CABRAL et al., 2015), nos quais foram mostrados variações de $E T$ diária entre 1,0 e 7,1 mm/d. Assim, foi possível observar que os valores obtidos neste trabalho para o Cerrado stricto sensu são semelhantes a outros obtidos no território nacional. O trabalho cujos resultados apresentam maior semelhança foi o de Oliveira et al. (2015), dado que a sua área de estudo no Instituto Arruda Botelho - IAB, fica aproximadamente $10 \mathrm{~km}$ da nossa. Nesse trabalho a faixa de ET diária esteve entre 1,91 e 2,60 $\mathrm{mm} / \mathrm{d}$. 
Figura 55 - Boxplots da evapotranspiração diária na zona de transição. Os rótulos numéricos em cada boxplot representam a mediana e os asterisco valores atípicos.

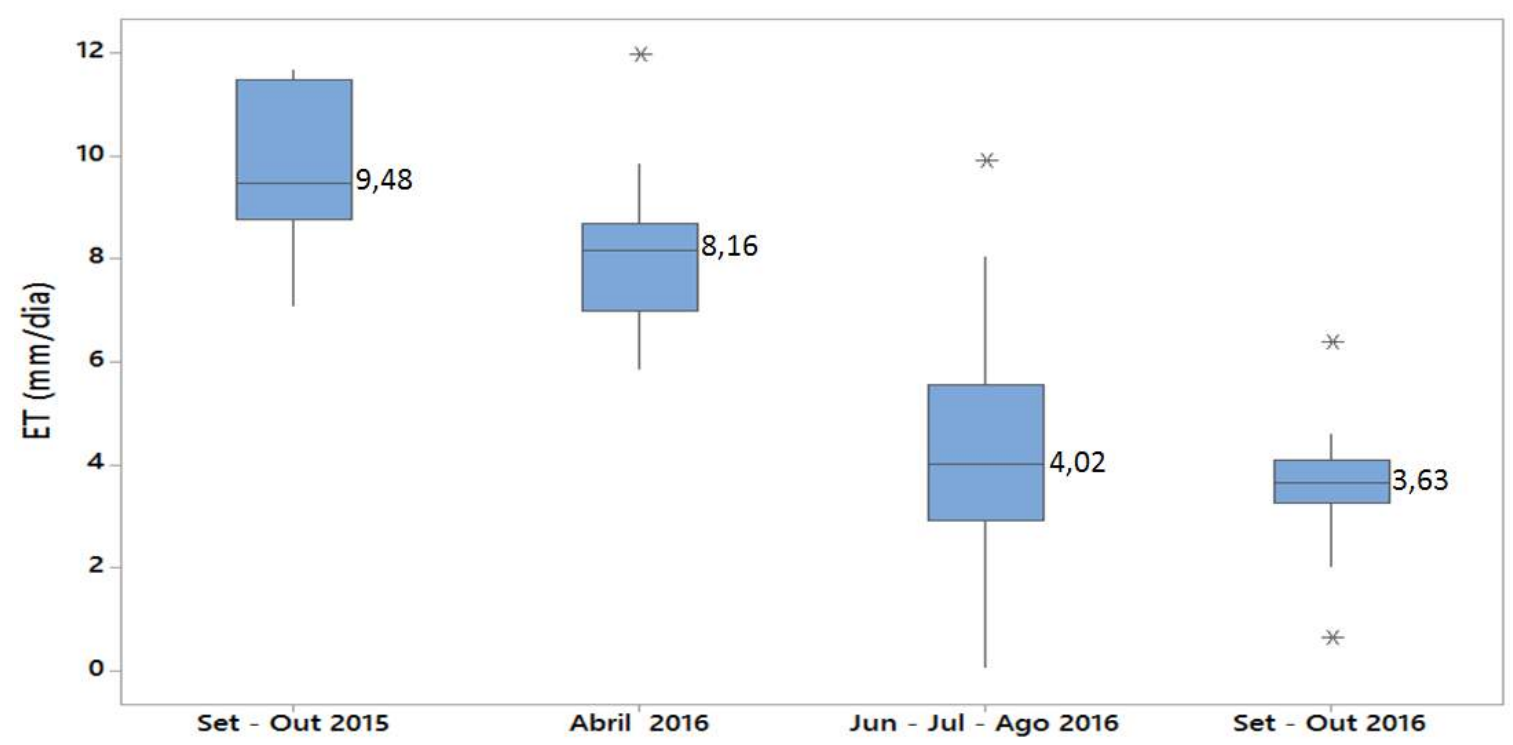

Fonte: Autor.

Figura 56 - Boxplots da evapotranspiração diária no Cerrado stricto sensu. Os rótulos numéricos em cada boxplot representam a mediana e os asterisco valores atípicos.

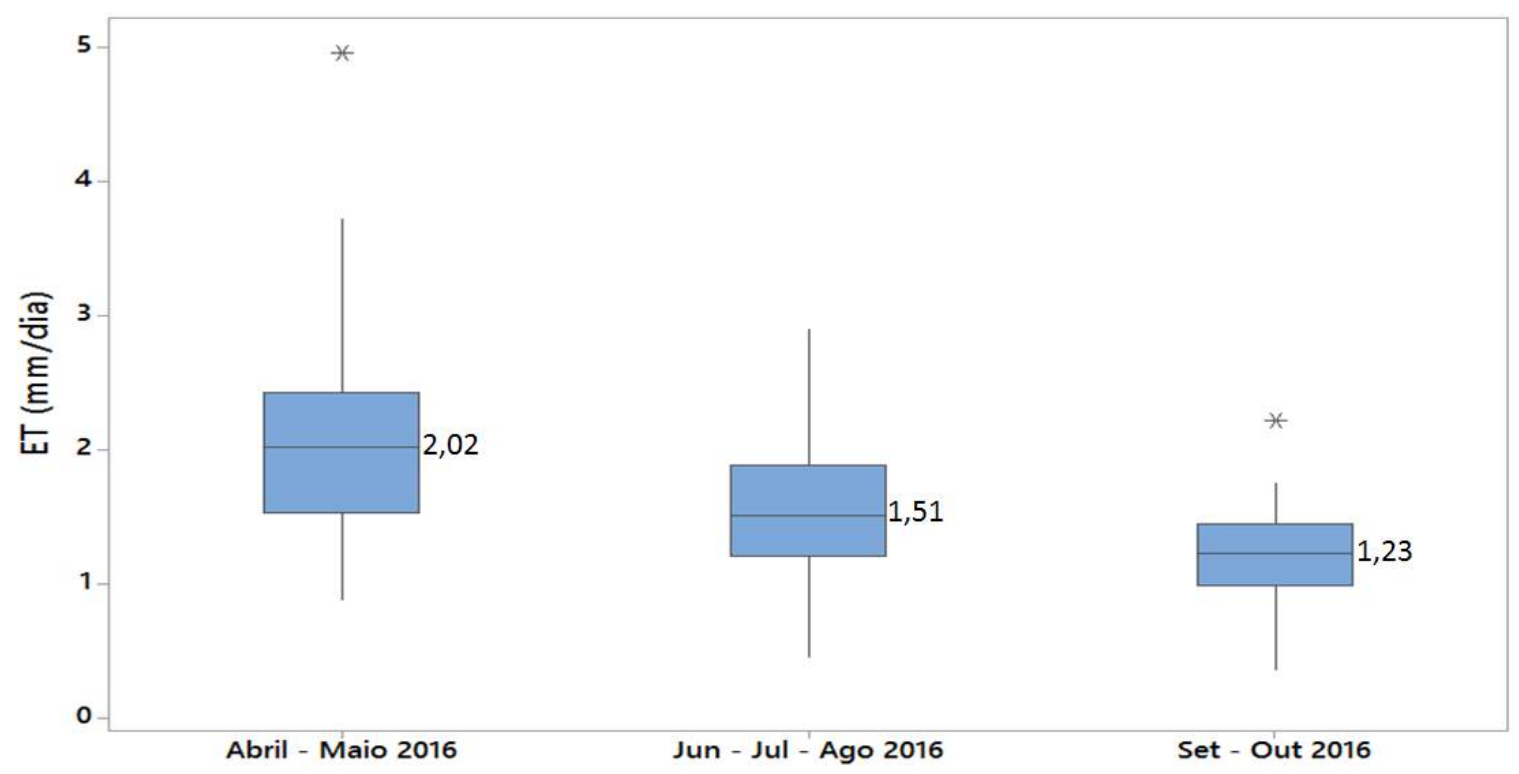

Fonte: Autor. 


\subsubsection{Análise de resultado da ET na área de eucalipto (poço 16)}

A faixa de valores da ET diária no eucalipto esteve entre 1,96 e 5,45 mm/d (Figura 57). O número de dias em que foi estimada a $E T$ foi de 168 , e a soma deles tem um valor total de 446,42 $\mathrm{mm}$ com uma ET média diária de 2,65 mm/d. Esse resultado explica o por que da amplitude da flutuação na Figura 40 não continuar diminuindo do poço 29 para o 16. Pode ser observado que embora o nível freático no eucalipto seja mais profundo, na área de estudo, a sua evapotranspiração é maior do que na zona de Cerrado stricto sensu. Esses valores puderam ser verificados com resultados encontrados na literatura (SOARES; ALMEIDA, 2001; CARNEIRO et al., 2008; CABRAL et al., 2010; MENEZES et al., 2011) nos quais foram mostrados variações de ET diária entre 2,00 e 6,72 mm/d.

Figura 57 - Boxplots da evapotranspiração diária no eucalipto. Os rótulos numéricos em cada boxplot representam a mediana e os asterisco valores atípicos.

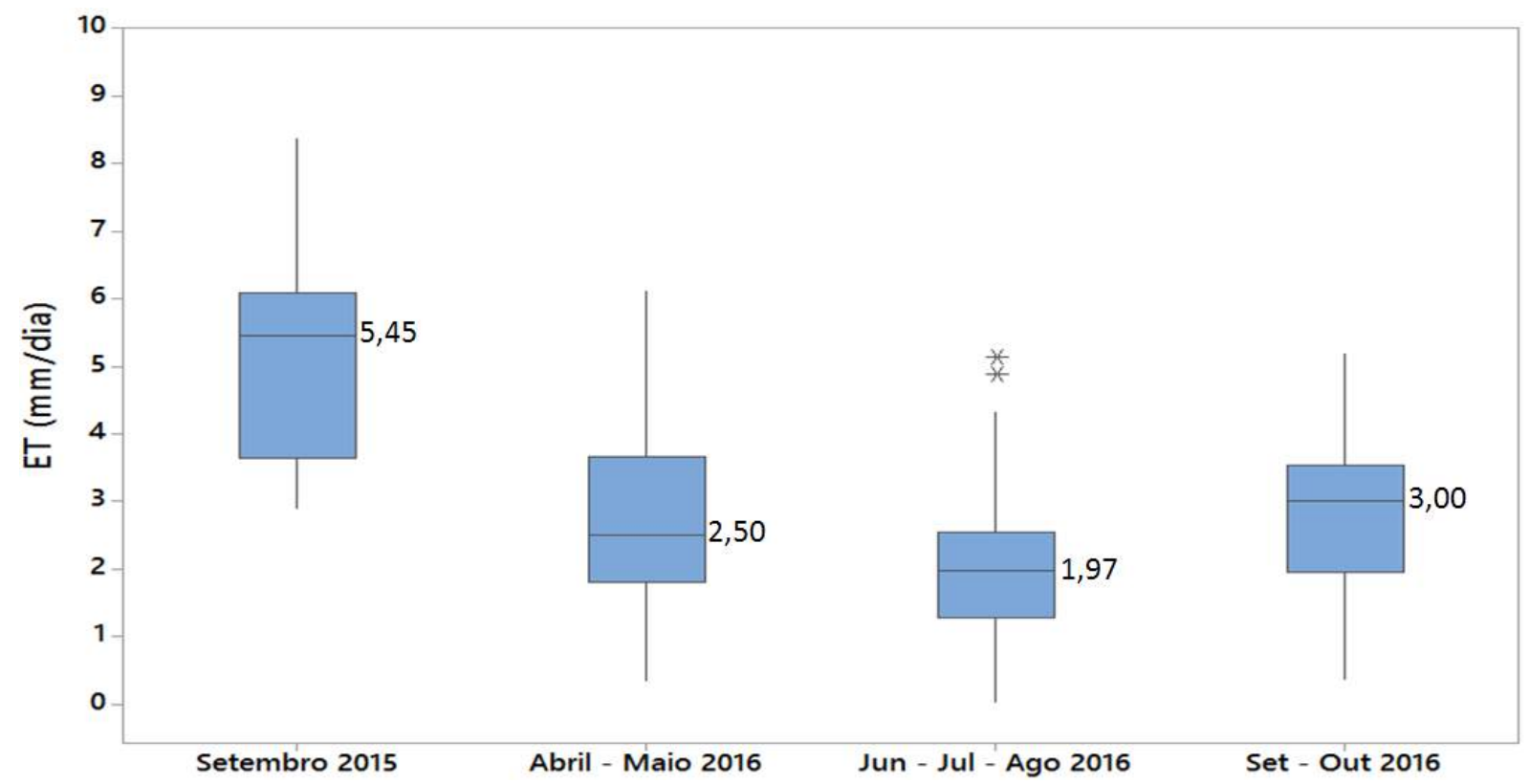

Fonte: Autor. 


\section{CONCLUSÃO}

Para a determinação da ET em zona ripária e áreas vizinhas (Cerrado stricto sensu e eucalipto), foram utilizados métodos empíricos baseados na flutuação diária do nível de água subterrânea. O estudo foi desenvolvido em um período de 413 dias (04/09/2015 a 20/10/2016). Os métodos foram aplicados aos dados relativos aos dias em que não aconteceram precipitações. Os níveis de água subterrânea foram obtidos em poços de monitoramento instalados na bacia hidrográfica do Ribeirão da Onça.

As amplitudes das flutuações do nível de água subterrânea mostram ser inversamente proporcionais à profundidade do nível freático. Pois quanto mais próximo da superfície encontra-se o nível freático, maior será o aporte de evaporação na ET (MAXWELL; CONDON, 2016).

A correlação cruzada entre a temperatura média diária do ar e a flutuação diária do nível freático é de 0,95 , indicando uma forte relação. Para a irradiância solar e a umidade relativa do ar, os valores de correlação com a variação do nível são de 0,85, e -0,93, respectivamente. Entre a mudança nessas três variáveis meteorológicas e a consequente variação do nível freático existe um atraso de $-2 h$.

Uma variável fundamental na aplicação dos métodos baseados na flutuação diária é o rendimento específico transiente $\left(S_{y}^{*}\right)$. A modernização do funil de Haines permite estimar o $S_{y}^{*}$ utilizando menos equipamentos que aqueles propostos por Loheide II, Butler e Gorelick (2005), Fahle e Dietrich (2014). Os valores do rendimento específico transiente (após $6 h$ de drenagem no funil de Haines) são 13, $90 \pm 0,31 ; 18,35 \pm 0,02 ; 11,20 \pm 0,10 \mathrm{e}$ $12,73 \pm 0,24 \%$, para as zonas ripária, de transição, de Cerrado stricto sensu e eucalipto, respectivamente. Uma característica importante do solo na zona ripária é o elevado teor de matéria orgânica $(54,91 \%)$. Esse tipo de solo possui uma estrutura semelhante à argila, isto é, a maior parte do seu volume é de água retida nos microporos.

Para determinar a ET diária utilizando as flutuações do nível freático como dado de entrada, é fortemente recomendável o uso do método de Gribovszki et al. (2008). Esse método leva em conta a variação do fluxo lateral $\left(Q_{l i q}\right)$, sem necessidade de incorrer em superestimativas no cálculo do fluxo máximo ao final da tarde. Os métodos que consideram o fluxo lateral constante durante o dia tendem a subestimar a evapotranspiração, pois analisam somente o fluxo lateral que acontece de manhã ( $Q_{l i q}$ mínimo).

Na coleta de dados foi apenas utilizado um poço de monitoramento por cada zona de estudo, devido a restrições no número de transdutores de pressão disponíveis. Portanto, os resultados de evapotranspiração apresentados representam valores pontuais, mas que permitiram desenvolver os diferentes métodos baseados na flutuação diária. Recomenda-se 
que seja ampliado, em futuras pesquisas, o número de poços de monitoramento por cada zona de estudo.

Na zona ripária (poço 27), a faixa de valores de $E T$ variou entre 2,74 e 14,90 mm/d. O número total de dias em que a $E T$ foi estimada foi de 162, e a soma deles teve um valor total de 1073,98 $\mathrm{mm}$ com uma ET média diária de 6,62 mm/d. Os resultados da ET na zona ripária foram complementados com estimativas da evaporação de seu solo, através da operação de microlisímetros expostos de forma direta à radiação solar. A faixa de valores de evaporação diária foi de 9 a $14 \mathrm{~mm}$. Mesmo que na zona ripária a exposição do solo à radiação solar seja menor, o aporte de evaporação foi significativo. Os fatores que favorecem o seu alto valor são o pequeno albedo (solo escuro) e a pouca profundidade (menos de 1,0 $\mathrm{m}$ ) do nível freático.

A faixa de $E T$ diária na zona de transição entre a zona ripária e o Cerrado variou entre 3,63 e 9,48 mm/d. O número de dias em que a $E T$ foi estimada foi de 125 , e a soma deles tem um valor total de 640,30 $\mathrm{mm}$ com uma ET média diária de 5,12 $\mathrm{mm} / \mathrm{d}$. A faixa de valores da ET diária no Cerrado stricto sensu (poço 29) variou entre 1,23 e 2,02 mm/d. O número de dias em que a $E T$ foi estimada foi de 162, e a soma deles tem um valor total de 250,09 $\mathrm{mm}$ com uma ET média diária de 1,54 mm/d. Para o eucalipto os valores de ET estiveram entre 1,96 e $5,45 \mathrm{~mm} / \mathrm{d}$. O número de dias em que $E T$ foi estimada foi de 168, e a soma deles tem um valor total de 446,42 $\mathrm{mm}$ com uma ET média diária de 2,65 $m m / d$.

Existe a necessidade de estudos como este na América Latina devido à riqueza hídrica do continente, que possui um grande número de rios nos quais o efeito da $E T$ nas zonas ripárias pode não estar sendo considerado. A bordadura estreita nessas zonas restringe o uso de equipamentos de medição da ET e a aplicação de métodos baseados na flutuação diária do nível freático oferece grande potencial. Para um melhor entendimento da evapotranspiração em zonas ripárias, os métodos baseados na flutuação diária do nível de água subterrânea devem ser aprimorados para que possam ser aplicados em dias com precipitação. 


\section{REFERÊNCIAS}

ALLEN, R. G.; PEREIRA, L. S.; RAES, D.; SMITH, M. Book. Crop Evapotranspiration - Guidelines for computing crop water requirements. FAO Irrigation and Drainage Paper 56. Rome: [s.n.], 1998.

Alves, M. E. A.-l. B.; MANTOVAnI, E. C.; SEDIYAMA, G. C.; NEVES, J. A. C. A. L. Estimate of the crop coefficient for Eucalyptus cultivated under irrigation during initial growth. CERNE, scielo, v. 19, p. 247 - 253, 06 2013. ISSN 0104-7760. Disponível em: <http://www.scielo.br/scielo.php?script=sci_arttext\&pid= $\mathrm{S} 0104-77602013000200008 \& \mathrm{nrm}=\mathrm{iso}>$.

ARAUJO, L. M.; FRANCA, A. B.; POTTER, P. E. Hydrogeology of the mercosul aquifer system in the parana and chaco-parana basins, south america, and comparison with the navajo-nugget aquifer system. Hydrogeology Journal, v. 7, p. 20, 1999.

BOUWER, H.; RICE, R. A slug test for determining hydraulic conductivity unconfined aquifers with completely or partially penetrating wells. Water Resources Ressearch, v. 12, n. 3, p. $6,1976$.

BOWEN, I. The ratio of heat losses by conduction and by evaporation from any water surface. Phys. Rev., American Physical Society, v. 27, p. 779-787, Jun 1926. Disponível em: <http://link.aps.org/doi/10.1103/PhysRev.27.779>.

BRUTSAERT, W. Book. Hydrology: An Introduction. [S.l.]: Cambridge University Press, 2005. ISBN 9780521824798.

BURBA, G. Eddy Covariance Method for Scientific, Industrial, Agricultural and Regulatory Applications: A Field Book on Measuring Ecosystem Gas Exchange and Areal Emission Rates. [S.l.]: LI-COR Biosciences, 2013. ISBN 9780615768274.

CABRAL, O. M. R.; ROCHA, H. R. da; GASH, J. H.; LIGO, M. A. V.; FREITAS, H. C.; TATSCH, J. D. The energy and water balance of a eucalyptus plantation in southeast brazil. Journal of Hydrology, v. 388, n. 3-4, p. 208 - 216, 2010. ISSN 0022-1694. Disponível em: <//www.sciencedirect.com/science/article/pii/S0022169410002404>.

CABRAL, O. M. R.; ROCHA, H. R. da; GASH, J. H.; FREITAS, H. C.; LIGO, M. A. V. Water and energy fluxes from a woodland savanna (cerrado) in southeast brazil. Journal of Hydrology: Regional Studies, v. 4, p. 22-40, 2015. ISSN 22145818.

CABRERA, M. C. M.; ANACHE, J. A. A.; YOULTON, C.; WEnDlAnD, E. Performance of evaporation estimation methods compared with standard $20 \mathrm{~m} 2$ tank. Revista Brasileira de Engenharia Agr Ãcola e Ambiental, scielo, v. 20, p. 874 - 879, 102016. ISSN 1415-4366. Disponível em: <http://www.scielo.br/scielo.php?script=sci_arttext\& pid $=$ S1415-43662016001000874\&nrm $=$ iso $>$.

CAMARGO, A.; M.B.P., C. Teste de uma equação simples para estimativa da evapotranspiração potencial baseada na radiação solar extraterrestre e na temperatura do ar. Cong. Bras. Agromet., Campinas, SP., p. 229-244, 1983. 
. Uma revisão analítica da evapotranspiração potencial. v. 59, p. 125-137, 2000. ISSN 00068705.

CAMARGO, A.; PEREIRA, A. R. Book. Prescrição de rega por modelo climatológico. [S.l.]: Fundação Cargill, Campinas, 1990. 27 p.

CARneiro, R. L. d. C.; RIBEIRO, A.; HUAMAN, C. A. Martinez y; LEITE, F. P.; SEDIYAMA, G. C.; NEVES, J. C. L. Consumo de água em plantios de eucalipto: parte 2 modelagem da resistência estomática e estimativa da transpiração em tratamentos irrigados e não-irrigados. Revista Árvore, scielo, v. 32, p. 11 - 18, 02 2008. ISSN 0100-6762. Disponível em: <http://www.scielo.br/scielo.php?script=sci_arttext\&pid= S0100-67622008000100002\&nrm=iso $>$.

CASTRO JUNIOR, P. R. Mapeamento Morfopedológico Aplicado à Bacia-Piloto do Ribeirão da Onça (SP) e À Bacia-Escola do Rio Cachoeirinha (MT) em Áreas de Recarga do Aquífero Guarani. Tese (Relatório de Pós Doutoramento), Escola de Engenharia de São Carlos, Universidade de São Paulo, 2008.

CHILDS, E. An introduction to the physical basis of soil water phenomena. WileyInterscience, New York, N.Y, 1972.

CLEVELAND, W. S. Robust locally weighted regression and smoothing scatterplots. Journal of the American Statistical Association, v. 74, p. 829-836, 1979.

CONTIN NETO, D. Balanço hídrico em bacia hidrográfica situada em região de recarga do aqüífero Botucatu. Tese (Doutorado em Hidráulica e Saneamento), Escola de Engenharia de São Carlos, Universidade de São Paulo, 1987.

DELYUKOV, A.; DIDYK, L. The effects of extra-low-frequency atmospheric pressure oscillations on human mental activity. Int J Biometeorol, p. 7, 1999.

DEVITT, D. A.; SALA, A.; SMITH, S. D.; CLEVERLY, J.; SHAULIS, L. K.; HAMMETT, $\mathrm{R}$. Bowen ratio estimates of evapotranspiration for tamarix ramosissima stands on the virgin river in southern nevada. Water Resources Research, v. 34, n. 9, p. 2407-2414, 1998. ISSN 1944-7973. Disponível em: <http://dx.doi.org/10.1029/98WR01551>.

DEVLIN, S. J. Locally-Weighted Multiple Regression: Statistical Properties and Its Use to Test for Linearity. Pitcataway, NJ, 1986.

DINGMAN, S. Physical Hydrology: Third Edition. [S.l.]: Waveland Press, 2015. ISBN 9781478628071.

DOLAN, T. J.; HERMANN, A. J.; BAYLEY, S. E.; ZOLTEK JOHN, J. Evapotranspiration of a florida, usa, fresh-water wetland. Journal of Hydrology, v. 74, p. 17, 1984.

DOREN, C. A. V.; KLINGEBIEL, A. A. Permeability studies on some illinois soils. Proceedings. Soil Science Society of America, v. 14, p. 5, 1949.

EMBRAPA. Manual de Métodos de Análise de Solo. [S.l.], 2011.

ESMAEILABADI, A. E. Evapotranspiration: Application, Scaling and Uncertainty. Tese (Doutorado) — University of New South Wales, Sydney, Australia, 2014. 
FAHLE, M.; DIETRICH, O. Estimation of evapotranspiration using diurnal groundwater level fluctuations: Comparison of different approaches with groundwater lysimeter data. Water Resources Research, v. 50, n. 1, p. 273-286, 2014. ISSN 00431397.

GEE, G.; BAUDER, J. Particle size analysis. In: Methods of Soil Analysis. 2. ed. [S.l.: s.n.], 1986. book section 1, p. 383-411.

GIAMBELlUCA, T. W.; SCHOLZ, F. G.; BUCCI, S. J.; MEINZER, F. C.; GOLDSTEIN, G.; HOFFMANN, W. A.; FRANCO, A. C.; BUCHERT, M. P. Evapotranspiration and energy balance of brazilian savannas with contrasting tree density. Agricultural and Forest Meteorology, v. 149, n. 8, p. 1365-1376, 2009. ISSN 01681923.

GOMES, L. H. Determinação da recarga profunda na bacia-piloto do Ribeirão da Onça em zona de afloramento do Sistema Aquífero Guarani a partir de balanço hídrico em zona saturada. Dissertação (Mestrado em Hidráulica e Saneamento), Escola de Engenharia de São Carlos, Universidade de São Paulo, São Carlos, 2008. Disponível em: <<http://www.teses.usp.br/teses/disponiveis/18/18138/tde-28042009-132417/>>.

GOODRICH, D.; SCOTT, R.; QI, J.; GOFF, B.; UNKRICH, C.; MORAN, M.; WILLIAMS, D.; SCHAEFFER, S.; SNYDER, K.; MACNISH, R.; MADDOCK, T.; POOL, D.; CHEHBOUNI, A.; COOPER, D.; EICHINGER, W.; SHUTTLEWORTH, W.; KERR, Y.; MARSETT, R.; NI, W. Seasonal estimates of riparian evapotranspiration using remote and in situ measurements. Agricultural and Forest Meteorology, v. 105, n. 1-3, p. 281 - 309, 2000. ISSN 0168-1923. Disponível em: <http: //www.sciencedirect.com/science/article/pii/S0168192300001970>.

GRENANDER, U.; ROSENBLATT, M. Statistical Analysis of Stationary Time Series. Wiley, 1957. (Wiley publication in mathematical statistics). Disponível em: <https: //books.google.com.br/books?id=B9tQAAAAMAAJ>.

GRIBOVSZKI, Z.; KALICZ, P.; SZILáGYI, J.; KUCSARA, M. Riparian zone evapotranspiration estimation from diurnal groundwater level fluctuations. Journal of Hydrology, v. 349, n. 1-2, p. 6-17, 2008. ISSN 00221694.

GROHMANN, F. Distribuição e tamanho de poros em três tipos de solos do estado de são paulo. Bragantia, v. 19, p. 319-328, 1960. ISSN 0006-8705. Disponível em: < http://www. scielo.br/scielo.php?script=sci_arttext\&pid=S0006-87051960000100021\&nrm $=$ iso $>$.

GUANABARA, R. C. Modelo transiente de fluxo em área de afloramento do Sistema Aquifero Guarani. Dissertação (Mestrado em Hidráulica e Saneamento), Escola de Engenharia de São Carlos, Universidade de São Paulo, São Carlos, 2011.

HALFORD, K. J.; KUNIANSKY, E. L. Catalog, Documentation of Spreadsheets for the Analysis of Aquifer-Test and Slug Test Data. [S.l.]: Open-File Report 02-197, 2002. $51 \mathrm{p}$.

HARGREAVES, G.; ALLEN, R. History and evaluation of hargreaves evapotranspiration equation. Journal of Irrigation and Drainage Engineering, v. 129, n. 1, p. 53-63, 2003.

HAYS, K. B. Water Use by Saltcedar (Tamarix sp.) and Associated Vegetation on the Canadian, Colorado and Pecos Rivers in Texas. Tese (Thesis), 2003. 
HILLEL, D. Book. Environmental Soil Physics: Fundamentals, Applications, and Environmental Considerations. Elsevier Science, 1998. ISBN 9780080544151. Disponível em: < https://books.google.com.br/books?id=tP__ y5xRd0oC $>$.

HÖYNG, D.; D'AFFONSECA, F. M.; BAYER, P.; OLIVEIRA, E. G. de; PERINOTTO, J. A. J.; REIS, F.; WEISS, H.; GRATHWOHL, P. High-resolution aquifer analog of fluvialaeolian sediments of the guarani aquifer system. Environmental Earth Sciences, v. 71, n. 7, p. 3081-3094, 2014. ISSN 1866-6299. Disponível em: <http://dx.doi.org/10.1007/ s12665-013-2684-5>.

IPT. Sistema aquífero guarani: Subsídios ao plano de desenvolvimento e proteção ambiental da Área de afloramento do sistema aquífero guarani no estado de são paulo. Instituto de Pesquisas Tecnológicas - Cadernos do Projeto Ambiental Estratégico Aquíferos, v. 5, p. 102, 2011.

JENSEN, M.; H.R., H. Estimating evapotranspiration from solar radiation. Journal of the Irrigation and Drainage Division, v. 89, p. 15-41, 1963.

KLUTE. Water retention: Laboratory methods. In: Methods of Soil Analysis: Part 1 - Physical and Mineralogical Methods. 2. ed. Agronomy Monograph 9, American Society of Agronomy and Soil Science Society of America, Madison, Winconsin: [s.n.], 1986. p. 635-662.

LANARV. Análise de corretivos, fertilizantes e inoculantes métodos oficiais. Ministerio da Agricultura. Secretaria Nacional de Defesa Agropecuaria, 1983.

LAUTZ, L. K. Estimating groundwater evapotranspiration rates using diurnal water-table fluctuations in a semi-arid riparian zone. Hydrogeology Journal, v. 16, n. 3, p. 483-497, 2008. ISSN 1435-0157. Disponível em: <http://dx.doi.org/10.1007/s10040-007-0239-0>.

LEAMER, R. W.; SHAW, B. A simple apparatus for measuring noncapillary porosity on an extensive scale. Jour. Amer. Soc. Agron, v. 33, p. 6, 1941.

LIBARDI, P. Book. Dinâmica da Água no Solo Vol. 61. EDUSP, 2005. ISBN 9788531407567. Disponível em: <https://books.google.com.br/books?id= qdZyHlGaXGsC $>$.

LOHEIDE II, S. P. A method for estimating subdaily evapotranspiration of shallow groundwater using diurnal water table fluctuations. Ecohydrology, v. 1, n. 1, p. 59-66, 2008. ISSN 1936058419360592.

LOHEIDE II, S. P.; BUTLER, J. J.; GORELICK, S. M. Estimation of groundwater consumption by phreatophytes using diurnal water table fluctuations: A saturated-unsaturated flow assessment. Water Resources Research, v. 41, n. 7, p. n/a-n/a, 2005. ISSN 00431397.

LUCAS, M.; OLIVEIRA, P. T. S.; MELO, D. C. D.; WENDLAND, E. Evaluation of remotely sensed data for estimating recharge to an outcrop zone of the guarani aquifer system (south america). Hydrogeology Journal, v. 23, n. 5, p. 961-969, 2015. ISSN 1431-2174 1435-0157.

MAKKINK, G. Ekzameno de la formula de penman. Netherlands Journal Agricultural Science, v. 5, p. 290-305, 1957. 
MARTINET, M. C.; VIVONI, E. R.; CLEVERLY, J. R.; THIBAULT, J. R.; SCHUETZ, J. F.; DAHM, C. N. On groundwater fluctuations, evapotranspiration, and understory removal in riparian corridors. Water Resources Research, v. 45, n. 5, p. n/a-n/a, 2009. ISSN 1944-7973. W05425. Disponível em: < http://dx.doi.org/10.1029/2008WR007152>.

MATLAB. version 8.5.0 (R2015a). Natick, Massachusetts: The MathWorks Inc., 2015.

MATTOS, T. S. Avaliação do impacto da substituição de pastagem por eucalipto na recarga de aquífero freático. Dissertação (Mestrado em Hidráulica e Saneamento), Escola de Engenharia de São Carlos, Universidade de São Paulo, São Carlos, 2015.

MAXWELL, R. M.; CONDON, L. E. Connections between groundwater flow and transpiration partitioning. Science, American Association for the Advancement of Science, v. 353, n. 6297, p. 377-380, 2016. ISSN 0036-8075. Disponível em: <http: //science.sciencemag.org/content/353/6297/377>.

MELO, D. d. C. D.; WENDLAND, E.; GUANABARA, R. C. Estimate of groundwater recharge based on water balance in the unsaturated soil zone. Revista Brasileira de Ciência do Solo, v. 39, n. 5, p. 1336-1343, 2015. ISSN 1806-9657.

MENEZES, S. J. M. da Costa de; SEDIYAMA, G.; SOARES, V.; GLERIANI, J.; ANDRADE, R. Estimativa dos componentes do balanÇo de energia e da evapotranspiraÇÃo em plantios de eucalipto utilizando o algoritmo sebal e imagem landsat 5 - tm1. Revista Árvore, v. 35, n. 3, p. 8, 2011.

MEYBOOM, P. Three observations on streamflow depletion by phreatophytes. Journal of Hydrology, v. 2, p. 14, 1964.

MILLAR, A. A. Book. Drenagem de terras agrícolas: bases econômicas. [S.l.: s.n.], 1988.

MONTEITH, J.; UNSWORTH, M. Principles of Environmental Physics. [S.l.]: Edward Arnold, 1990. (A series of student text in contemporary biology). ISBN 9780713129311.

NACHABE, M. H. Analytical expressions for transient specific yield and shallow water table drainage. Water Resources Research, v. 38, n. 10, p. 11-1-11-7, 2002. ISSN 1944-7973. 1193. Disponível em: <http://dx.doi.org/10.1029/2001WR001071>.

NISH, R. M.; UNKRICH, C.; SMYTHE, E.; GOODRICH, D.; III, T. M. Comparison of riparian evapotranspiration estimates based on a water balance approach and sap flow measurements. Agricultural and Forest Meteorology, v. 105, n. 1-3, p. $271-279$, 2000. ISSN 168-1923. Disponível em: <http://www.sciencedirect.com/science/article/pii/ S0168192300001969>.

OEA. Aquífero Guarani - Programa estratégico de ação. [S.l.], 2009. Disponível em: <http://www.ana.gov.br/bibliotecavirtual/arquivos/20100223172711_PEA_ GUARANI_Port_Esp.pdf $>$.

OLIVEIRA, J. C. M.; REICHARDT, K.; VAZ, C. M. P.; SWARTZENDRUBER, D. Improved soil particle-size analysis by gamma-ray attenuation. Soil Science Society of America Journal, v. 61, p. 23-26, 1997. Disponível em: <http://dx.doi.org/10.2136/ sssaj1997.03615995006100010004x>. 
OLIVEIRA, L. B. Determinação da macro e microporosidade pela mesa de tensão em amostras de solo com estrutura indeformada. Pesquisa Agropecuária Brasileira, v. 3, p. 4, 1968.

OLIVEIRA, P. T. S.; WENDLAND, E.; NEARING, M. A.; SCOTT, R. L.; ROSOLEM, R.; ROCHA, H. R. da. The water balance components of undisturbed tropical woodlands in the brazilian cerrado. Hydrology and Earth System Sciences, v. 19, n. 6, p. 2899-2910, 2015. ISSN 1607-7938.

OLIVEIRA, R. S.; BEZERRA, L.; DAVIDSON, E. A.; PINTO, F.; KLINK, C. A.; NEPSTAD, D. C.; MOREIRA, A. Deep root function in soil water dynamics in cerrado savannas of central brazil. Functional Ecology, Blackwell Science Ltd, v. 19, n. 4, p. 574-581, 2005. ISSN 1365-2435. Disponível em: <http://dx.doi.org/10.1111/j.1365-2435. 2005.01003.x>.

PEELE, T. C. Relation of percolation rates through saturated soil cores to volume of pores drained in 15 and 30 minutes under $60 \mathrm{~cm}$. tension. Proceedings. Soil Science Society of America, v. 14, p. 3, 1949.

PEREIRA, A. R.; SEDIYAMA, G. C.; NOVA, N. A. V. Book. Evapotranspiração. Campinas, SP: [s.n.], 2013. ISBN 978-85-62435-06-5.

POMPêO, C. A. Balanço hídrico da zona não-saturado solo na bacia do ribeirão da onça. Tese (Doutorado em Hidráulica e Saneamento), Escola de Engenharia de São Carlos, Universidade de São Paulo, São Carlos, 1990.

PRIESTLEY, C.; TAYLOR, R. On the assessment of surface heat flux and evaporation using large-scale parameters. Monthly Weather Review, v. 100, p. 11, 1972.

QUEIROZ, J. E.; CRUCIANI, D. E.; LIBARDI, P. L. Estimativa da porosidade drenÁvel de um solo de vÂrzea a partir da tensÃo da Água no solo. Scientia Agrícola, v. 52(3), p. 469-475, 1995.

RABELO, J. L.; WENDLAND, E. Assessment of groundwater recharge and water fluxes of the guarani aquifer system, brazil. Hydrogeology Journal, v. 17, n. 7, p. 1733-1748, 2009. ISSN 1431-2174 1435-0157.

RAMOS, F.; OCCHIPINTI, A. G.; NOVA, N. A. V.; REICHARDT, K.; AES, P. C. M.; CLEARY, R. Engenharia Hidrológica. [S.l.: s.n.], 1989.

SOARES, J.; ALMEIDA, A. Modeling the water balance and soil water fluxes in a fast growing eucalyptus plantation in brazil. Journal of Hydrology, v. 253, n. 1-4, p. 130 - 147, 2001. ISSN 0022-1694. Disponível em: <http://www.sciencedirect.com/science/ article/pii/S0022169401004772>.

SRACEK, O.; HIRATA, R. Geochemical and stable isotopic evolution of the guarani aquifer system in the state of são paulo, brazil. Hydrogeology Journal, v. 10, n. 6, p. 643-655, 2002. ISSN 1431-2174.

TAYLOR, J. Introdução à Análise de Erros: O Estudo de Incertezas em Medições Físicas. Bookman, 2009. ISBN 9788540701373. Disponível em: < https: //books.google.com.br/books?id=-KiLlh3641sC $>$. 
THORNTHWAITE, C. An approach toward a rational classification of climate. [S.l.]: American Geographical Society, 1948.

UHLAND, R. E. Physical properties of soils as modified by crops and management. Proceedings. Soil Science Society of America, v. 14, p. 6, 1949.

VAZ, C.; MACEDO, A.; INAMASU, R.; MONTAGNOLI, A. Analisador granulométrico de solos por atenuação de raios gama. CONGRESSO BRASILEIRO DE CIÊNCIA DO SOLO, v. 25, 1995.

VAZ, C.; NAIME, J.; MACEDO, A. Análise da textura de solos por atenuação de raios gama. SIMPÓSIO NACIONAL DE INSTRUMENTAÇÃO AGROPECUÁRIA, v. 1, 1996.

Determinação da distribuição do tamanho de partículas por atenuação de raios gama. CONGRESSO BRASILEIRO DE SISTEMAS PARTICULADOS, v. 24 (XXIV ENEMP), 1996.

Equipamento para a determinação da granulometria de solos. CONGRESSO LATINO AMERICANO DE CIÊNCIA DO SOLO, v. 13, 1996.

Analisador granulométrico de solos. São Carlos: EMBRAPA-CNPDIA, 1997.

. Equipamento para determinação da textura, densidade e umidade de solos. CONGRESSO BRASILEIRO DE CIÊNCIA DO SOLO, v. 26, 1997.

VAZ, C.; OLIVEIRA, J.; REICHARDT, K.; CRESTANA, S.; CRUVINEL, P.; BACCHI, O. Soil mechanical analysis through gamma ray attenuation. Soil Technology, Cremlingen, 1992.

VAZ, C. M. P.; NAIME, J.; SILVA, A. M.; MELLO, S. ANÁLISE GRANULOMÉTRICA POR RAIOS GAMA. [S.l.], 1997.

WANG, K.; DICKINSON, R. E. A review of global terrestrial evapotranspiration: Observation, modeling, climatology, and climatic variability. Reviews of Geophysics, v. 50, n. 2, p. n/a-n/a, 2012. ISSN 1944-9208. RG2005. Disponível em: < http: //dx.doi.org/10.1029/2011RG000373>.

WENDLAND, E.; BARRETO, C.; GOMES, L. H. Water balance in the guarani aquifer outcrop zone based on hydrogeologic monitoring. Journal of Hydrology, v. 342, n. 3-4, p. 261-269, 2007. ISSN 00221694.

WENDLAND, E.; GOMES, L. H.; TROEGER, U. Recharge contribution to the guarani aquifer system estimated from the water balance method in a representative watershed. An Acad Bras Cienc, v. 87, n. 2, p. 595-609, 2015. ISSN 1678-2690. Disponível em: <http://www.ncbi.nlm.nih.gov/pubmed/25993364>.

WHITE, W. N. Method of estimating groundwater supplies based on discharge by plants and evaporation from soil. results of investigation in Escalante Valley, Utah, US Geological Survey, n. Water Supply Paper 659-A, p. 1-105, 1932. 
Apêndices 


\section{APÊNDICE A - RELATÓRIO DE POÇOS}

A.1 Relatório do poço 27 - Zona ripária

Poço 27

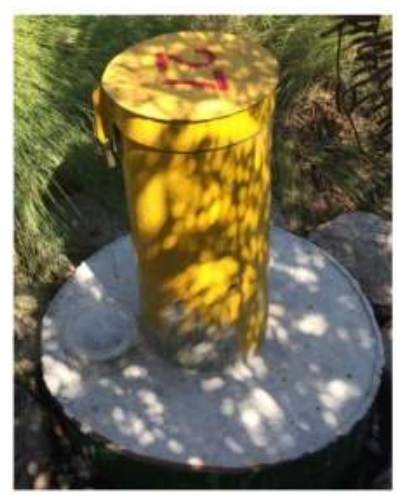

m

o

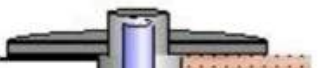

Monte Alegre

LOCALIZAÇÃO

Município: Brotas-SP

Coordenadas Geográficas:

$22^{\circ} 10^{\prime} 27,6^{\prime \prime} \boldsymbol{S}$ e 47 $57^{\prime} 14,2^{\prime \prime}$ W

Cota do Terreno (m): 700,076

Data inicio: 03/09/2015 Data final: Ativo

\section{PERFURAÇÃO}

Profundidade (m): 1,44 Tipo de Ferramenta: Trado

Diâmetro (mm): 150

Método: Rotativo

\section{CARACTERISTICAS TÉCNICAS}

Profundidade (m): 1,44 Diâmetro (mm): 75

Material: $P V C$

Filtro: De 0,94 até $1,44 \mathrm{~m}$

Boca do poço (m): 0,68 Malha Geotêxtil:

De 0,5 até $1,44 \mathrm{~m}$

Sedimento

cenozoico

Matéria

Orgânica

$54,9 \%$

Franco

Arenoso

1
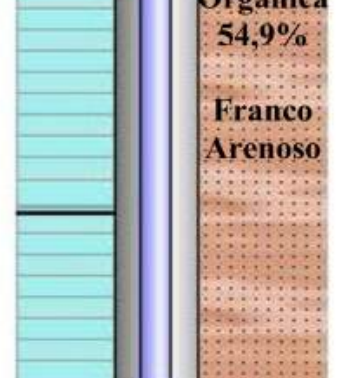

a:

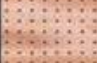

1,44

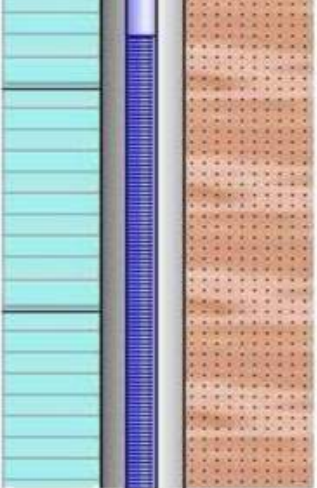

\section{VEGETAÇÃO AO REDOR DO POÇO:}

Vegetação nativa da zona ripária

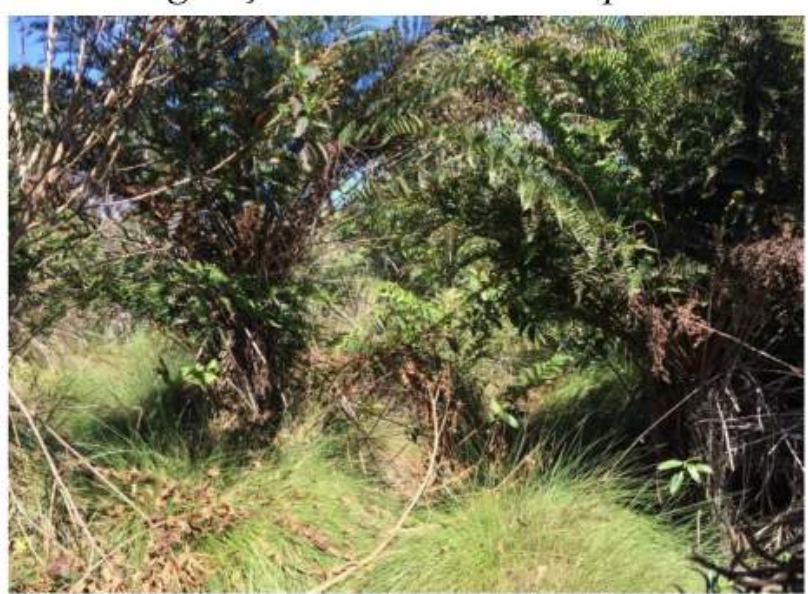

Filtro

- Profundidade média do nivel freático 
A.2 Relatório do poço 28 - Zona de transição

Poço 28
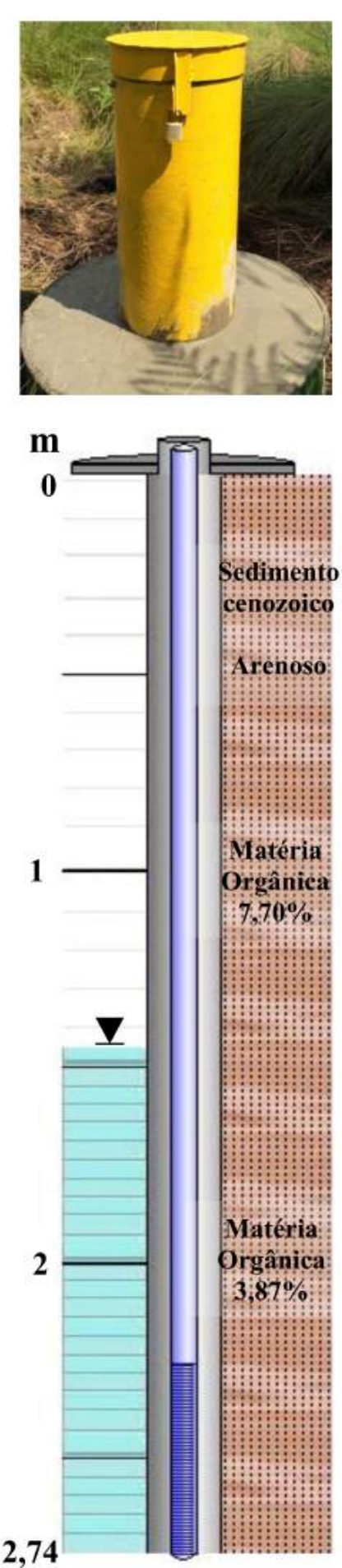

\section{LOCALIZAÇÃO}

Município: Brotas-SP

Localidade: Fazenda

Monte Alegre

Coordenadas Geográficas:

$22^{\circ} 10^{\prime} 28,1^{\prime \prime} \boldsymbol{S}$ e $47^{\circ} 57^{\prime} 14,2^{\prime \prime} \boldsymbol{W}$

Cota do Terreno (m): 702,671

Data inicio: 03/09/2015 Data final: Ativo

\section{PERFURAÇÃO}

Profundidade (m): 2,74

Tipo de Ferramenta: Trado

Diâmetro (mm): 150

Método: Rotativo

\section{CARACTERISTICAS TÉCNICAS}

Profundidade (m): 2,74

Diâmetro (mm): 75

Material: $P V C$

Filtro: De 2,26 $\mathrm{m}$ até $2,76 \mathrm{~m}$

Boca do poço (m): 0,54

Malha Geotêxtil:

De $1,26 \mathrm{~m}$ até $2,76 \mathrm{~m}$

\section{VEGETAÇÃO AO REDOR DO POÇO:}

Vegetação nativa na zona de transição

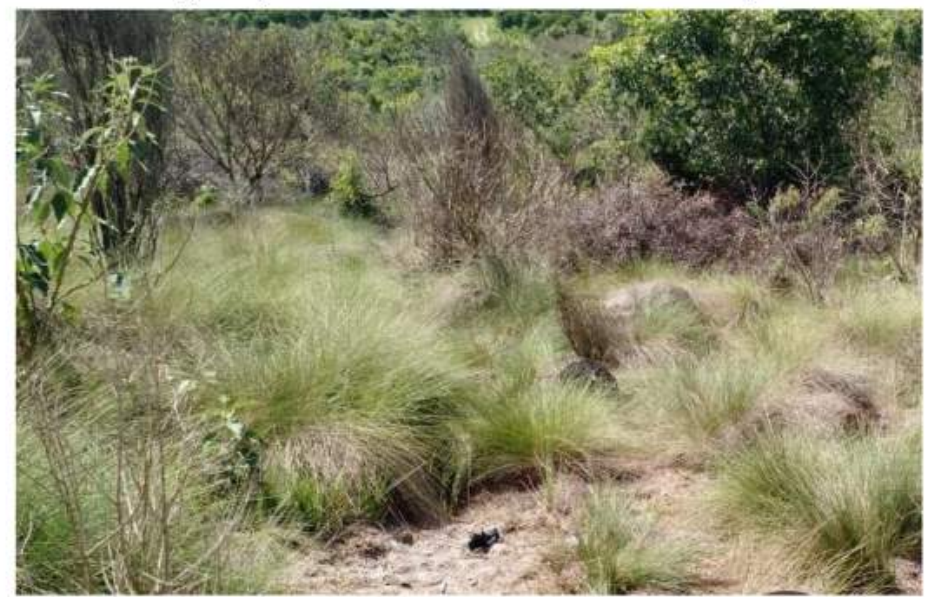

$=$ Filtro

$\nabla$ Profundidade média do nivel freático 
A.3 Relatório do poço 29 - Cerrado stricto sensu

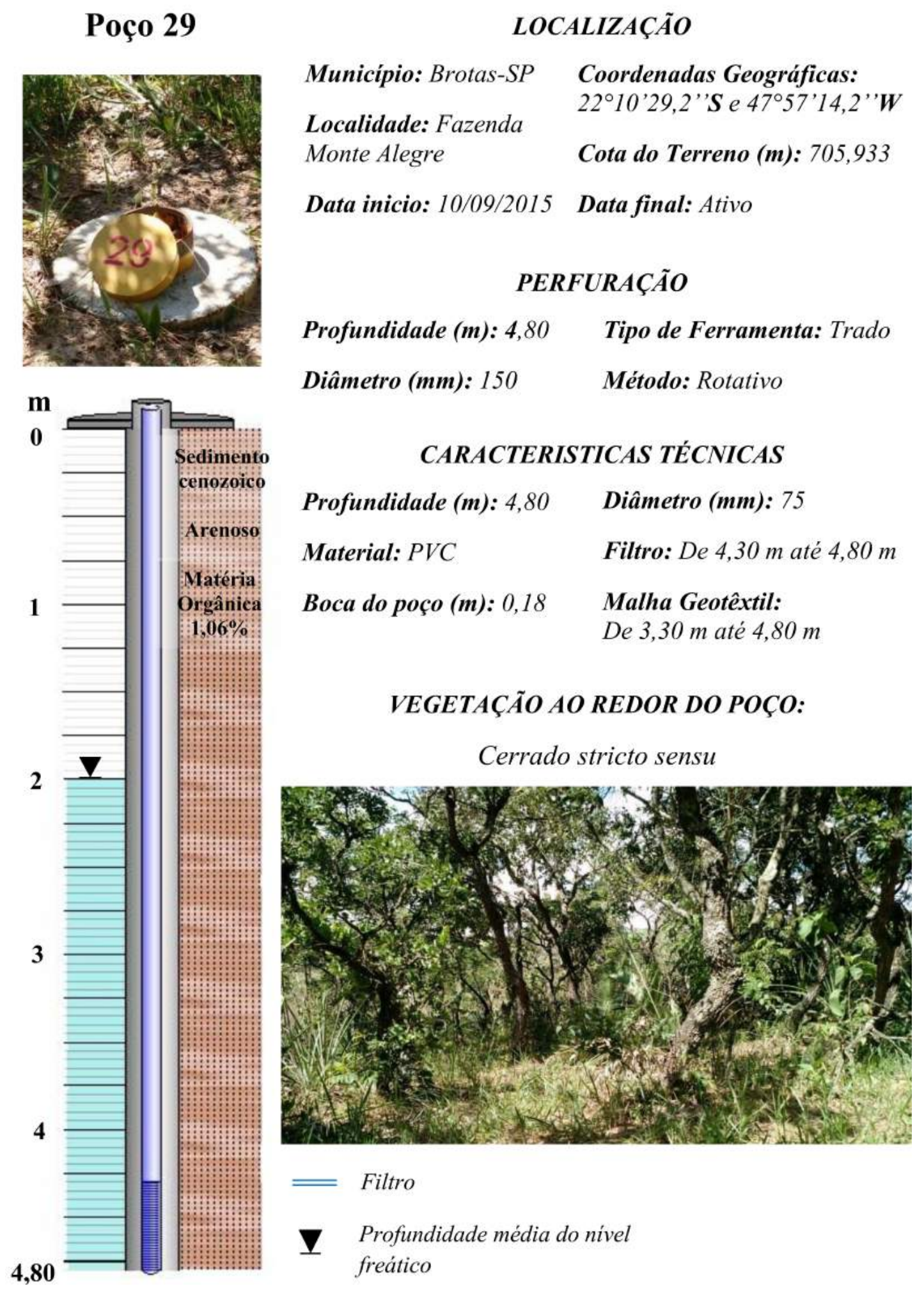


A.4 Relatório do poço 16 - Eucalipto

Poço 16
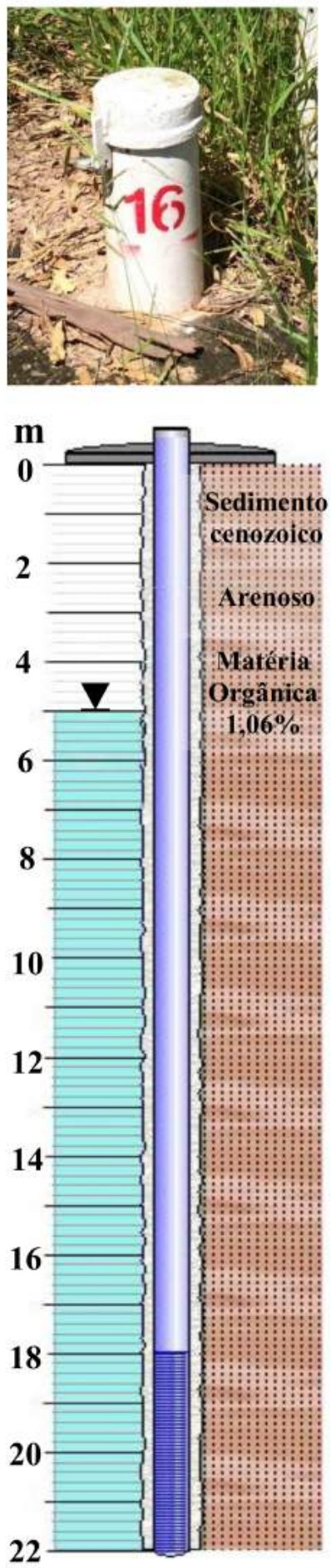

LOCALIZAÇÃO

Municipio: Brotas-SP Coordenadas Geográficas:

$22^{\circ} 10^{\prime} 29,74^{\prime \prime} \boldsymbol{S}$ e 47057'14,04' $\boldsymbol{W}$

Localidade: Fazenda

Monte Alegre

Cota do Terreno (m): 709,900

Data inicio: 31/08/2004 Data final: Ativo

\section{PERFURAÇÃO}

Profundidade (m): 22 Máquina: Perfuratriz

Diâmetro (mm): $150 \quad$ Método: Rotativo

\section{CARACTERISTICAS TÉCNICAS}

Profundidade (m): $22 \quad$ Diâmetro (mm): 100

Material: $P V C$

Filtro: De $18 m$ até $22 \mathrm{~m}$

Boca do poço (m): 0,37

VEGETAÇÃO AO REDOR DO POÇO:

Eucalipto

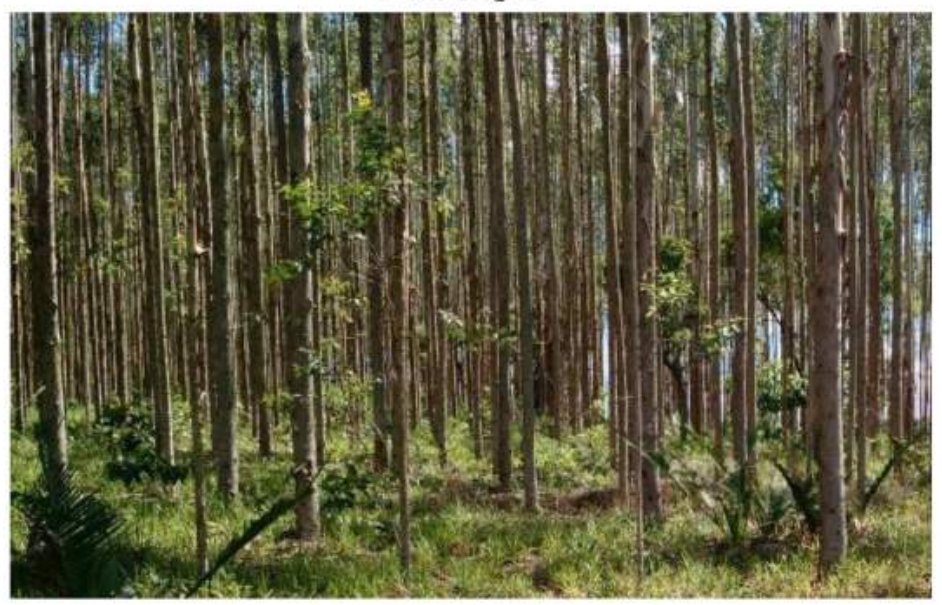

Filtro

\ Profundidade média do nivel freático 


\section{APÊNDICE B - BOCA DOS POÇOS}

a) Posicionamento do tubo de ferro para proteção dos tubos PVC. b) Preenchimento parcial da base com areia. c) Preenchimento total da base com concreto

a)

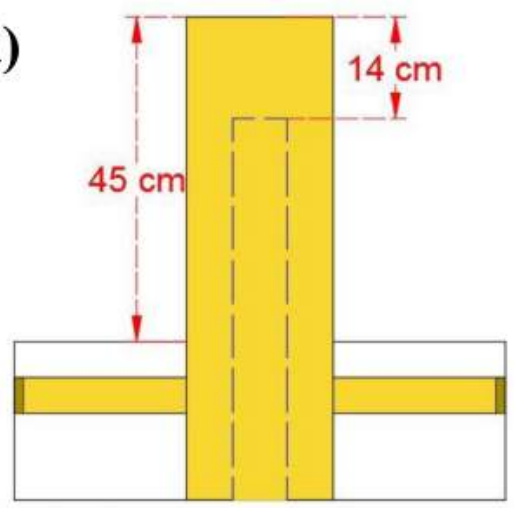

b)

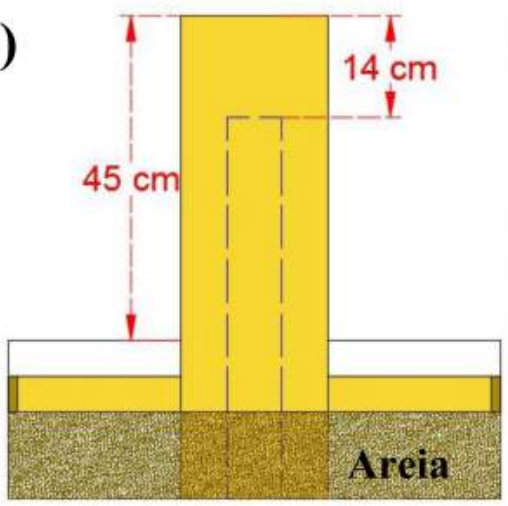

c)

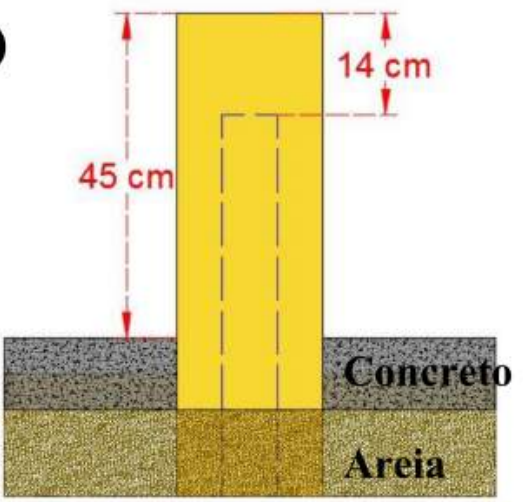

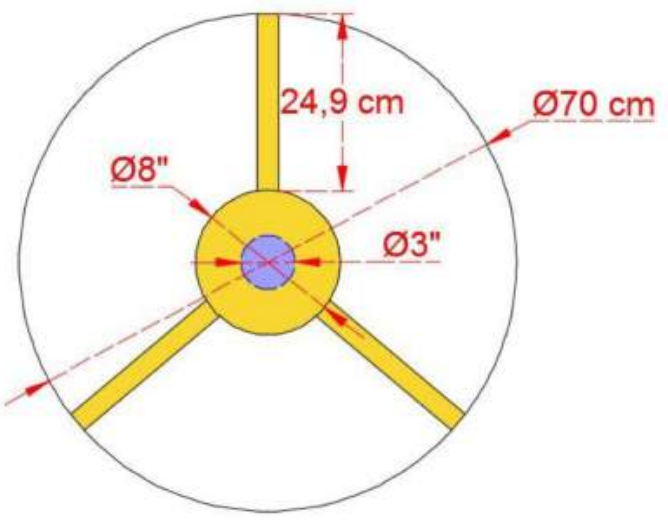
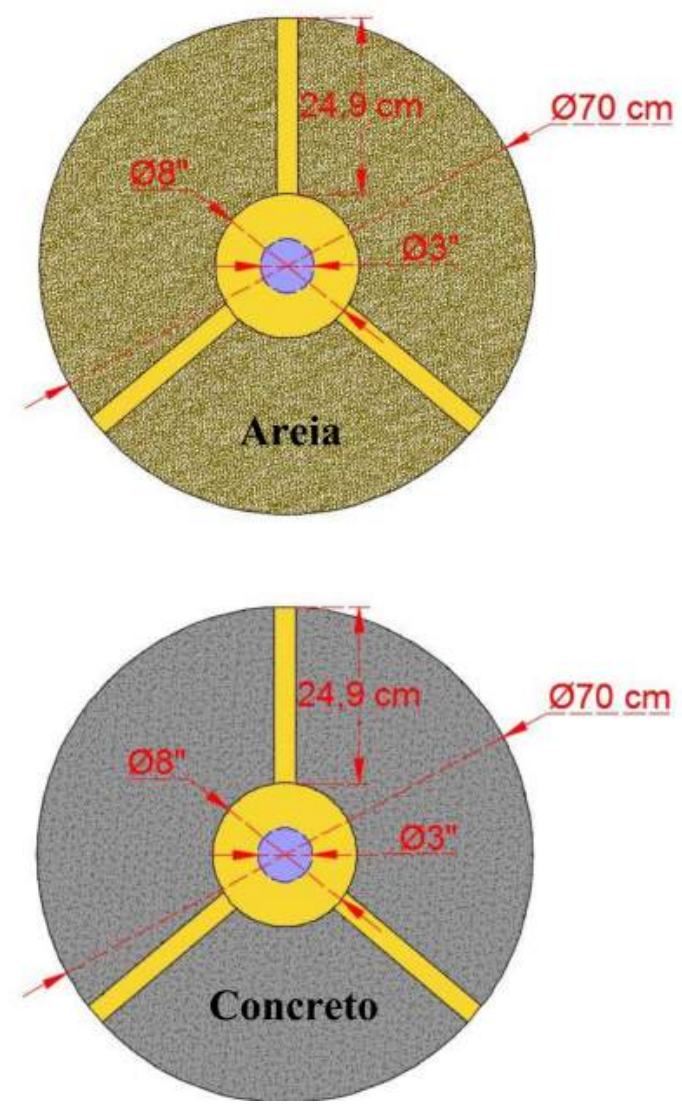


\section{APÊNDICE C - PEDRA POROSA}

As pedras porosas foram utilizadas para gerar uma ascensão capilar e saturar as amostras de solo utilizadas no funil de Haines. Os passos para a sua construção foram os seguintes:

a) Coleta de aproximadamente $700 \mathrm{~g}$ de um solo arenoso e secado em estufa a $105^{\circ} \mathrm{C}$ durante $24 h$.

b) Peneiramento, sendo selecionada a fração que passa pela peneira $n^{\circ} 16(1,19 \mathrm{~mm})$ e retida na $n^{\circ} 30(0,59 \mathrm{~mm})$ para a sua posterior lavagem e secagem a $105^{\circ} \mathrm{C}$ durante $24 h$.

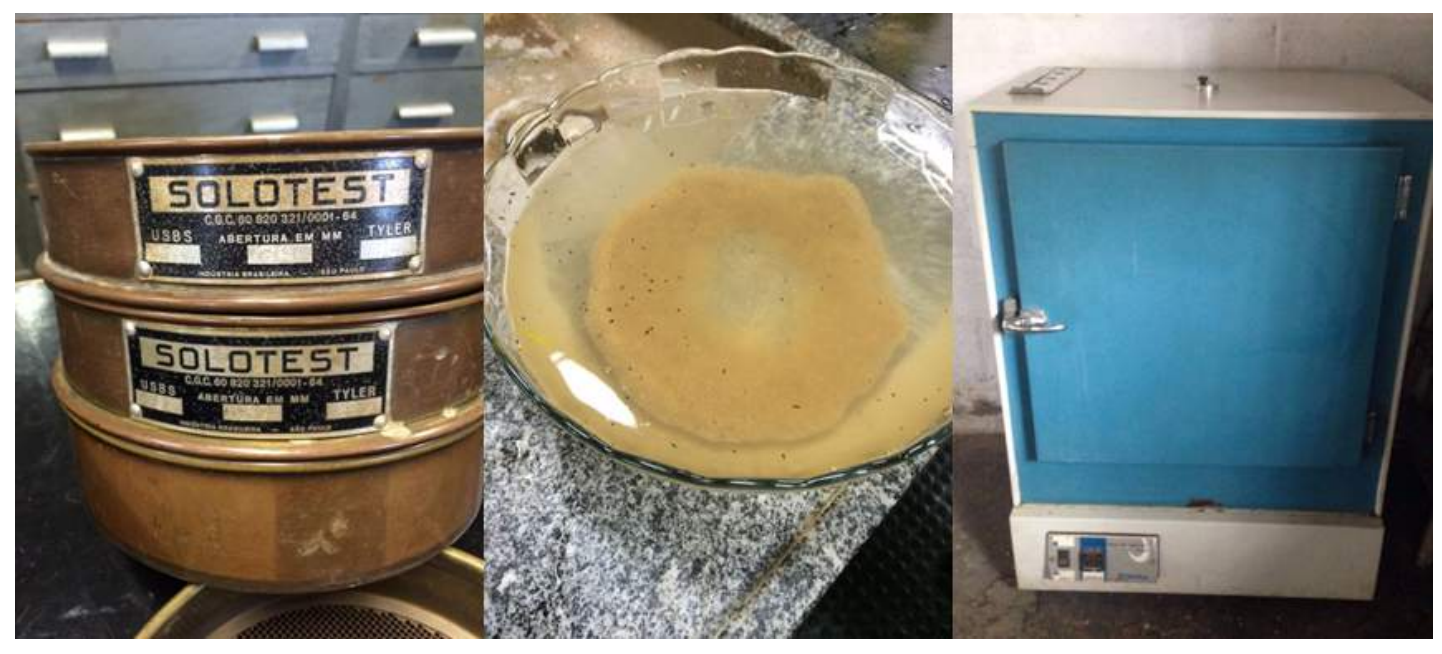

c) Para cada pedra porosa foram utilizadas $35 \mathrm{~g}$ da fracção peneirada $+10 \%$ de desperdício $+5 \%$ de Araldite de 90 min e misturada até ficar uma distribuição homogênea.

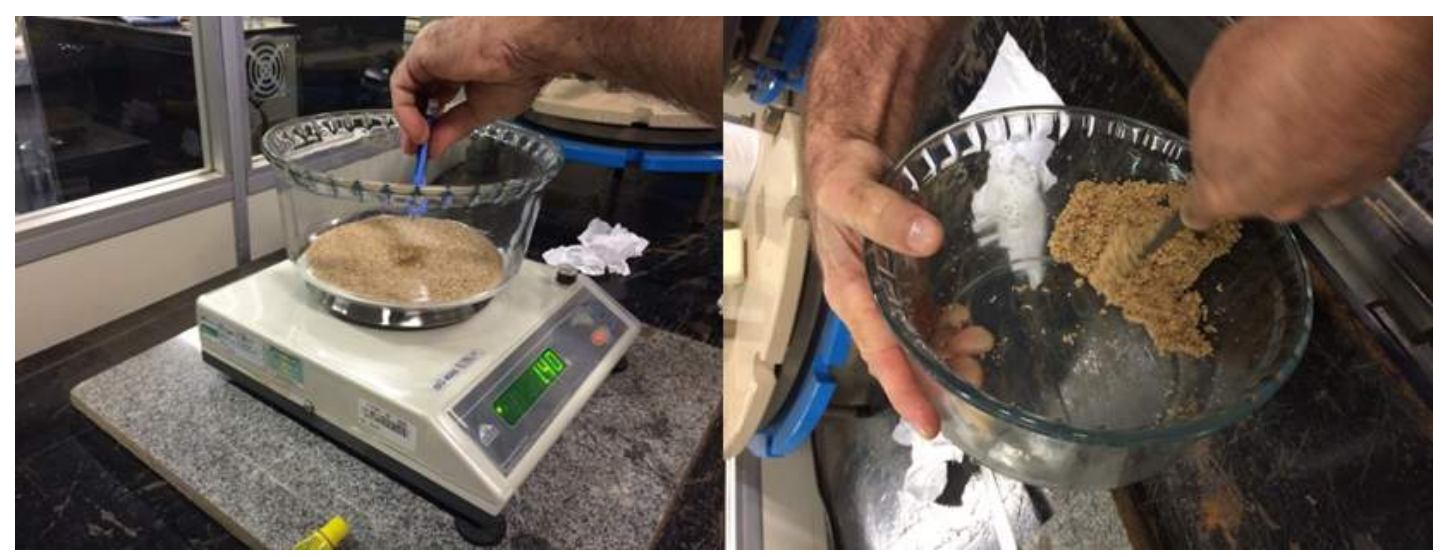


d) Toda a areia misturada com Araldite ficou contida em três (3) anéis de PVC de 53 $\mathrm{mm}$ de diâmetro e $11 \mathrm{~mm}$ de altura durante 2 dias. Posteriormente foi retirada dos anéis com cuidado e finaliza o processo de elaboração da pedra porosa.

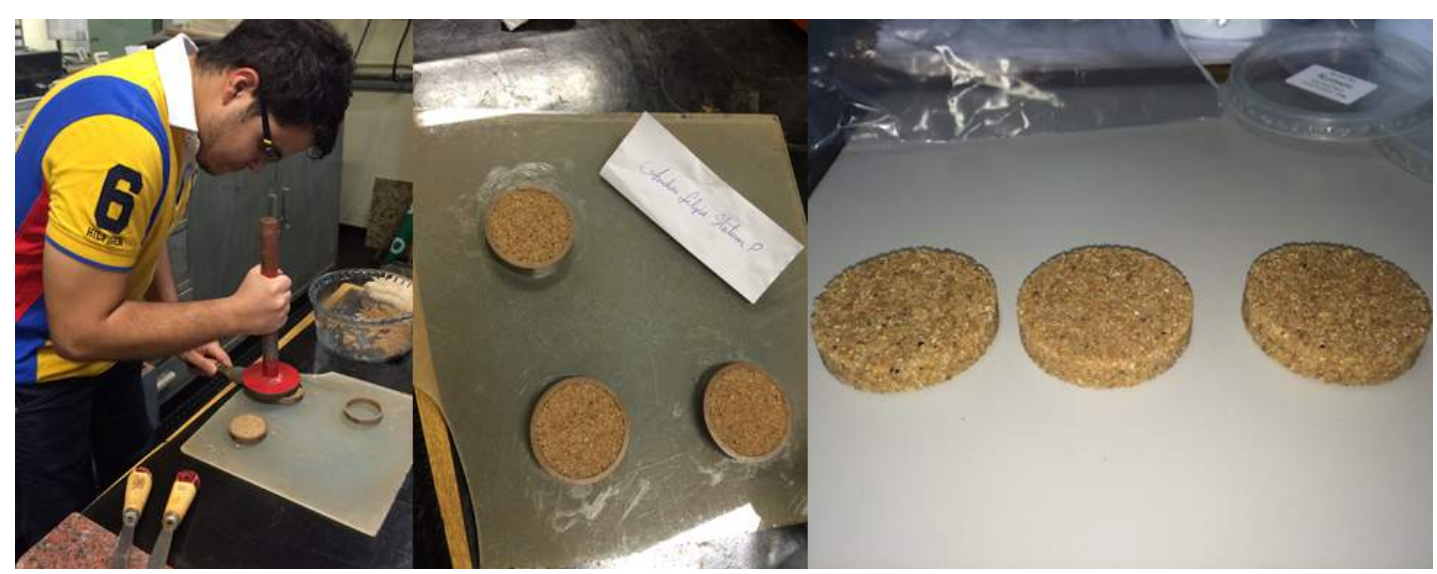




\section{APÊNDICE D - SCRIPTS EM MATLAB DOS MÉTODOS BASEADOS FLUTUAÇÃO DIARIA DO NÍVEL FREÁTICO}

As letras e acentos que são exclusivos do alfabeto português não aparecem nos Scripts, com o fim de garantir o bom funcionamento deles.

\section{D.1 Script do método de White (1932)}

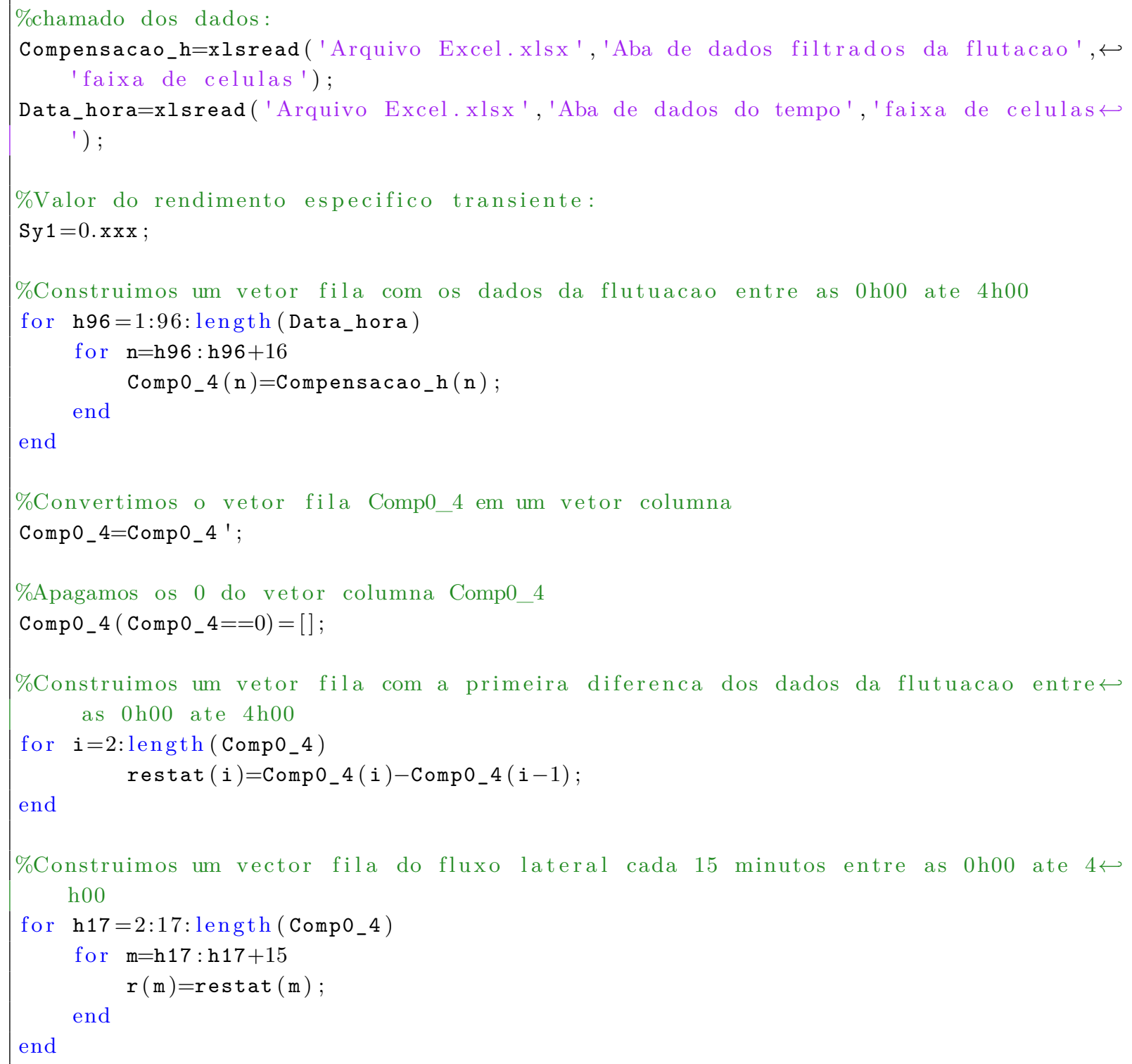




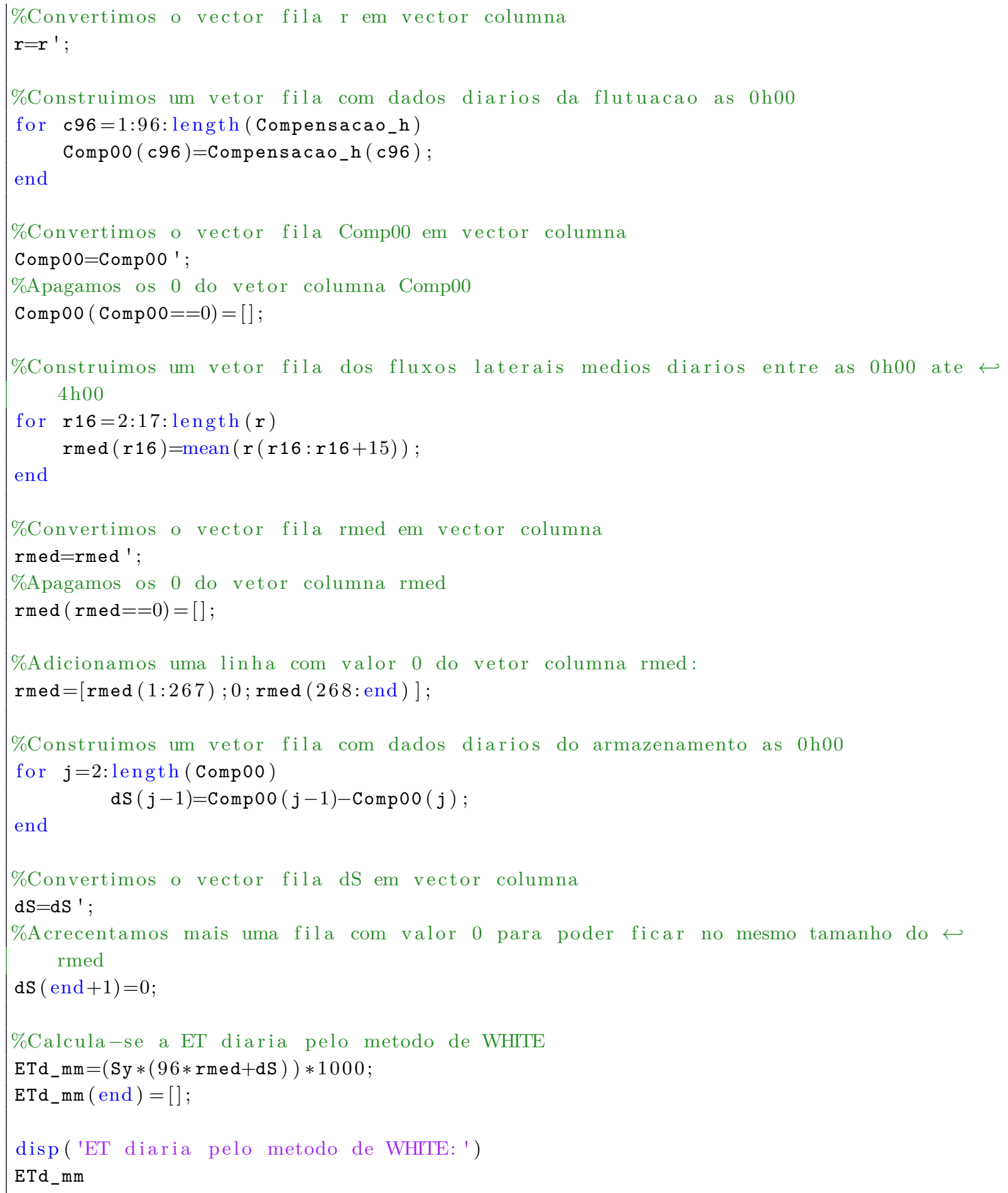




\section{D.2 Script do método de Dolan et al. (1984)}

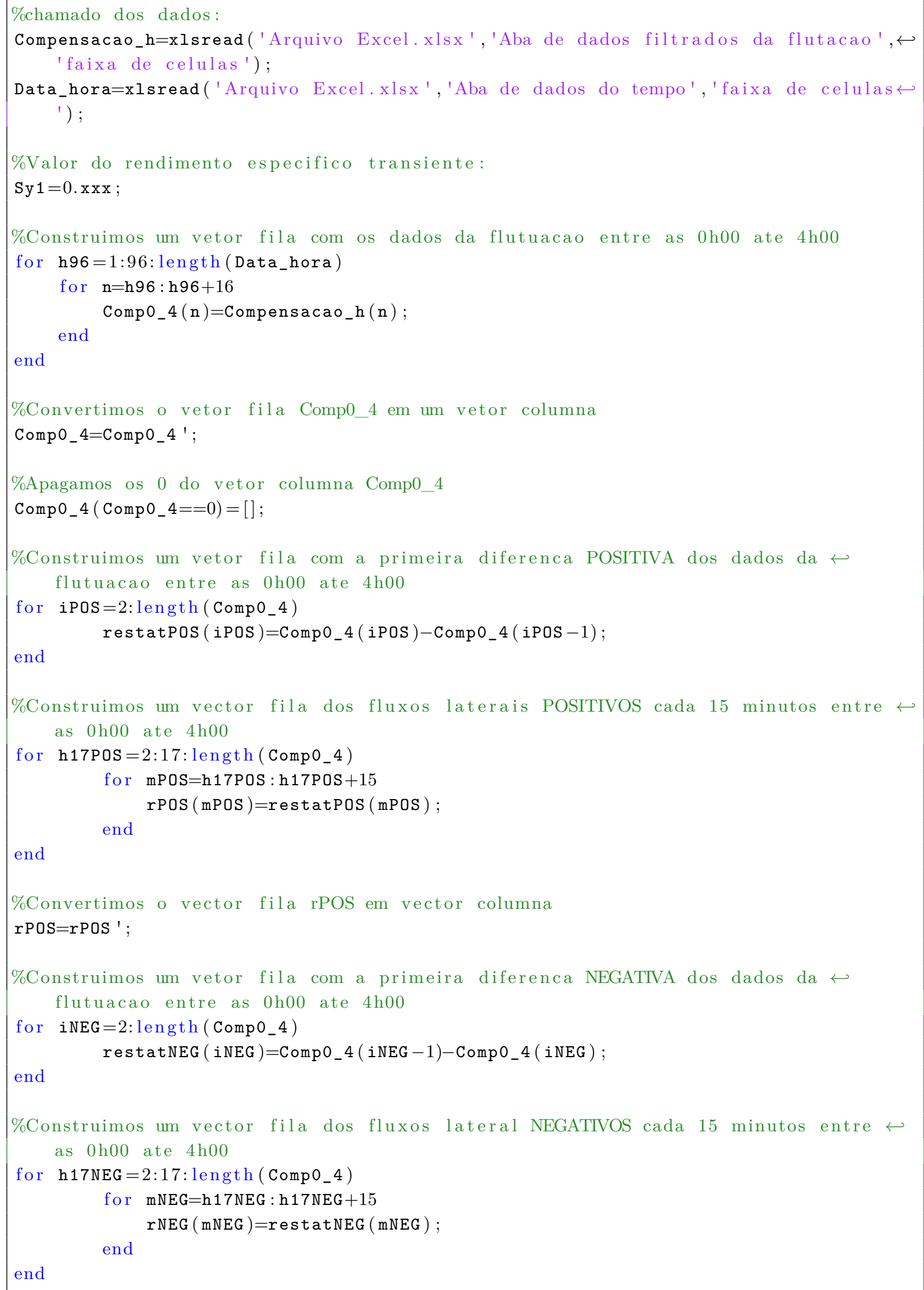




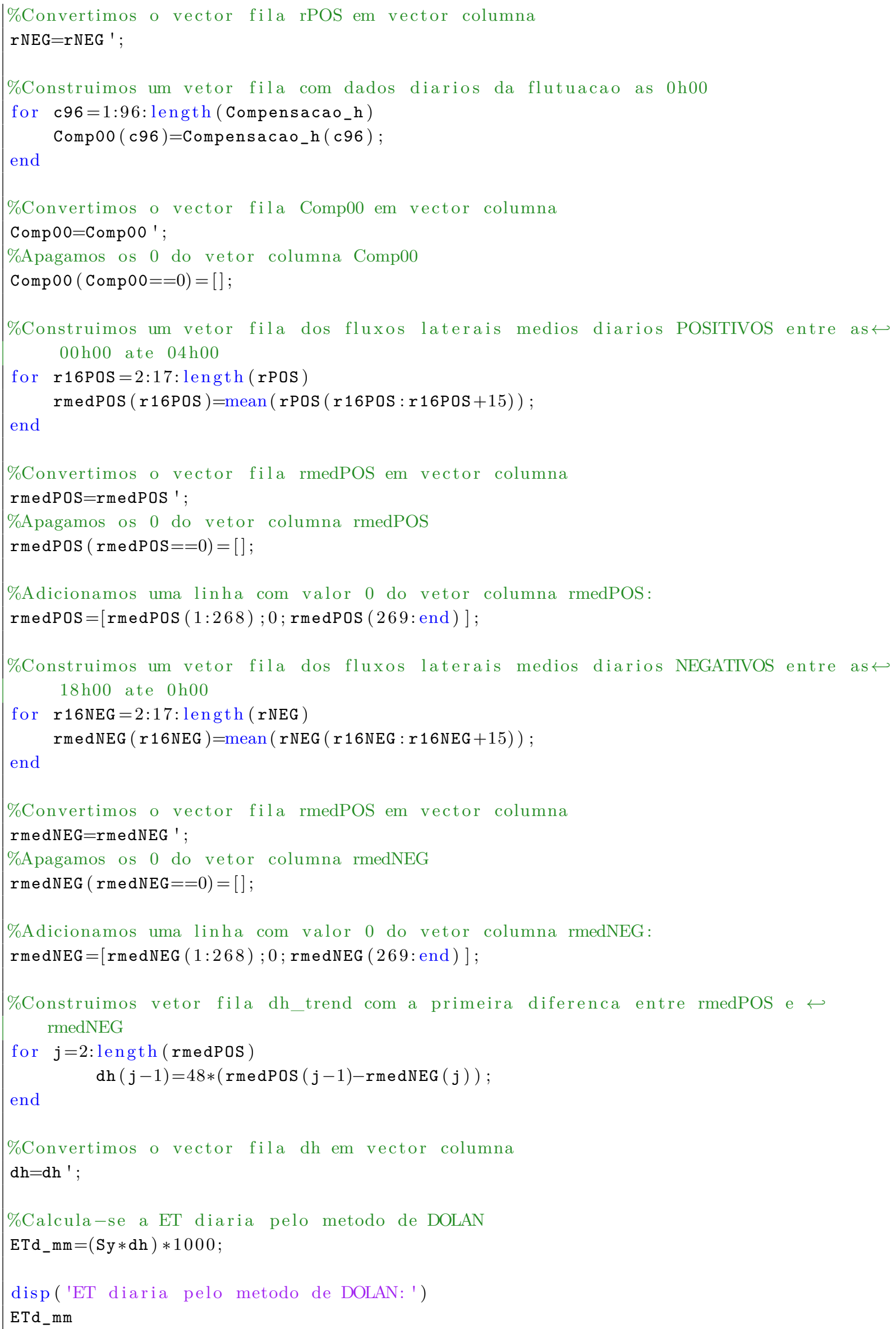




\section{D.3 Script do método de Hays (2003)}

\%chamado dos dados:

Compensacao_h=xlsread ('Arquivo Excel.xlsx', 'Aba de dados filtrados da flutacao', 'faixa de celulas');

Data_hora=xlsread('Arquivo Excel.xlsx', 'Aba de dados do tempo','faixa de celulas ') ;

\%uda-se o formato da data modo diario para dados cada 15 minutos

Data_hora15M=Data_hora $* 96$;

\%Valor do rendimento especifico transiente:

Sy $1=0 . \mathrm{xxx}$

\%Construimos um vetor fila dos dados MAXIMOS diarios da flutuacao e a sua $\hookleftarrow$ posicao

for hMAX96 =1:96: length (Data_hora)

[ compMAX (hMAX96), POScompMAX $($ hMAX96) $]=\max ($ Compensacao_h $($ hMAX96: hMAX96+95)); end

\%Convertimos o vectores fila compMAX e POScompMAX em vectores columna

compMAX = compMAX ';

POS compMAX=POS compMAX ';

\%Apagamos os 0 dos vetores coluna compMAX e POScompMAX:

compMAX $(\operatorname{compMAX}==0)=[]$;

POS compMAX $($ POS compMAX $==0)=[]$;

\%Colocamos um incremento de 24 horas nos dados de POScompMAX

for $\operatorname{iMAX}=1$ : length (POScompMAX)

POS compMAX $($ iMAX $)=$ POS compMAX $($ iMAX $)+($ iMAX -1$) * 96$;

end

\%Construimos um vetor coluna com a hora que correspondiente para cada dado de $\leftarrow$ compMAX

$\mathrm{h}_{-} \operatorname{compMAX}=($ Data_hora15M $($ POScompMAX $))$;

\%Construimos um vetor fila dos dados MINIMOS diarios da flutuacao e a sua $\hookleftarrow$ posicao

for hMIN96 =1:96: length (Data_hora)

[ compMIN (hMIN96), POScompMIN $($ hMIN96) $]=\min ($ Compensacao_h $($ hMIN96:hMIN96+95)); end

\%Convertimos o vectores fila compMIN e POScompMIN em vectores columna

compMIN= CompMIN ';

POS CompMIN=POS compMIN ';

\%Apagamos os 0 dos vetores coluna compMIN e POScompMIN:

compMIN $(\operatorname{compMIN}==0)=[]$;

POS compMIN $($ POS compMIN $==0)=[]$;

\%Colocamos um incremento de 24 horas nos dados de POScompMIN

for $\quad$ iMIN=1:length (POScompMIN)

POS compMIN $($ iMIN $)=$ POS compMIN $($ iMIN $)+($ iMIN -1$) * 96$; end 


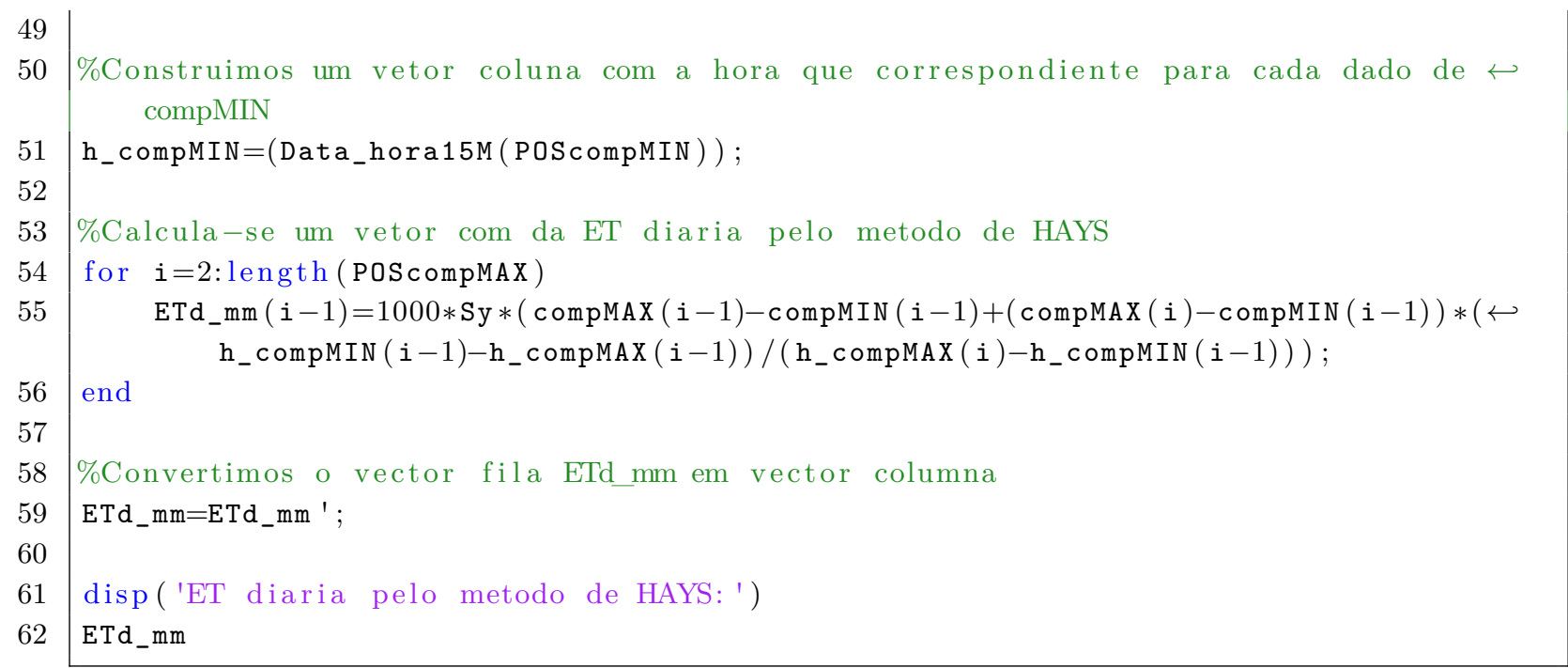




\section{D.4 Script do método de Gribovszki et al. (2008)}

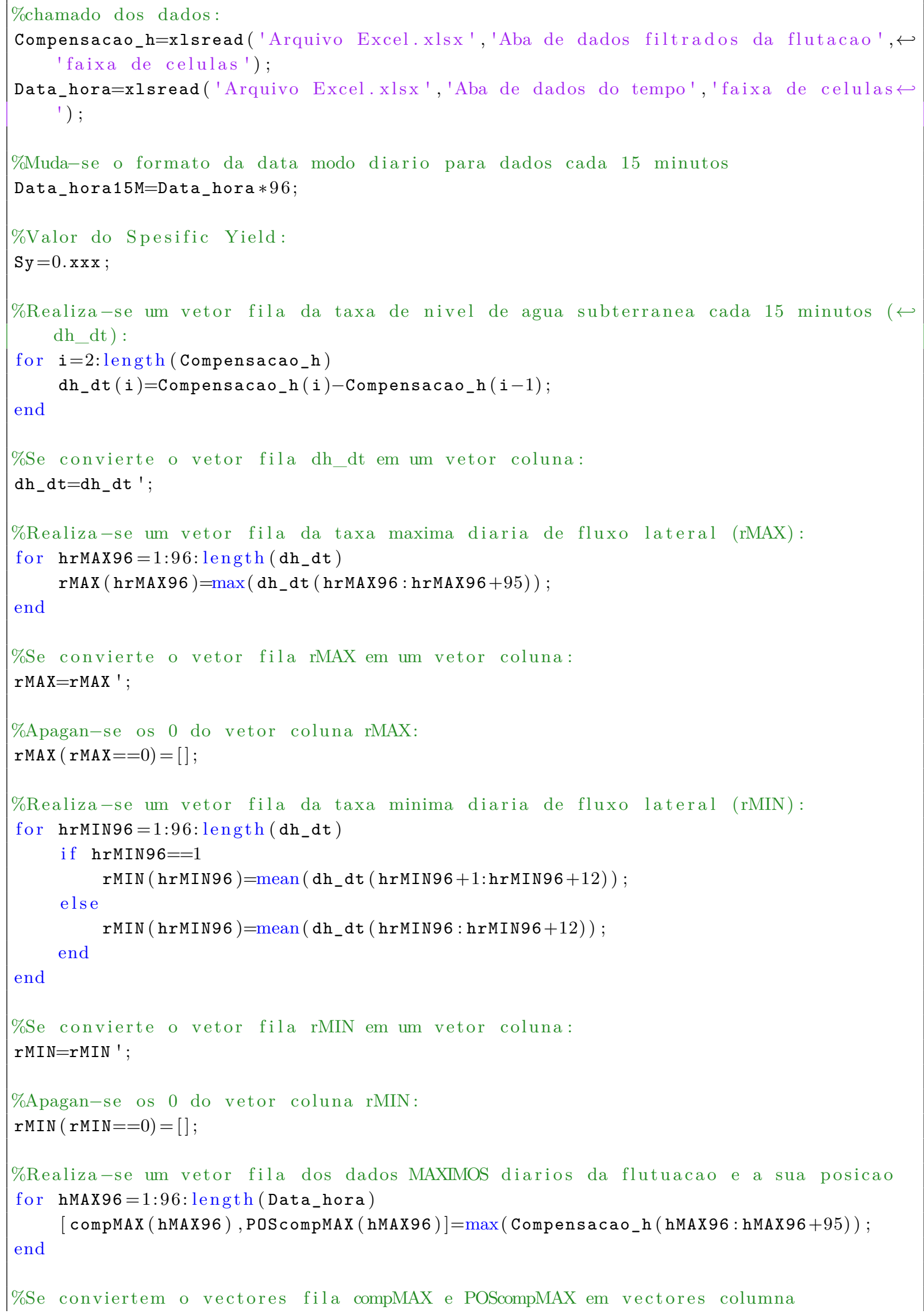




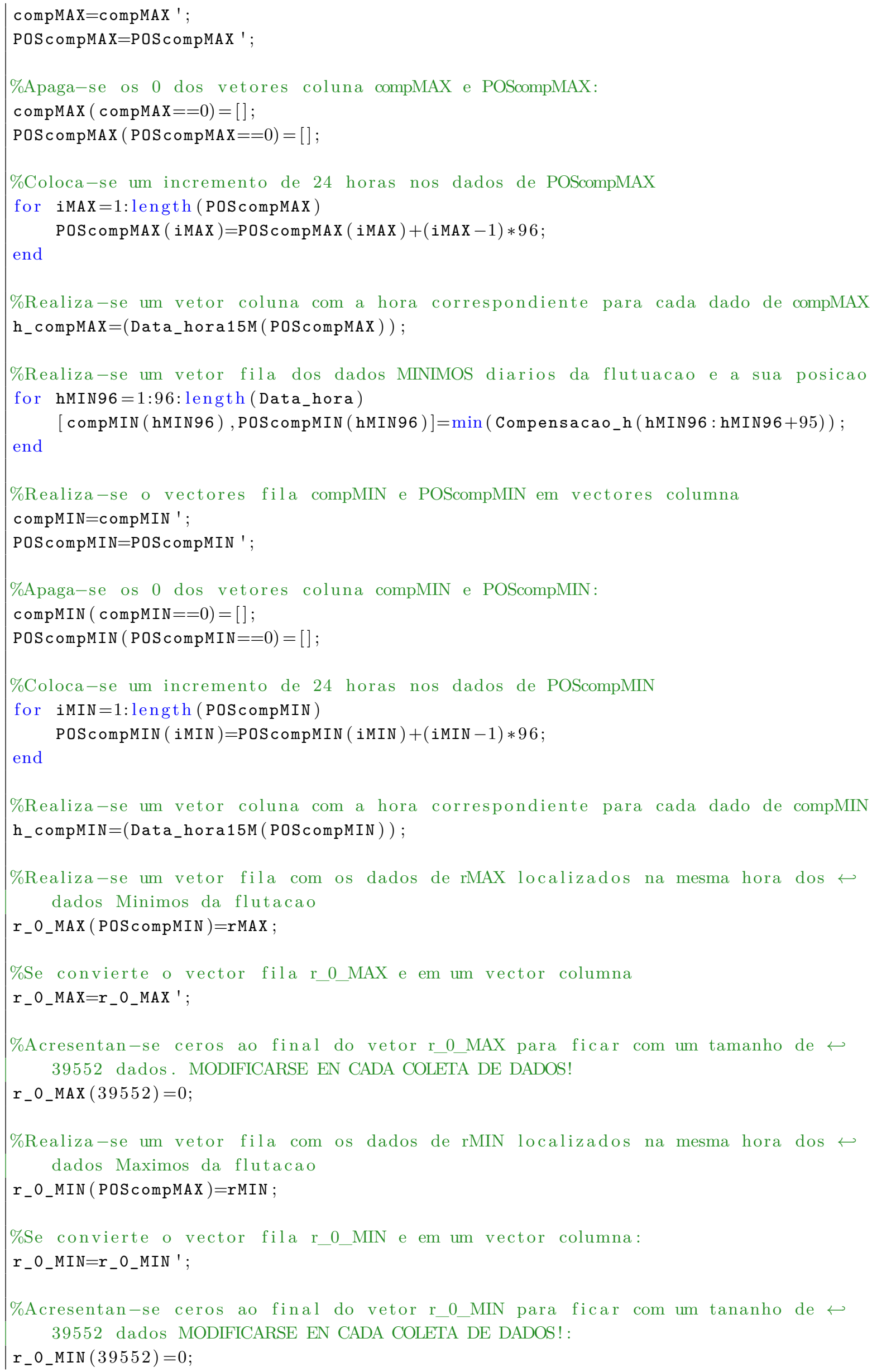


104

105

106

107

108

109

110

111

112

113

114

115

116

119

120

121

122

123

124

125

126

127

128

129

130

131

132

133

134

135

136

137

138

139

140

141

\%Realiza-se a suma dos vetores r_0_MAX e r_o_MIN para ter um dado MAXIMO e $\leftarrow$ MINIMO de taxa horaria de fluxo lateral:

$r M M=r_{-} 0_{-} M A X+r_{-} 0_{-} M I N$;

\%Apaga-se os 0 do vetor rMM:

$r M M(r M M==0)=[]$;

\%Realiza-se um vetor fila com os dados MAXIMOS diarios da flutuacao e os outros $\hookleftarrow$ horarios ficam em 0

h_o_compMAX ( POS compMAX $)=\mathrm{h}_{-}$compMAX ;

\%Se convierte o vector fila h_0_compMAX e em um vector columna:

h_o_compMAX $=\mathrm{h}_{-} 0_{-}$compMAX ';

\%Acresentan-se ceros ao final do vetor h_0_compMAX para ficar com um tananho de $\hookleftarrow$ 39552 dados MODIFICARSE EN CADA COLETA DE DADOS!:

h_o_compMAX $(39552)=0$;

\%Realiza-se um vetor fila com os dados MINIMOS diarios da flutuacao e os outros $\hookleftarrow$ horarios ficam em 0

h_0_compMIN ( POS compMIN $)=\mathrm{h}_{-}$compMIN

\%Se convierte o vector fila h_0_compMIN e em um vector columna:

h_O_compMIN=h_O_compMIN ';

\%Acresentan-se ceros ao final do vetor h_0_compMIN para ficar com um tananho de $\hookleftarrow$ 39552 dados MODIFICARSE EN CADA COLETA DE DADOS! :

h_0_compMIN $(39552)=0$;

\%Realiza-se a suma dos vetores h_0_compMAX e h_0_compMIN para ter um dado $\hookleftarrow$ horario MAXIMO e MINIMO taxa horaria de fluxo lateral:

h compMM $=h_{-} 0_{-}$compMAX + h_o_compMIN ;

\%Apaga-se os 0 do vetor hompMM:

$\mathrm{h} \operatorname{compMM}(\mathrm{h} \operatorname{compMM}==0)=[]$;

\%Realiza-se uma interpolacao spline com os dados de rMM (deve ser realizada para os dias sem precipitacao sendo, recomendavel a realizacao de um grafico $\hookleftarrow$ dela com o fim de verificar e evitar que algum dia com uma flutuacao atipica possa gerar defeito na interpolacao)

r1=interp1 (hcompMM (27:42),rMM (27:42), Data_hora15M(1249:2016));

r2=interp1 (hcompMM (53:72), rMM (53:72), Data_hora15M (2497:3456));

r3=interp1 (hcompMM $(77: 96)$,rMM $(77: 96)$, Data_hora15M (3649:4608));

r4=interp1 (hcompMM (199:214),rMM (199:214), Data_hora15M(9505:10272));

r5=interp1 (hcompMM (301:310),rMM (301:310), Data_hora15M(14401:14880));

r6=interp1 (hcompMM (423:470), rMM (423:470), Data_hora15M(20257:22560));

r7=interp1 (hcompMM (481:498), rMM (481:498), Data_hora15M(23041:23904));

r8=interp1 (hcompMM (571:632), rMM (571:632), Data_hora15M(27361:30336));

r9=interp1 (hcompMM (637:692),rMM (637:692), Data_hora15M(30529:33216));

r10=interp1 (hcompMM (741:824),rMM (741:824), Data_hora15M(35521:39552));

\%Juntan-se as interpolacoes em um mesmo vetor (modificar para cada projeto):

$r(1249: 2016)=r 1$;

$r(2497: 3456)=r 2$;

$r(3649: 4608)=r 3$;

$r(9505: 10272)=r 4$; 


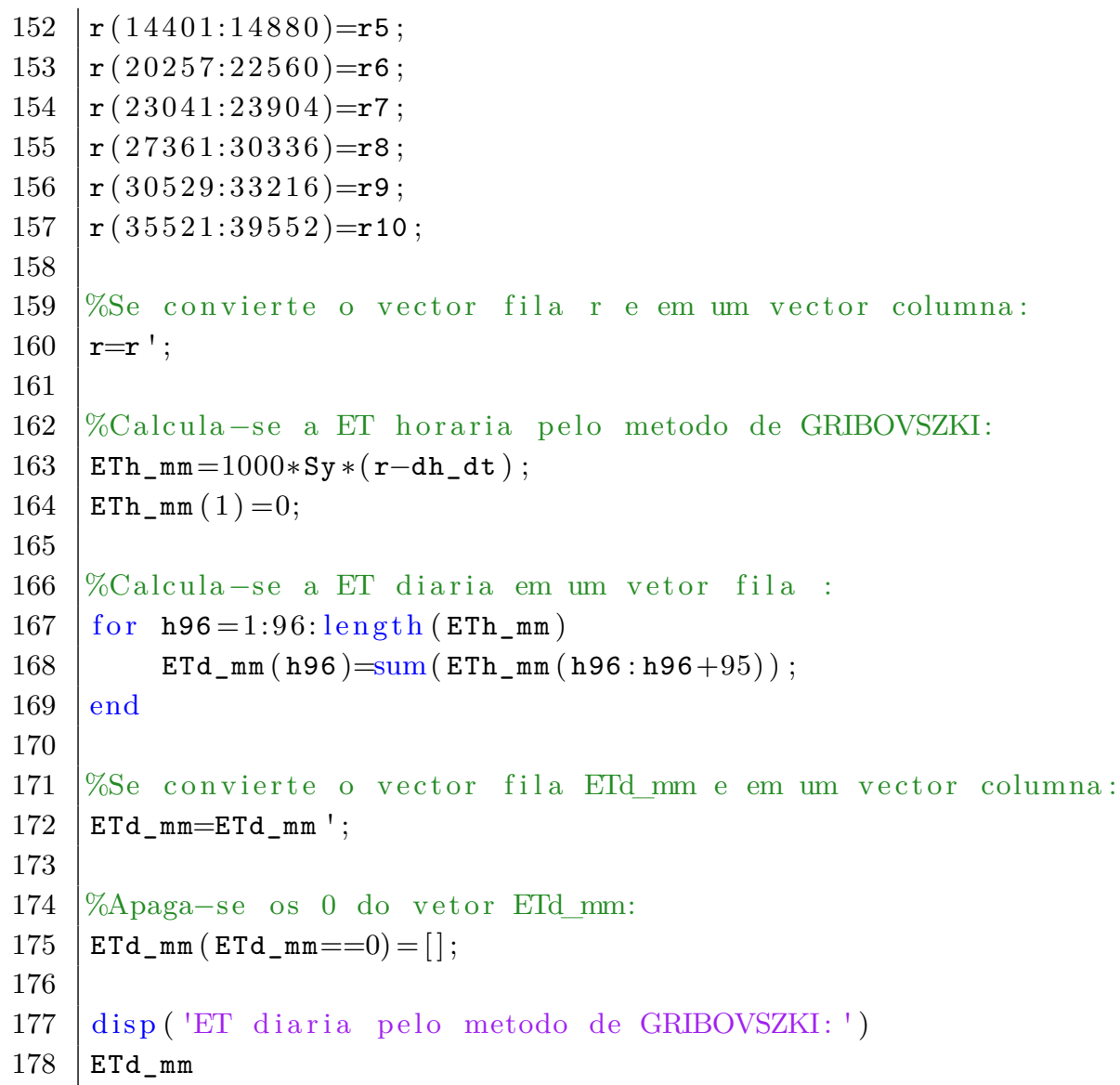




\section{D.5 Script do método de Loheide II (2008)}

O numero de linhas script é demasiado grande dado que o tratamento dos dados é realizado através da repetição de muitos vetores. Por esse motivo será abreviado o código, mas sem perder a logica da a sua estrutura.

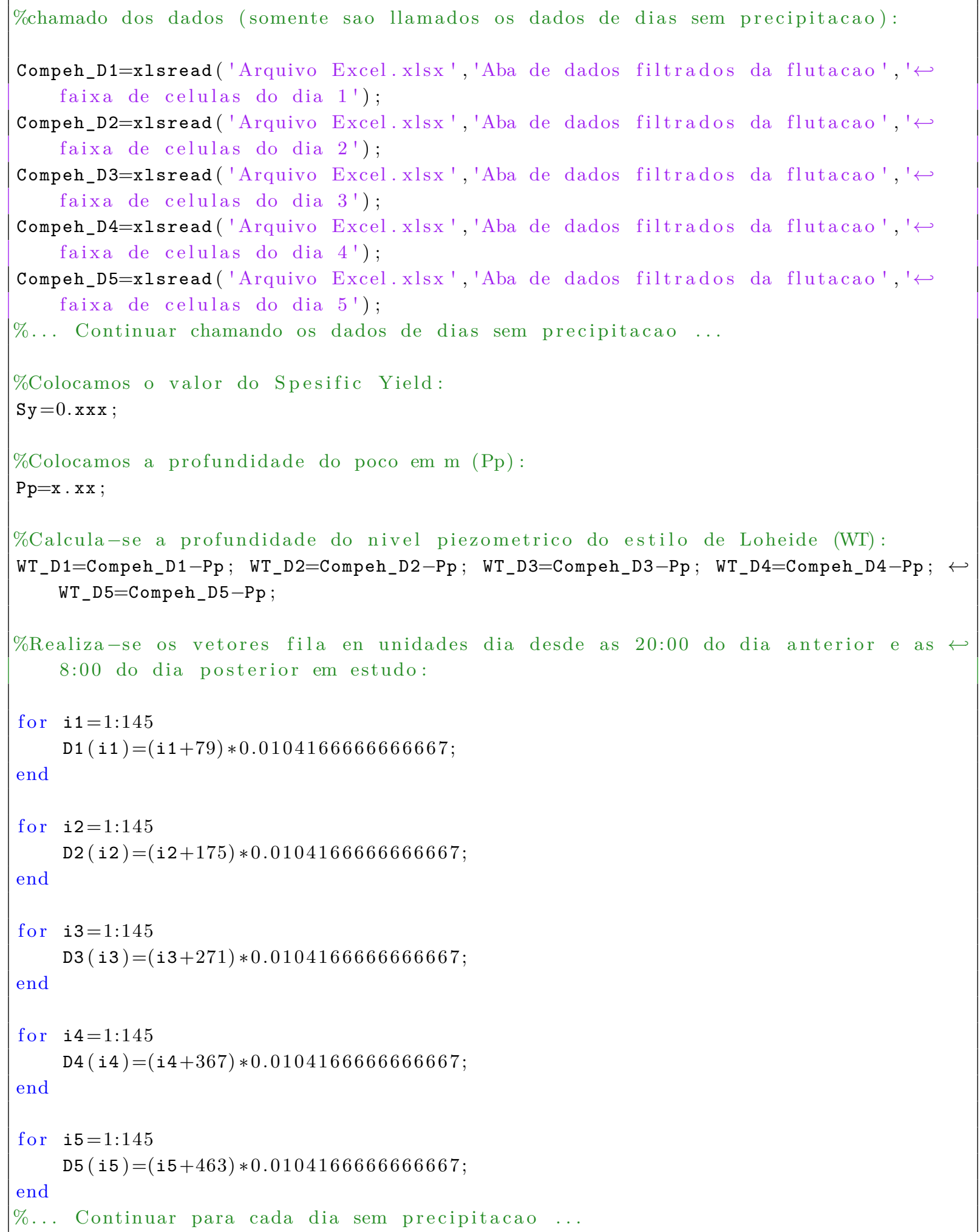


\%Se conviertem os vetores fila Di em um vetores coluna:

$\mathrm{D} 1=\mathrm{D} 1{ }^{\prime} ; \mathrm{D} 2=\mathrm{D} 2{ }^{\prime} ; \mathrm{D} 3=\mathrm{D} 3{ }^{\prime} ; \mathrm{D} 4=\mathrm{D} 4{ }^{\prime} ; \mathrm{D} 5=\mathrm{D} 5$ ' $^{\prime}$

$\%$... Continuar para cada dia sem precipitacao ...

\%Realiza-se uma regressao lineal entre as variaveis Di e WT_Di:

RL_D1=polyfit (D1, WT_D1,1);RL_D2=polyfit (D2,WT_D2,1);RL_D3=polyfit (D3,WT_D3,1);↔

RL_D4=polyfit (D4,WT_D4,1); RL_D5=polyfit (D5,WT_D5,1); 


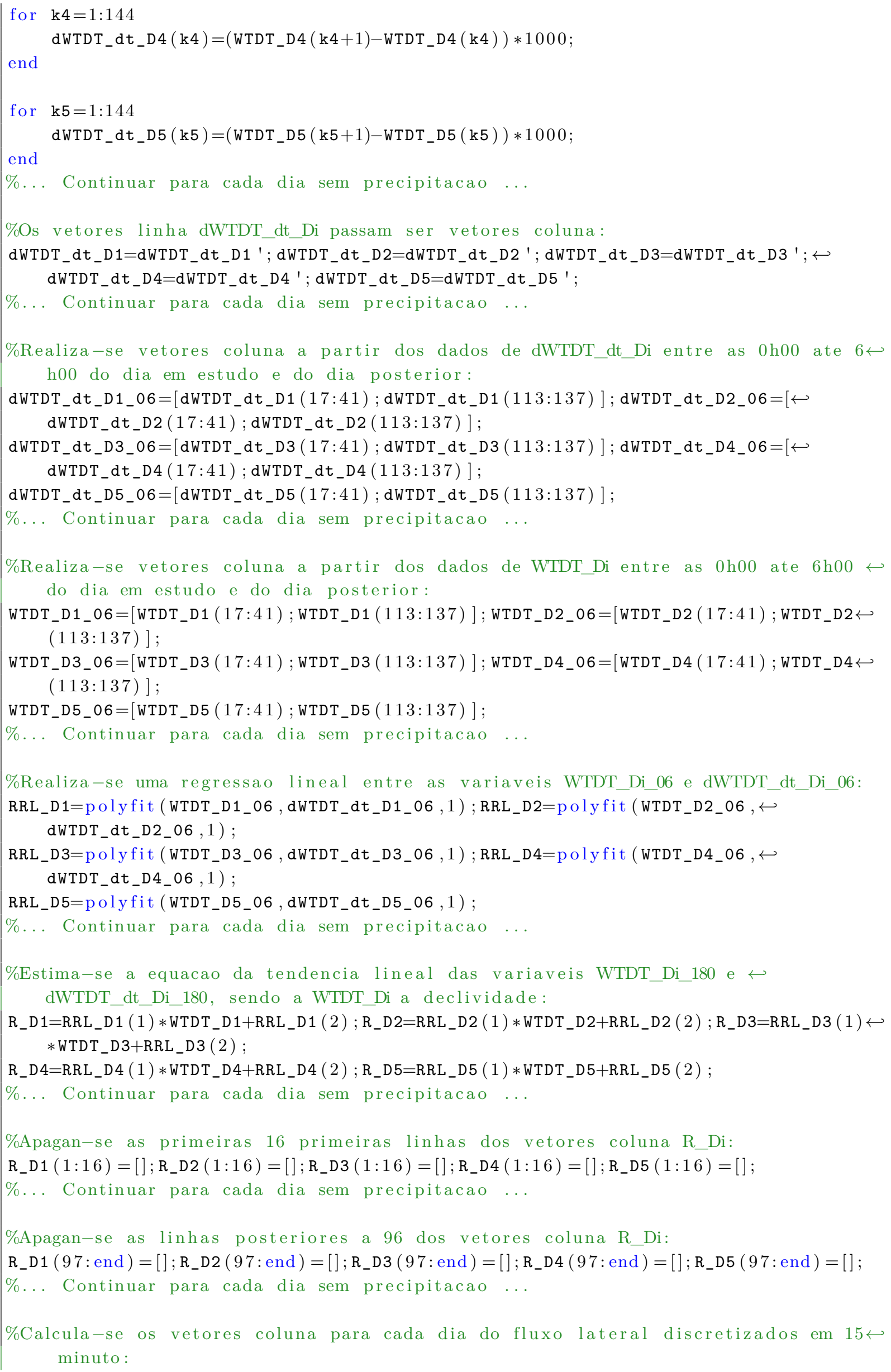




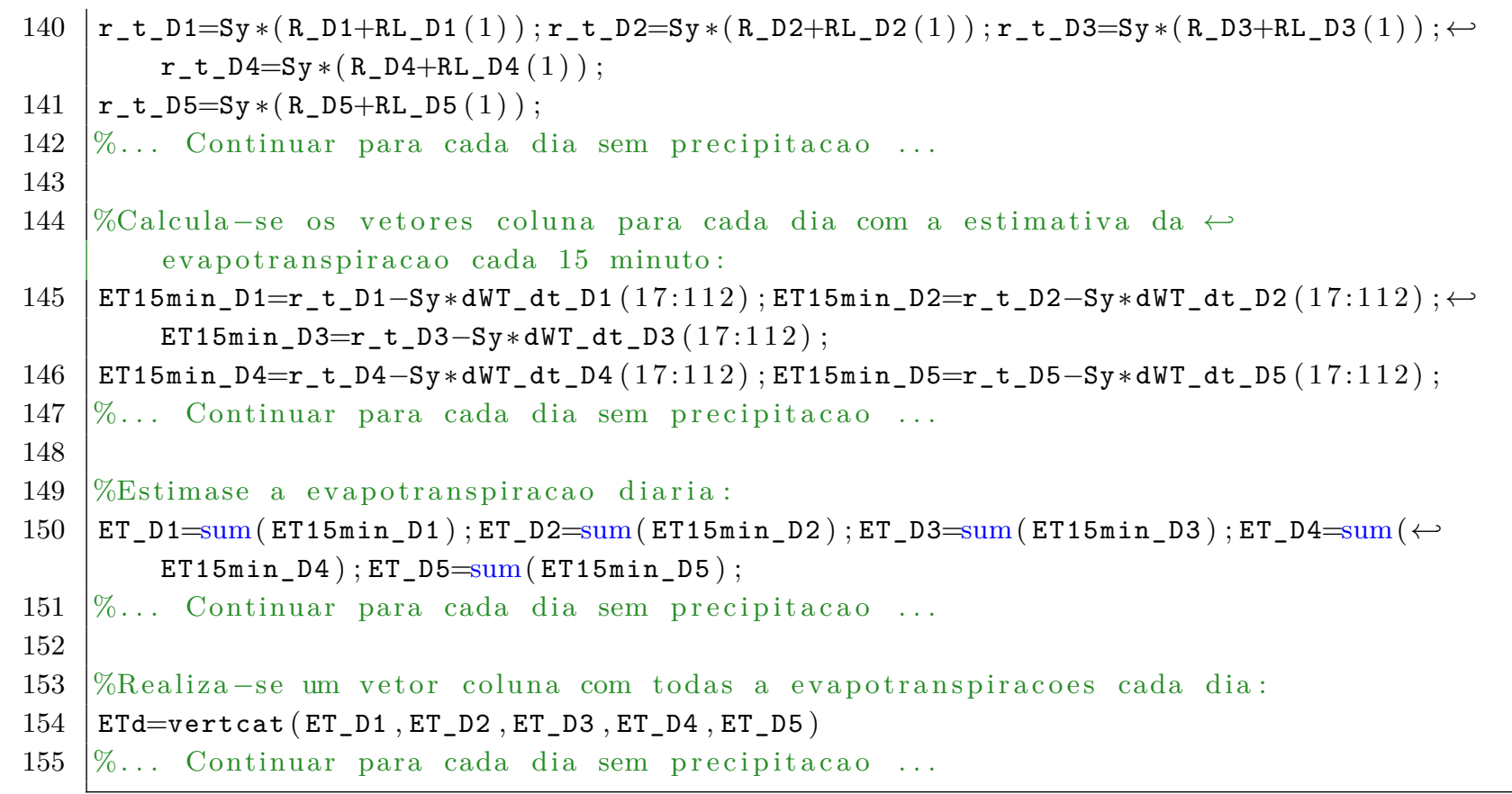




\section{APÊNDICE E - PROFUNDIDADES DO NÍVEL FREÁTICO}

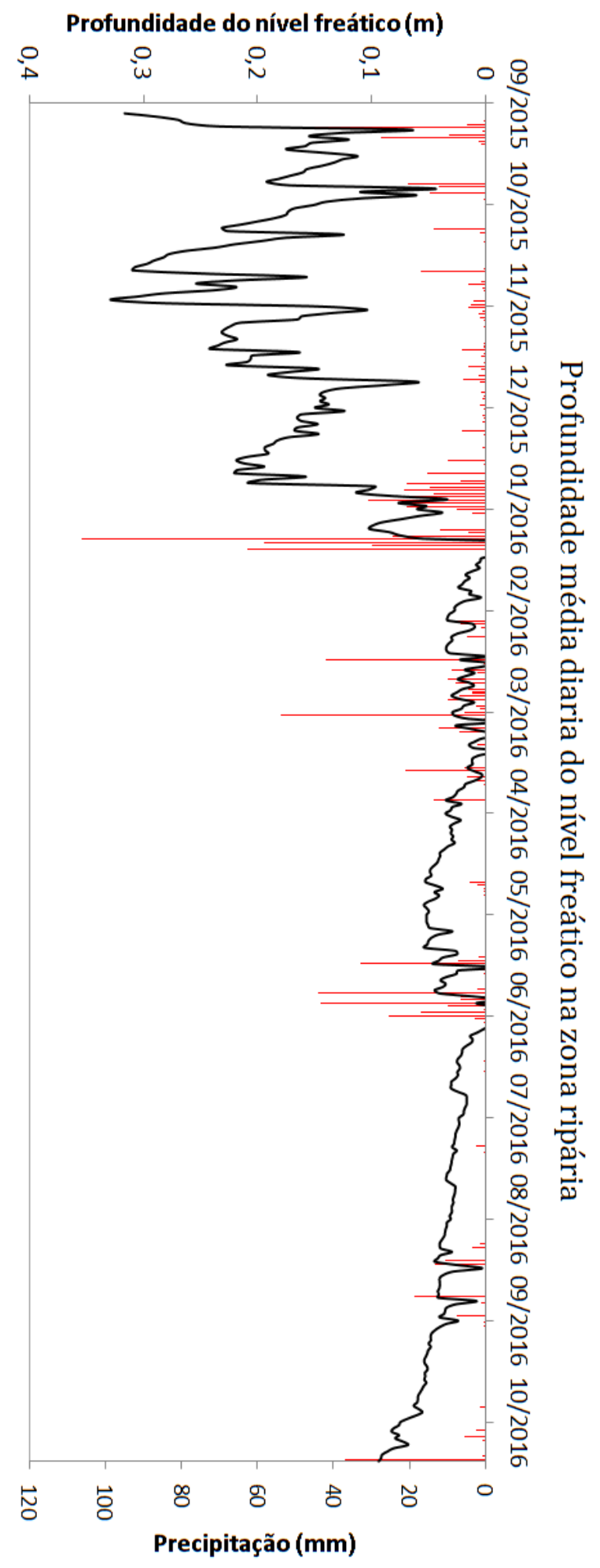




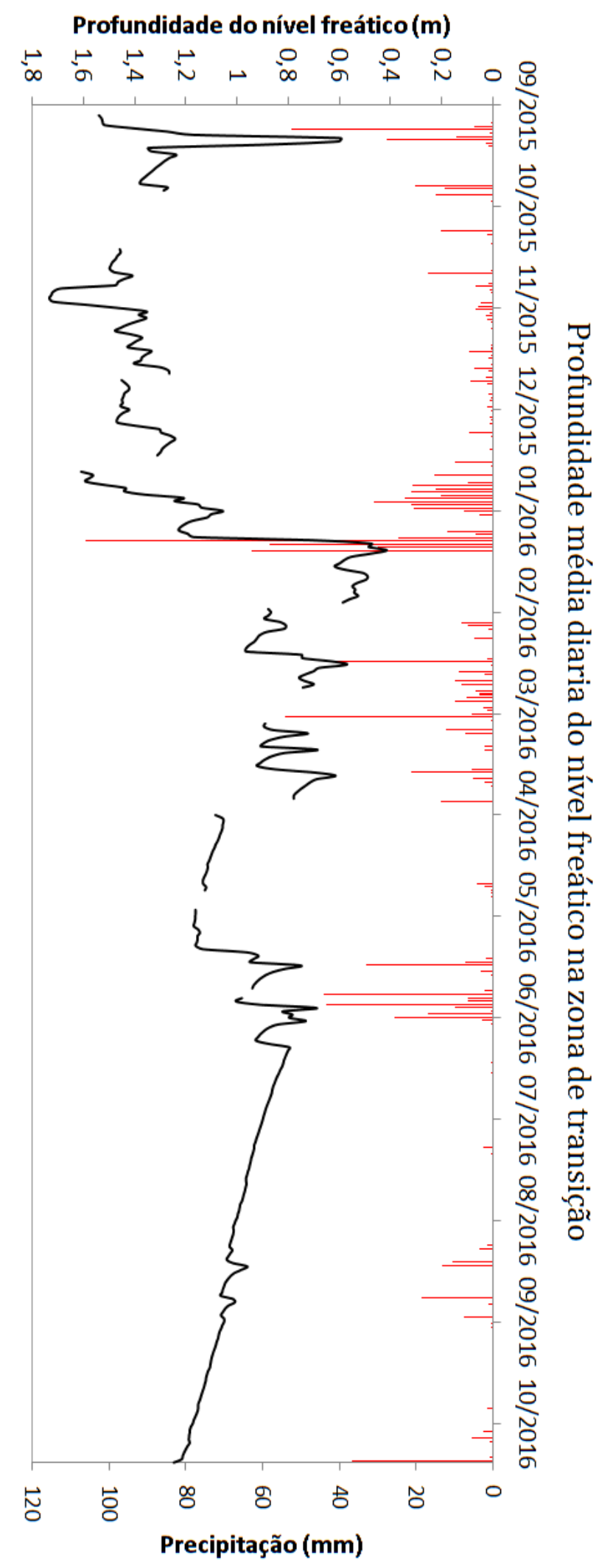




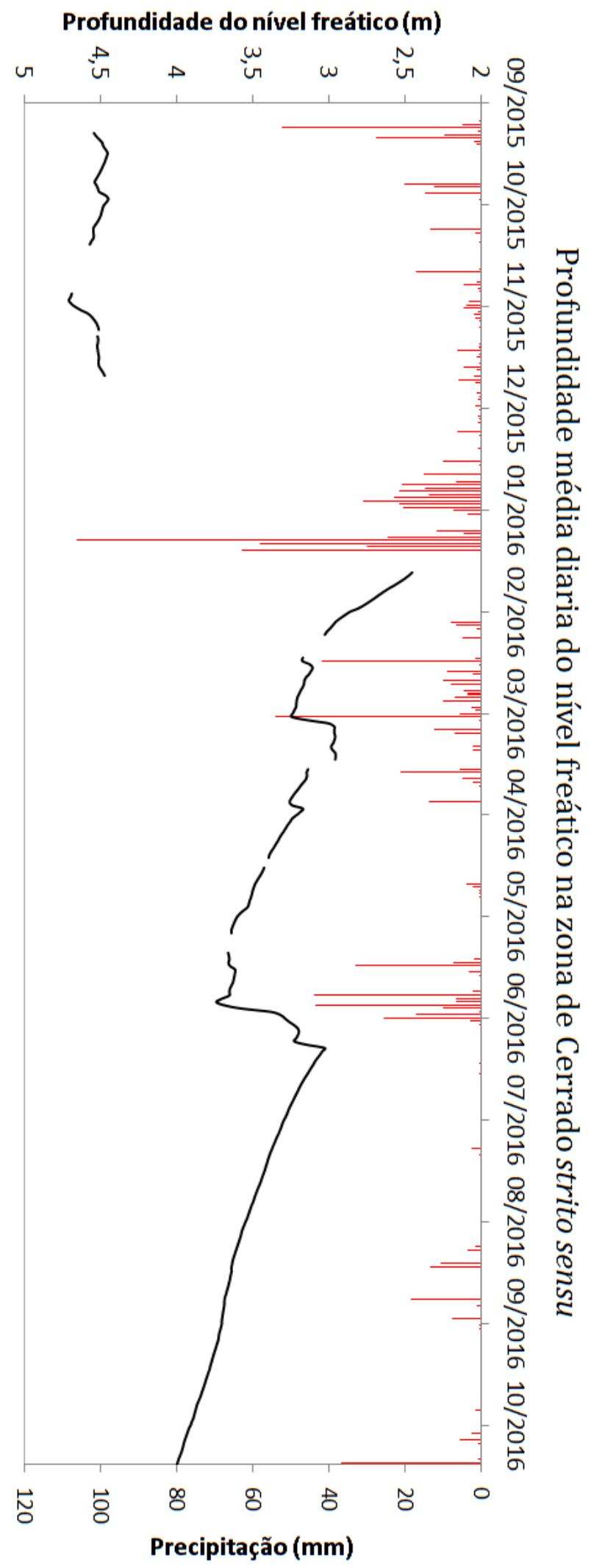


Profundidade do nível freático $(\mathrm{m})$

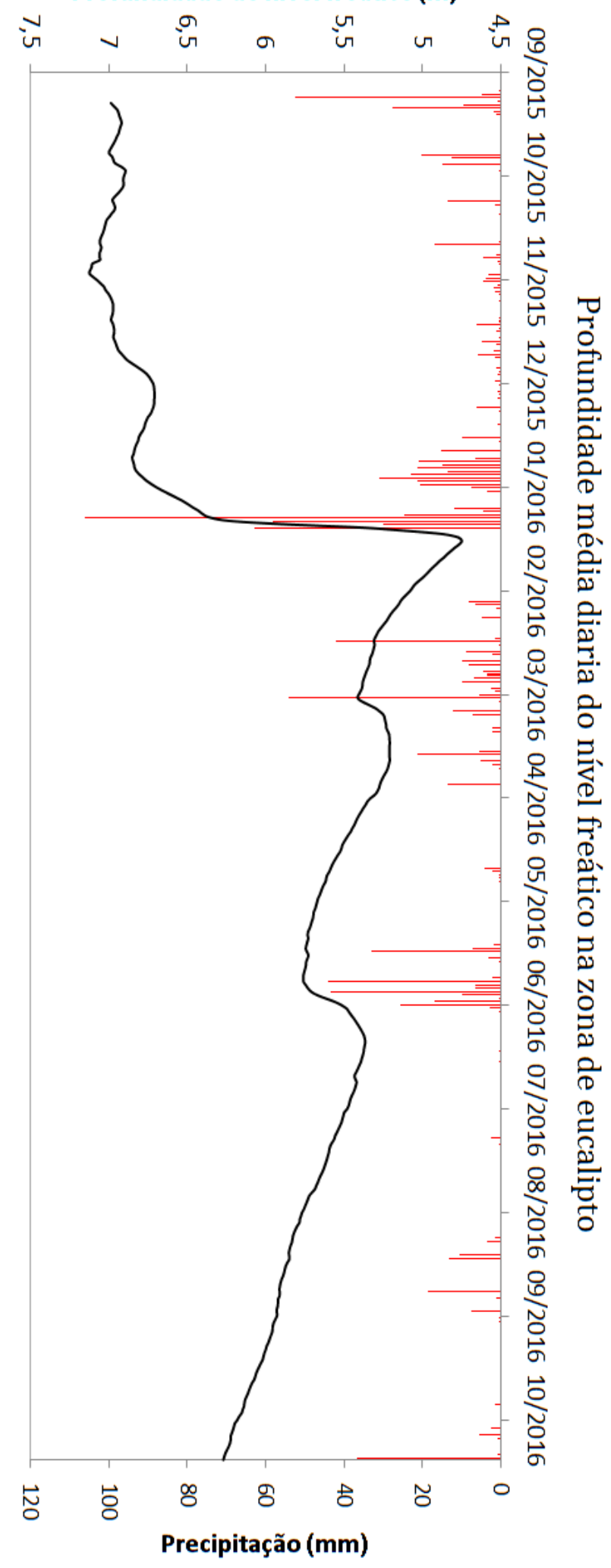




\section{APÊNDICE F - VARIAÇÃO DO $S_{y}$ COM O TEMPO}

F.1 Zona ripária - Poço 27
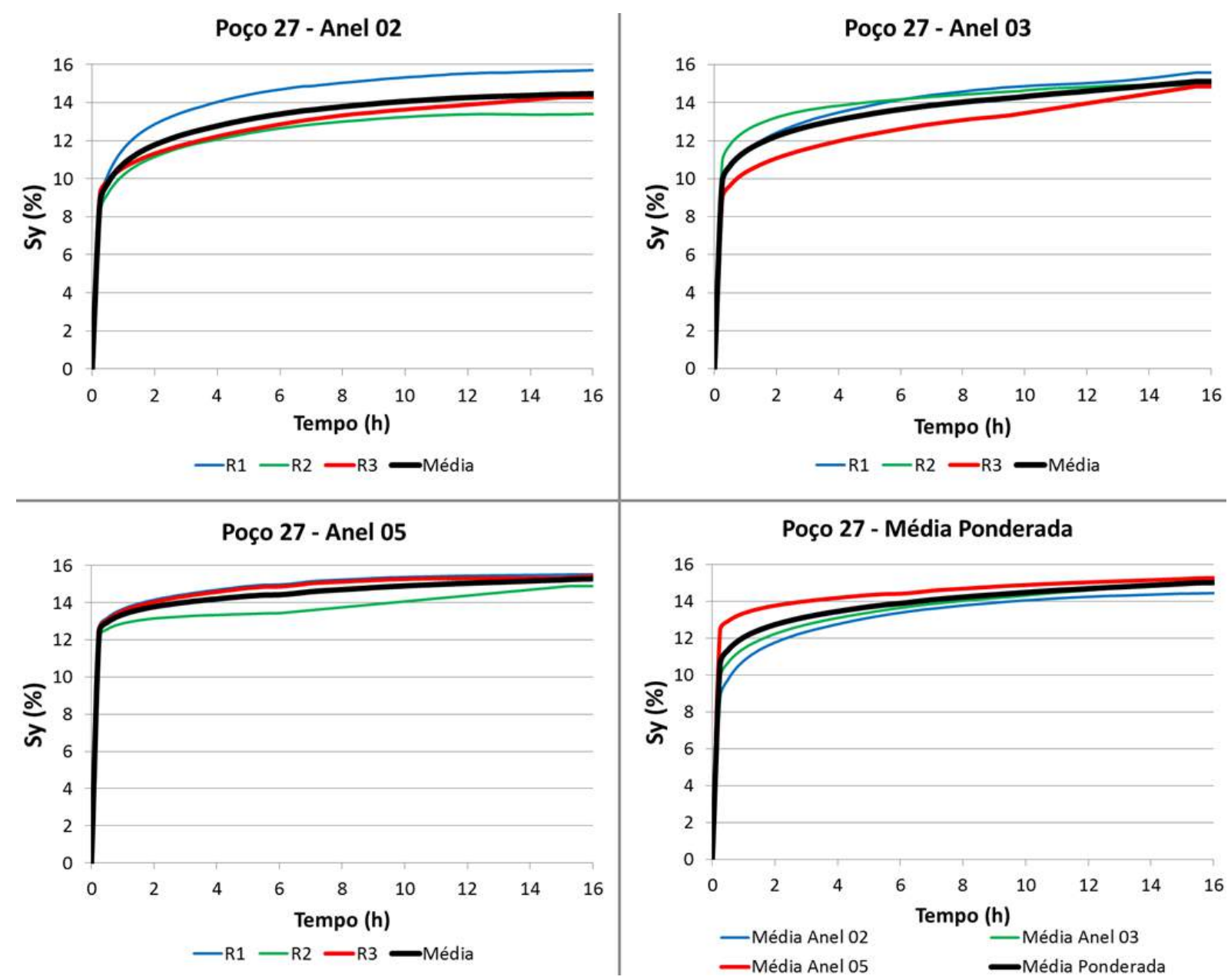


\section{F.2 Zona de transição - Poço 28}
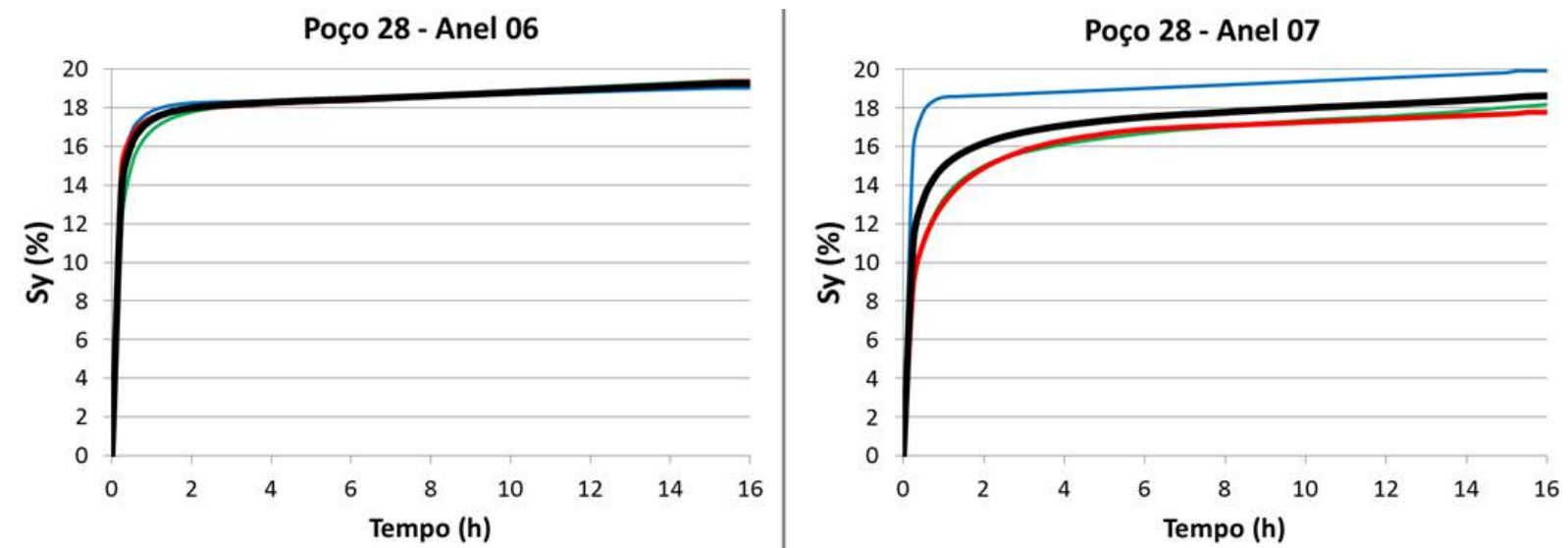

$-\mathrm{R} 1-\mathrm{R} 2-\mathrm{R} 3{ }^{-M e ́ d i a}$

-R1 -R2 - R3 -Média
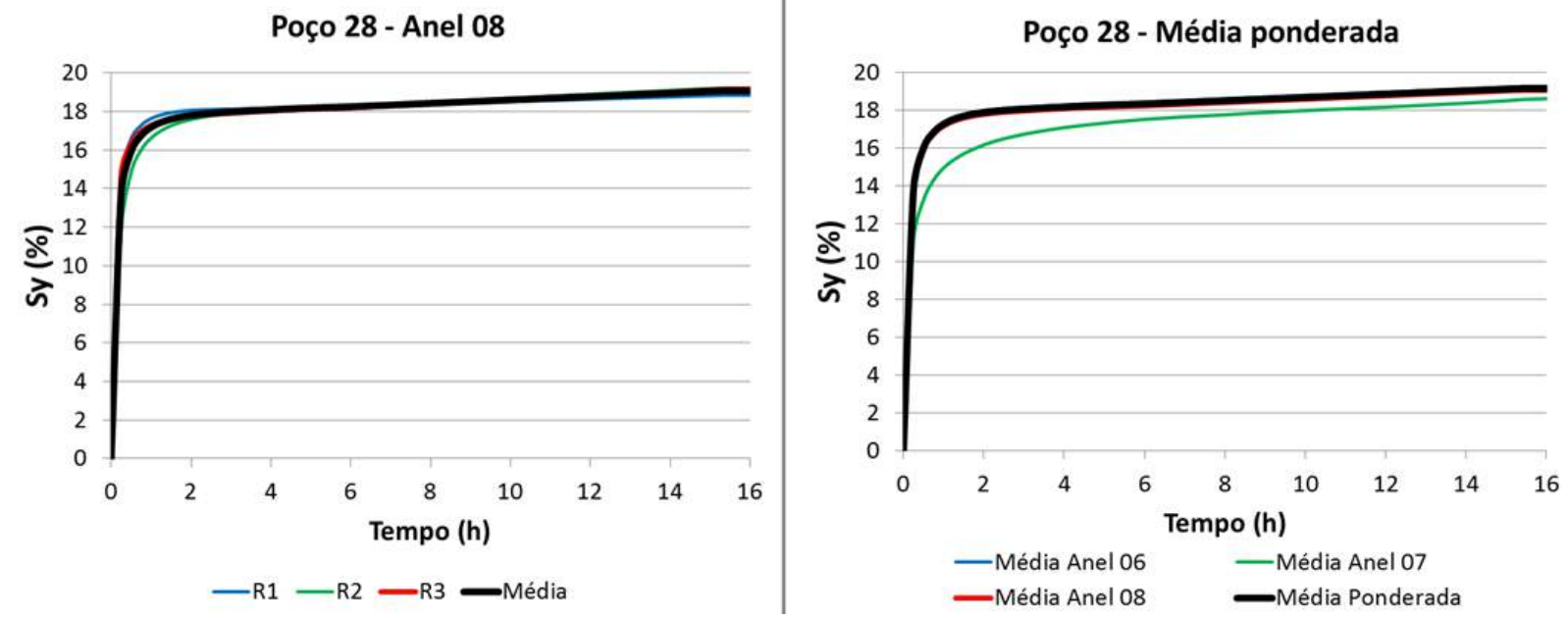

\section{F.3 Área de Cerrado stricto sensu - Poço 29}
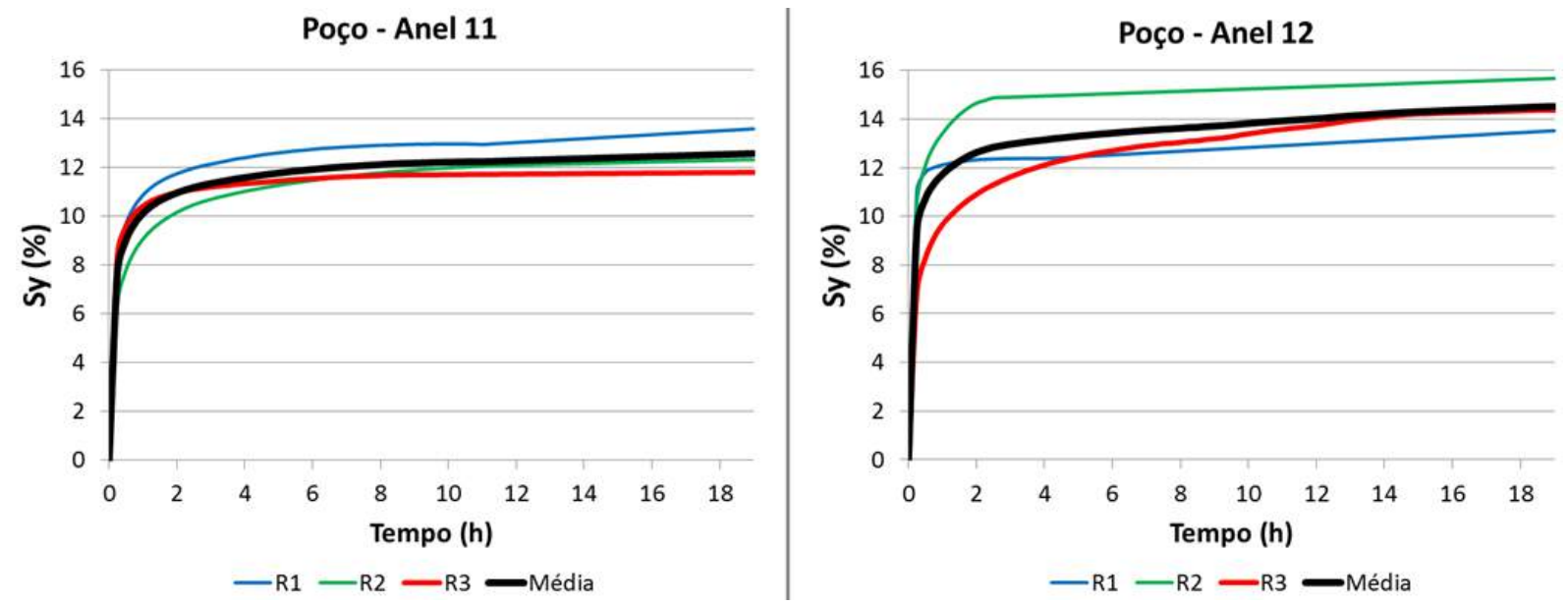

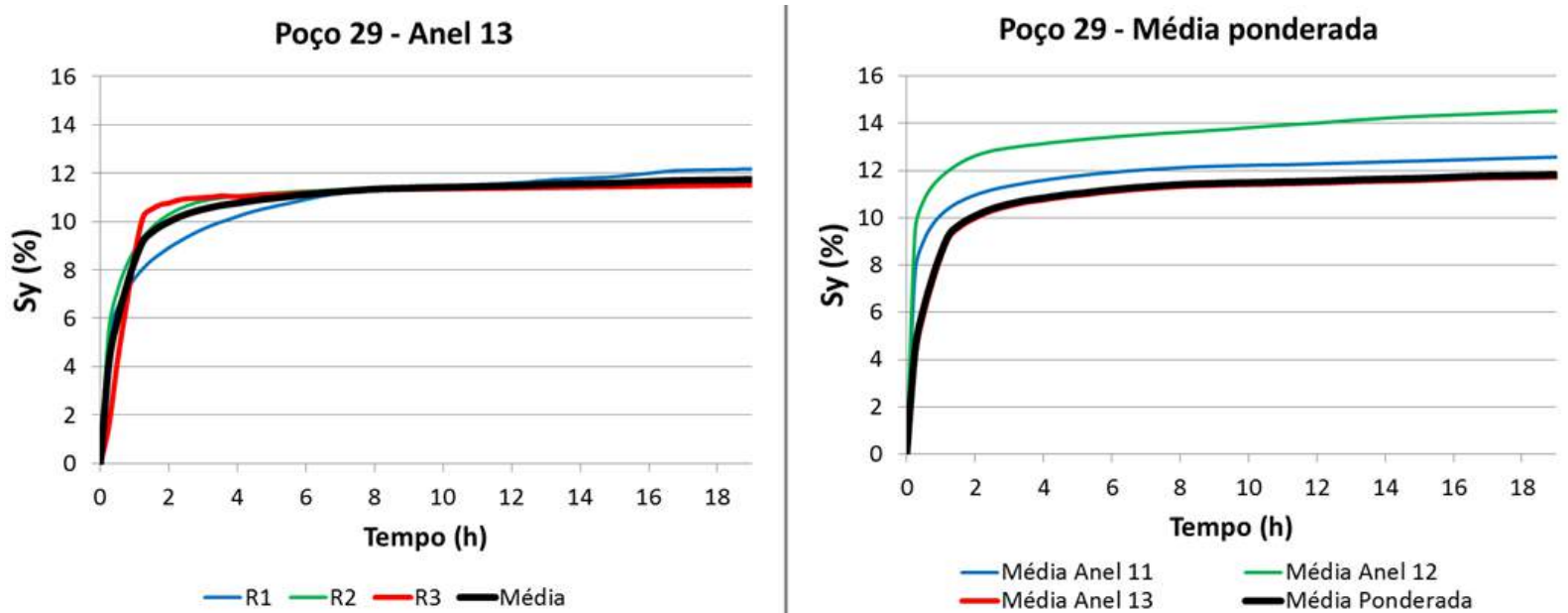

\section{F.4 Área de eucalipto - Poço 16}
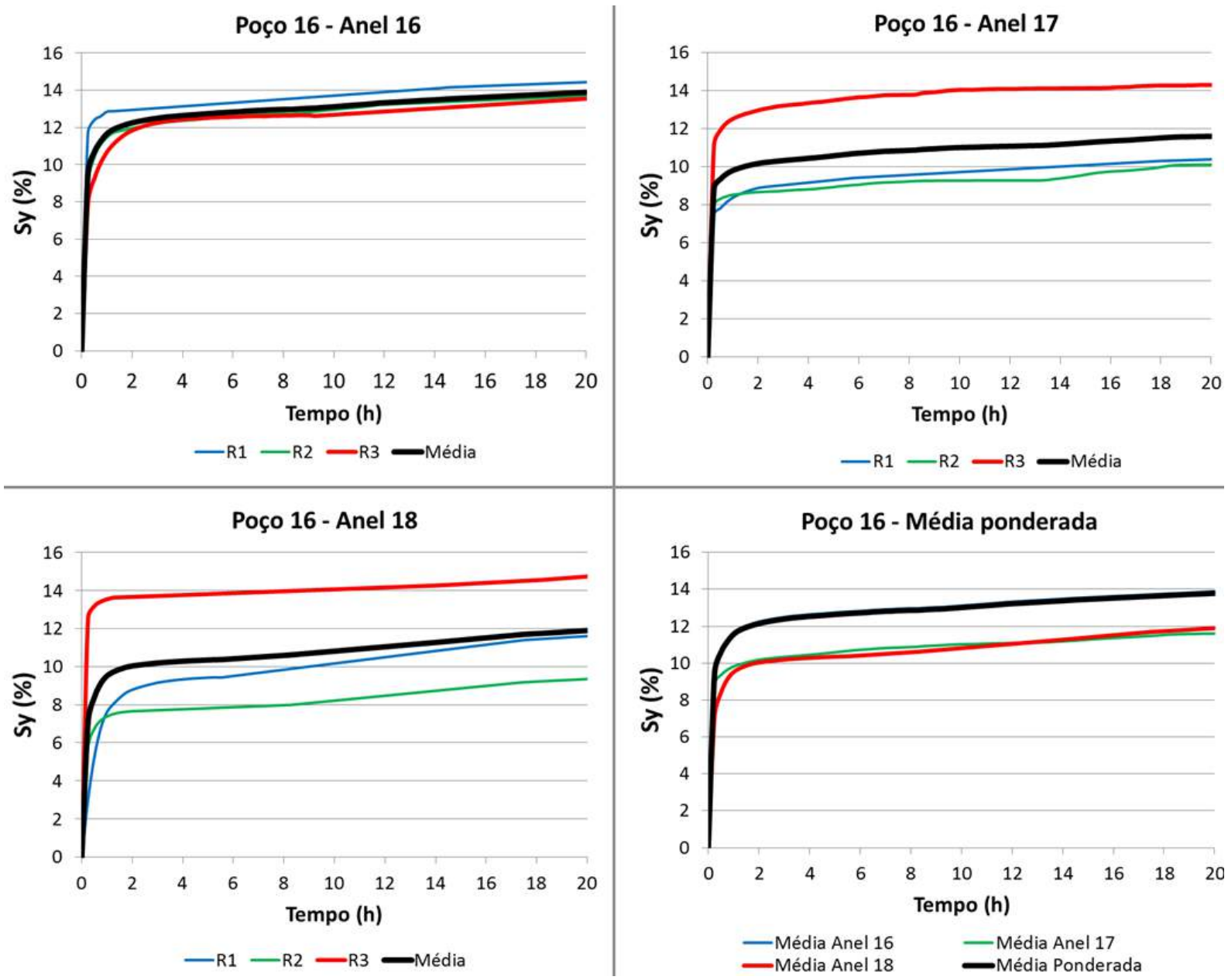


\section{APÊNDICE G - CURVAS MÉDIAS GRANULOMÉTRICAS}

G.1 Zona ripária - Poço 27

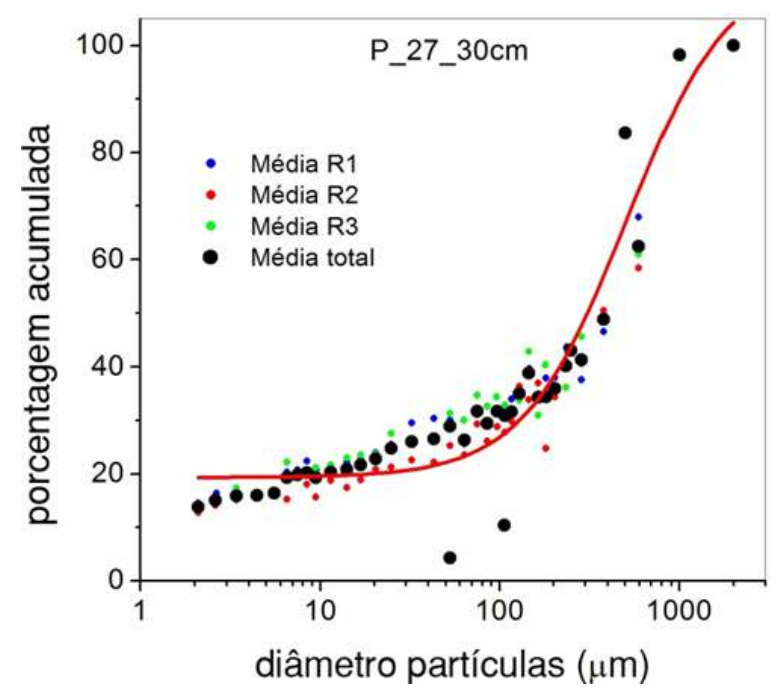

G.2 Zona de transição - Poço 28
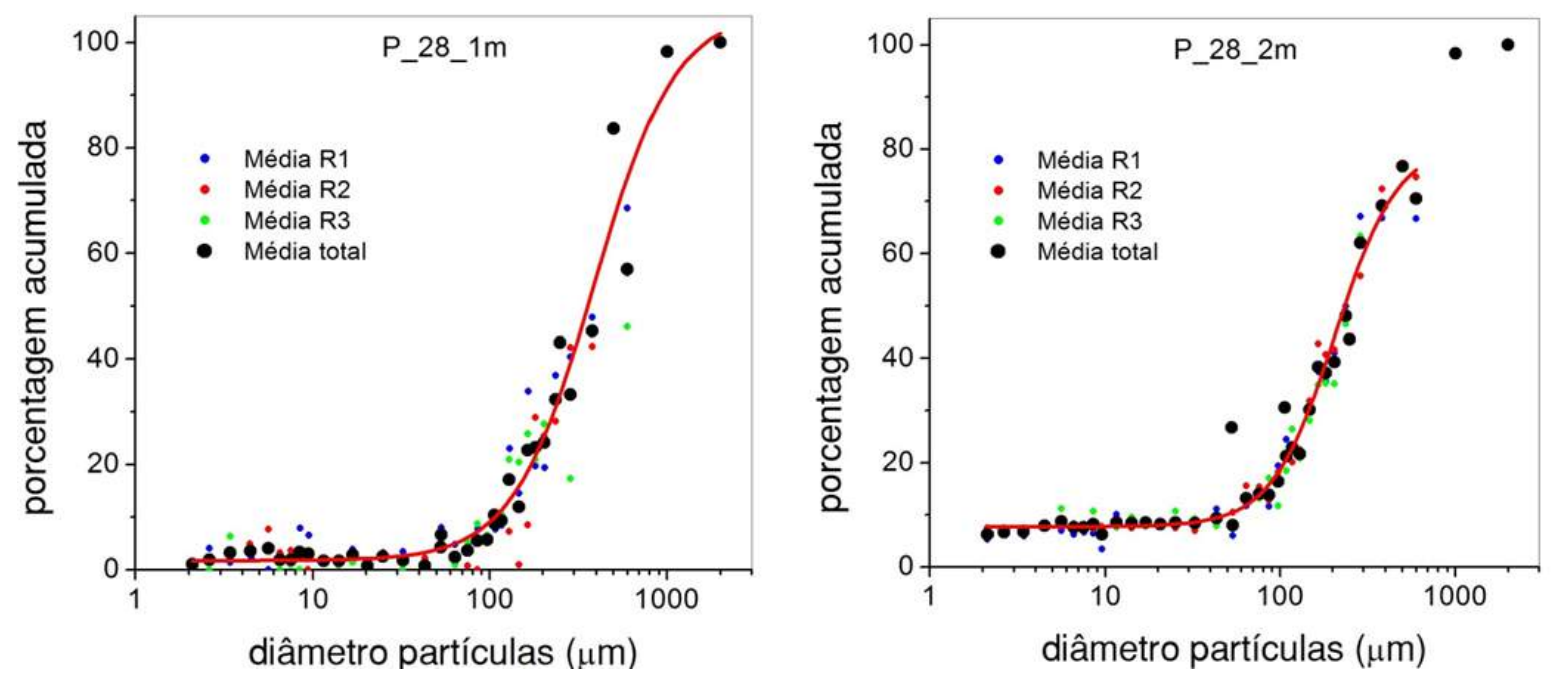


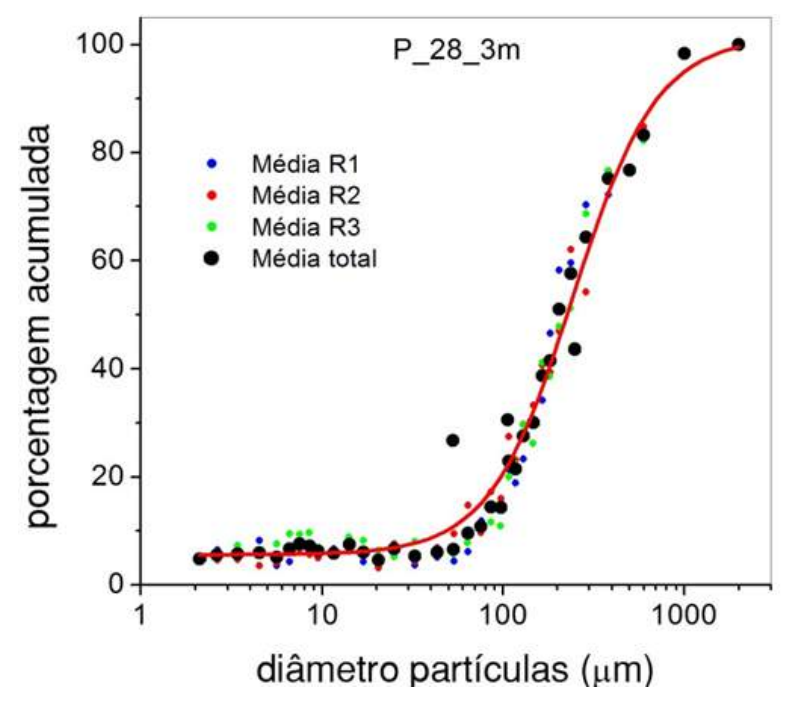

G.3 Área de Cerrado stricto sensu - Poço 29
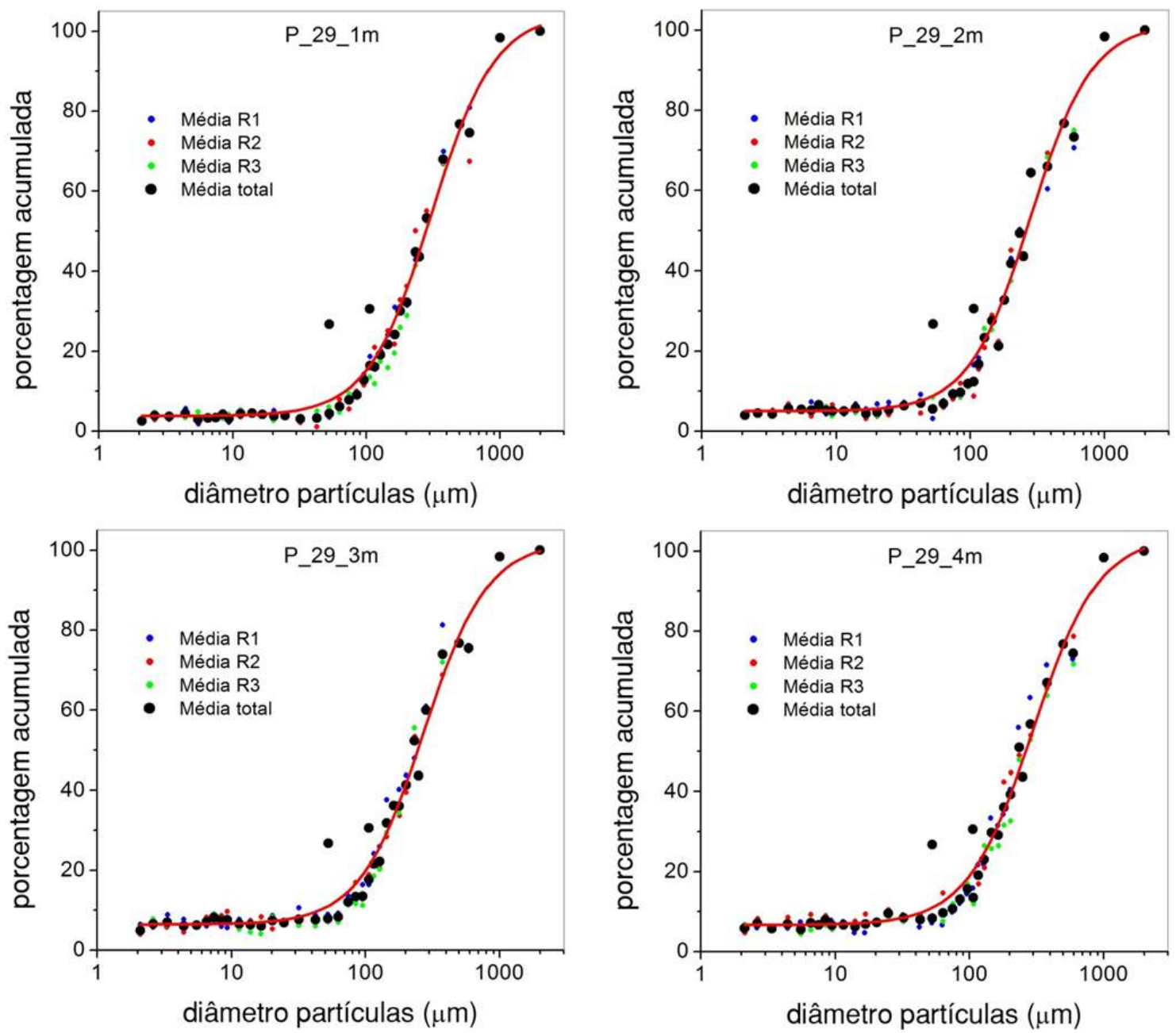


\section{APÊNDICE H - VARIÁVEIS METEOROLÓGICAS MONITORADAS}

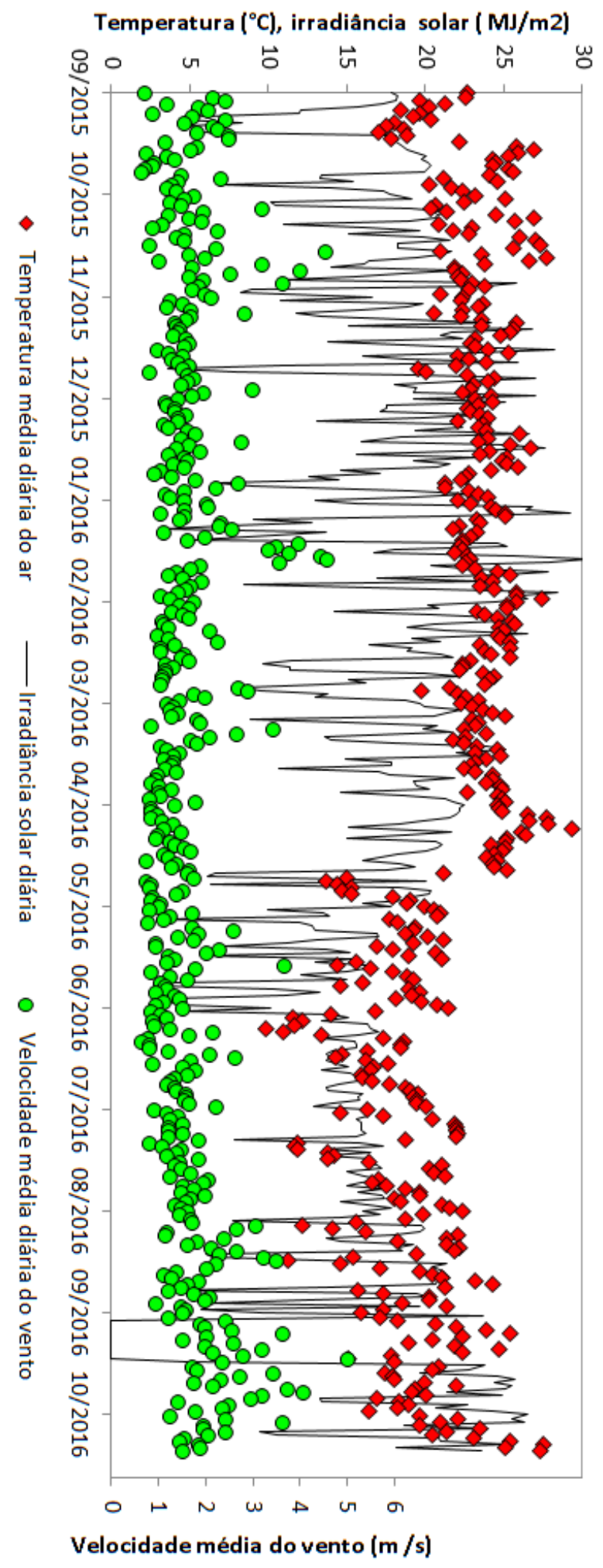




\section{APÊNDICE I - CONDUTIVIDADE HIDRÁULICA $(K)$ - SLUG TEST}

O Slug Test foi realizado nos poços de monitoramento 16, 27, 28 e 29. Os equipamentos utilizados no ensaio foram: 2 slugs, um de 4 e outro de $1 m$ de comprimento, corda de $30 \mathrm{~m}$, fio de nylon $(30 \mathrm{~m})$, medidor de nível, transdutor de pressão, barra de ferro, notebook e trena. A barra de ferro foi usada para prender a corda amarrada ao slug e mantê-lo fixo. O transdutor de pressão foi programado para realizar as coletas a cada $2 s$.

Os dados do nível freático coletado foram inseridos, juntamente com as medidas dos perfis dos poços, em uma planilha disponibilizada pelo United States Geological Survey - USGS (HALFORD; KUNIANSKY, 2002) para solução do Slug Test pelo método de Bouwer e Rice (1976).

Ensaio de Slug Test no poço 16 - Introdução do slug (tubo PVC marrom) amarrado a uma corda

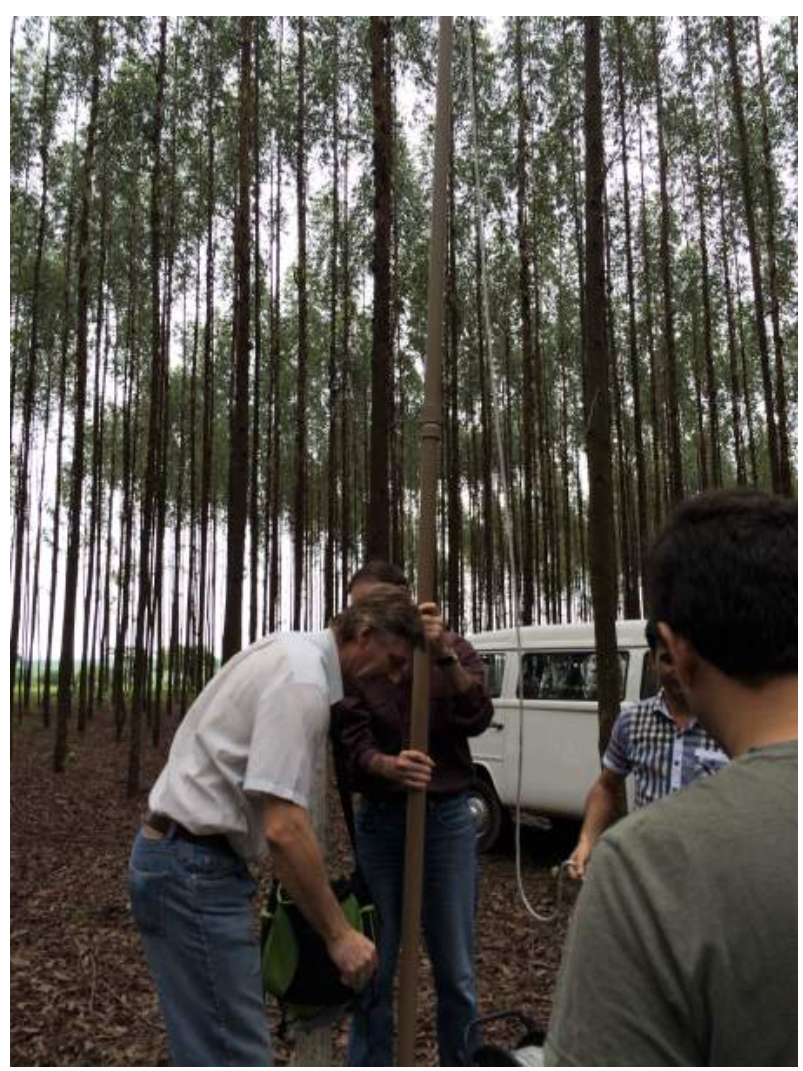


Ensaio de Slug Test no poço 16 - Coleta de dados do nível freático

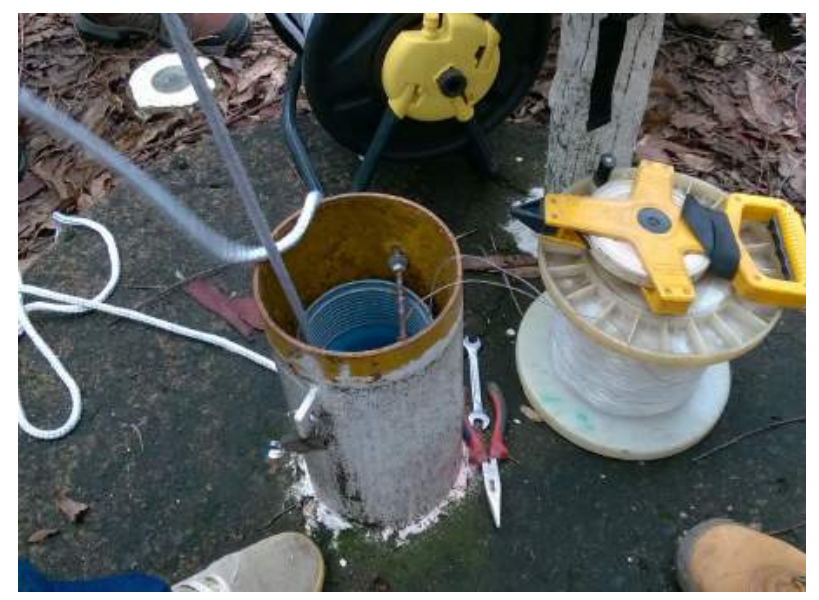

Dados de entrada (Curvas) e condutividades hidráulicas resultantes $(K)$ para cada poço em estudo.
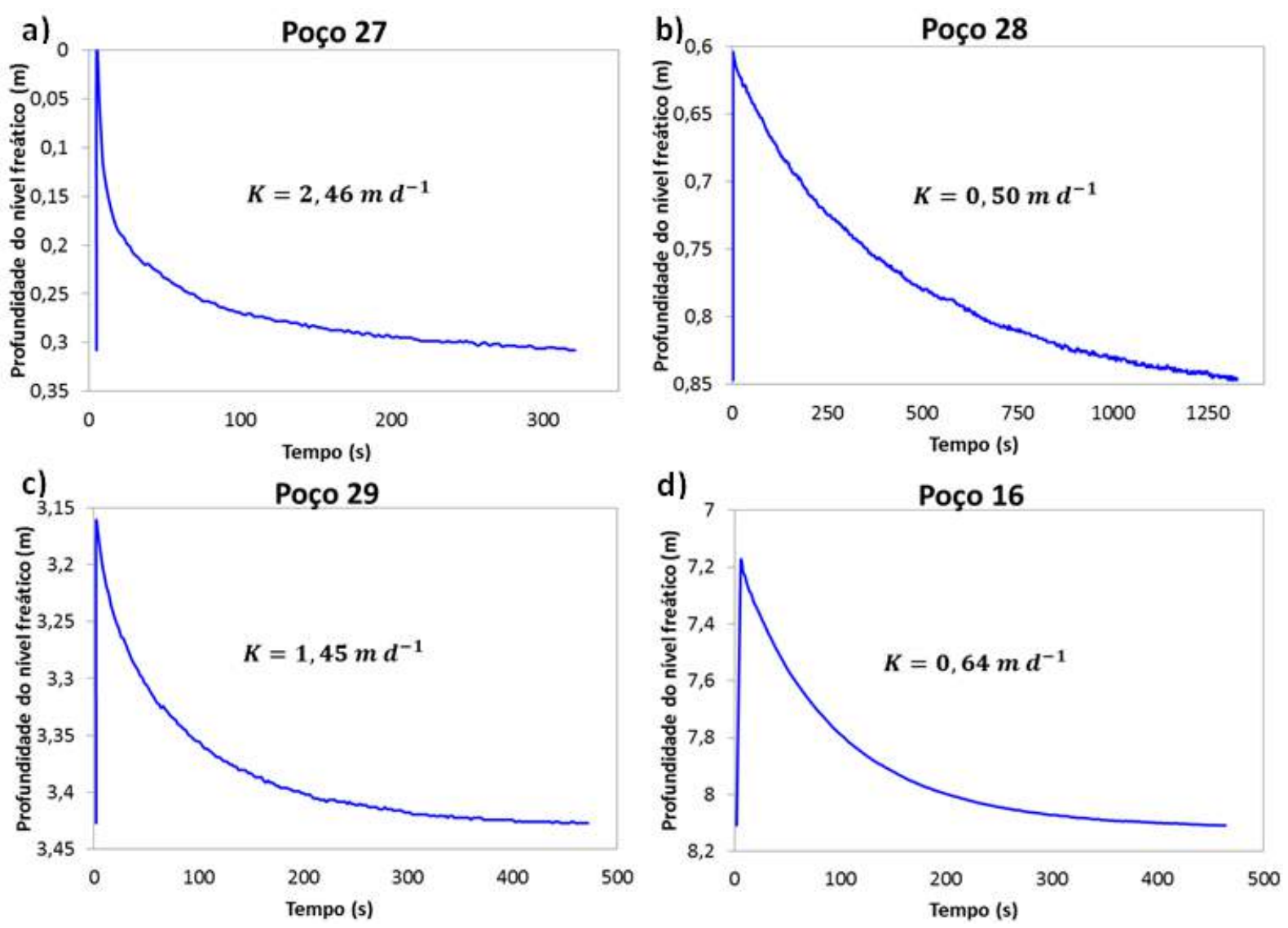
Planilhas disponibilizadas pelo United States Geological Survey (USGS)- método de Bower e Rice para a estimativa da condutividade hidráulica.

WELL ID: Poço 27 - Diver

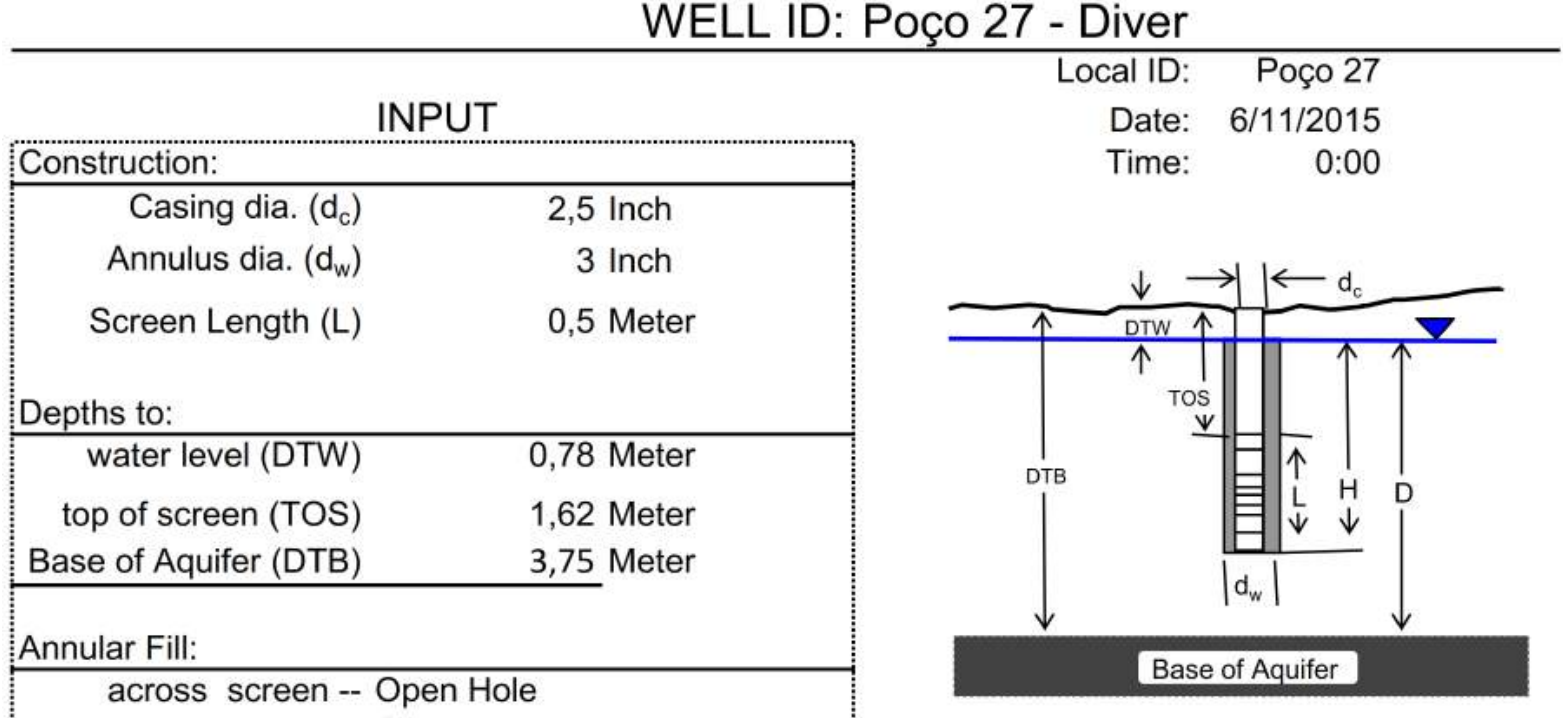

above screen -- Open Hole

Aquifer Material -- Surficial Aquifer, central Florida

\section{COMPUTED}

\begin{tabular}{rr}
\hline$L_{\text {wetted }}$ & 0,5 Meter \\
$D=$ & 2,967303337 Meter \\
$H=$ & 1,337303337 Meter \\
$L_{r_{w}}=$ & 13,13 \\
yo-DISPLACEMENT $=$ & 0,30 Meter \\
yo-SLUG $=$ & 0,27 Meter
\end{tabular}

From look-up table using $\mathrm{L} / \mathrm{r}_{\mathrm{w}}$

\begin{tabular}{rc}
\hline Partial penetrate $\mathrm{A}=$ & 2,003 \\
$\mathrm{~B}=$ & 0,297 \\
& \\
$\operatorname{In}(\mathrm{Re} / \mathrm{rw})=$ & 1,829 \\
$\mathrm{Re}=$ & $0,78 \mathrm{Meter}$ \\
Slope $=$ & $0,006714769 \mathrm{log}_{10} / \mathrm{sec}$ \\
$\mathrm{t}_{90 \%}$ recovery $=$ & $149 \mathrm{sec}$ \\
\hline Input is consistent. & \\
\hline $\mathrm{K}=$ & 2,5 Meter/Day \\
\hline
\end{tabular}

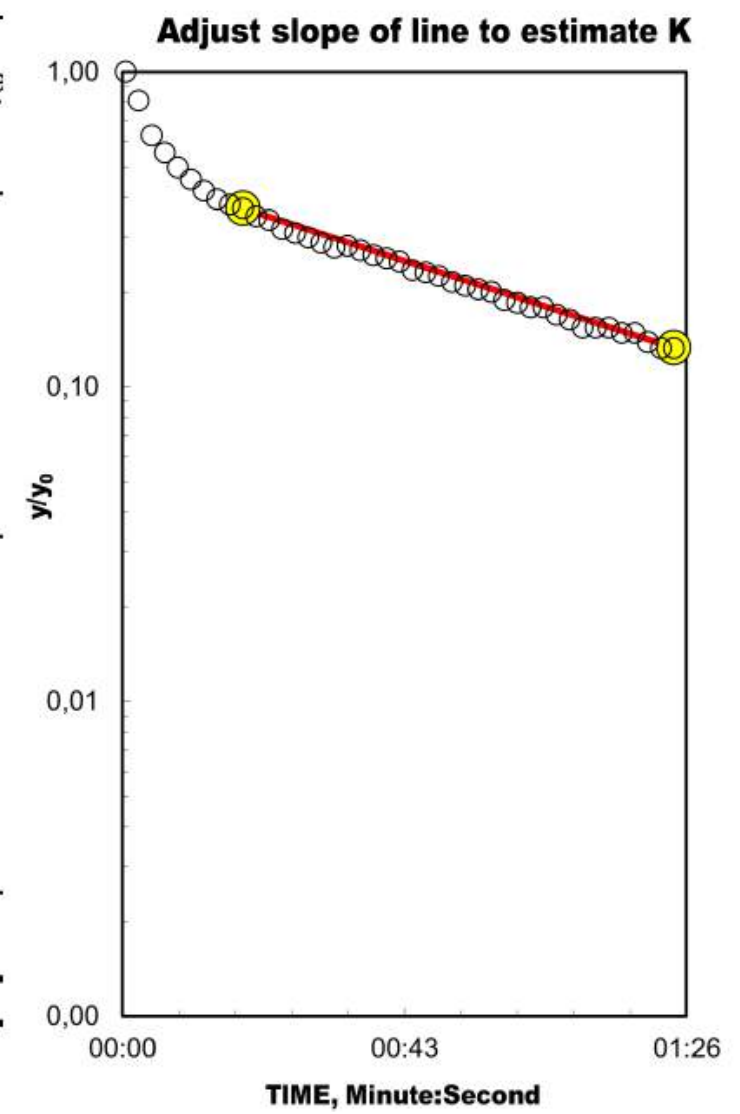


WELL ID: Poço 28 - Diver

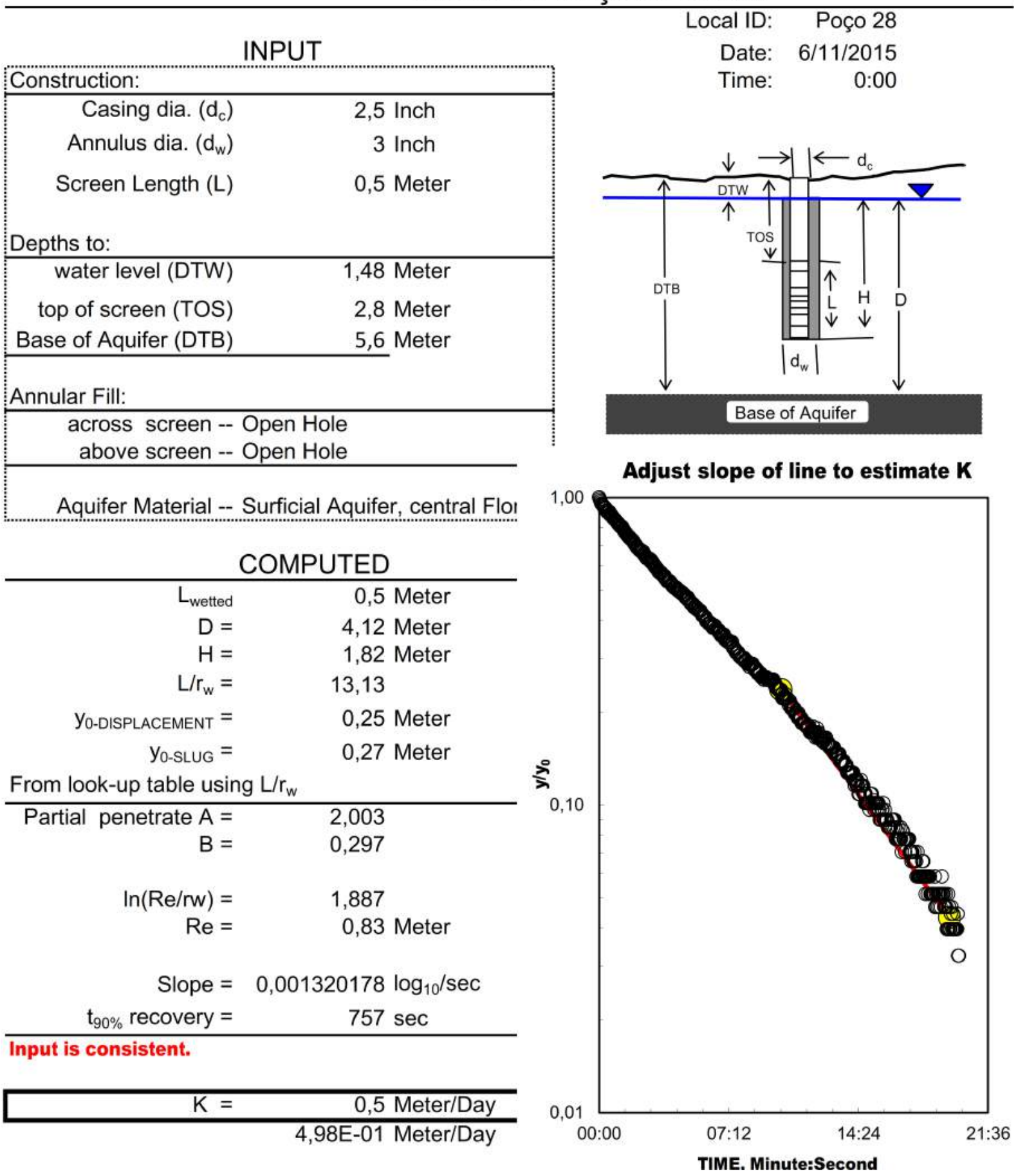


WELL ID: Poço 29 - Diver

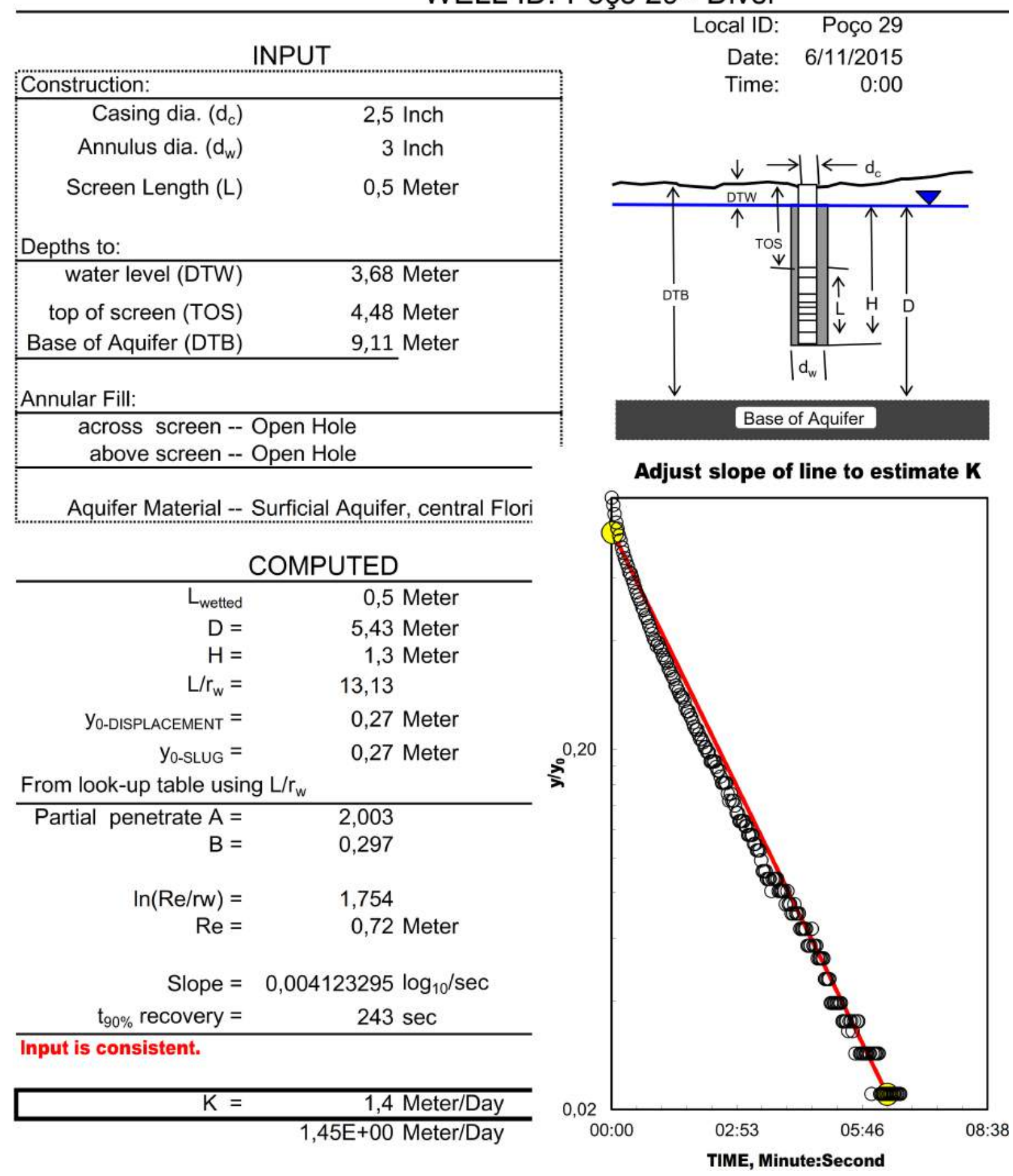


WELL ID: Poço 16 - Diver

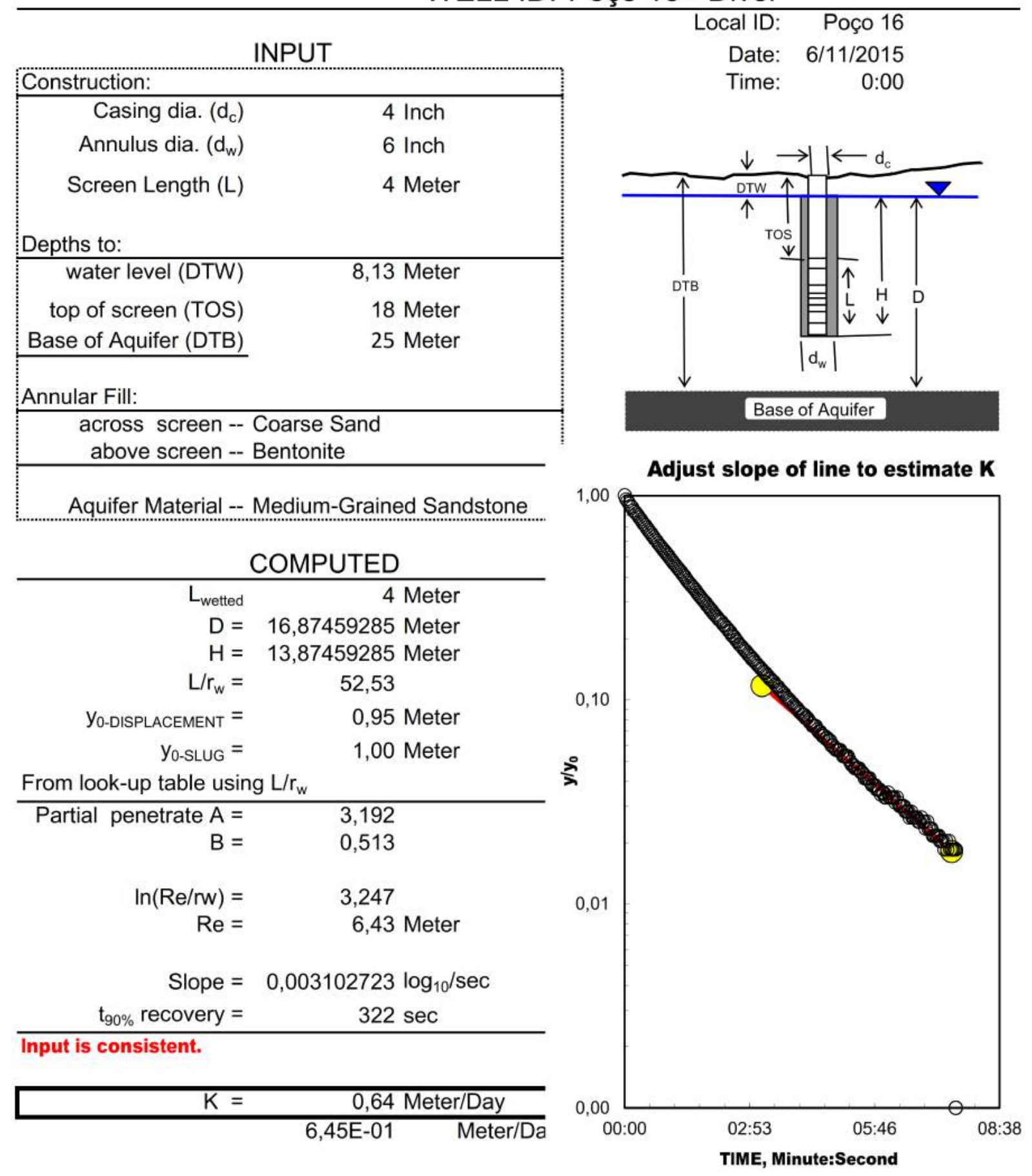

